University of Rhode Island

DigitalCommons@URI

Open Access Master's Theses

1983

\title{
Effect of Horizontal Shear Transfer on Stresses Beneath Steel Bearing Plates
}

Hasan S. Arouri

University of Rhode Island

Follow this and additional works at: https://digitalcommons.uri.edu/theses

\section{Recommended Citation}

Arouri, Hasan S., "Effect of Horizontal Shear Transfer on Stresses Beneath Steel Bearing Plates" (1983). Open Access Master's Theses. Paper 1420.

https://digitalcommons.uri.edu/theses/1420

This Thesis is brought to you for free and open access by DigitalCommons@URI. It has been accepted for inclusion in Open Access Master's Theses by an authorized administrator of DigitalCommons@URI. For more information, please contact digitalcommons-group@uri.edu. 


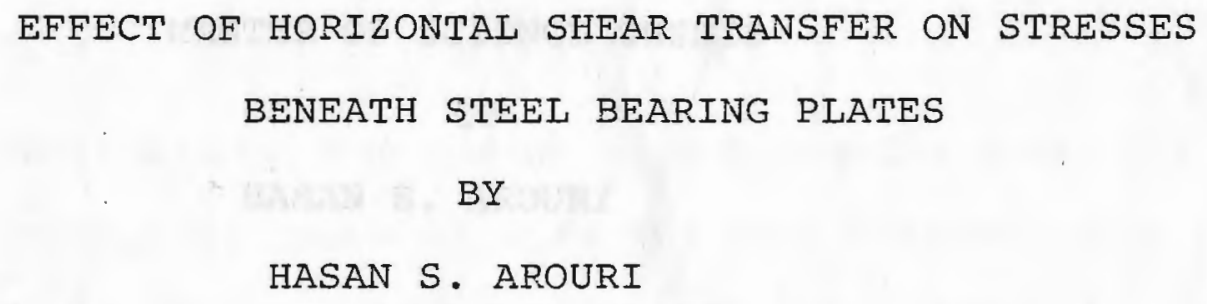

A TYESIS SUBMITTED IN PARTIAL FULFILLMENT OF THE RECUIREMENTS FOR THE DEGREE OF MASTER OF SCIENCE IN CIVIL ENGINEERING 
MASTER OF SCIENCE THESIS

$\mathrm{OF}$

HASAN S. AROURI

APPROVED :

Thesis committee

Major Professor

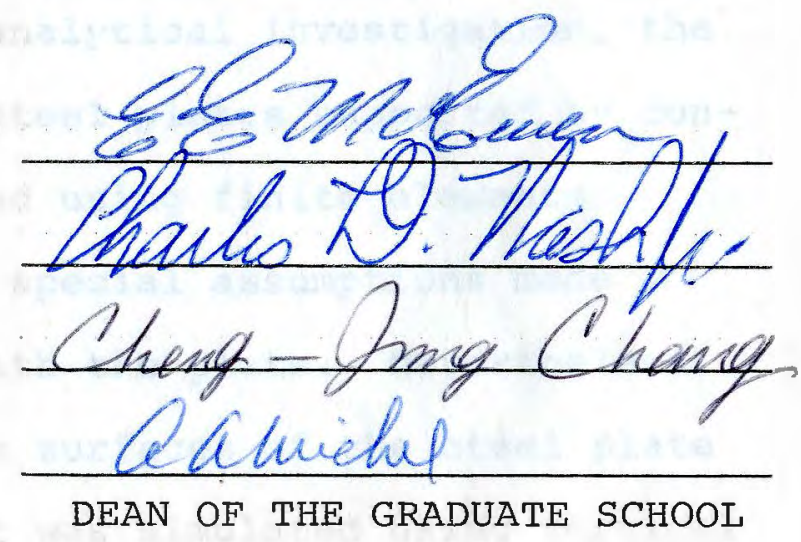

UNIVERSITY OF RHODE ISLAND

1983 


\section{ABSTRACT}

In practice, the design of pot bearing steel plates is usually based on assuming that stresses beneath the plate are uniformly distributed. There is also no consideration given to the effect of shear stresses transmitted through the interface between the surfaces of the plates and the supporting concrete abutment.

However, in this analytical investigation, the behavior of pot bearing steel plates supported by concrete abutment was studied using finite elements analysis. There were no special assumptions made concerning stresses beneath the plate. Nevertheless, the interface between the surfaces of the steel plate and the concrete abutment was simulated using vertical and horizontal interface spring elements. Normal and shear stresses were permitted to be transferred through the interface with slip occurring beyond some limiting shear strength value.

Different shear transfer conditions were induced and stresses resulting in the bearing system were studied using axisymmetric and plane strain solution methods. Results indicated that assuming uniform stress 
distribution beneath the plate is rather too conservative. However, results from different shear transfer conditions showed that the effect of shear transfer is practically insignificant for design purposes. 


\section{ACKNOWLEDGEMENTS}

I am greatly indebted to and wish to thank with sincere gratitude:

Dr. Everett E. McEwen, my major professor, for his constructive and valuable guidance in the preparation of this thesis, and for his teaching and advice throughout my graduate studies.

Professor Cheng-Jung Chang, Professor Charles Nash, and Professor Martin Sadd for their assistance in so many ways.

Professor Fadel Al-Kazily for his invaluable help in preparation for my thesis defense.

My parents, Mr. and Mrs. Arouri, for their love, sacrifice, encouragement, and unlimited support.

My sister Rima Arouri, and my friends Georgette and Samia Kiriaki for all the help they gave me in assembling the thesis to its final form.

Mrs. Donna Brightman for her concern and good will. The University of Rhode Island Computer Laboratory, for the use of their facilities.

Mrs. Frances Harvey for typing the final draft of my thesis. 
TABLE OF CONTENTS

CHAPTER

PAGE

INTRODUCTION

PREVIOUS ANALYSIS AND SCOPE OF STUDY • . • . 4

2.1 Previous Analysis of

the Bearing System . . . . . . . . 4

2.2 Scope of Study . . . . . . . . . . 5

3 THE FINITE ELEMENT METHOD . • . . . . . . 10

3.1 Historical Review . . . . . . . . 11

3.2 Finite Element Procedure . . . . . . 13

3.2.1 The Grid System . . . . . . 14

3.2.2 Elements Variety . . . . . 16

3.2.3 Displacement Functions... . . 17

3.2.4 Formulation of Stiffness 25

3.3 A General Purpose Finite Element

Program (NONSAP) . . . . . . . . 28

3.3.1 Element Types . . . . . . 29

3.3.2 Material Models . . . . . 37

4 MODELING OF THE BEARING SYSTEM . . . • • . . 42

4.1 Capacity and Dimensions . . . . . . 44

4.2 The Finite Element Grid System

for the Different Shear Transfer

Conditions . . . . . . . . . . 48

4.3 Possible Solution Methods . . . . . 53

4.3.1 The Axisymmetric Solution . . . 53

4.3.1.1. Axisymmetric elements

4.3.1.2. Axisymmetric loading

4.3.2 The Plane Strain Plane Stress

Solution . . . . . . 58

4.3.2.1. Plane strain elements

4.3.2.2. Plane stress elements

4.3.2.3. Plane strain plane

stress loading

4.3.3 A Comparative Look at the

Proposed Solution Methods . . 62 
MATERIAL ELEMENT MODELS . . . . . . . 63

5.1 Steel Elements......... 64

5.1.1 Linear Elastic Isotropic Model. 65

5.2 Concrete Elements .. . . . . . 66

5.2.1 von Mises Yield Condition . . 69

5.2.2 Deviatoric Stress Invariants . 70

5.3 Interface Elements . . . . . . . . 73

5.3.1 The Case of Zero Shear Transfer 74

5.3.2 The Case of Infinite Shear

5.3.3 The Case with Shear Transferred

75

Through Interface Elements . . 76

5.3.3.1. Linkage element by

Ngo and Scordelis

5.3.3.2. Two-dimensional

interface element by

Ghaboussi, wilson, and Isenberg

MODELING OF BEARING SYSTEM

INTERFACE ELEMENTS

6.1 Interface Spring Elements . . . . 84

6.2 Interface spring Elements Stiffness . 91

6.2.1 Example Problem . . . . . . 94

6.3 The Bearing System Modeled with

Interface Spring Elements . . . . . 101

6.4 A Nonlinear Description of Slip . . . 117

6.5 Remarks . . . . . . . . . 118

7 EFFECT OF SHEAR TRANSFER . . . . . . . 123

7.1 Assumed Different Shear

Transfer Conditions . . . . . . 123

7.2 Results and Discussion .... . . . 134

7.2.1 Effect of Shear Transfer on

the Pot Bearing and Masonry

Steel Plates Deformation . . 135

7.2.2 Effect of Shear Transfer on

the Pot Bearing and Masonry

Steel Plates Bending Stresses. 138

7.2.3 Effect of Shear Transfer on

the Normal and Shear Stress

Distribution in the concrete

Abutment 
CHAPTER

PAGE

8

SUMMARY AND CONCLUSIONS

LIST OF REFERENCES

APPENDIX A

A.1 Formulation of the Linkage Element by Ngo and Scordelis

A.2 Formulation of the Two-Dimensional Interface Element by Ghaboussi, Wilson, and Isenberg

A.2.1 Plane Interface Element

A.2.2 Axisymmetric Interface Element

APPENDIX B

B.l Horizontal Interface Spring Element Stress - Strain Diagrams for the Different Slip Conditions

B.2 Normal Stresses transferred through the Vertical Interface Spring Elements

B. 3 Normal Stresses transferred through the Interface Spring Elements for the Different Shear Transfer Conditions

APPENDIX C - BEARING SYSTEM MATERIAL PROPERTIES .

C.I Pot Bearing and Masonry Steel Plates

C.2 Concrete Abutment 


\section{LIST OF TABLES}

NO.

PAGE

3.1 Some typical types of elements . . . . . . . 18

3.2 Truss element material models . . . . . . 38

3.3 Two-dimensional material models . . . . . . 39

3.4 Three-dimensional material models . . . . . 4 I

6.1 Plane strain solution. Averaged

bending stresses (Ksi) in the top

elements of the upper beam. Gauss

integration points 2 and 4... . . . . . 98

6.2 Plane strain solution. List of relative

vertical and horizontal displacements

between various nodes adjacent to the

interface zone (inches).

6.3.a Vertical interface spring elements cross-sectional areas

6.3.b Horizontal interface spring elements cross-sectional areas . . . . . . . 103

6.4.a Axisymmetric solution. Averaged bending stresses (Ksi) in top of the pot bearing steel plate. Gauss integration points 2 and 4 .

6.4.b Plane strain solution. Averaged bending stresses ( $\mathrm{Ksi}$ ) in top of the pot bearing steel plate. Gauss integration points 2 and 4

6.5.a Axisymmetric solution. Averaged bending stresses (Ksi) in top of the masonry steel plate. Gauss integration points 2 and 4 .

6.5.b Plane strain solution. Averaged bending stresses (Ksi) in top of the masonry steel plate. Gauss integration points 2 and 4 
NO.

PAGE

6.6.a Axisymmetric solution. Averaged vertical stresses (Ksi) in concrete elements. Gauss integration points 2 and 4.............. . 110

6.6.b Plane strain solution. Averaged vertical stresses (Ksi) in concrete elements. Gauss integration points

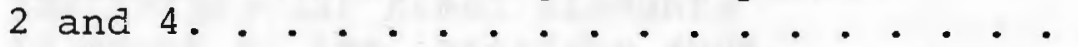

6.7.a Axisymmetric solution. Averaged shearing stresses (Ksi) in concrete elements. Gauss integration points 2 and 4.

6.7.b Plane strain. Averaged shearing stresses (Ksi) in concrete elements. Gauss integration points 2 and 4 . . . . . . . .

6.8 Effect of using interface spring elements on maximum bearing system stresses modeled to represent the cases of infinite and zero shear transfer conditions for axisymmetric and plane strain solution methods.

6.9 Shear stresses transferred through the horizontal interface spring elements in the case of infinite shear transfer. . . .

7.1.a Infinite shear transfer condition . . .

7.1.b Shear transfer condition resulting from assuming the horizontal spring elements equal $70 \%$ of the maximum shear stress transferred in the infinite shear transfer condition

7.1.c Shear transfer condition resulting from assuming the horizontal spring elements equal $50 \%$ of the maximum shear stress transferred in the infinite shear transfer condition. . . . . . . . . . . . . .

7.1.d Shear transfer condition resulting from assuming the horizontal spring elements equal $30 \%$ of the maximum shear stress transferred in the infinite shear transfer condition.

7.1.e Zero shear stress condition 
7.2 Percentage of change in the shear stresses transferred through the interface spring elements in both the axisymmetric and plane strain solutions.

7.3.a Axisymmetric solution. Vertical and horizontal displacements in top of the triangular steel elements adjacent to the interface zone. . . . . . 140

7.3.b Plane strain solution. Vertical and horizontal displacements in top of the triangular steel elements adjacent to the interface zone. . . . . . . 142

7.4.a Axisymmetric solution. Averaged bending stresses (Ksi) in the top of the pot bearing steel plate.

7.4.b Plane strain solution. Averaged bending stresses in the top of the pot bearing steel plate. Gauss integration points 2 and 4............... 150

7.5.a Axisymmetric solution. Averaged bending stresses (Ksi) in the top of the masonry steel plate. Gauss integration points

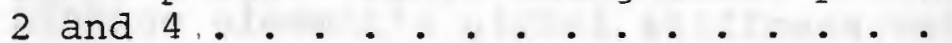

7.5.b Plane strain solution. Pveraged bending stresses (Ksi) in the top of the masonry steel plate. Gauss integration points 2 and $4 .$. . . . . . . . . . . . 158

7.6.a Axisymmetric solution. Averaged vertical stresses (Ksi) in concrete elements. Gauss integration points 2 and 4 . . . . 169

7.6.b Plane strain solution. Averaged vertical stresses (Ksi) in concrete elements. Gauss integration points 2 and 4. . . . . 170

7.6.c Axisymmetric solution. Percentage of change in averaged normal concrete compressive stresses. 
7.7.a Axisymmetric solution. Averaged shear stresses (Ksi) in concrete elements. Gauss integration points 2 and 4. . . . . 175

7.7.b Plane strain solution. Averaged shear stresses (Ksi) in concrete elements. Gauss integration points 2 and 4... . . . 176

7.8.a Axisymmetric solution. Average decrease of concrete shear stresses in conjunction with the average decrease of shear stresses transferred through the interface zone................ . 177

7.8.b Plane strain solution. Average decrease of concrete shear stresses in conjunction with the average decrease of shear stresses transferred through the interface zone. . .

7.9.a Axisymmetric solution. Concrete yield status in different shear transfer conditions.

7.9.b Plane strain solutikn. Concrete yield status in different shear transfer conditions. . . . . . . . . . . . . . . .

A.I Linkage element's global stiffness matrix . . 197

A.2 Plane interface element "global stiffness matrix for nondilatant materials. . . . . 205

A.3 [B] matrix in the axisymmetric element strain-displacement relation........ 208

A.4 Axisymmetric interface element global stiffness matrix for nondilatant material..

B.1 Horizontal interface spring elements stress - strain relation .. . . . . . . 212

B.2 Horizontal interface spring elements stress - strain relation . . . . . . . . 213

B.3 Horizontal interface spring elements stress - strain relation 
B. 4 Normal stresses transferred through the vertical springs... . . . . . . 215

B.5.a Axisymmetrical solution . . . . . . . 216

B.5.b Plane strain solution .......... . 217 
LIST OF FIGURES

NO.

PAGE

1.1 Bearing System . . . . . . . . . . . . 3

2.1 Beam on elastic foundation model used in the previous analysis . . . . . . .

2.2 Bearing system finite element two-dimensional model used in the previous analysis . . . .

2.3 Actual and assumed stress distribution in the concrete beneath the masonry plate . .

3.1 Actual structure and finite element grid system . . . . . . . . . . . . 15

3.2 Beam element . . . . . . . . . . . . 23

3.3 Truss element in space . . . . . . . . . . 30

3.4 Possible two-dimensional finite element analysis . . . . . . . . . . 32

3.5 A general two-dimensional element . . . . . . 33

4.1 Three-dimensional solid model . . . . . . . 43

4.2 Axisymmetric cylindrical model . . . . . . . 45

4.3 Two-dimensional 1-inch wide model . . . . . . 46

4.4 Dimensions of 150-Kips bearing system . . . . 47

4.5 Finite element grid system for the
zero shear transfer case . . . . . . . . . 49

4.6 Finite element grid system for the continuum case . . . . . . . . . 51

4.7 Finite element grid system for the bearing system including interface spring elements . . . . . . . . . . . . 
NO.

4.8 Cylindrical coordinates . . . . . . . 55

4.9 Top view of the axisymmetric section of the pot plate

4.10 Distribution of the axisymmetrical model nodal loads . . . . . . . . . .

4.11 Top view of the plane-strain or plane-stress section of the pot plate... 60

4.12 Distribution of the plane strain or plane stress nodal loads

5.1 Typical concrete compressive stress - strain curves . . . . . . . . .

5.2 General stress components......... 71

5.3 Linkage element............ . 78

5.4 Two-dimensional interface element..... . 80

5.5 Interface element displacements... . . . 81

5.6.a Stress - strain relation in the normal direction . . . . . . . . . . . 83

$5.6 . b$ Stress - strain relation in the tangential direction . . . . . . . . . .

6.1 Vertical and horizontal interface spring elements . . . . . . . .

6.2.a Vertical spring stress - strain diagram . . . 87

6.2.b Horizontal spring stress - strain diagram . . 87

6.3 Spring element . . . . . . . . . . 88

6.4 Case of infinite shear transfer . . . . . 92

6.5 Case of zero shear transrer . . . . . . 93

6.6.a Two beams with infinite shear transfer condition . . . . . . . . . . . . . .

6.6.b Two beams with zero shear transfer condition 
NO.

6.6.C Two beams with

interface spring elements . . . . . . . .

6.7 Top part of the bearing system

including interface spring elements. . . 105

7.1 Axisymmetric solution. Shear stress

distribution along the horizontal

interface spring elements ........ 133

7.2 Axisymmetric solution. Horizontal

displacement curves for the different shear transfer conditions........ 144

7.3 Axisymmetric solution. Vertical displacement curves for the different shear transfer conditions . . . . . . 145

7.4 Axisymmetric solution. Deformation of the top nodes of the triangular steel elements adjacent to the interface zone. . 146

7.5.a Plane strain solution. Horizontal displacement curves for the different shear transfer conditions . . . . . . 147

7.5.b Plane strain solution. Vertical displacement curves for the different shear transfer conditions . . . . . . . . . 148

7.6 Percentage of change in bending stresses in top of the pot bearing steel plate. . 152

7.7.a Axisymmetric solution. Bending stress distribution in top of the pot bearing plate .............. 153

7.7.b Plane strain solution. Bending stress distribution in top of the pot bearing plate................ 154

7.8 Bending stresses along a normal line through elements at the center of the pot bearing and masonry plates . . . . 155

7.9.a Axisymmetric solution. Distribution of averaged bending stresses in top of the masonry plate. Gauss integration points 2 and 4 
NO.

PAGE

7.9.b Plane strain solution. Bending stress

distribution in top of the masonry

steel plate. Gauss integration points

2 and $4 . . . . . . . . . . . .161$

7.10.a Axisymmetric solution. Bending stress

distribution along a vertical line

passing through the critical section

of the masonry steel plate ... . . . 163

7.10.b Axisymmetric solution. Bending stress

distribution along a vertical line

passing through the end steel elements

of the masonry steel plate ....... . 164

7.11.a Axisymmetric solution. Averaged normal

stresses in concrete elements. Gauss

integration points 2 and 4 ....... 167

7.11.b Plane strain solution. Averaged normal

stresses in concrete elements. Gauss

integration points 2 and 4 ...... 168

7.12 Axisymmetric solution. Averaged shear

stresses in concrete elements.

Gauss integration points 2 and 4. . . . 174

A.I Geometry of the 2-D interface element... 200

A.2 Interface element relative displacements

in local coordinates ... . . . . . 201

B.1 Horizontal interface spring elements stress - strain diagram (not to scale) . . 211

C. 1 Concrete stress - strain diagram . . . . . 219 
CHAPTER 1

INTRODUCTION

Pot bearing steel plates have been successfully used for many years in bridges with varying span and magnitude. Pot bearing steel plates can be physically described as steel plates containing a circular disc of an elastomeric material confined in a pot. A "masonry" steel plate is usually placed beneath the pot to distribute stresses to the supporting concrete abutment as shown in fig. (1.1). The width and length of the masonry plate are sized to keep the stresses in the concrete less than an allowable value to avoid failure of the concrete. Normally, for design purposes, a uniform distribution of concrete stresses beneath the masonry plate is assumed. The thickness of the masonry plate is controlled by bending stresses. It is assumed that the critical section of the masonry plate is near the end of the pot bearing. Allowable concrete stresses as given by AASHTO [1] vary from $0.30 \mathrm{f}_{\mathrm{C}}^{\prime}$ to a maximum of $0.60 \mathrm{f}_{\mathrm{c}}^{\prime}$ depending on the ratio of the supporting concrete area to the loaded concrete area, where $f_{c}^{\prime}$ is the compressive strength of the concrete. The large allowable values attempt to take account of the effect of confining pressure on the failure strength of the concrete. 
Allowable steel stresses are taken as 0.55 of the yield stress. Bearing plates of this type permit the bridge girders to expand due to temperature without developing large lateral forces at the supports. They also distribute vertical reactions through the pot to the masonry plate below.

Although the bearing system designed according to the normal design procedure described above does in fact show great performance in actual situations, it should be expected that allowable bending stresses in the critical section of the masonry plate would be very large because of the uniform stress distribution beneath the masonry plate.

Results from previous analysis indicated that stresses beneath the masonry plate actually have shown little lateral stress distribution. Therefore, from the basic knowledge of structural analysis it is expected that the maximum stress in the critical section of the masonry plate should actually be lower than the design stress. Hence, those findings are examined extensively in this investigation in an attempt to study the effect of shear transfer between the surface of the masonry plate and the concrete abutment, on the stresses of the bearing system. 


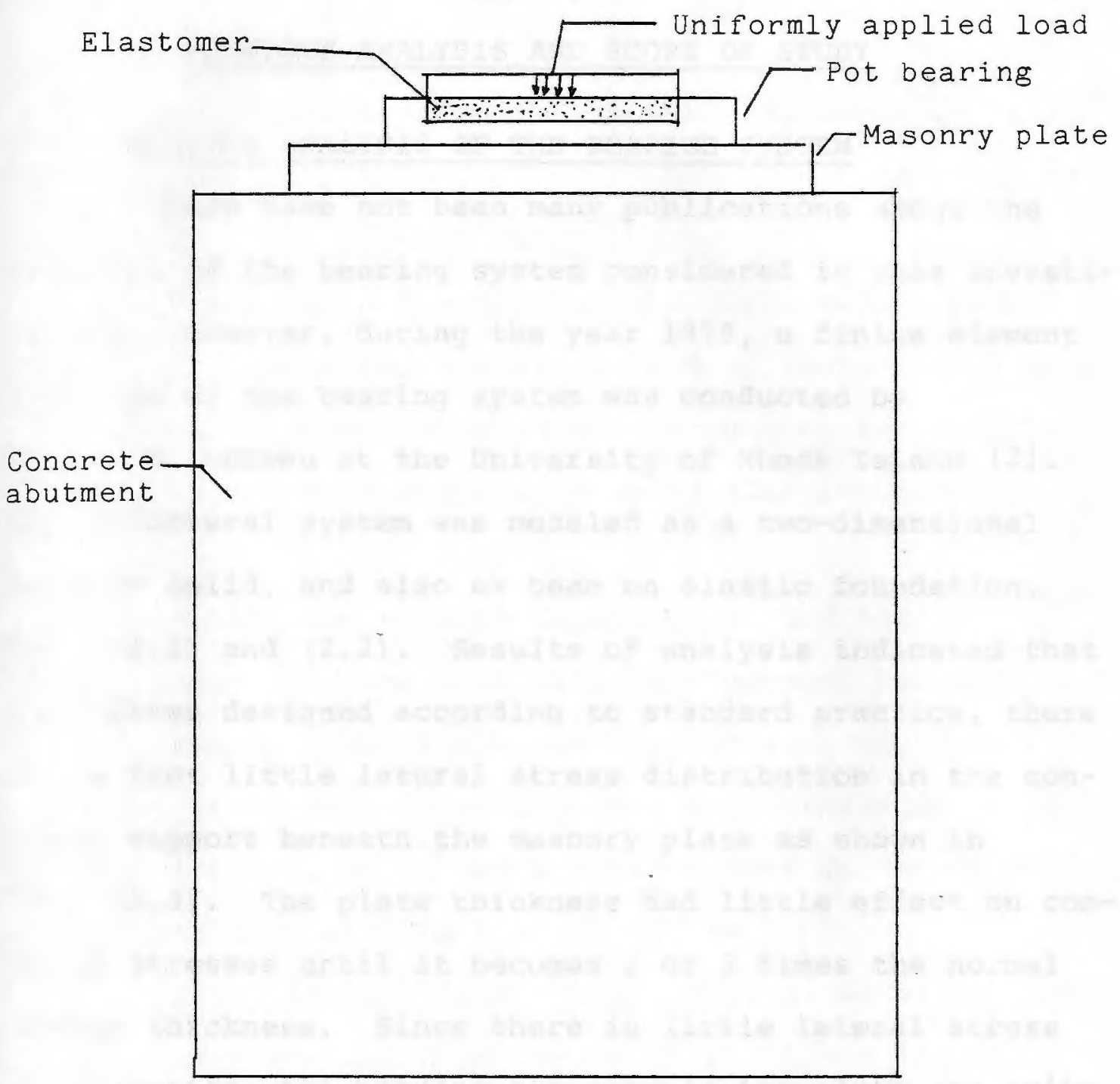

Fig. (1.1) Bearing System 


\section{CHAPTER 2 PREVIOUS ANALYSIS AND SCOPE OF STUDY}

\subsection{PREVIOUS ANALYSIS OF THE BEARING SYSTEM}

There have not been many publications about the analysis of the bearing system considered in this investigation. However, during the year 1979, a finite element analysis of the bearing system was conducted by Dr. E. E. McEwen at the University of Rhode Island [2], The structural system was modeled as a two-dimensional elastic solid, and also as beam on elastic foundation, fig. (2.1) and (2.2). Results of analysis indicated that for plates designed according to standard practice, there is in fact little lateral stress distribution in the concrete support beneath the masonry plate as shown in fig. (2.3). The plate thickness had little effect on concrete stresses until it becomes 2 or 3 times the normal design thickness. Since there is little lateral stress distribution, the bending stresses in the plate are quite small. Plates that are one-half the normal thickness have stresses less than the allowable. Results also indicated that stresses in the concrete are extremely high approaching the applied pressure on the bearing, and this is due to the little lateral stress distribution. However, as 
between the steel masonry plate and the concrete abutment was represented by vertical and horizontal interface spring elements. The horizontal interface spring elements transfer shear until an ultimate shear strength value is reached, where the bond between the steel and concrete elements breaks and slip takes place. Slip along the interface was described as a nonlinear function, and different shear transfer conditions were assumed. The study was conducted using finite element analysis with the aid of the general-purpose finite element computer program NONSAP [4] (Nonlinear Structural Analysis Program). 


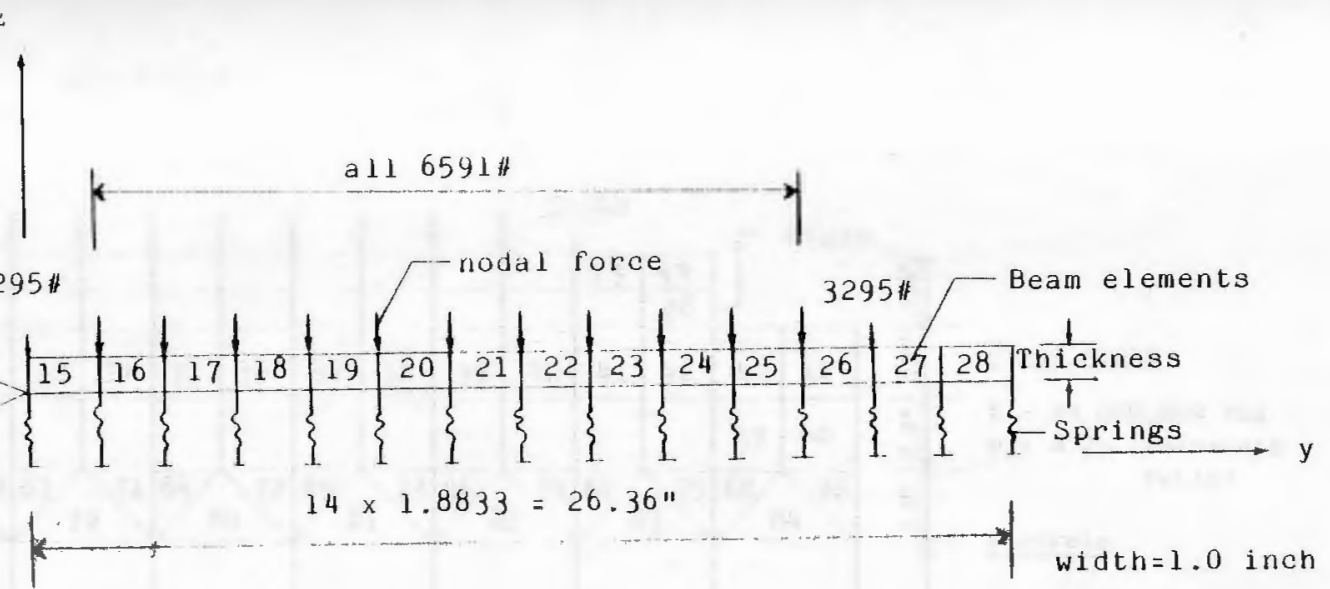

Steel Plate

$E=29,000,000$ Psi (modulus of elasticity)

$I$ = varies with thickness (moment of' inertia)

Concrete Springs

$E=3,605,000 \mathrm{Psi}$

$\mathrm{f}_{\mathrm{C}}^{\prime}=4,000 \mathrm{Psi}$

$K=\frac{A E}{L}=\frac{(1 .)(1.8833)(3,605,000)}{18}=377,000$ \#/inch, $K=$ spring stifrness

= cross sectional area

$L=$ length

fig. (2.1.) lieam on elastl: pumbation model used in the previous analysis. 


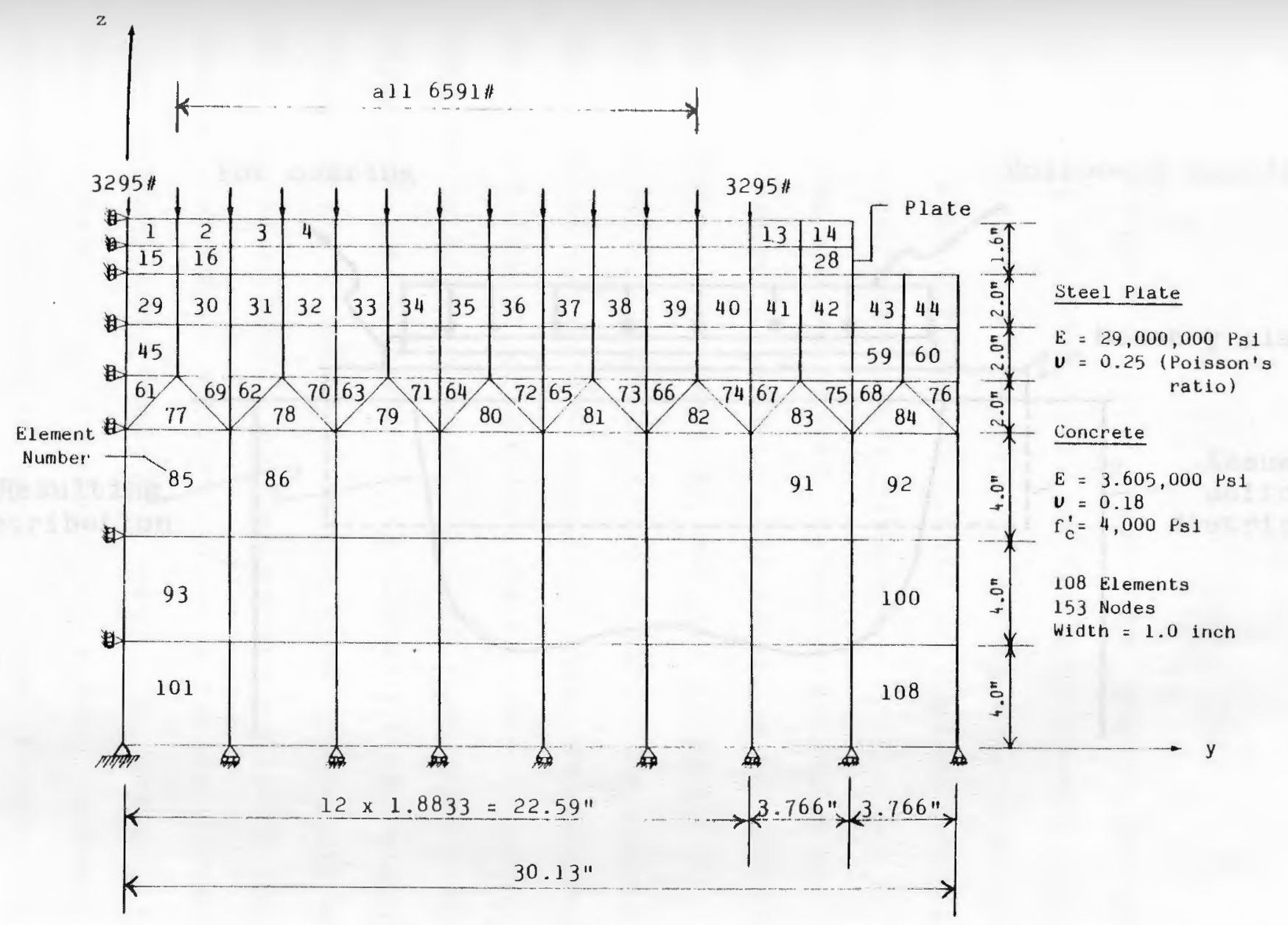

Fig. (2.2) Bearing system finite element two-dimensional model used In the previous analysis. 


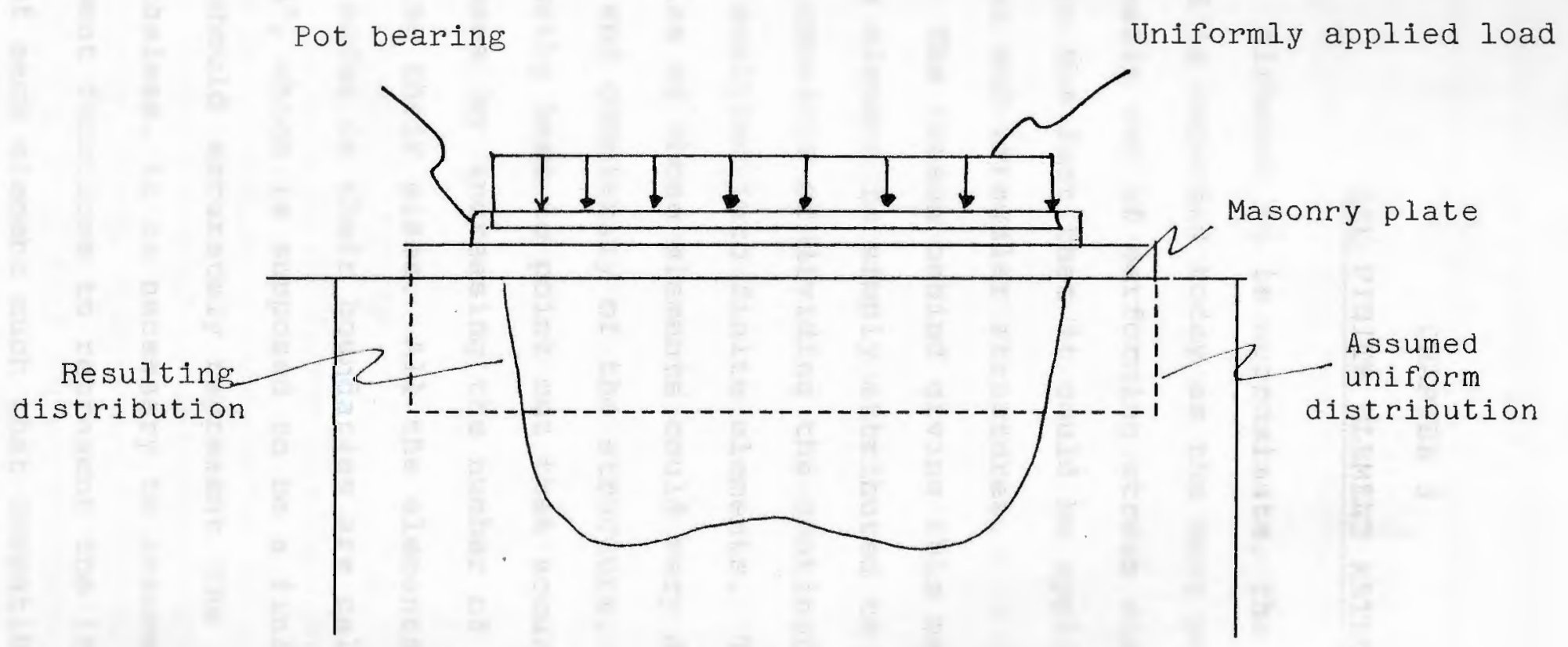

Fig. (2.3) Actual and assumed stress distribution in the concrete beneath the masonry plate. 


\section{CHAPTER 3}

\section{THE FINITE ELEMENT METHOD}

Although it is approximate, the finite element method is regarded today as the most powerful and systematic way of performing stress analysis. Its power lies in the fact that it could be applied on very highly complex and irregular structures.

The reason behind giving this method the name finite element is simply attributed to the procedure, which consists of dividing the continuum of the structure to be analyzed into finite elements. The number, shape, and size of those elements could vary depending on the shape and complexity of the structure. However, it is noteworthy here to point out that accuracy of the results increases by increasing the number of the elements and reducing their sizes. All the elements connected together by nodes on their boundaries are called a "grid system", which is supposed to be a finite element model that should accurately represent the actual structure. Nevertheless, it is necessary to assume adequate displacement functions to represent the internal displacement of each element such that compatibility is satisfied 
along common nodes and boundaries.

Generally speaking, the finite element method is composed of two major solution steps. 1) The element solution dealing with the individual elements. Adequate displacement functions are assumed for the different types of elements, such that internal displacements of each element are uniquely described in terms of nodal displacements. Nodal strains are acquired through the derivation of nodal displacements and then related to symbolic nodal stresses through a stress-strain relation. Using energy methods, we could construct a relationship between nodal forces and nodal displacements represented by a stiffness matrix for each individual element. 2) The system solution which is simply combining the stiffness matrices of all the individual elements to construct the structure stiffness matrix. The system solution is independent from the different types of elements used to model the structure.

\subsection{HISTORICAL REVIEW}

Authors of different finite element textbooks disagreed on selecting a time period as a start of the finite element method of analysis. Moe suggested that the concept of the method was "originally introduced" by Argyris in a series of papers published in 1954-55 [5]. On the other hana, Cook [6] refers to the year 1906 as 
the start of the concept which the finite element method was based on. Researchers suggested the "lattice analogy" to solve the continuum problems by approximating the continuum by a regular mesh of elastic bars. Others like Gallagher [7] consider the period from 1850 to 1875 as the "logical starting point" of a review of the history of the finite element method. During this period, the framework analysis developed due to the work of Maxwell, Castigliano, and Mohr, among others. Framework analysis is the base of matrix analysis on which the finite element solution depends to a great extent.

Finite element method is part of a science that depends for its progress on the experiences and accomplishments of past generations. However, progress was extremely slow due to difficulties concerning the solution of algebraic system of equations with many unknowns. Since mid 1950's there has been a concurrent and rapid development of matrix analysis methods and electronic digital computers, and the finite element method was put into practical use. Many important conferences have been devoted exclusively to these subjects, and the first textbooks appeared in 1967 and 1968 [5]. By 1976, about two decades after engineering applications began, there have been more than 7000 publications about the finite element method [6]. General purpose computer programs of finite element analysis are now extensively dispersed 
in practice.

\subsection{FINITE ELEMENT PROCEDURE}

The finite element method is an extension of the stiffness or displacement method. However, unlike skeletal structures, there are now well defined joints where equilibrium of forces can be established. In finite element method, the continuum is divided into elements of different shapes and sizes, and each element is bounded by artificial nodes (internal nodes could exist as well). The system of elements is called the grid system which represents the finite element model that approximates the actual structure. Each node in the grid system has a number of degrees of freedom, which combined, give a number of algebraic equations to be solved numerically so that the analysis would be completed.

It is worthwhile mentioning. at this point that there are three types of commonly used elements, [8], 1) Displacement element, using assumed displacement functions, forms the majority of known finite elements; 2) Equilibrium element, based on assumed stress functions; and 3) Hybrid element, which is based on both assumed displacement and stress functions. Elements (2) and are used to a much lesser extent. As described in the next chapter, displacement elements are used in the modeling of the bearing system. 


\subsubsection{THE GRID SYSTEM}

A continuum is divided into two-dimensional finite elements, which are separated by straight or curved lines and bounded by nodal points (internal nodal points could exist), or it could be divided into threedimensional finite elements, which are separated by flat or curved surfaces. The shapes, sizes, material properties and thicknesses of the elements within the grid system could vary. Therefore, the finite element method could handle problems involving nonhomogeneous properties, complex geometry and support conditions, and various types of loading situations.

A cantilever beam, shown in fig. (3.1.a), is loaded uniformly at its edge. The continuum is approximated by a grid system, shown in fig. (3.1.b), composed of triangular (two-dimensional) elements separated by straight lines, and each element is bounded by three nodal points at its corners. The uniform load on the actual structure is represented by a load system applied at the nodes. Boundary conditions are satisfied through carefully selected characteristics of the boundary nodal points representing the fixed end of the cantilever beam. In many problems, only one type of element is needed to construct a grid system of a structure. Nevertheless, it is also possible to mix elements of different types, as will be shown in the next chapter, where the steel bearing system is divided into linear elastic 

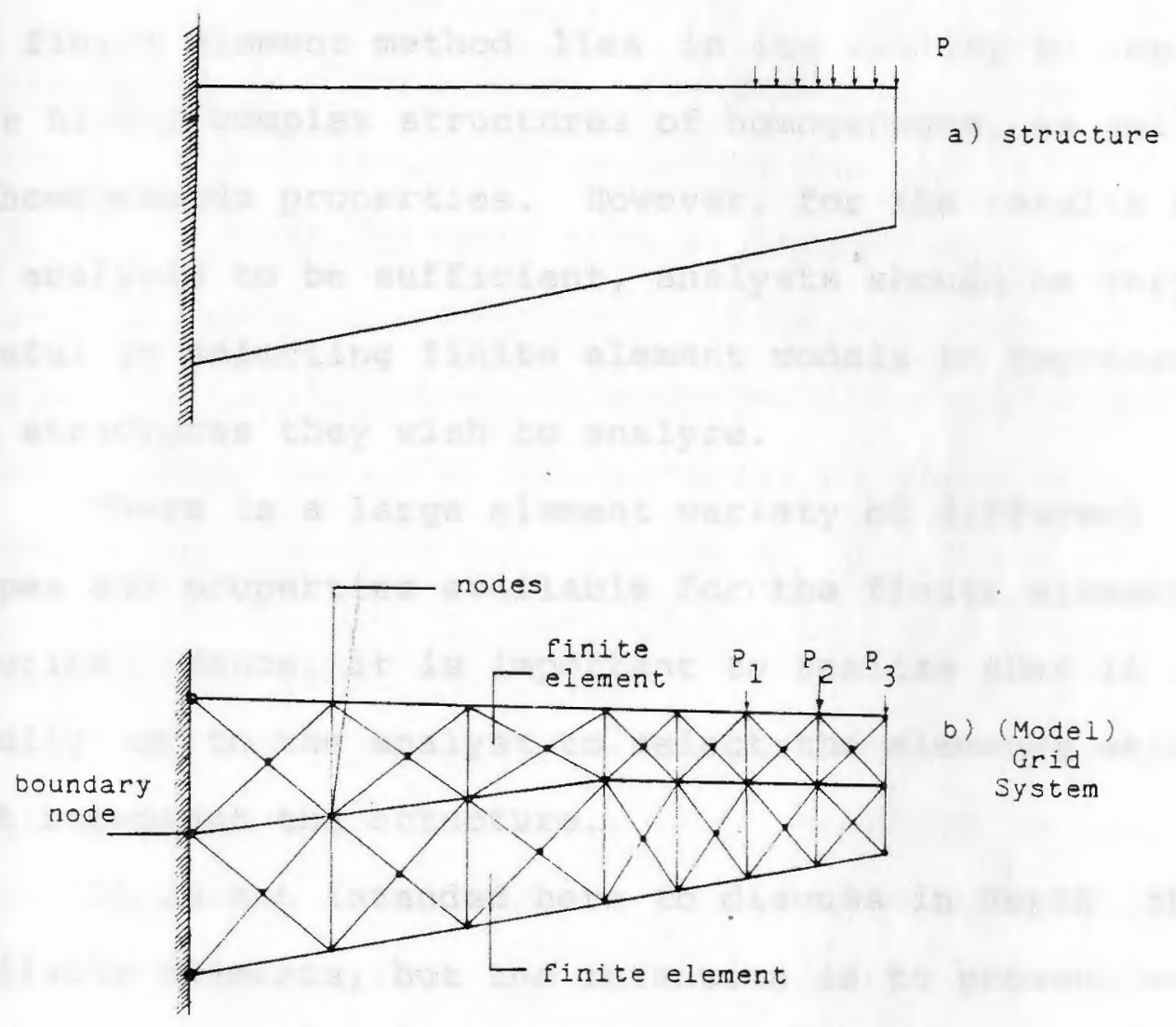

Eig. 3.1 Actual structure and finite element grid system. 
isotropic elements, the concrete abutment is divided into nonlinear elasto-plstic isotropic elements, and both are connected by interface spring elements.

\section{2 .2 ELEMENTS VARIETY}

As mentioned in previous sections, the power of the finite element method lies in its ability to represent highly complex structures of homogeneous, as well as nonhomogeneous properties. However, for the results of the analysis to be sufficient, analysts should be very careful in selecting finite element models to represent the structures they wish to analyze.

There is a large element variety of different shapes and properties available for the finite element solution. Hence, it is important to realize that it is totally up to the analyst to select the elements which best represent the structure.

It is not intended here to discuss in depth the available elements, but the intention is to present some of the simple and important ones. Available elements could be separated into three main categories: 1) onedimensional, 2) two-dimensional, and 3) threedimensional. Moreover, elements belonging to each of the three mentioned categories also vary in shape, number of degrees of freedom, number of nodes; all could have different material properties depending on the problem. 
Some of the elements used in modeling the bearing system will be discussed with more depth in later chapters. Table (3.1) presents some of the simplest types of one-, two-, and three-dimensional elements as examples of available ones [5].

The nodal degrees of freedom normally refer to the displacements and rotations. The order of the element stiffness matrix is usually equal to the number of degrees of freedom in the element, that is because each degree of freedom produces an algebraic equation with one unknown, usually the displacement. The degrees of freedom could also represent relative displacements as shown in Appendix A.

\subsubsection{DISPLACEMENT FUNCTIONS}

Once the grid system is constructed and the elements are selected, then it is very important to select what is called a "displacement funçtion" which represents internal element displacements expressed in terms of nodal displacements. Displacement functions must be selected such that compatibility along the boundaries of adjacent elements is satisfied.

A displacement function could be defined as an interpolation function which describes the element internal displacement in terms of the nodal displacements. Discussion of displacement functions of three 


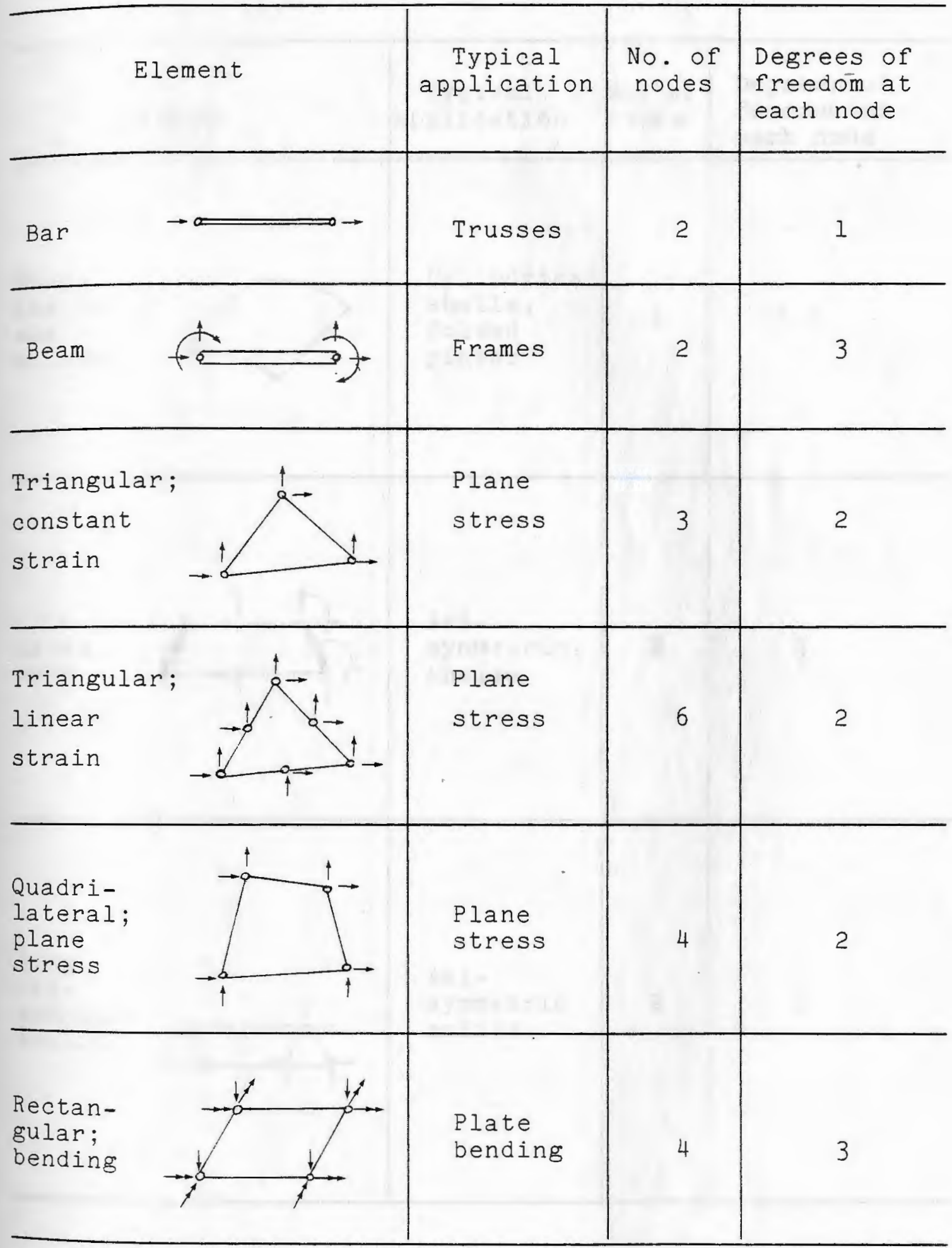

Table (3.1) Some typical types of elements (continued on next page) 


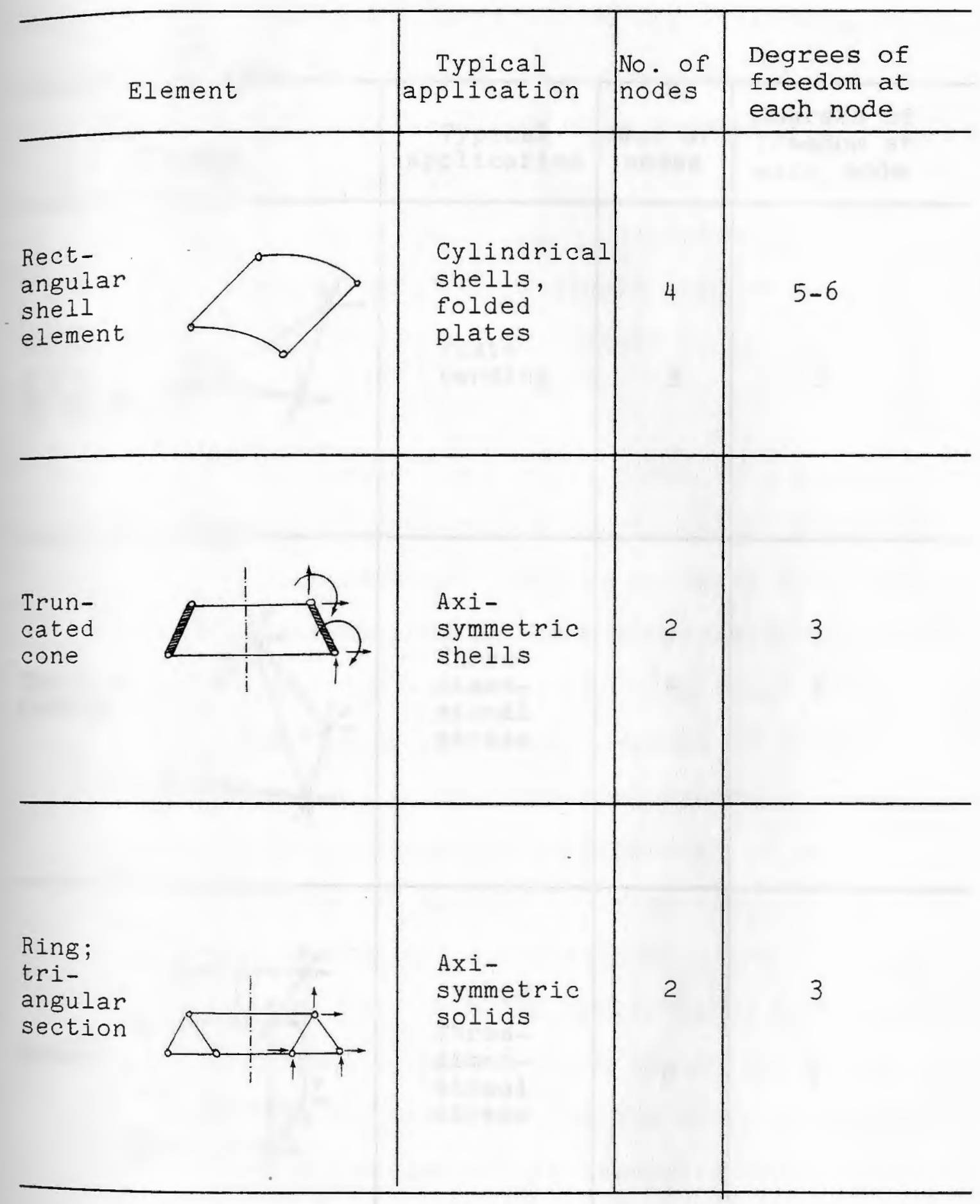

Table ( 3.1 ) continued 


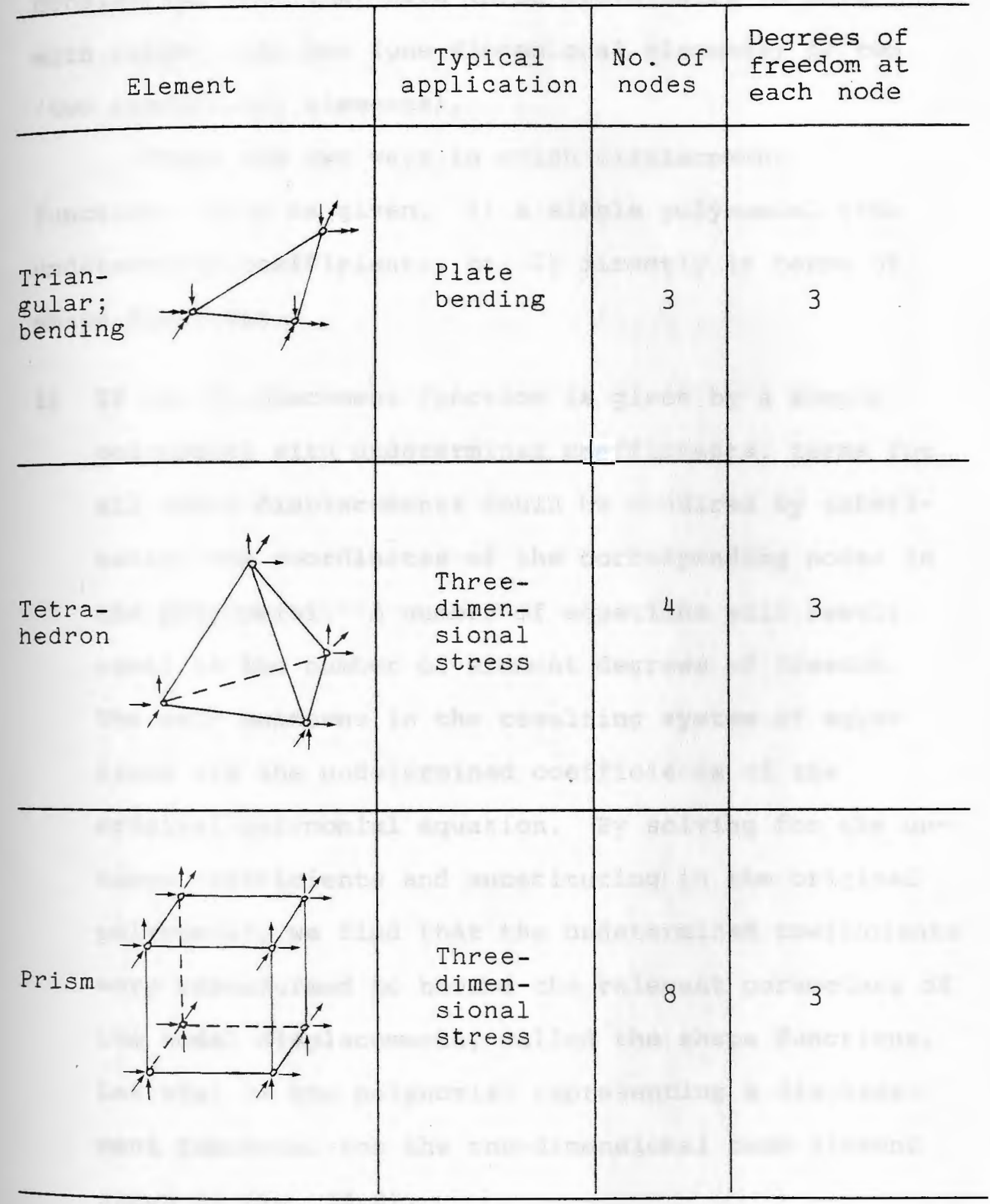

Table (3.1) continued 
dimensional elements will not be necessary in the scope of this thesis; however, they follow the same pattern considering that they have three coordinates to work with rather than one (one-dimensional elements) or two (two dimensional elements.).

There are two ways in which displacement functions could be given, 1) a simple polynomial with undetermined coefficients, or 2) directly in terms of shape functions.

1) If the displacement function is given by a simple polynomial with undetermined coefficients, terms for all nodal displacements could be acquired by substituting the coordinates of the corresponding nodes in the polynomial. A number of equations will result equal to the number of element degrees of freedom. The only unknowns in the resulting system of equations are the undetermined coefficients of the original polynomial equation. By solving for the unknown coefficients and substituting in the original polynomial, we find that the undetermined coefficients were transformed to become the relevant parameters of the nodal displacements, called the shape functions. Let $u(x)$ be the polynomial representing a displacement function, for the one-dimensional beam element shown in fig. (3.2). 
$u(x)=a_{1}+a_{2} x+a_{3} x^{2}+a_{4} x^{3}$

$\theta(x)=0+a_{2}+2 a_{3} x+3 a_{4} x^{2}$

where $\theta$ is the first partial derivative of $u(x)$ representing nodal rotations.

Expressing (3.1) in matrix notation,

$u(x)=[G]\{a\}$

where $[G]=\left[\begin{array}{llll}1 & x & x^{2} x^{3}\end{array}\right] ; \quad\{a\}^{T}=\left\{a_{1} a_{2} a_{3} a_{4}\right\}$

As shown, the number of degrees of freedom equals the number of undetermined coefficients in (3.1). Substituting the coordinates of nodes 1 and 2 in (3.1), we acquire terms for the corresponaing nodal displacements, $\left(u_{1}, \theta_{1}, u_{2}, \theta_{2}\right)$.
a $x=0$
$\mathrm{u}=\mathrm{u}_{7}$
$\theta=\theta_{1}$
a $x=L$
$\mathrm{u}=\mathrm{u}_{2}$
$\theta=\theta_{2}$

resulting
$\left\{\begin{array}{l}u_{1} \\ \theta_{1} \\ u_{2} \\ \theta_{2}\end{array}\right\}=\left[\begin{array}{l}1 \\ 0 \\ 1 \\ 0\end{array}\right.$
$\begin{array}{cc}0 & 0 \\ I & 0 \\ L & L^{2} \\ I & 2 L\end{array}$
$\left.\begin{array}{c}0 \\ 0 \\ L^{3} \\ 2\end{array}\right]\left\{\begin{array}{l}a_{1} \\ a_{2} \\ a_{3} \\ a_{4}\end{array}\right\}$

in short form 


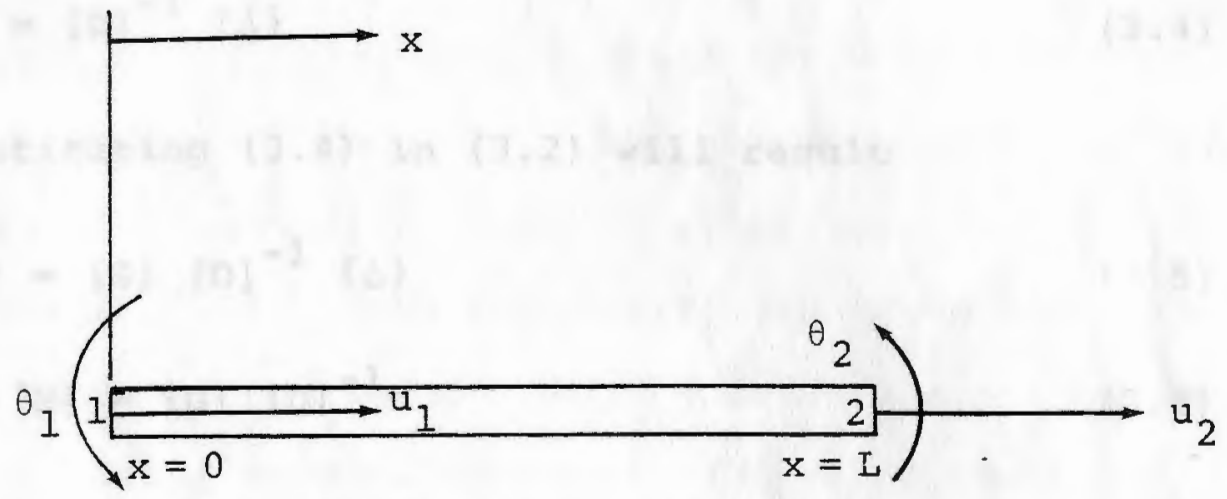

Fig. (3.2) Beam element. 
$\{\Delta\}=[D]\{a\}$

where $\{\Delta\}=$ nodal displacements.

solving (3.3) for $\{a\}$ will result

$\{a\}=[D]^{-1}\{\Delta\}$

Substituting (3.4) in (3.2) will result

$u(x)=[G][D]^{-1}\{\Delta\}$

Let $[N]=[G][D]^{-1}$

then the displacement function becomes

$u(x)=[N]\{\Delta\}$

where $[\mathrm{N}]=\left[\begin{array}{llll}\mathrm{N}_{1} & \mathrm{~N}_{2} & \mathrm{~N}_{3} & \mathrm{~N}_{4}\end{array}\right]$

and

$\mathrm{N}_{1}, \mathrm{~N}_{2}, \mathrm{~N}_{3}$ and $\mathrm{N}_{4}$ are the shape functions for the corresponding element degrees of freedom. It could be easily verified that $\mathrm{N}_{i}$ is equal unity only at node (i), and zero at all other nodes. That gives us the displacement field over an element when node (i) is given unit displacement while keeping all other nodes fixed.

For displacement functions of two-dimensional elements given in terms of simple polynomials, the analyst could use the Pascal triangle [8] to determine the combination of terms which should be 
used.

2) Displacement functions could also be given directly in terms of shape functions as shown in (3.7). There are interpolation functions which state the shape functions directly, avoiding all the work seen in equations (3.2) to (3.7). This is done by replacing (a's) in equation (3.1) by (N's) as seen in equation (3.7). Many polynomial functions such as the Lagrange polynomial and the Hermitian polynomial [8] among others, could be used to represent a displacement function. Shape functions for most available elements can be found tabulated and ready for use; in fact many are used in general purpose finite element computer programs.

3.2.4 FORMULATION OF STIFFNESS MATRIX AND LOAD MATRIX The next step which immediately follows the formulation of the displacement function, is to find nodal strains and stresses. Those strains and stresses will be used to construct the stiffness matrix of the element and its equivalent nodal forces. A general brief description of the procedure used to formulate the element stiffness matrix will be presented in this section. The principle of minimum total potential energy will be used in the formulation.

As shown in the above section in equation (3.7), the displacements are expressed in terms of the nodal 
displacements by the use of the shape functions which are functions of the coordinates. The strains are calculated by making appropriate differentiation of the displacement function, thus

$$
\{\varepsilon\}=[B]\{\Delta\}
$$

where $\{\varepsilon\}=$ strain matrix

[B] = appropriate derivative of [N]

The stresses are related to the strains by the [C] matrix, which is called the elasticity or the property matrix.

$\{\sigma\}=[C]\{\varepsilon\}$

Substituting (3.8) in (3.9)

$\{\sigma\}=[C][B]\{\Delta\}$

Total potential energy $(I I)$ is the sum of the strain energy (U) and the potential energy ( $V)$, thus

II $=\mathrm{U}+\mathrm{V}$

The strain energy

$U=\frac{1}{2} \int_{\text {vol }}\{\varepsilon\}^{T}\{\sigma\} \quad d_{\text {vol }}$

Substituting (3.8) and (3.10) in (3.12)

$U=\frac{1}{2} \int_{v o l}\{\Delta\}^{T}[B]^{T}[C][B][\Delta\} \quad d_{\text {vol }}$ 
The potential energy is

$\mathrm{v}=-\int_{\operatorname{vol}}\{\mathrm{u}\}^{\mathrm{T}}\{\mathrm{q}\} \quad \mathrm{d}_{\mathrm{vol}}$

where $\{u\}$ is taken from equation (3.7)

and $\{q\}$ is the distributed load matrix

$v=-\int_{\text {vol }}\{\Delta\}^{T}[N]^{T}\{q\} \quad d_{\text {vol }}$

Substituting (3.13) and (3.15) in (3.11)

$\mathbb{I}=\frac{1}{2} \int_{\text {vol }}\{\Delta\}^{\mathrm{T}}[B]^{\mathrm{T}}[\mathrm{C}][B]\{\Delta\} \quad \mathrm{d}_{\mathrm{vol}}$

$-\int_{\operatorname{vol}}\{\Delta\}^{\mathrm{T}}[\mathrm{N}]^{\mathrm{T}}\{\underline{q}\} \quad \mathrm{d}$ vol

The principle of stationary potential energy requires that the first partial differential of the total potential energy with respect to any nodal displacement must be zero. Thus, the equilibrium condition to be satisfied is,

$\frac{\partial \Pi}{\partial \Delta}=0$

Substituting $(3.16)$ in $(3.17)$ 


$$
\begin{aligned}
\frac{\partial I}{\partial \Delta}= & \int_{v o l}[B]^{T}[C][B]\{\Delta\} \quad d_{v o l} \\
& -\int_{v o l}[N]^{T}\{q\} \quad d_{v o l}=0
\end{aligned}
$$

or

$$
[\mathrm{K}]\{\Delta\}-\{\mathrm{P}\}=0
$$

where

$[\mathrm{K}]$ is the element stiffness matrix and

$\{P\}$ is the equivalent element nodal force

$$
[K]=\int_{\operatorname{vol}}[B]^{T}[C][B] \quad d_{\operatorname{vol}}
$$

$\{\mathrm{P}\}=\int_{\operatorname{vol}}[\mathrm{N}]^{\mathrm{T}} \mathrm{q} \quad \mathrm{d}_{\mathrm{vol}}$

\subsection{A GENERAL PURPOSE FINITE ELEMENT PROGRAM (NONSAP)} As described in the sections above, the finite element method of analysis involves rather.lengthy and complex computations. In practice, structures might have hundreds or even thousands of nodes resulting in stiffness matrices of very large orders. Hence, it is impossible to perform the analysis without the aid of digital computers. However, many general-purpose finite element programs have been developed to perform the analysis in a matter of minutes of computer time for large problems. The analysis of the bearing system in 
this thesis was performed by NONSAP [4], a generalpurpose nonlinear finite element structural analysis program. Several element types as well as a selection of material models are available in this program.

\subsubsection{ELEMENT TYPES}

There are three types of elements available for

use in NONSAP: (1) truss elements, (2) two-dimensional elements, and (3) three-dimensional elements. Since elements used in modeling the bearing system were twodimensional, special attention will be given to this type of element in this section.

(1) Truss Elements

A truss element is one-dimensional, has two nodes, and is only capable of transmitting axial forces, see fig. (3.3). For the truss element, the following formulations have been incorporated into NONSAP :

a) Linear elastic, small displacement analysis.

b) Small displacement analysis with material nonlinearities only.

c) Updated Lagrangian, but assuming small strains (with large displacements).

Since the material models considered are only defined for small strains, small strains are assumed in the calculation of stresses, and the changes in the cross sectional areas of the truss 


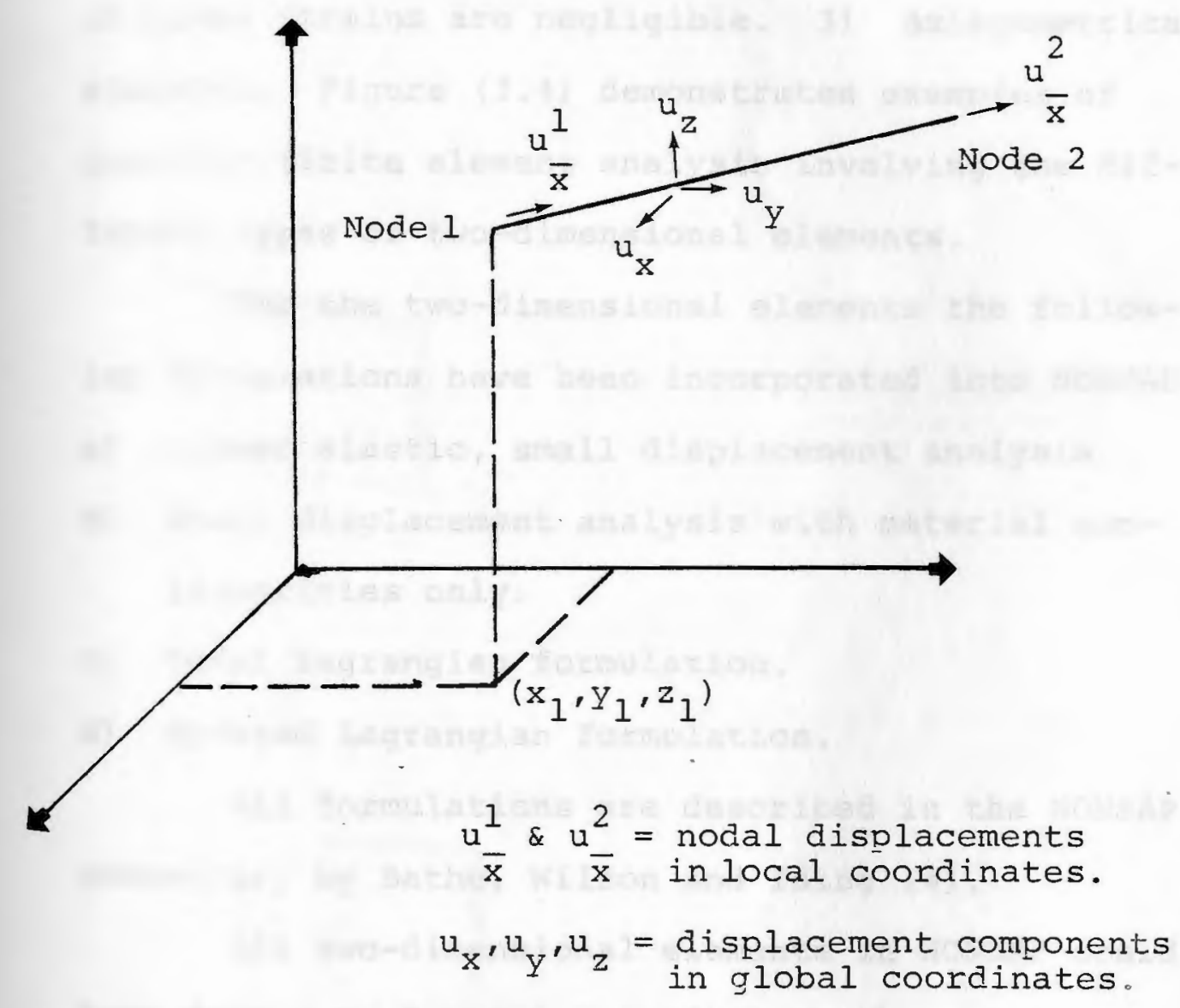

Fig. (3.3) Truss element in space. 
element is neglected during deformation.

(2) Two-dimensional Elements

The two-dimensional elements available in

NONSAP are: 1) Plane stress elements, with the assumption that out of plane shears and stresses are negligible. 2) Plane strain elements where the out of plane strains are negligible. 3) Axisymmetrical elements. Figure (3.4) demonstrates examples of possible finite element analysis involving the different types of two-dimensional elements.

For the two-dimensional elements the following formulations have been incorporated into NONSAP:

a) Linear elastic, small displacement analysis.

b) Small displacement analysis with material nonlinearities only.

c) Total Lagrangian formulation.

d) Updated Lagrangian formulation.

All formulations are described in the NONSAP commentary by Bathe, Wilson and Iding [4].

All two-dimensional elements in NONSAP could have from 3 to 8 nodes depending on the nature of the problem and the choice of the analyst.

Figure (3.5) represents a general two-dimensional element with the nodal points numbered as shown. 


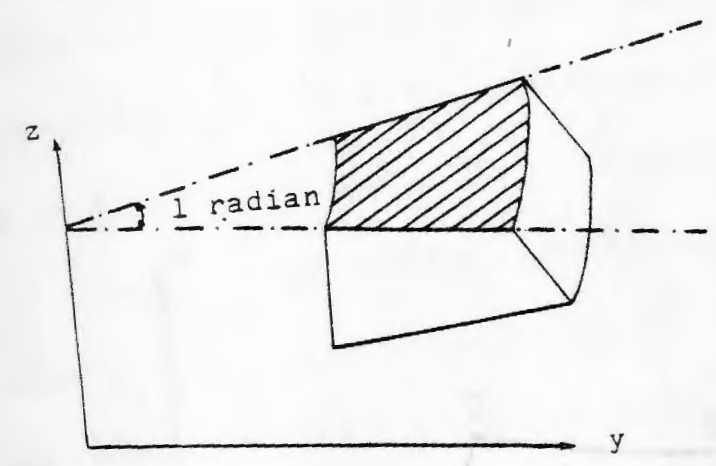

3
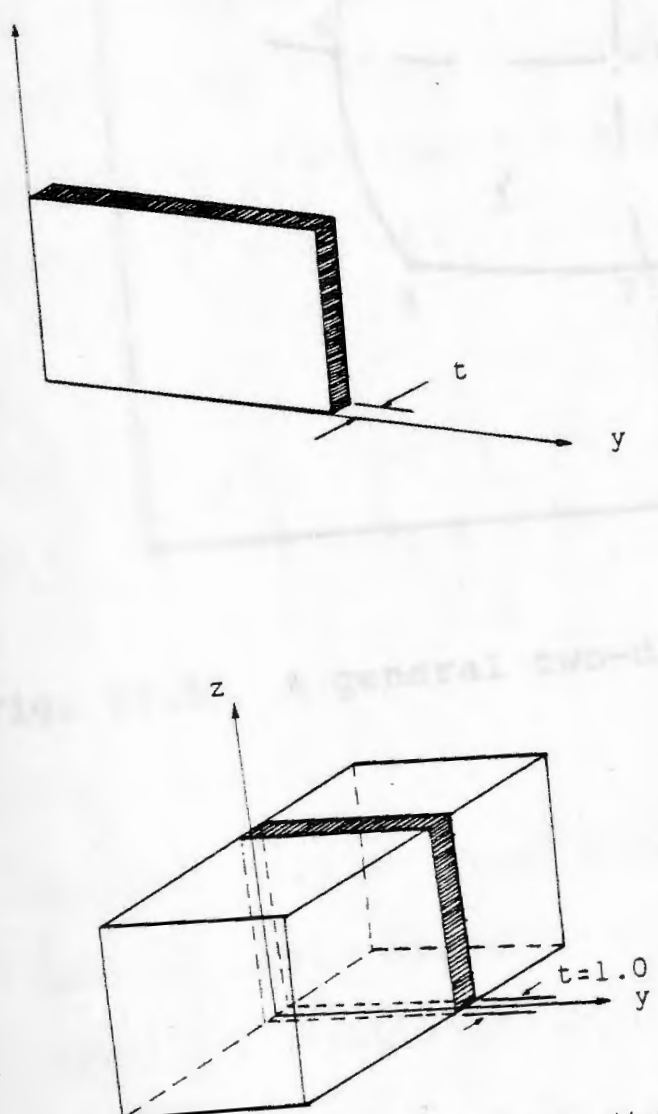

Fig. (3.4) gossiole
Axi-symmetric finite element model of a ring. Plane stress finite a cantilever beam
Plane strain finite element model of a concrete abutment. 


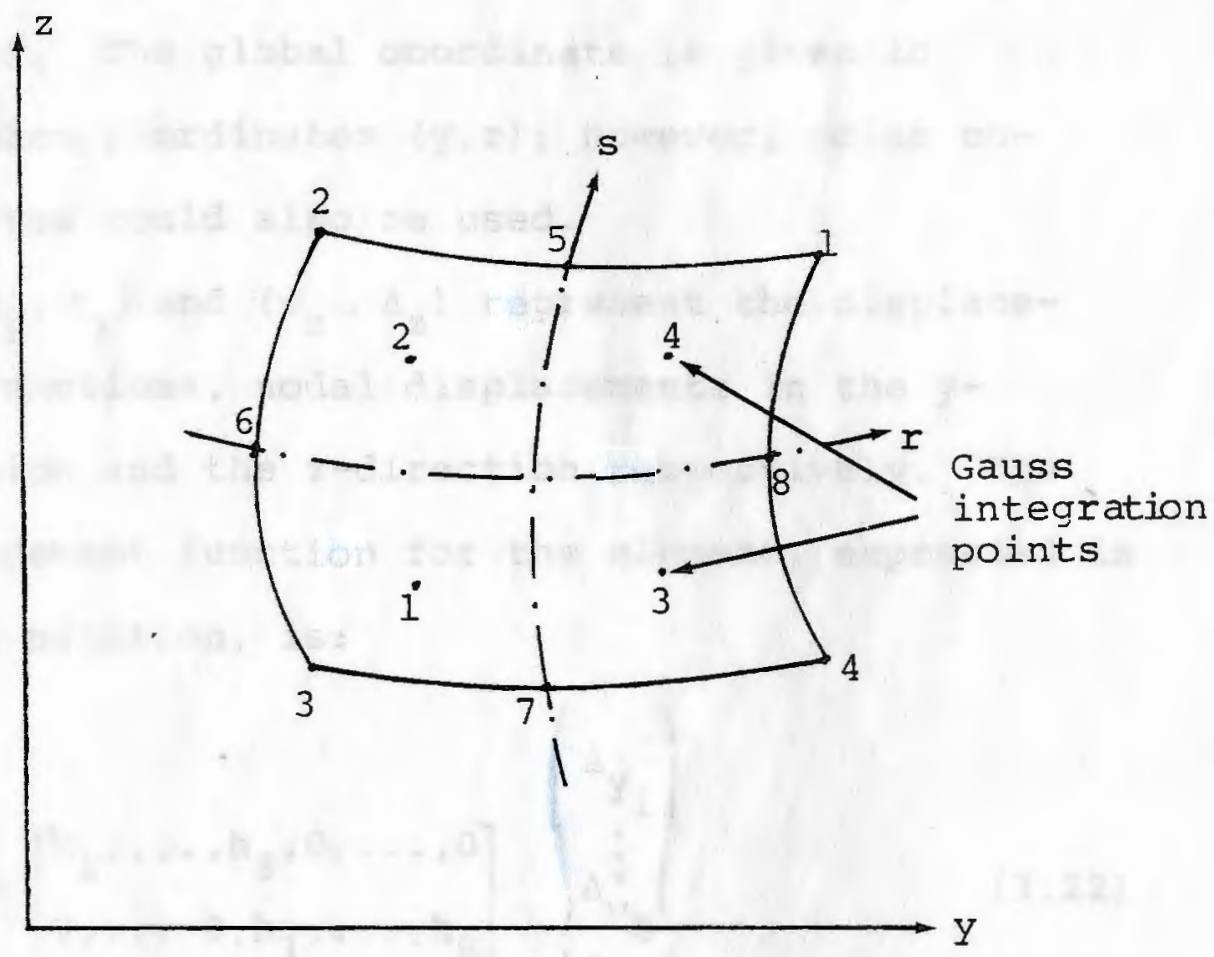

Fig. (3.5) A general two-dimensional element. 
A system of natural coordinates $(r, s)$ were given to the element such that $r=+1$ along edge $(1-8-4)$, and $r=-1$ along edge $(2-6-3)$; while $s=+1$ along edge $(2-5-1)$ and $s=-1$ along edge $(3-7-4)$. The global coordinate is given in cartesian coordinates $(y, z)$; however, polar coordinates could also be used.

Let $\left(u_{y}, \Delta_{y}\right)$ and $\left(u_{z}, \Delta_{z}\right)$ represent the displacement functions, nodal displacements in the $y-$ direction and the $z$-direction respectively. The displacement function for the element, expressed in matrix notation, is:

$$
\left\{\begin{array}{c}
u_{y} \\
u_{z}
\end{array}\right\}=\left[\begin{array}{c}
h_{1}, \ldots, h_{8}, 0, \ldots, 0 \\
0, \ldots, 0, h_{1}, \ldots, h_{8}
\end{array}\right]\left\{\begin{array}{c}
\Delta_{y_{1}} \\
\vdots \\
\Delta_{y_{8}} \\
\Delta_{z_{1}} \\
\vdots \\
\Delta_{z_{8}}
\end{array}\right\}
$$

where $h_{i}$ is the shape function associated with node $i$, given directly in terms of the element natural coordinates $(r, s)$.

Rewriting (3.22) in short form

$$
\left\{\begin{array}{c}
u_{y} \\
u_{z}
\end{array}\right\}=\left[\begin{array}{ll}
h & 0 \\
0 & h
\end{array}\right]\left\{\begin{array}{l}
\Delta_{y} \\
\Delta_{z}
\end{array}\right\}
$$


Recalling (3.7), we notice that the shape function matrix [N] is expressed in global coordinates, while in (3.23) of NONSAP, shape functions are expressed in terms of the element natural coordinate system as shown in (3.22). However, derivatives of the shape functions are needed to evaluate the [B] matrix in equation (3.8) which evaluates the nodal strains in the global coordinate system.

The derivatives needed are:

$$
\left\{\begin{array}{c}
\frac{\partial u_{y}}{\partial y} \\
\frac{\partial u_{y}}{\partial z} \\
\frac{\partial u_{z}}{\partial y} \\
\frac{\partial u_{z}}{\partial z}
\end{array}\right\}=\left[\begin{array}{cccc}
\frac{\partial h}{\partial y} & 0 & 0 & 0 \\
\frac{\partial h}{\partial z} & 0 & 0 & 0 \\
0 & 0 & \frac{\partial h}{\partial y} & 0 \\
0 & 0 & \frac{\partial h}{\partial z} & 0
\end{array}\right]\left\{\begin{array}{c}
\Delta_{y} \\
0 \\
0
\end{array}\right\}
$$

The derivatives in (3.24) are calculated using a Jacobian transformation, where the chain rule relating $(y, z)$ to $(r, s)$ derivatives is:

$$
\left\{\begin{array}{c}
\frac{\partial}{\partial r} \\
\frac{\partial}{\partial s}
\end{array}\right\}=[J]\left\{\begin{array}{l}
\frac{\partial}{\partial y} \\
\frac{\partial}{\partial z}
\end{array}\right\}
$$

where $\mathrm{J}$ is the Jacobian operator, written as 
$J=\left[\begin{array}{ll}\frac{\partial y}{\partial r} & \frac{\partial z}{\partial r} \\ \frac{\partial y}{\partial s} & \frac{\partial z}{\partial s}\end{array}\right]$

Inverting $J$ and multiplying it by both sides of (3.25), we get

$\left\{\begin{array}{l}\frac{\partial}{\partial y} \\ \frac{\partial}{\partial z}\end{array}\right\}=\frac{1}{\operatorname{det} J}\left[\begin{array}{cc}\frac{\partial z}{\partial s} & -\frac{\partial z}{\partial r} \\ -\frac{\partial y}{\partial z} & \frac{\partial y}{\partial r}\end{array}\right]\left\{\begin{array}{c}\frac{\partial}{\partial r} \\ \frac{\partial}{\partial s}\end{array}\right\}$

where the Jacobian determinant is

det $J=\left(\begin{array}{ll}\frac{\partial y}{\partial r} & \frac{\partial z}{\partial s}\end{array}\right)-\left(\begin{array}{ll}\frac{\partial y}{\partial s} & \frac{\partial z}{\partial r}\end{array}\right)$

Once the derivatives are evaluated, the [B] matrix could be determined. Following the formulation incorporated in NONSAP, the stiffness matrix could be evaluated to complete the analysis.

(3) Three-dimensional Elements

The general three-dimensional element in

NONSAP is an 8 to 21 variable-number-nodes element. For this element, the following formulations have been incorporated in NONSAP:
a) Linear elastic small displacement analysis.
b) Small displacement analysis with material nonlinearities only. 
The formulation of the three-dimensional element is similar to the formulation of the twodimensional element, with the consideration of the difference in the element shape function.

\section{3 .2 MATERIAL MODELS}

Several different material models, presented in the NONSAP commentary [4], were incorporated in NONSAP. The material model library of NONSAP [9] is shown in tables (3.2), (3.3), and (3.4) for the truss element, two-dimensional element, and the three-dimensional element respectively.

Nevertheless, NONSAP has been written to accept material models not currently available in the NONSAP material model library, where the overlay subroutines for the new material model must be provided by the user. 


\begin{tabular}{|c|c|}
\hline FORMULATION & MATERIAL MODEL \\
\hline Linear analysis & Linear elastic \\
\hline $\begin{array}{c}\text { Materially nonlinear } \\
\text { only }\end{array}$ & Nonlinear elastic \\
\hline $\begin{array}{c}\text { Updated Lagrangian } \\
\text { formulation }\end{array}$ & $\begin{array}{c}\text { Linear elastic } \\
\text { and nonlinear } \\
\text { elastic }\end{array}$ \\
\hline
\end{tabular}

Table (3.2) Truss element material models. 


\begin{tabular}{|c|c|}
\hline FORMULATION & MATERIAL MODEL \\
\hline Linear analysis & $\begin{array}{l}\text { Linear isotropic and } \\
\text { linear orthotropic }\end{array}$ \\
\hline $\begin{array}{c}\text { Materially nonlinear } \\
\text { only }\end{array}$ & $\begin{array}{l}\text { Variable tangent moduli. } \\
\text { Curve description model } \\
\text { (plane strain or axi- } \\
\text { symmetric only.) } \\
\text { Curve description model } \\
\text { with tension weakening } \\
\text { (plane strain only) }\end{array}$ \\
\hline & $\begin{array}{l}\text { Elastic-plastic, von Mises } \\
\text { yield condition. } \\
\text { Elastic-plastic, Drucker } \\
\text { Prager yield condition. }\end{array}$ \\
\hline
\end{tabular}

Table (3.3) Two-dimensional material models (continued next page) 


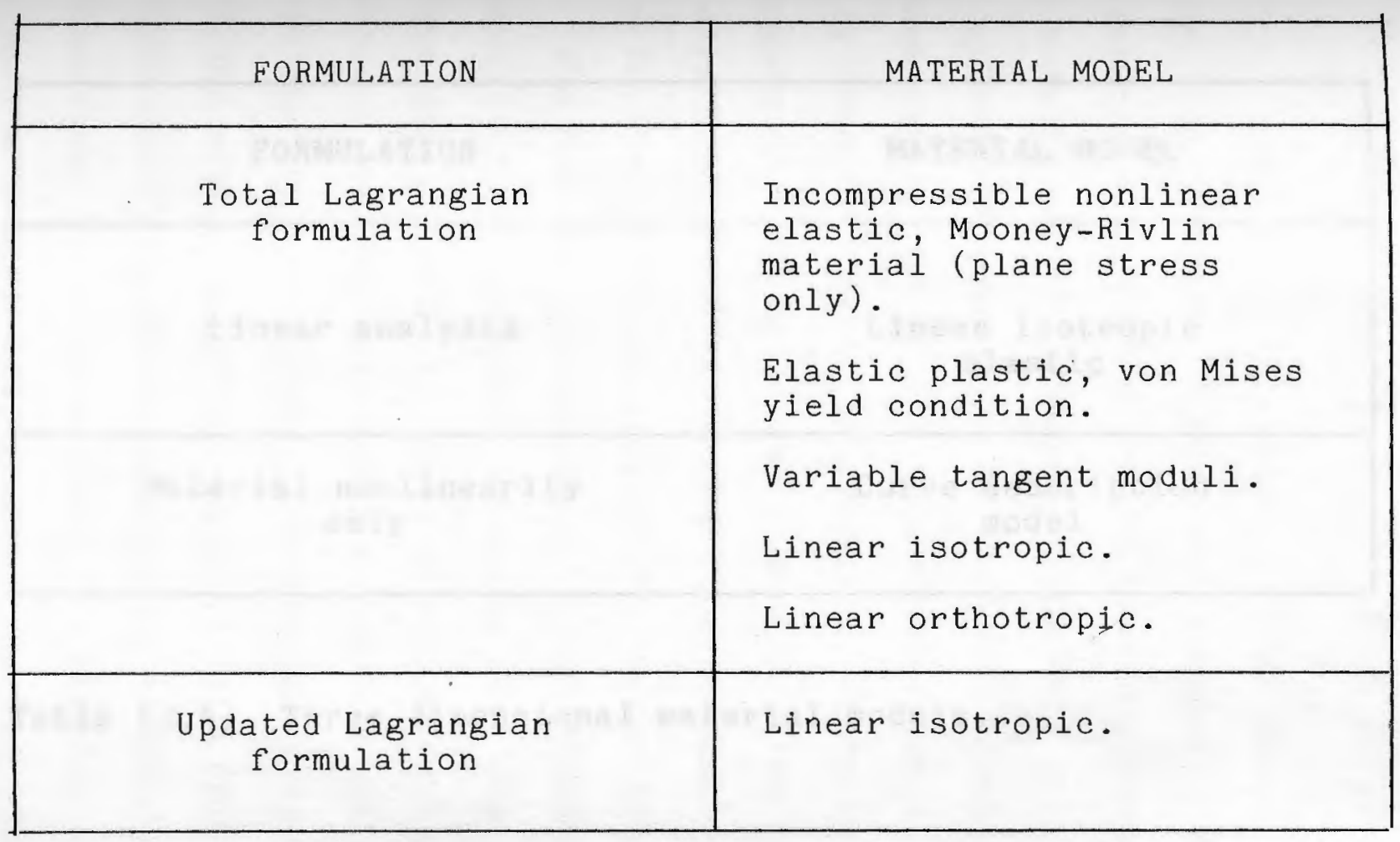

Table (3.3) Continued 


\begin{tabular}{|c|c|}
\hline FORMULATION & MATERIAL MODEL \\
\hline Linear analysis & $\begin{array}{c}\text { Linear isotropic } \\
\text { elastic }\end{array}$ \\
\hline Material nonlinearity \\
only
\end{tabular}

Table (3.4) Three-dimensional material models. 
CHAPTER 4

MODELING OF THE BEARING SYSTEM

Consider a concrete abutment loaded in several locations by steel or concrete girders. The load is transferred vertically by pot bearing plates as described in chapter 2. For analysis purposes, a single bearing is considered to act on an isolated block of concrete as shown in fig. (4.1). A three-dimensional solid model will require a great calculation effort and computer time because of its complexity. However, the complexity of the problem could be reduced significantly by the use of the following models as possible approximations.

1) The bearing system could be represented by an axisymmetrical solid which requires that the pot bearing plate and the masonry plate have a circular shape and requires the concrete block to have a cylindrical shape. Then the finite element grid system representing the bearing system could be composed of a number of twodimensional axisymmetric elements instead of threedimensional solid elements. 2) Another approximation is to take a 1-inch strip through the bearing system and analyze it as a two-dimensional plane strain or plane 


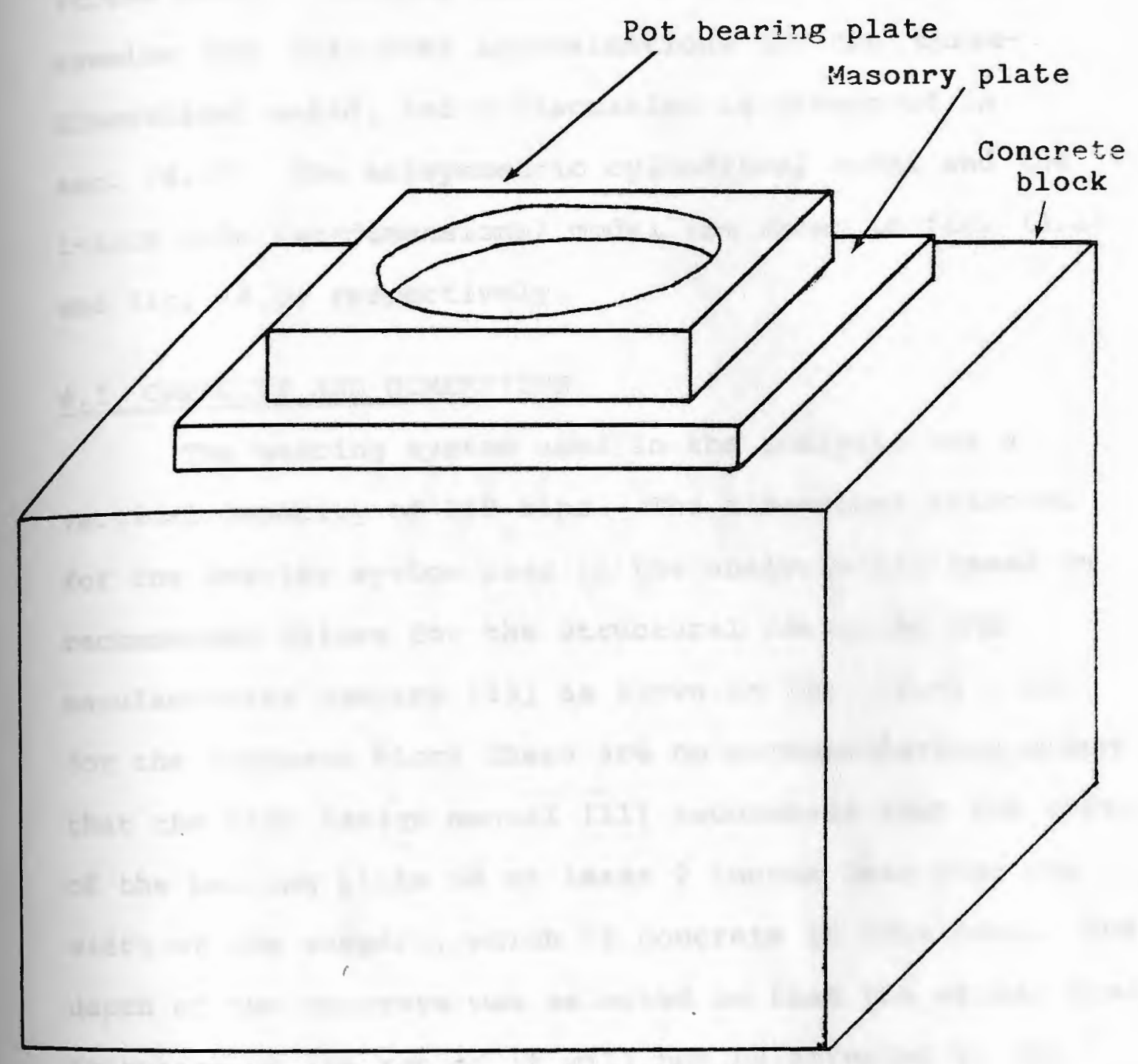

Fig. (4.1) Three-dimensional solid mode? 
stress model. Example problems have been executed to examine the different approximations of the threedimensional solid, and a discussion is presented in sec. (4.3). The axisymmetric cylindrical model and the 1-inch wide two-dimensional model are shown in fig. (4.2) and fig. (4.3) respectively.

4.1 CAPACITY AND DIMENSIONS

The bearing system used in the analysis has a vertical capacity of 150 kips. The dimensions selected for the bearing system used in the analysis are based on recommended values for the structural design by the manufacturing company [10] as shown in fig. (4.4). As for the concrete block there are no recommendations except that the AISC design manual [11] recommends that the width of the bearing plate be at least 2 inches less than the width of the support, which is concrete in this case. The depth of the concrete was selected so that the stress distribution on the top of it will not be affected by the boundary conditions applied at the nodal points at the bottom supports. For the axisymmetric model, all square surfaces are changed to circular such that, referring to fig. (4.4), (A) is the radius of the pot bearing plate, (B) is the radius of the masonry plate, and (C) is the radius of the concrete surface. 


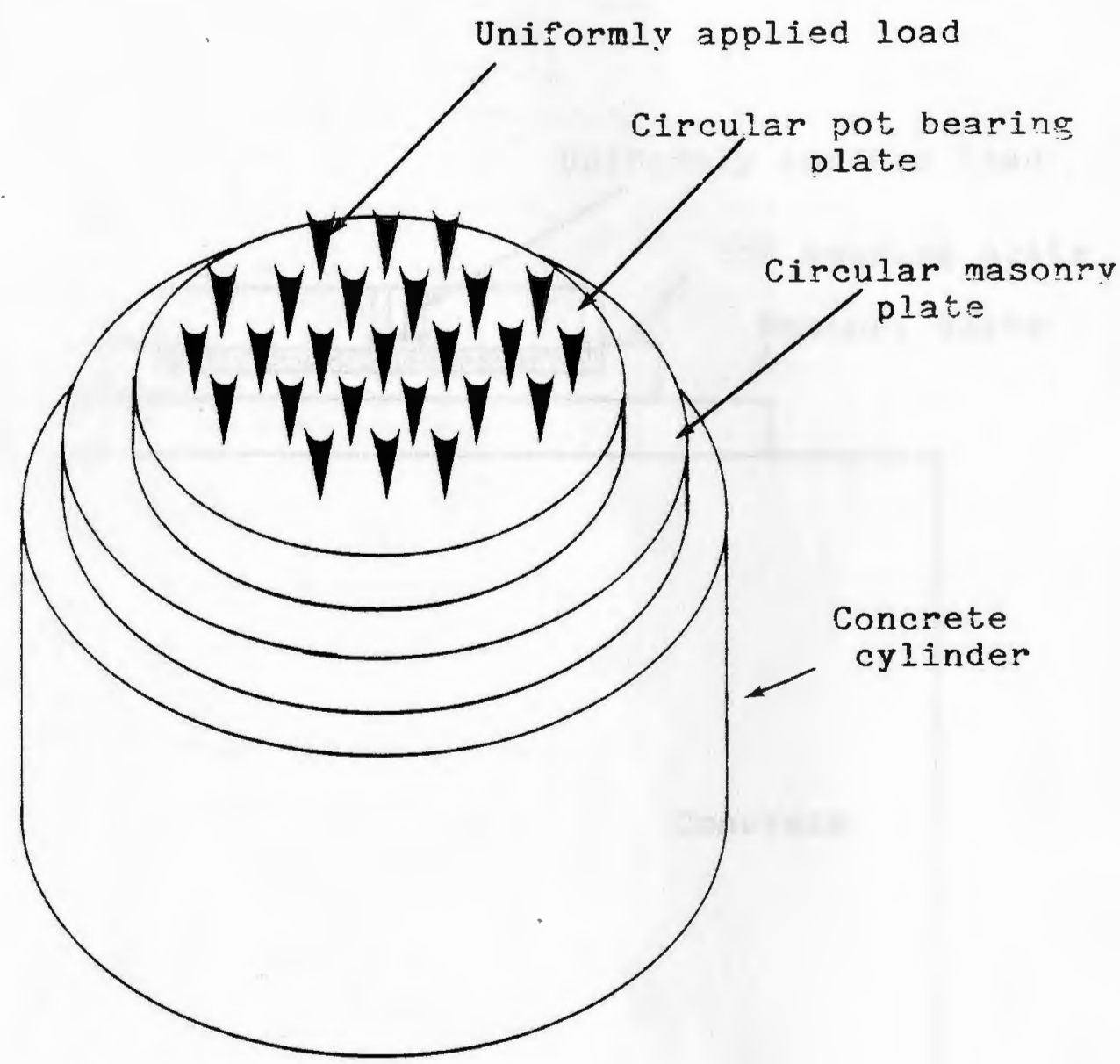

Fig. (4.2) Axisymmetric cylindrical model 


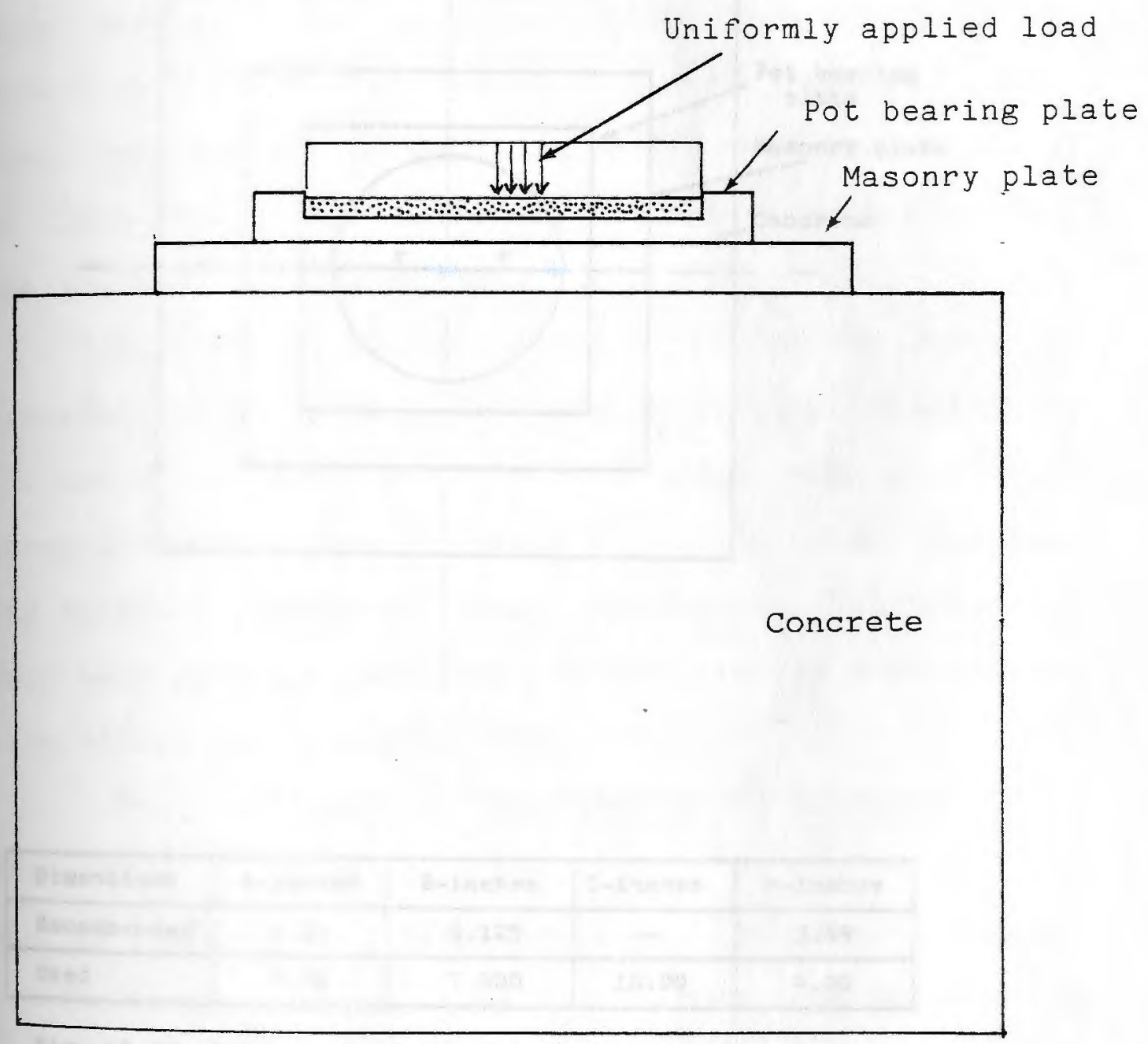

Fig. (4.3) Two-dimensional l-inch wide model 


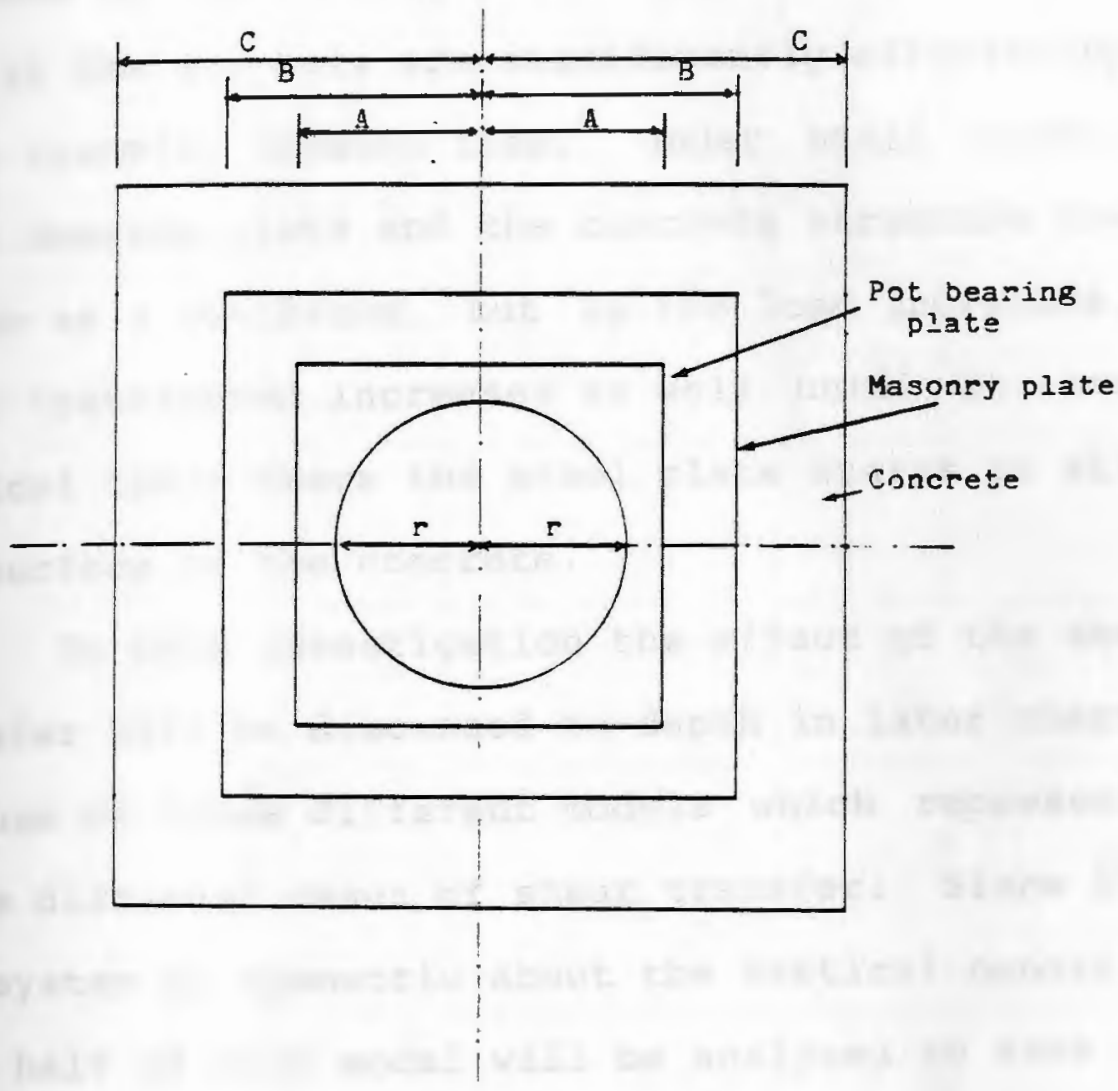

\begin{tabular}{|l|c|c|c|c|}
\hline Dimensions & A-inches & B-inches & C-inches & $r$-inches \\
\hline Recommended & 4.56 & 6.125 & - & 3.69 \\
\hline Used & 5.00 & 7.000 & 10.00 & 4.00 \\
\hline
\end{tabular}

Fig. (4.4) Dimensions of 150-Kips bearing system 
4.2 THE FINITE ELEMENT GRID
SYSTEMS FOR THE DIFFERENT
SHEAR TRANSFER CONDITIONS

Preliminary studies have shown that bending stresses in the bearing plates and the stress distribution in the concrete are significantly affected by the shear transfer between them. Under small loads, the steel bearing plate and the concrete structure tend to behave as a continuum, but as the load increases, the shear transferred increases as well until it reaches a critical limit where the steel plate starts to slip over the surface of the concrete.

In this investigation the effect of the shear transfer will be discussed in depth in later chapters by the use of three different models which represent the three different cases of shear transfer. Since the bearing system is symmetric about the vertical central axis, only half of each model will be analyzed to save calculation effort and computer time.

The following are the three cases of shear transfer:

1) The case of zero shear transfer. There is no shear force transferred along the contact zone between the steel masonry plate and the concrete abutment. The finite element grid system shown in fig. (4.5) consists of 165 nodes and 132 elements. The interface zone is represented by stiff springs (one- 


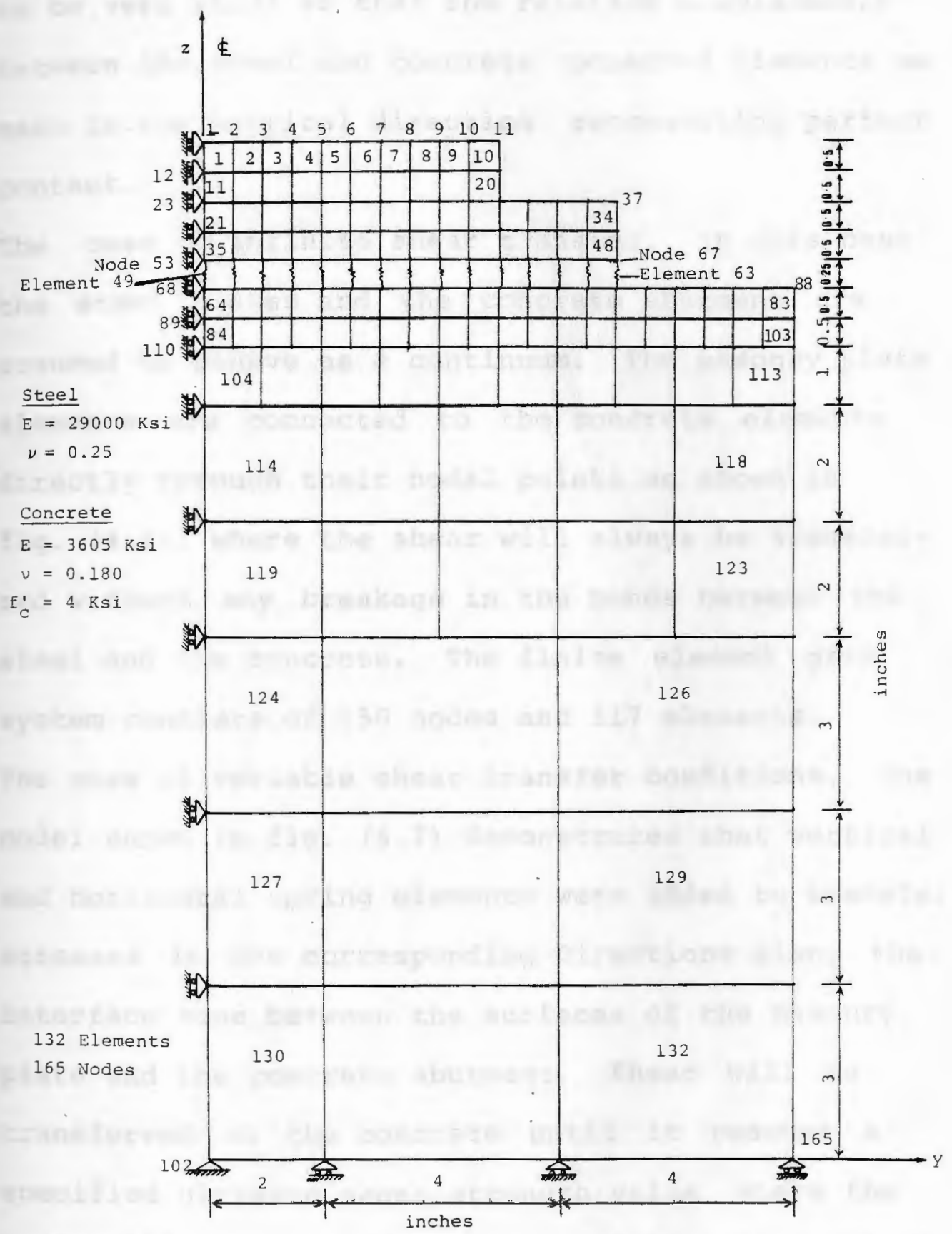

Fig. (4.5) Finite element grid system for the zero shear transfer case. 
dimensional truss elements) which only transfer axial stresses. The springs are linear-elastic; they have to be very stiff so that the relative displacement between the steel and concrete connected elements be zero in the vertical direction representing perfect contact.

2) The case of infinite shear transfer. In this case the steel plates and the concrete abutment are assumed to behave as a continuum. The masonry plate elements are connected to the concrete elements directly through their nodal points as shown in fig. (4.6), where the shear will always be transferred without any breakage in the bonds between the steel and the concrete. The finite element grid system consists of 150 nodes and 117 elements.

3) The case of variable shear transfer conditions. The model shown in fig. (4.7) demonstrates that vertical and horizontal spring elements were added to transfer stresses in the corresponding directions along the interface zone between the surfaces of the masonry plate and the concrete abutment. Shear will be transferred to the concrete until it reaches a specified ultimate shear strength value, where the bonds will break and the masonry plate will start to slip over the surface of the concrete abutment. Characteristics of all material elements are presented 


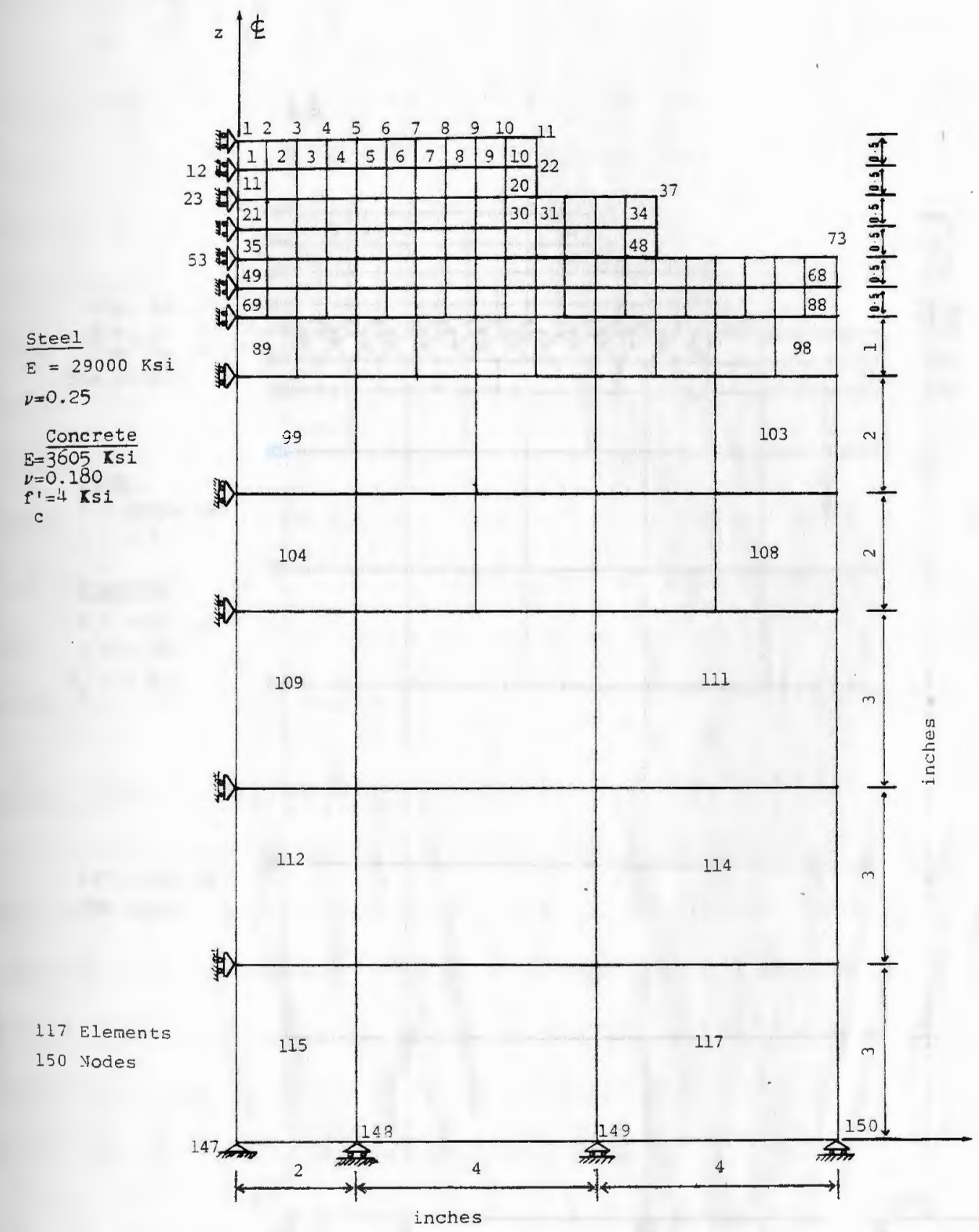

Fig. (4.6) Finite element grid system for the continuum case. 


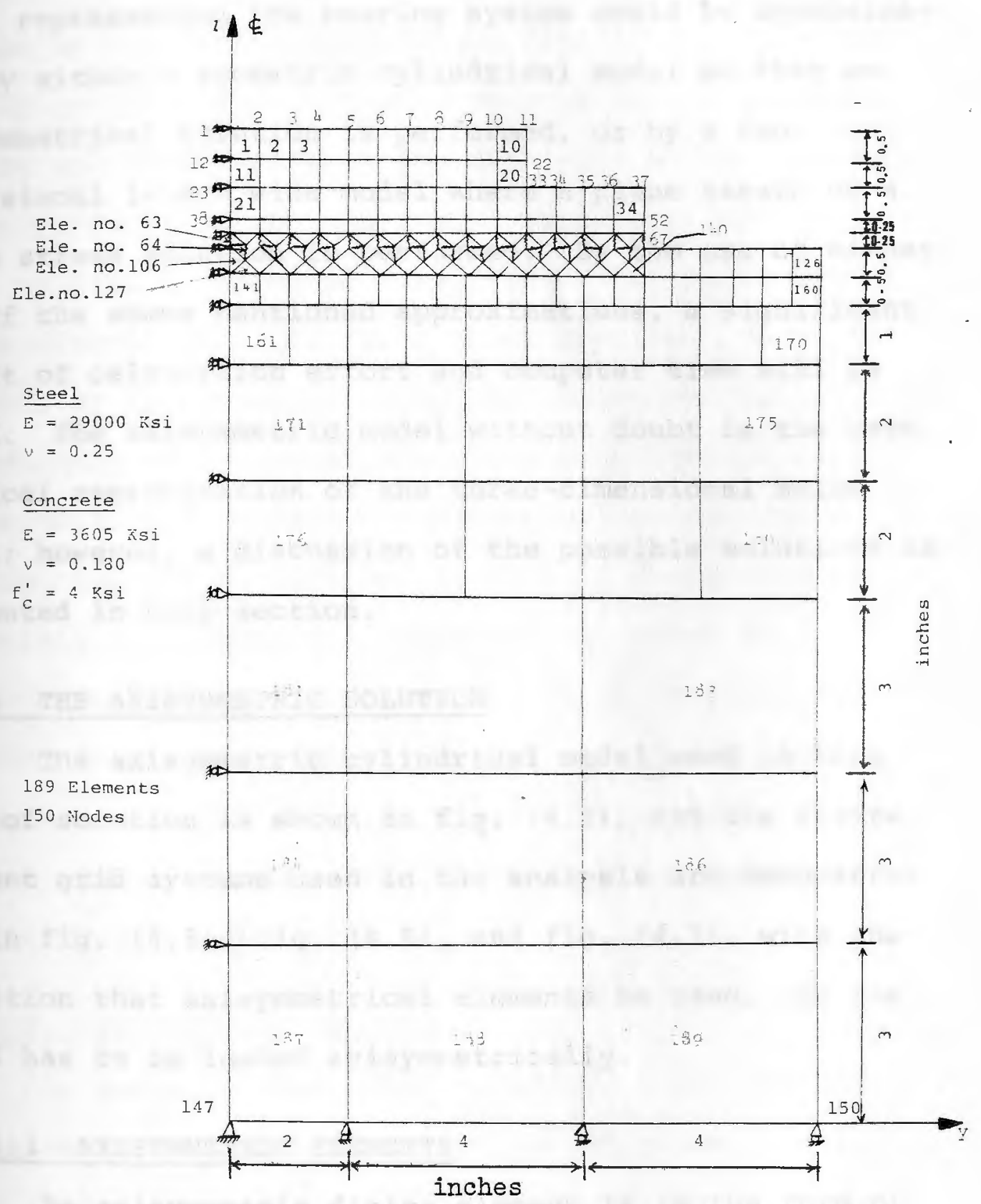

Fig. (4.7) Finite element grid system for the bearing system including interface spring elements. 
presented in chapter 5 .

\section{POSSIBLE SOLUTION METHODS}

As mentioned above, the three-dimensional solid model representing the bearing system could be approximated by either a symmetric cylindrical model so that an axisymmetrical solution is performed, or by a twodimensional l-inch wide model where a plane strain or a plane stress solution is performed. By the use of either one of the above mentioned approximations, a significant amount of calculation effort and computer time will be saved. The axisymmetric model without doubt is the best physical approximation of the three-dimensional solid model; however, a discussion of the possible solutions is presented in this section.

\subsubsection{THE AXISYMMETRIC SOLUTION}

The axisymmetric cylindrical model used in this type of solution is shown in fig. (4.2), and the finite element grid systems used in the analysis are demonstrated in fig. (4.5), fig. (4.6), and fig. (4.7), with the condition that axisymmetrical elements be used, and the model has to be loaded axisymmetrically.

\subsubsection{AXISYMMETRIC ELEMENTS}

An axisymetric finite element is in the form of a ring of constant cross-section as shown in fig. (3.4). 
The element is usually described in a cylindrical coordinate system whose axis of symmetry is the (z-axis) and for which radial distances are defined by the coordinate $(r)$ and the circumferential coordinate is described by an angle $\theta$ as shown in fig. (4.8). However, in this investigation the axisymmetric set of elements will be selected such that (z-axis) will be the axis of symmetry, (y-axis) is the radial direction and $\theta=1$ radians as shown in fig. (4.9). The nodal points of the element are, in fact, nodal circles. Thus, the analysis of axisymmetric solids for axisymmetric loads is a two-dimensional problem since the displacement field can be described by just two components on the crosssection, the radial $\left(u_{y}\right)$ and axial $\left(u_{z}\right)$ displacements. The strain components are radial $\left(\varepsilon_{y}\right)$, axial $\left(\varepsilon_{z}\right)$, circumferential $\left(\varepsilon_{\theta}\right)$, and shearing $\left(\gamma_{\mathrm{yz}}\right)$ strains. The corresponding stress components are $\sigma_{y}, \sigma_{z}, \sigma_{\theta}$, and $\tau_{y z}$. Circumferential stresses and strains exist because the uniform radial displacement increases the circumferential (or hoop) length [7].

\subsubsection{AXISYMMETRIC LOADING}

As shown in fig. (4.2) and fig. (4.3), the uniform load is applied directly to the elastomeric disc which is 8 inches in diameter. Referring to fig. (4.9), (A) is the loaded area where 


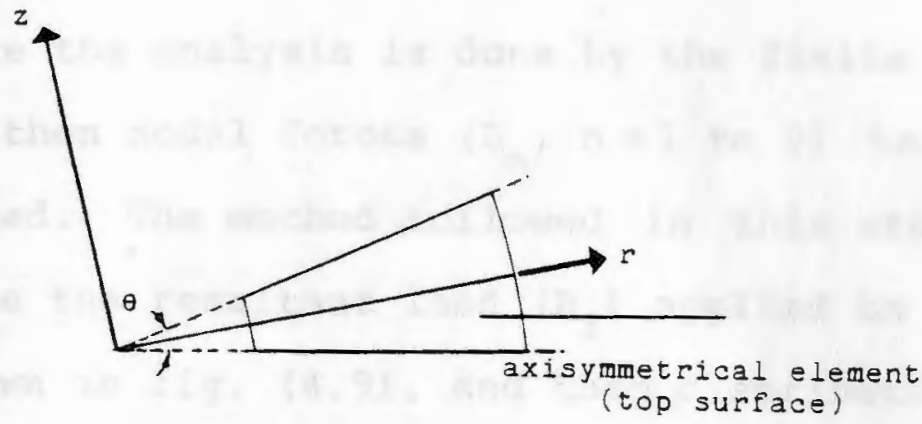

Fig. (4.8) Collidrical coordinates.

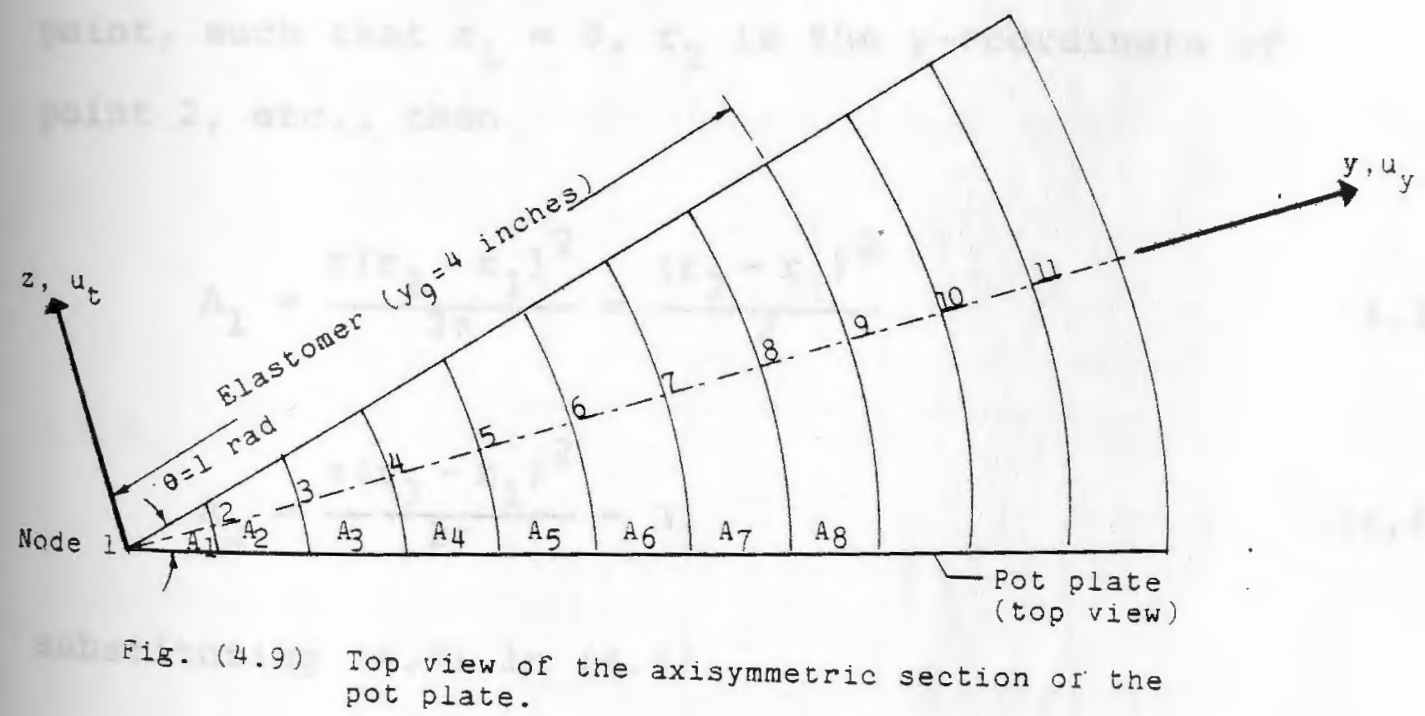




$$
A=\sum_{i=1}^{8} \quad A_{i}
$$

and if $(P)$ is the uniformly applied, load, then the resultant load is ( $R)$, where

$$
R=P \cdot A
$$

but since the analysis is done by the finite element method, then nodal forces $\left(I_{n}, n=1\right.$ to 9 ) have to be calculated. The method followed in this study is to calculate the resultant load $\left(R_{i}\right)$ applied on each area $\left(A_{i}\right)$ shown in fig. (4.9), and then distributing them on the nodal points.

Let $r_{i}$ be the $y$-coordinate (radial) of the $i^{\text {th }}$ nodal point, such that $r_{1}=0, r_{2}$ is the $y$-coordinate of point 2 , etc., then

$$
\begin{aligned}
& A_{1}=\frac{\pi\left(r_{2}-r_{1}\right)^{2}}{2 \pi}=\frac{\left(r_{2}-r_{1}\right)^{2}}{2} \\
& A_{2}=\frac{\pi\left(r_{3}-r_{1}\right)^{2}}{2 \pi}-A_{1}
\end{aligned}
$$

substituting $(4.3)$ in $(4.4)$,

$$
A_{2}=\frac{\left(r_{3}-r_{1}\right)^{2}}{2} \quad \frac{\left(r_{2}-r_{1}\right)^{2}}{2}
$$




\begin{tabular}{|c|c|c|}
\hline $\begin{array}{c}\text { Node number } \\
n\end{array}$ & $\begin{array}{c}\text { Applied nodal } \\
\text { Load }\left(L_{n}\right)\end{array}$ & Magnitude \\
\hline 1 & $L_{1}$ & $\frac{1}{3} R_{1}$ \\
\hline 2 & $L_{2}$ & $\frac{2}{3} R_{1}+\frac{1}{2} R_{2}$ \\
\hline 3 & $L_{3}$ & $\frac{1}{2}\left(R_{2}+R_{3}\right)$ \\
\hline 4 & $L_{4}$ & $\frac{1}{2}\left(R_{3}+R_{4}\right)$ \\
\hline 5 & $L_{5}$ & $\frac{1}{2}\left(R_{4}+R_{5}\right)$ \\
\hline 6 & $L_{6}$ & $\frac{1}{2}\left(R_{5}+R_{6}\right)$ \\
\hline 7 & $L_{7}$ & $\frac{1}{2}\left(R_{6}+R_{7}\right)$ \\
\hline 8 & $L_{8}$ & $\frac{1}{2}\left(R_{7}+R_{8}\right)$ \\
\hline 9 & $L_{9}$ & $\frac{1}{2} R_{8}$ \\
\hline
\end{tabular}

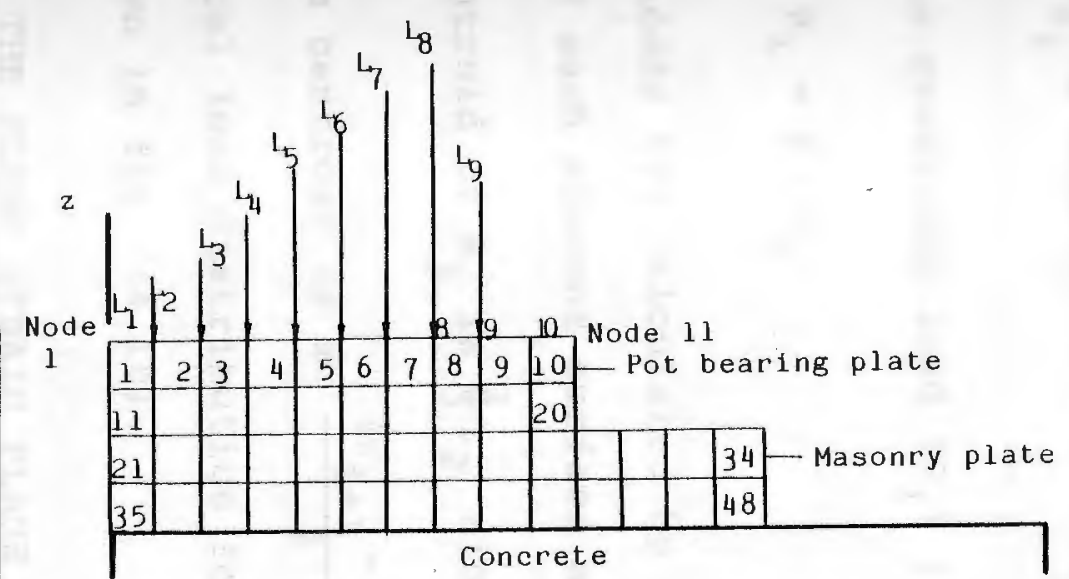

$$
\sum_{n=1}^{9} L_{n}=\sum_{1=1}^{8} R_{1}=R
$$

Fig. (4.10) vistribution of the axisymmetrical model nodal loads. 
Generalizing (4.5),

$$
A_{i}=\frac{\left(r_{i+1}-r_{1}\right)^{2}}{2}-\frac{\left(r_{i}-r_{1}\right)^{2}}{2}, i=2 \text { to } 8
$$

then the resultant load $\left(R_{i}\right)$ is

$$
R_{i}=P \cdot A_{i}
$$

Nodal loads are calculated by proportioning the resultant load of each element surface area. It is assumed that the centroid of $A_{i}$ is $\frac{2}{3} r_{2}$ along the $y$-axis, where for $A_{i}$, the centroid is at $\frac{\left(r_{i+1}-r_{i}\right)}{2}$, ( $i=2$ to 8 ). The nodal load distribution for the axisymmetrical model is shown in fig. (4.10).

AT.2 THE PLANE STRAIN PLANE STRESS SOLUTION

The two-dimensional l-inch wide model used in this type of solution is shown in fig. (4.3). The finite element grid systems for the plane strain or plane stress solution are the same used for the axisymmetrical problem. However, plane strain or plane stress elements are used instead of axisymmetrical elements. The uniform load is distributed evenly among the nodal points of the loaded surface except for the ones which are on its edges as explained in sec. $(4 \cdot 3 \cdot 2 \cdot 3)$. 
3.2.1 PLANE STRAIN ELEMENTS

Consider the plane strain element shown in

fig. (3.4); the element is fixed against displacement in the $x$-direction. Under this condition, the longitudinal strain $\left(\varepsilon_{\mathrm{x}}\right)$ is zero, as well as the shear stresses ( $\tau_{\mathrm{yx}}$ ) and $\left(\tau_{z x}\right)[7]$.

3.2.2 PLANE STRESS ELEMENTS

A plane stress element is shown in fig. (3.4). The element is assumed to be very thin so that the inplane stresses $\left(\sigma_{y}\right.$ and $\left.\sigma_{z}\right)$ and the shearing stresses $\left(\tau_{z y}\right.$ and $\left.\tau_{y z}\right)$ are constant across the thickness $(t)$. Nevertheless, the out-of-plane stress $\left(\sigma_{x}\right)$ and the shear stresses ( $\tau_{y x}$ and $\tau_{z x}$ ) are assumed to be negligible.

\subsubsection{PLANE STRAIN PLANE STRESS LOADING}

A top view of the loaded pot plate is shown in fig. (4.11), considering that a 1-inch wide strip was cut out from the bearing system so that it could be analyzed as a two-dimensional model representing the structure. All areas shown in fig. (4.1l) are l-inch wide and of equal lengths (b). If the uniformly applied load is (P), then the resultant load $\left(R_{i}\right)$ in equation (4.7) is equal for all areas. The nodal load distribution for the plane strain or plane stress model is shown in fig. (4.12). 


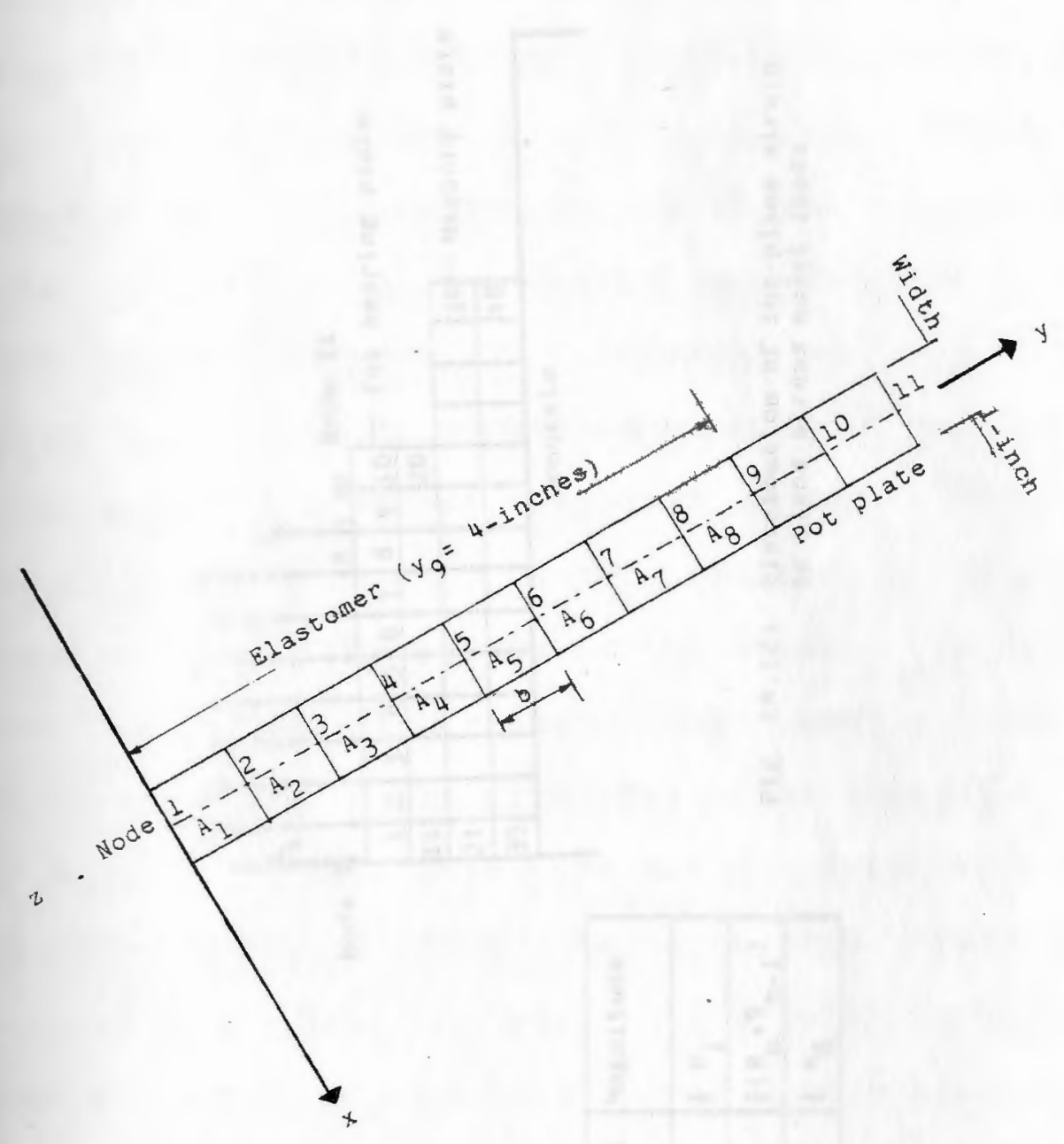

Fig. (4.11) Top view of the plane-strain or plane-stress section of the pot plate. 


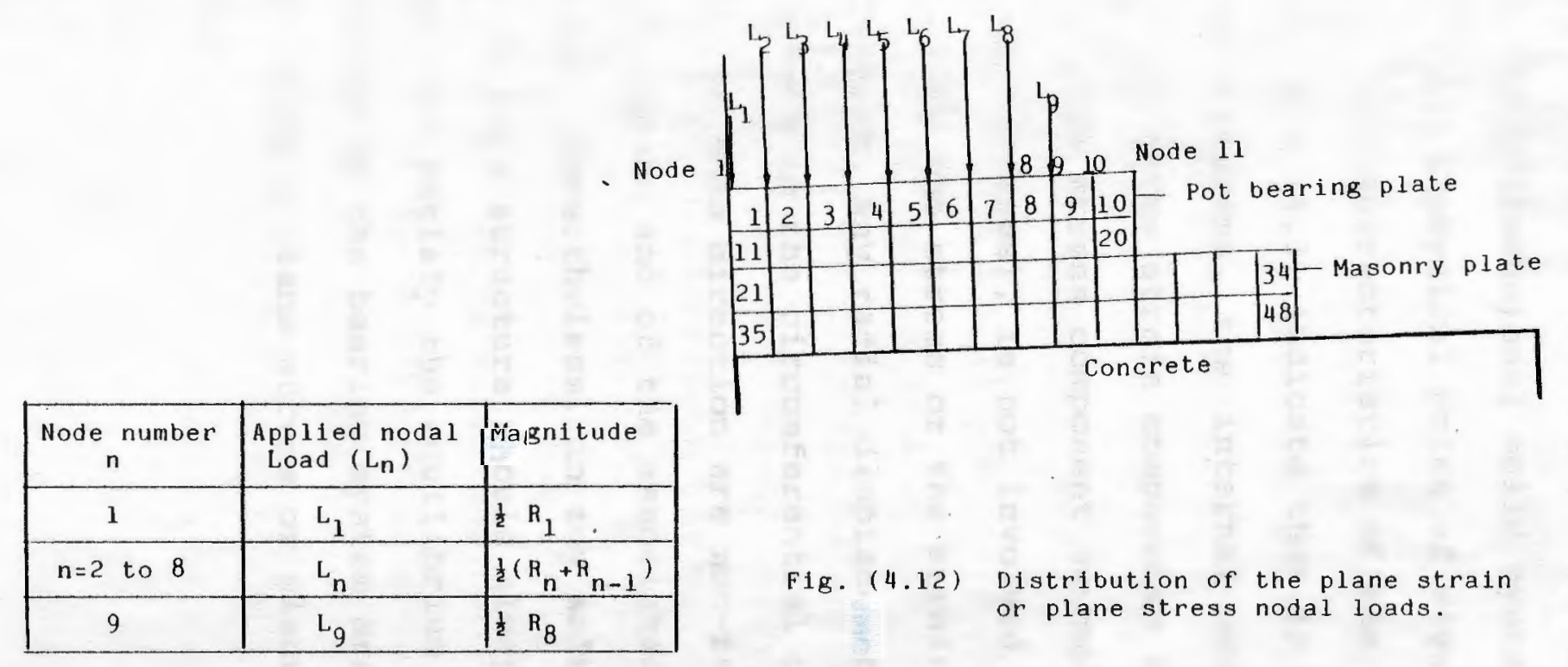




\subsubsection{A COMPARATIVE LOOK AT THE} PROPOSED SOLUTION METHODS

It has been mentioned earlier that an axisymmetrical solution would seem to be the best approximation to analyze the three-dimensional solid system shown in fig. (4.1), from a physical point of view. However, Malytically, the characteristics of the elements discussed in section (4.3) indicate that in plane strain or plane stress problems, the internal work is always associated with three strain components in the coordinate plane $(y, z)$. The stress component normal to this plane, (out-of-plane stresses), is not involved due to zero values of either the stress or the strain. In the axisymmetric problem, any radial displacement automatically induces a strain in the circumferential direction. As the stresses in this direction are non-zero, this fourth component of strain and of the associated stress has to be considered. Nevertheless, in any solution method, Internal work in a structure should always balance the external work to satisfy the equilibrium condition. Hence, stresses in the bearing system are expected to be larger when using a plane stress or plane strain solution method, [12]. 
CHAPTER 5

\section{MATERIAL ELEMENT MODELS}

The modeling of the bearing system has been discussed in chapter (4), however, the discussion of the material element models which represent the properties and behavior of the different materials used in the construction of such a structure, is left to this chapter. The different materials used in the construction of the bearing system are divided into three main groups, 1) steel, which is used to manufacture the pot bearings and masonry plates, 2) concrete, which is usually used to build abutments for such structures, and 3) material model to simulate the interface between the steel masonry plate and the concrete abutment. It is noteworthy here to point out that there is no such material that exists in nature; however, it is essential for the completion of this investigation to develop certain material models which best approximate the behavior of the interface zone fepending on which case of shear transfer is being investigated, see sec. (4.2). Since it is assumed that the load will be uniformly applied in all loading stages at all times, there were no material elements used to represent the elastomeric material, see chapter (1). 
Nevertheless, a complete discussion of the elastomeric material properties and behavior is presented in the National Cooperative Highway Research Program Report 248 [13].

\section{- 1 STEEL ELEMENTS}

All bearing plates used in the bearing system under investigation are fabricated from ASTM A-36 steel, the pot being machined from a solid steel plate to provide complete security and eliminate welding and distortion problems. All surfaces internal and external are treated with a $10 \mathrm{mil}$ epoxy coal tar paint system to resist corrosion.

According to the manufacturing company, Spencer Dynamics [10], bending stresses used in the design of the bearings are a maximum of $16 \mathrm{Ksi}$; due to the rather conservative stressing method and design assumptions, actual stresses are about half this value. Thus, the bearing plates can be supplied proof-loaded to twice the rated capacity specified for the bearing system, under investigation, as 150 Kips. Hence, if the bearing was loaded uniformly by a relatively small load, such as 3500 Psi, the steel plate will not yield, and it will always stay in the elastic range. With respect to the above-mentioned information, a linear elastic isotropic material model was used to represent all the steel ele- 
ments of the pot bearing and masonry plates.

\section{LINEAR ELASTIC ISOTROPIC MODEL}

This model assumes that the elements of the constitutive matrix are constant, i.e., independent of magnitude or history of stresses and strains. The material (property) matrix, which relates element strains to element stresses in (3.9), is formed from the two elastic constants $\mathrm{E}$ (Young's modulus of elasticity) and $v$ (Poisson's ratio) [9].

For axisymmetric analysis the material matrix is,

$$
[c]=\left[\begin{array}{cccc}
c_{1} & c_{2} & 0 & c_{2} \\
c_{2} & c_{1} & 0 & c_{2} \\
0 & 0 & c_{3} & 0 \\
c_{2} & c_{2} & 0 & c_{1}
\end{array}\right]
$$

where

$$
\begin{aligned}
& c_{3}=\frac{E}{2(1+v)} \\
& c_{2}=\frac{2 v c_{3}}{(1-2 v)} \\
& c_{1}=c_{2}+c_{3}
\end{aligned}
$$


and the corresponding stress $\sigma$ and strain $\varepsilon$ vectors are, for example, in small displacement analysis at time $(t)$

$$
\begin{aligned}
& \left\{t_{\sigma_{y y}} t_{\sigma_{z z}} t_{\sigma_{y z}} t_{\sigma_{x x}}\right\} ; \\
& \left\{^{t} \varepsilon_{y y} t_{\varepsilon_{z z}}{ }^{t} \varepsilon_{y z} t_{\varepsilon_{x x}}\right\}
\end{aligned}
$$

respectively.

\section{5 . 2 CONCRETE ELEMENTS}

No one mathematical model can describe the actual behavior and strength of concrete materials because it is very complex, however, the properties that are essential to the problem being considered will be represented by a simple model.

Typical concrete compressive stress - strain curves are shown in in fig. (5.1) obtained by appropriate strain measurements on cylinder tests at moderate testing spees on concrete 28 days old, for various cylinder compressive strength $f_{C}^{\prime}[14]$. All curves shown in the figure have somewhat similar character. They consist of an initial relatively straight elastic portion, then begin to curve to the horizontal, reaching the maximum compressive strength at a strain of approx- 


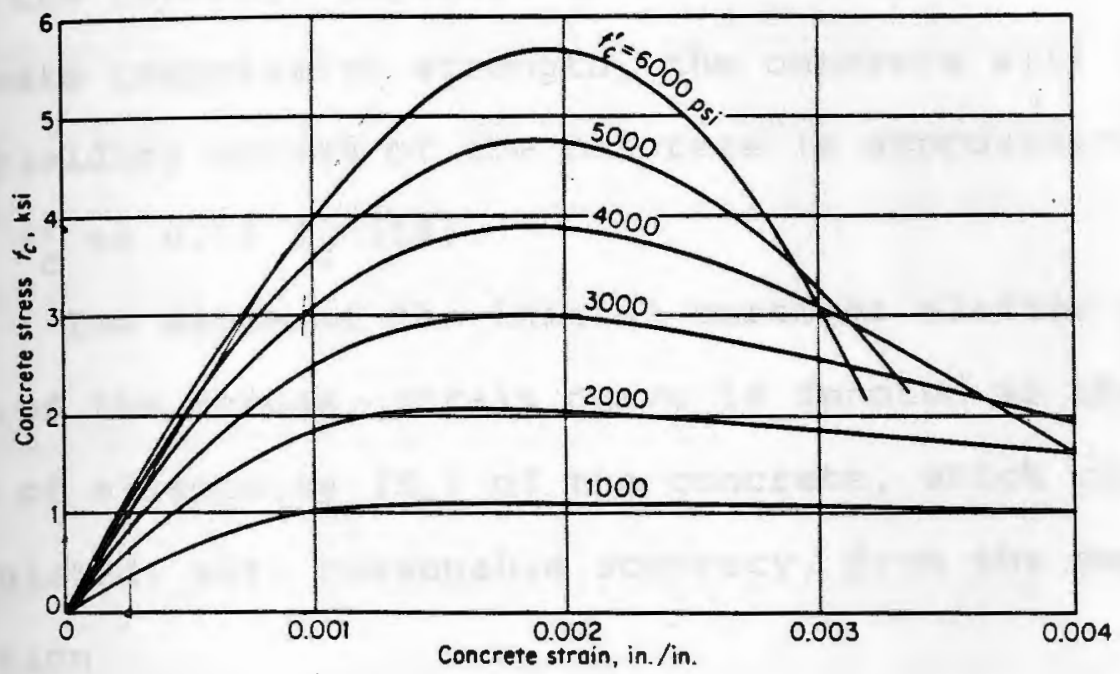

\author{
Fig. (5.1) Typical concrete compressive \\ stress-strain curves
}


imately 0.002 in/in, and finally show a descending branch. This is described as the elastic-plastic behavior of the concrete, which is attributed to the fact that under uniformly applied load, increasing at a moderate speed, micro cracks within the concrete will take place and become larger as the load increases. When the internal stresses in the concrete reach the ultimate compressive strength, the concrete will crush. The yielding stress of the concrete is approximately $0.45 \mathrm{f}_{\mathrm{C}}^{\prime}$ to $0.50 \mathrm{f}_{\mathrm{C}}^{\prime}[14]$.

The slope of the initial straight elastic portion of the stress - strain curve is denoted as the modulus of elasticity $\left(E_{C}\right)$ of the concrete, which could be calculated, with reasonable accuracy, from the empirical equation

$$
E_{C}=33 w^{3 / 2} \sqrt{f_{c}^{\prime}} \text { Psi }
$$

where $\mathrm{w}$ is the unit weight of the hardened concrete in pcf. Equation (5.2) has been obtained by testing structural concretes with values of $w$ from 90 to 155 pcf.

Tensile strength $\left(f_{t}\right)$ is a more variable property than compressive strength, and is about $0.10 \mathrm{f}_{\mathrm{C}}^{\prime}$ to $0.15 \mathrm{f}_{\mathrm{C}}^{\prime}[14]$. It has been found to be proportional to $\sqrt{f_{C}^{T}}$. The ACI code has indirectiy used $f_{t}=6.7 \sqrt{f_{c}^{T}}$ psi for normal-weight concrete and 
$f_{t}=5.7 \sqrt{f_{C}^{1}}$ for all light-weight concrete (ACI-11.2). There are two elastic-plastic material models vailable in the NONSAP library, elastic-plastic von Mises yield condition, and elastic-plastic Drucker Prager yield condition, see table (3.3). However, the latter is formulated for an elastic-perfectly plastic material behavior; hence the concrete element in this investigation will be represented by the elastic-plastic von Mises yield condition element material model, assuming that it is the best approximation of the concrete stress - strain curve discussed above.

\subsubsection{VON MISES YIELD CONDITION}

The von Mises yield criterion considers the octahedral shearing stress as the key variable for causing yield of materials which are pressure independent. It states that yielding begins when the octahedral shearing stress reaches a critical value, $\mathrm{K}$, which is defined as the yield stress in pure shear, such that the octahedral shearing stress is, [3]:

$$
\tau_{\text {oct }}=\sqrt{\frac{2}{3} \mathrm{~J}_{2}}=\sqrt{\frac{2}{3}} \mathrm{~K}
$$

where $\left(\mathrm{J}_{2}\right)$ is the second invariant of the deviatoric stress vector. The material yielding function is obtained by reducing (5.3) to the simple form 


$$
f\left(J_{2}\right)=J_{2}-K^{2}=0
$$

\section{DEVIATORIC STRESS INVARIANTS}

Consider the general stress matrix $\left[\sigma_{i j}\right]$ where

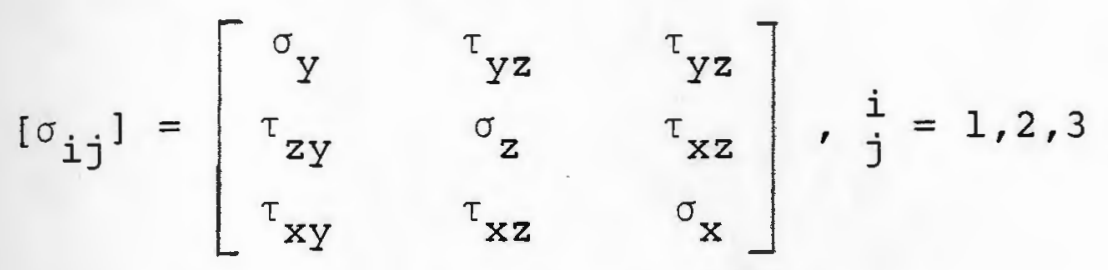

for the solid shown in fig. (5.2), and let the principal stresses be defined as $\sigma_{1}, \sigma_{2}$, and $\sigma_{3}$.

The deviatoric stress vector which represents a state of pure shear is defined by

$$
\left[s_{i j}\right]=\left[\sigma_{i j}\right]-\sigma_{m}\left[\delta_{i j}\right]
$$

where

$$
\sigma_{m}=\frac{1}{3}\left(\sigma_{y}+\sigma_{z}+\sigma_{x}\right)
$$

and $\delta_{i j}$ is the Kronecker delta such that

$$
\delta_{i j}=\mid \begin{array}{cc}
+1 & \text { if } i=j \\
0 & \text { if } i \neq j
\end{array}
$$

The invariants of $\left[S_{i j}\right]$ are obtained by setting the Peterminant of $\left[S_{i j}-S \delta_{i j}\right]$ equal to zero, resulting in the cubic equation

$$
s^{3}-J_{1} s^{2}-J_{2} s-J_{3}=0
$$



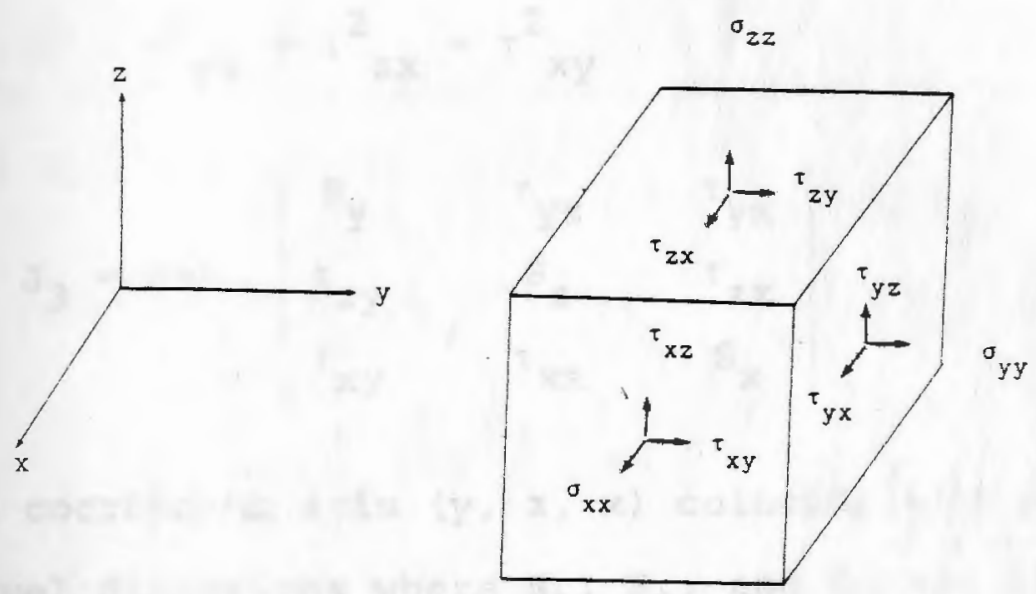

Eig. (5.2) General stress components. 
where $\mathrm{J}_{1}, \mathrm{~J}_{2}$, and $\mathrm{J}_{3}$ are the three invariants of the deviatoric stress vector.

Solving (5.7),

$$
\begin{aligned}
J_{1} & =s_{y}+s_{z}+s_{x}=0 \\
J_{2} & \left.=\frac{1}{6}\left[\sigma_{y}-\sigma_{z}\right)^{2}+\left(\sigma_{z}-\sigma_{x}\right)^{2}+\left(\sigma_{x}-\sigma_{y}\right)^{2}\right] \\
& +\tau_{y z}^{2}+\tau_{z x}^{2}+\tau_{x y}^{2} \\
J_{3} & =\operatorname{det} .\left|\begin{array}{ccc}
s_{y} & \tau_{y z} & \tau_{y x} \\
\tau_{z y} & s_{z} & \tau_{z x} \\
\tau_{x y} & \tau_{x z} & s_{x}
\end{array}\right|
\end{aligned}
$$

If the coordinate axis $(y, z, x)$ coincide with the principal directions where $S_{1}, S_{2}$, and $S_{3}$ are the principal deviatoric stresses, then

$$
\begin{aligned}
J_{1} & =s_{1}+s_{2}+s_{3}=0 \\
J_{2} & =\left(s_{1}^{2}+s_{2}^{2}+s_{3}^{2}\right)=\frac{1}{6}\left(\sigma_{1}-\sigma_{2}\right)^{2} \\
& \left.+\left(\sigma_{3}-\sigma_{1}\right)^{2}\right] \\
J_{3} & =\frac{1}{3}\left(s_{1}^{3}+s_{2}^{3}+s_{3}^{3}\right)=s_{1} s_{2} s_{3}
\end{aligned}
$$

However, in a uniaxial tension test, yielding will occur when $\sigma_{1}=\sigma_{z}$ and $\sigma_{2}=\sigma_{3}=0$, where $\sigma_{1}, \sigma_{2}, \sigma_{3}$ are the 
principal stresses. Substituting in (5.9.b),

$$
J_{2}=\frac{\sigma_{z}^{2}}{3}
$$

and substituting $(5.10)$ in $(5.4)$,

$$
\mathrm{k}^{2}=\frac{\sigma_{\mathrm{z}}^{2}}{3}
$$

Then the general von Mises yield function is written, from (5.8.b) and (5.11), as

$$
\begin{aligned}
f\left(J_{2}\right) & =\frac{1}{6}\left[\left(\sigma_{y}-\sigma_{z}\right)^{2}+\left(\sigma_{z}-\sigma_{x}\right)^{2}+\left(\sigma_{x}-\sigma_{y}\right)^{2}\right] \\
& +\tau_{y z}^{2}+\tau_{z x}^{2}+\tau_{x y}^{2}-k^{2}
\end{aligned}
$$

However, equation (5.12) only represents the simplest form of the yield function because it depends fully on the proposed hardening rule for work-hardening materials. A complete description of the NONSAP formulation of the elastic-plastic, von Mises yield criterion is presented in the NONSAP commentary [ 4 ] and ref. [9].

\section{INTERFACE ELEMENTS}

This investigation is primarily concerned with the study of the effect of the shear transfer between the masonry plate and the concrete abutment, on the stress distribution in the concrete, and on the steel bearing plates bending stresses. The analysis is done 
by considering the three cases of shear transfer presented in sec. (4.2), however, because of their great importance, the interface material models for each case will be discussed separately in this section.

\subsubsection{THE CASE OF ZERO SHEAR TRANSFER}

The finite element grid system representing this case is shown in fig. (4.5) where the contact zone between the masonry steel plate and the concrete is modeled by very stiff spring elements.

The springs shown in the grid system are actually one-dimensional truss elements with one degree of freedom on each side, and they are only capable of transferring axial stresses. Hence, only vertical stresses will be transferred from the masonry steel plate elements to the concrete elements. Since the springs are very stiff, their axial displacement will approach zero, so that the vertical displacements of the connected nodes of the steel and concrete elements will be approximately equal, minimizing any portion of the vertical stresses absorbed for the springs axial deformation. However, since there will be no horizontal stresses (shear stresses) transferred, there will be nothing to prevent the bearing plates from slipping over the concrete surface. There are two material models available in the NONSAP element library for truss elements, linear elastic or nonlinear elastic, see table (3.2). 
However, since vertical springs here are only used to transfer vertical stresses, they will be represented by the linear elastic material model.

The stiffness matrix of each spring is

$$
[K]=\frac{A E}{L}\left[\begin{array}{cc}
1 & -1 \\
-1 & 1
\end{array}\right]
$$

where

$A=$ the cross sectional area of the spring, calculated to be proportional to the connected areas of concrete and steel elements.

$\mathrm{E}=$ Young's modulus of elasticity

$I=$ length of the spring.

It is noteworthy to point out that the stiffness of the springs is increased by selecting a very large (E), so the magnitudes of the area (A) and the length ( $L$ ) of the springs will have very little significance.

5.3.2 THE CASE OF INFINITE SHEAR TRANSFER

The finite element grid system representing this case is shown in fig. (4.6) where no special consideration has been given to model the interface between the steel and the concrete. As shown in the grid system, the steel elements are directly connected to the concrete elements through their nodal points. In other words, the interface elements in this case are nothing 
but the common nodal points of the two different materials. Hence, not only vertical stresses will be transferred, but shear stresses will be transferred infinitely as well, so that the steel bearing plates and the concrete will behave as a continuum.

5.3.3. THE CASE WITH SHEAR TRANSFERRED
THROUGH INTERFACE ELEMENTS

The behavior of the interface between material elements is one of great complexity because of the difficulty in finding the most suitable function that describes the slip. Straight interface elements with linear description of slip between rock joints were first introduced by Goodman, Taylor and Brekke (1968) [15]. The bond behavior between steel and concrete was simulated by Ngo and Scordelis (1967) [16], with the help of linear springs placed between element nodes. However, this method leads to incompatibilities between nodes if higher order finite elements were used. Ghaboussi, Wilson and Isenberg (1969) [17,18], have also formulated an interface element covering a wide range of joint properties. Schafer (1975) [19], has developed straight bond elements with linear and parabolic behavior of slip. In 1977, Buragohain and Shah $[20,21]$ proposed curved isoparametric line and axisymmetric interface elements with zero thickness to 
simulate curved surfaces and parabolic variation of slip. None of the interface elements mentioned above was used in this investigation. They were studied in order to help in developing the interface spring elements used to simulate the behavior of the interface zone between the masonry steel plate and the concrete abutment. It has been found that there are two different general pproaches in modeling the interface zone. It could be represented by interface spring elements simply transferring horizontal and vertical stresses, or by twodimensional finite elements. In either approach, the slip could be described by either linear or nonlinear functions as long as compatibility conditions are satisfied. In the following two sections, two different interface elements, each representing a different approach, will be introduced. The discussion of the interface spring elements used to simulate the interface zone in the bearing system will be left to chapter (6) .

\subsubsection{LINKAGE ELEMENT BY \\ NGO AND SCORDELIS}

The "linkage element" shown in fig. (5.3) consists of two linear springs parallel to a set of orthogonal local axes $H$ and $V$. For generality, the linkage element can be oriented at any arbitrary angle $\theta$ with the global horizontal y-axis. The linkage element has no physical dimension at all, and only its mechanical properties are 

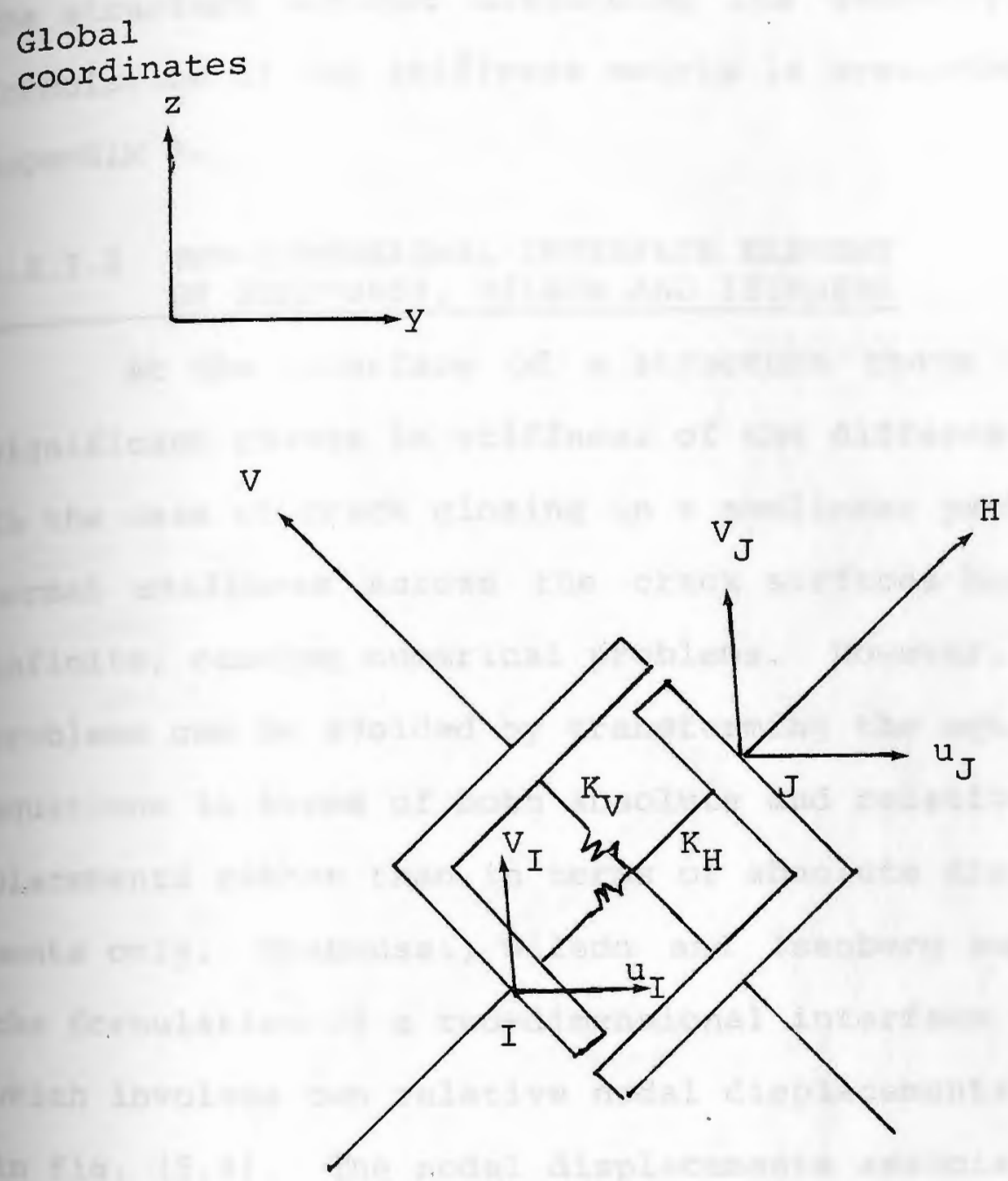

Fig. (5.3) Linkage element. 
of importance. Th erefore, it can be placed anywhere in the structure without disturbing its geometry. The formulation of the stiffness matrix is presented in Appendix A.

5.3.3.2 TWO-DIMENSIONAL INTEPFACE ELEMENT BY GHABOUSSI, WILSON AND ISENBERG

At the interface of a structure there can be a significant change in stiffness of the different elements. In the case of crack closing in a nonlinear problem, the normal stiffness across the crack surfaces becomes infinite, causing numerical problems. However, those problems can be avoided by transforming the equilibrium equations in terms of both absolute and relative displacements rather than in terms of absolute displacements only. Ghaboussi, Wilson and Isenberg suggested the formulation of a two-dimensional interface element which involves two relative nodal displacements as shown in fig. (5.4). The nodal displacements associated with the interface element are shown in fig. (5.5), where u's and $\Delta$ 's represent the absolute and relative displacements respectively. Notice that if the interface thickness $h$ is considered to be very small compared to the size of the upper and lower two standard finite elements, then the assumption that strains a not vary in the thickness direction is valid. The physical behavior of the 

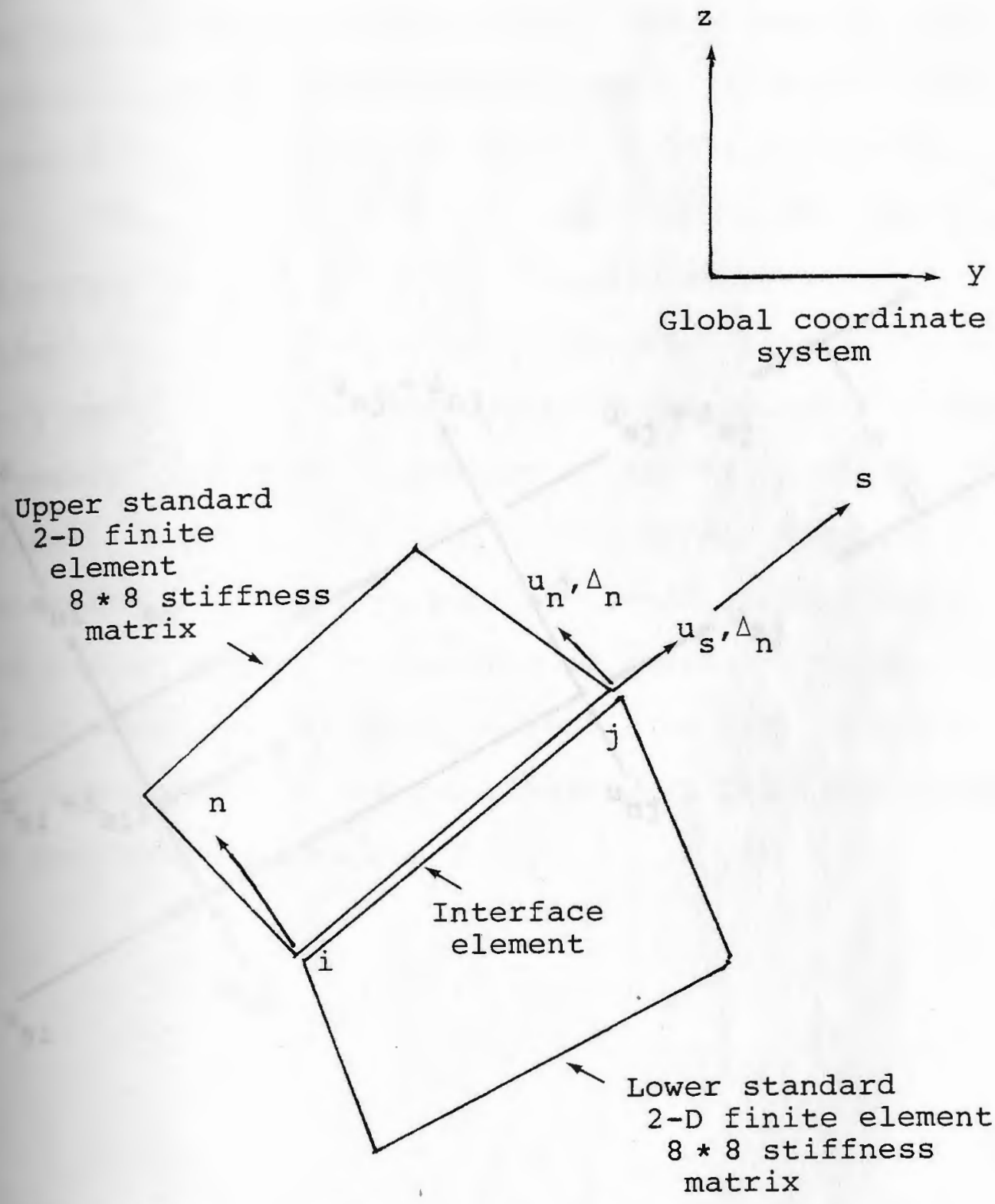

Fig. (5.4) Two-dimensional interface element. 


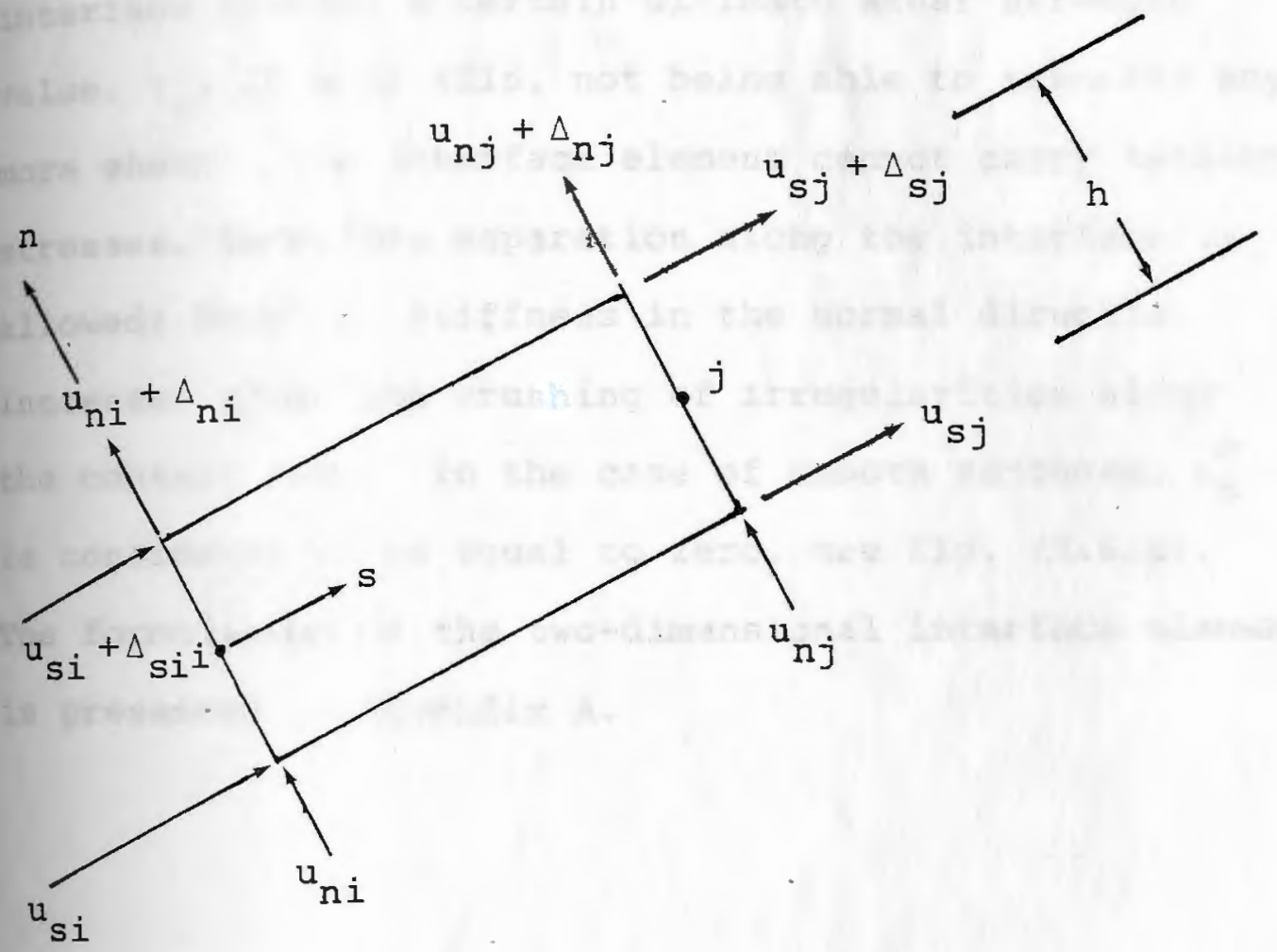

Fig. (5.5) Interface element displacements. 
wo-dimensional interface element involves separation and slip along the contact zone. The stress - strain relations in the normal and horizontal direction are shown in fig. (5.6.a) and fig. (5.6.b) respectively. When the shear stress transferred along the interface reaches a certain ultimate shear strength value, $\tau_{u}$, it will slip, not being able to transfer any more shear. The interface element cannot carry tension stresses, therefore separation along the interface is allowed; however, stiffness in the normal direction increases after the crushing of irregularities along the contact zone. In the case of smooth surfaces, $\varepsilon_{n}^{c}$ is considered to be equal to zero, see fig. (5.6.a). The formulation of the two-dimensional interface element is presented in Appendix A. 


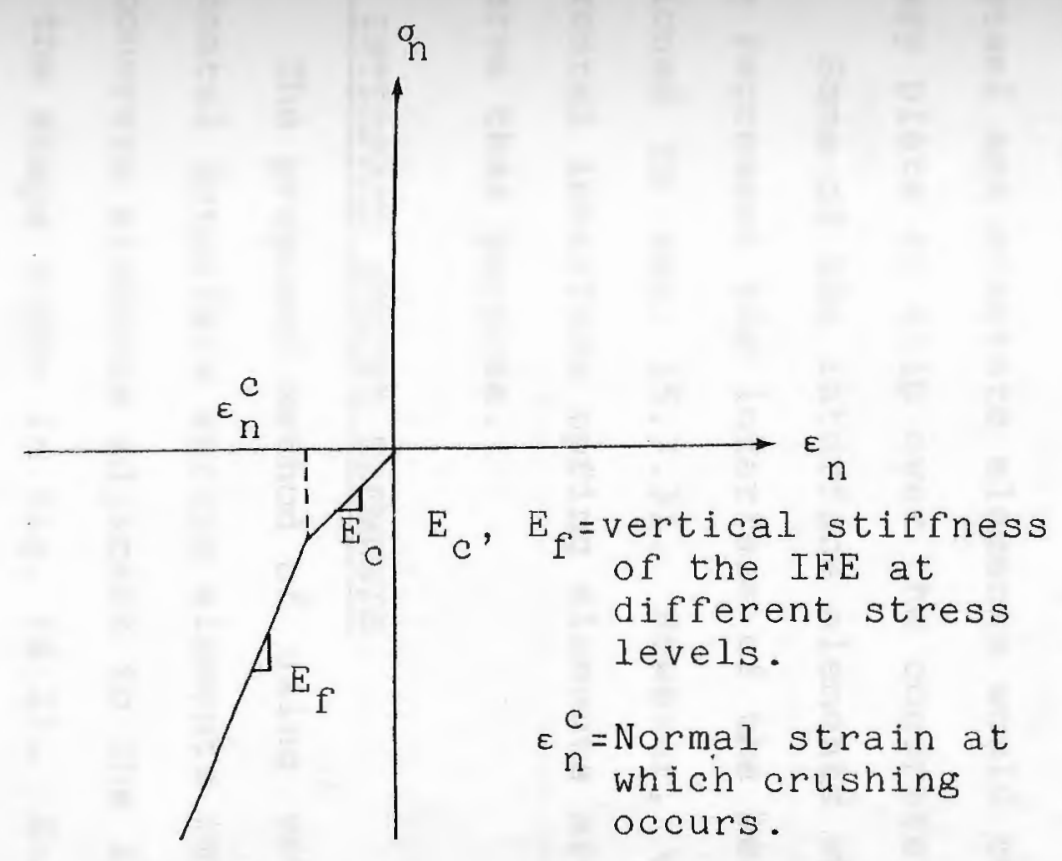

Fig. (5.6.a) Stress-strain relation in the normal direction.

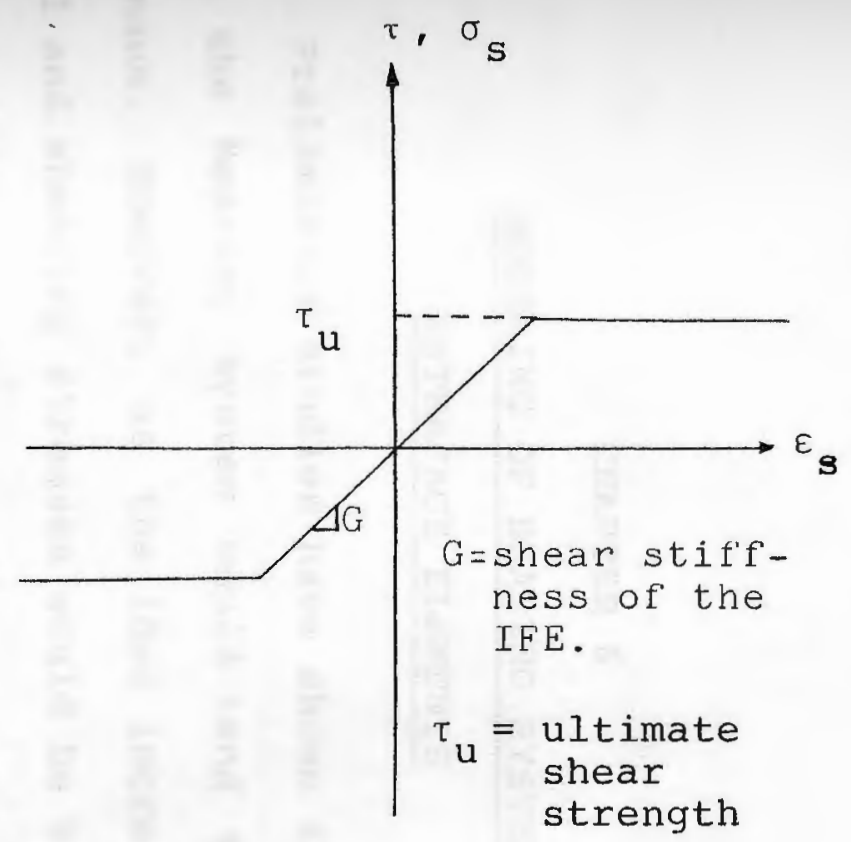

Fig. (5.E.b) Stress-strain relation in the tangential direction. 
CHAPTER 6

MODELING OF BEARING SYSTEM

INTERFACE ELEMENTS

Preliminary studies have shown that under small loads the bearing system would tend to behave as a continuum. However, as the load increases, larger normal and shearing stresses would be transferred along the interface zone between the masonry steel plate and the concrete abutment. When the shear stress reaches a certain ultimate shear strength value, the bond between the steel and concrete elements would break, causing the masonry plate to slip over the concrete surface.

Some of the interface elements which could possibly represent the interface of the bearing system were mentioned in sec. (5.3.3). However, vertical and horizontal interface spring elements are proposed here to serve that purpose.

\subsection{INTERFACE SPRING ELEMENTS}

The proposed method of using vertical and horizontal interface spring elements requires the steel and concrete elements adjacent to the interface zone to have the shape shown in fig. (6.1). Each vertical 


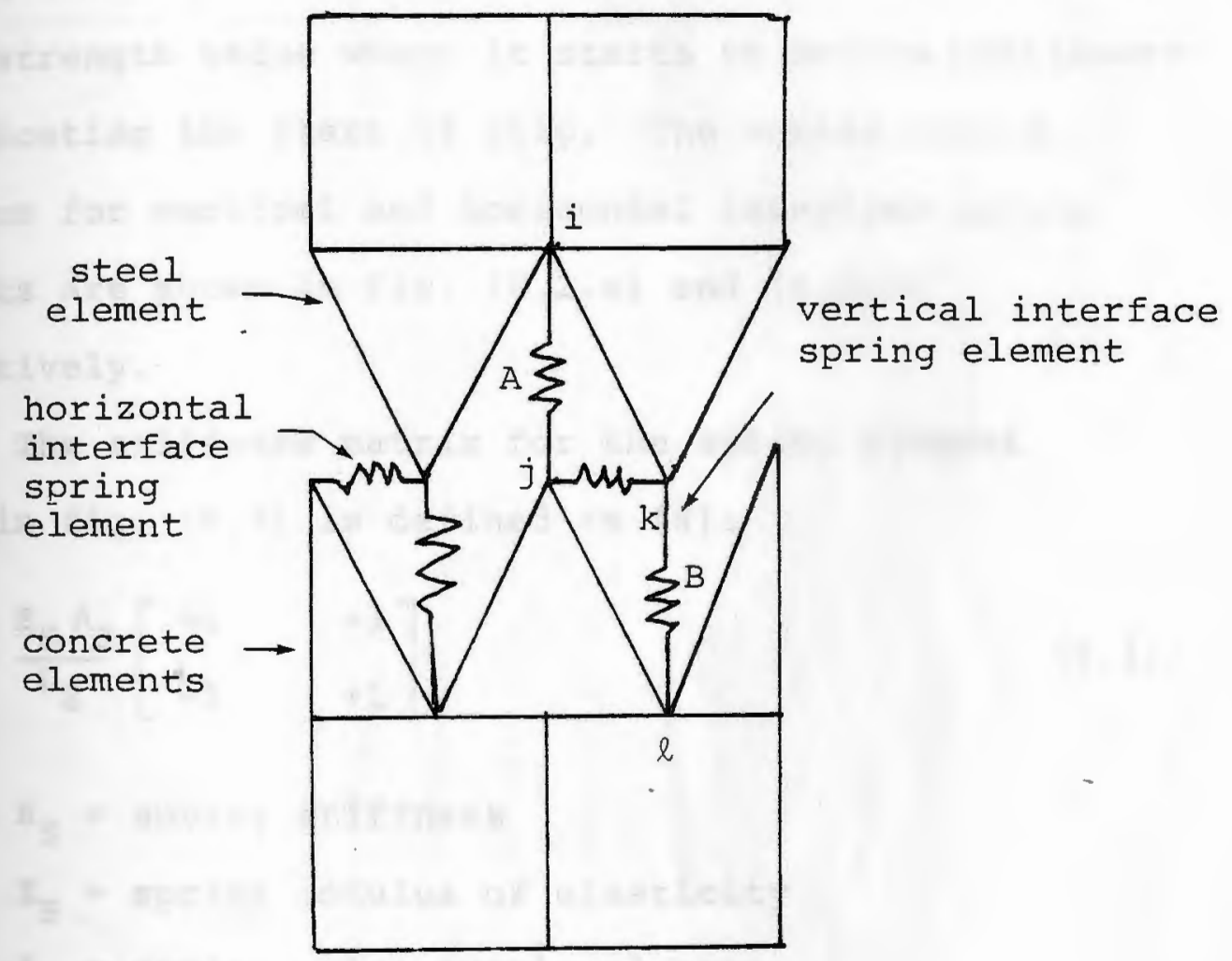

Fig. (6.1) Vertical and horizontal interface spring elements. 
spring is assumed to be a linear-elastic onedimensional element transferring normal stresses along its axis. On the other hand, each horizontal spring is assumed to be a nonlinear elastic-plastic onedimensional element which stays in the elastic range until the shear transferred through it reaches an ultimate shear strength value where it starts to deform nonlinearly indicating the start of slip. The stress-strain diagrams for vertical and horizontal interface spring elements are shown in fig. (6.2.a) and (6.2.b) respectively.

The stiffness matrix for the spring element shown in fig. (6.3) is defined as [8]:

$$
\left[K_{S}\right]=\frac{E_{S} A_{S}}{L_{S}}\left[\begin{array}{ll}
+1 & -1 \\
-1 & +1
\end{array}\right]
$$

where $\mathrm{K}_{\mathrm{S}}=$ spring stiffness

$$
\begin{aligned}
& \mathrm{E}_{S}=\text { spring modulus of elasticity } \\
& \mathrm{A}_{S}=\text { spring cross sectional area } \\
& \mathrm{L}_{S}=\text { length of the spring }
\end{aligned}
$$

and the spring stiffness equation is given as

$$
\left\{\begin{array}{l}
F_{I} \\
F_{2}
\end{array}\right\}=\left[R_{S}\right] \quad\left\{\begin{array}{l}
u_{1} \\
u_{2}
\end{array}\right\}
$$



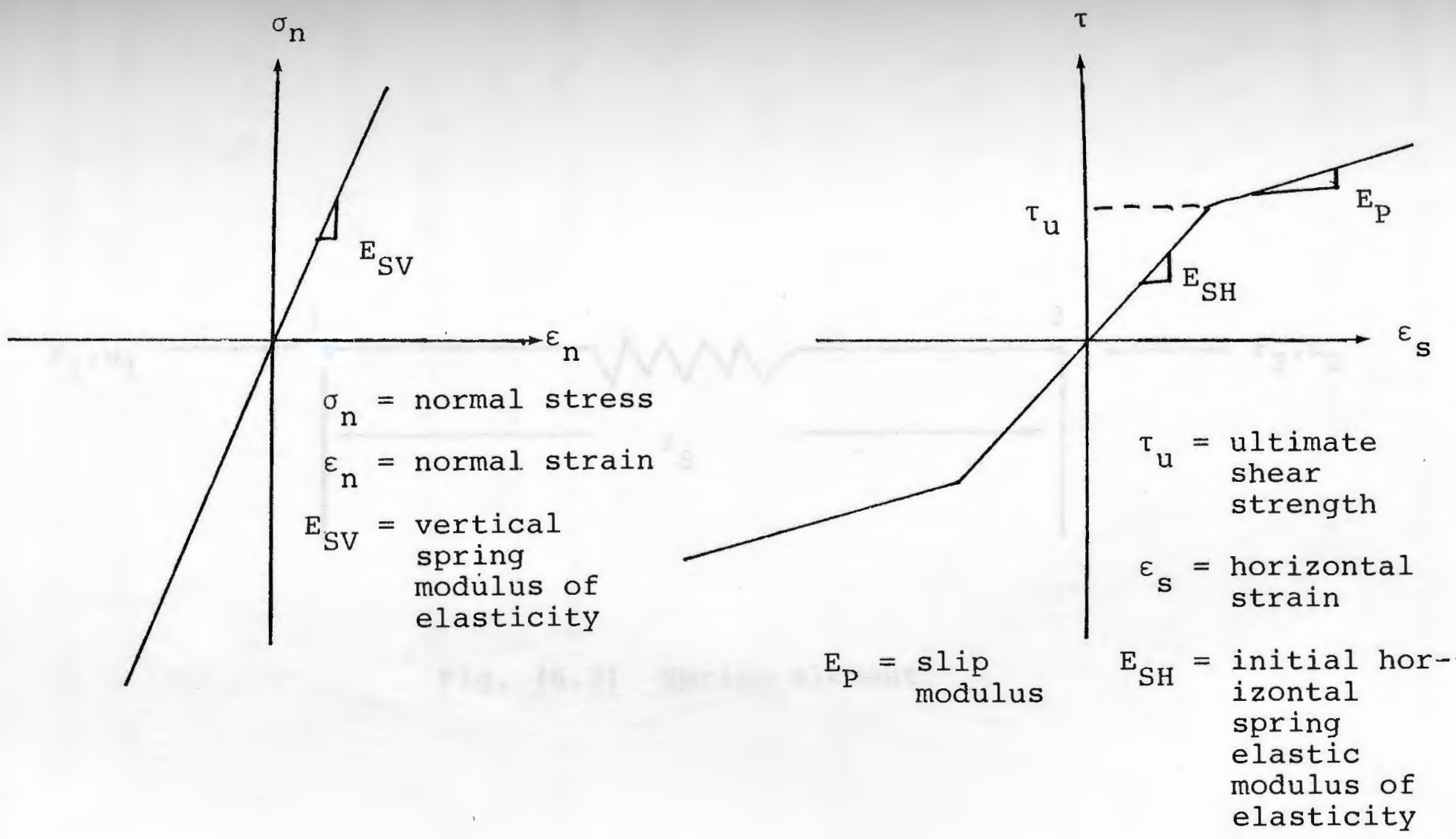

Fig. (6.2.a) Vertical spring

Fig. (6.2.b) Horizontal spring

stress - strain

stress - strain diagram.

diagram. 


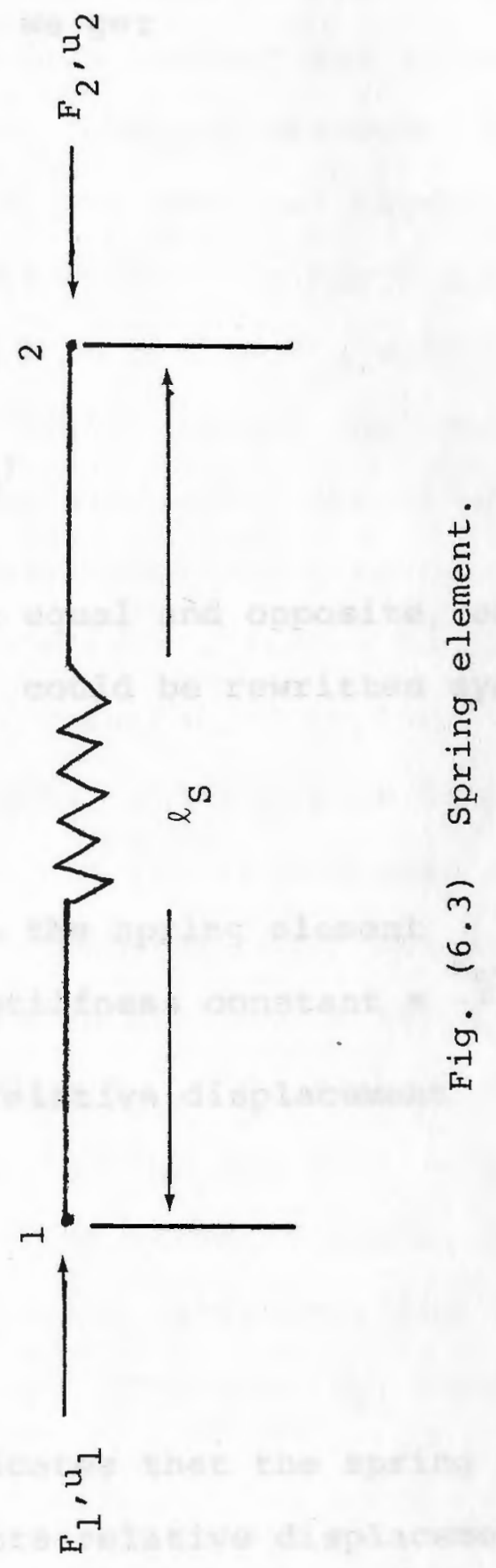


where $F_{1}, u_{1}$ and $F_{2}, u_{2}$ represent spring forces and dislacements at nodes 1 and 2 respectively.

From equation (6.2) we get

$F_{1}=\frac{E_{S} A_{S}}{L_{S}}\left(u_{1}-u_{2}\right)$

and

$F_{2}=\frac{E_{S} A_{S}}{L_{S}}\left(-u_{1}+u_{2}\right)$

Since $F_{1}$ and $F_{2}$ are equal and opposite, equations

(6.3.a) and (6.3.b) could be rewritten symbolically as

$\mathrm{F}_{\mathrm{S}}=\mathrm{k}_{\mathrm{S}} \cdot \Delta_{\mathrm{S}}$

where $F_{S}$ = force in the spring element

$$
\begin{aligned}
& \mathrm{k}_{S}=\text { spring stiffness constant }=\frac{E_{S}{ }^{A_{S}}}{I_{S}} \\
& \Delta_{S}=\text { spring relative displacement. }
\end{aligned}
$$

Rearranging (6.4),

$\Delta_{S}=\frac{1}{k_{S}} \cdot F_{S}$

Equation (6.5) indicates that the spring stiffness constant controls its relative displacements. If $A_{S}$ and $L_{S}$ were assumed to be kept constant, the spring relative displacement will depend on the value of the 
spring modulus of elasticity $\mathrm{E}_{\mathrm{S}}$.

Referring back to the vertical and horizontal

stress-strain diagrams shown in fig. (6.2.a) and

fig. (6.2.b), if perfect contact was assumed between the masonry plate and the concrete abutment, the relative displacements of the vertical interface spring elements are expected to be very small approaching zero; therefore, $E_{S V}$ should be assigned a very large value which approaches infinity. Since the masonry plate is not restrained in the horizontal direction and because different displacement functions were assumed for the steel and concrete elements adjacent to the interface zone, when the shear transferred is less than the ultimate shear strength, the relative displacements in the horizontal interface spring elements are not expected to approach zero; however, they are very small. Therefore, $\mathrm{E}_{\mathrm{SH}}$ should be assigned a large value but significantly less than $\mathrm{E}_{\mathrm{SV}}$. However, when shearing stresses transferred through the horizontal springs reach the ultimate shear strength value, those springs will start to slip having large relative displacements indicating that the slip modulus, $E_{P^{\prime}}$ should be assigned a very small value.

Nevertheless, there remain two critical unsolved problems. Firstly, what are the values of the moduli of lasticity discussed above? Secondly, what is the shear 
thength in the horizontal interface spring elements?

\subsection{INTERFACE SPRING ELEMENTS STIFFNESS}

The vertical spring element stiffness has to be large enough so that the relative vertical displacements mproach zero. However, if the interface zone is too thin, a large normal stiffness might cause an illconditioning problem resulting from dividing a very big number by a very small one. The spring stiffness constant was defined in equation (6.4), showing that an illconditioning problem will arise if $\mathrm{E}_{S}>\mathrm{L}_{\mathrm{S}}$. It was recommended that the interface normal stiffness be equal to $10^{5}$ times the stiffness of the adjacent elements [6]. The horizontal interface spring element stiffness could be determined by either a classical theoretical "exact" solution, or experimentally. However, a theoretical solution might involve tedious lengthy calculations, and experimental results might complicate the problem by adding more variable parameters. Therefore, the procedure adopted here for determining the horizontal spring stiffnesses involves trying different values, then comparing the outcoming results against those of known solutions, such as the infinite shear transfer case with $E_{S H}$ equals infinity, and the case of zero shear transfer with $\mathrm{E}_{\mathrm{SH}}$ equals zero. The interface zone for the infinite and zero shear transfer cases hodeled as shown in fig. (6.4) and fig. (6.5) respectively. 


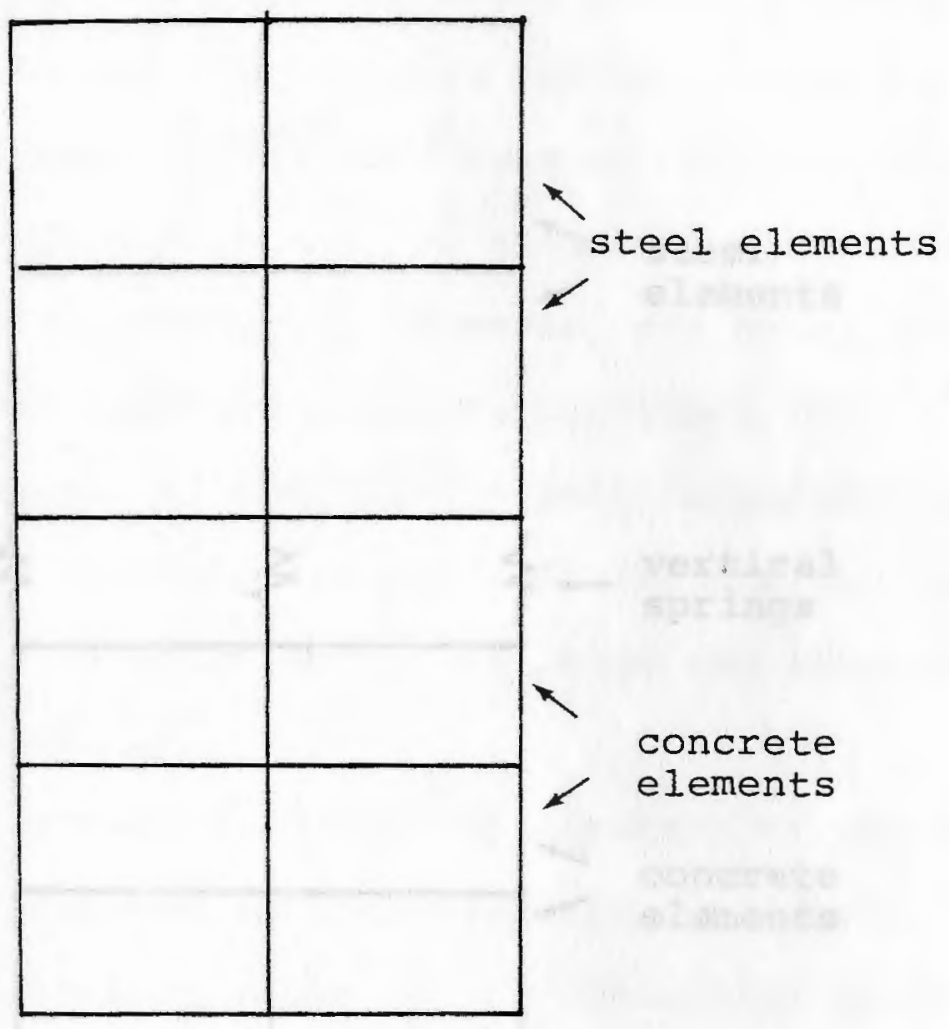

Fig. (6.4) Case of infinite shear transfer. 


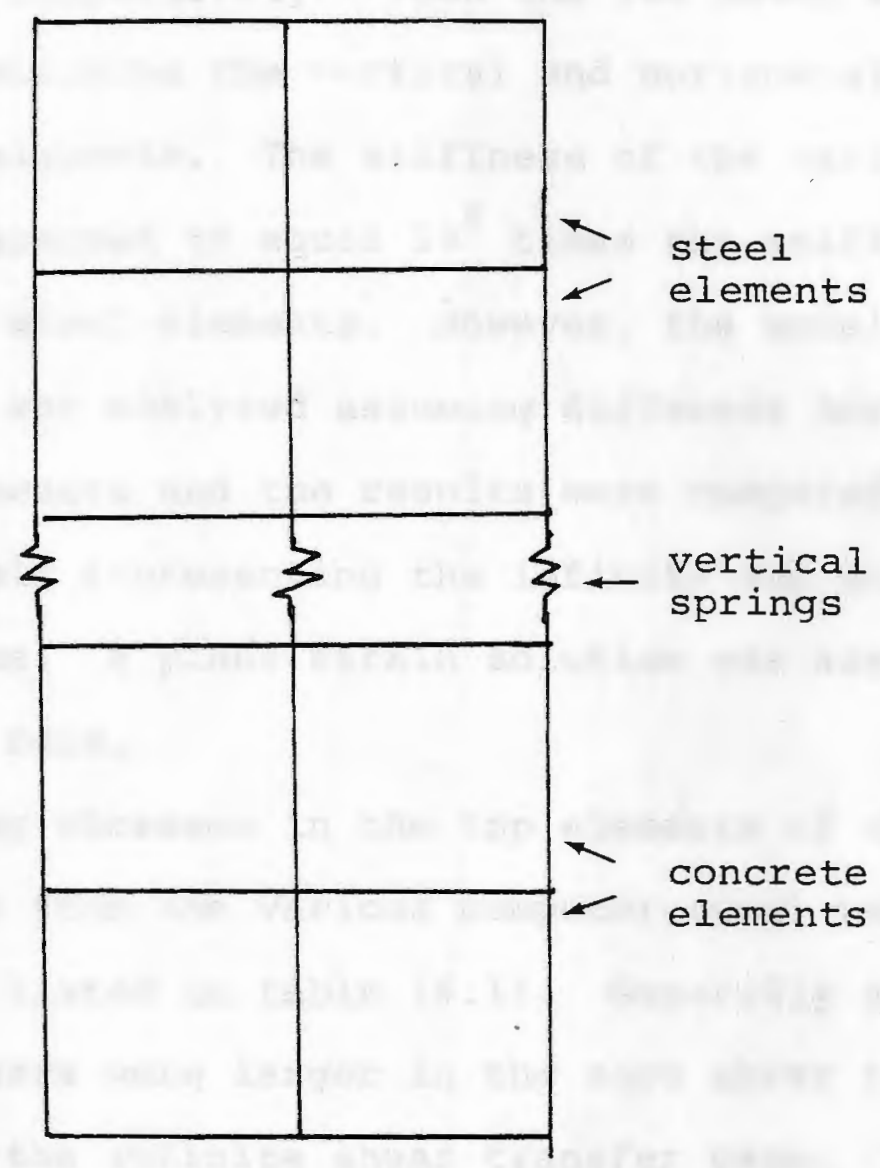

Fig. (6.5) Case of zero shear transfer. 


\section{EXAMPLE PROBLEM}

Two steel beams laying on top of each other were analyzed, assuming infinite shear transfer and zero shear transfer conditions modeled as shown in fig. (6.6.a) and fig. (6.6.b) respectively. Then the two beams were modeled by including the vertical and horizontal interface spring elements. The stiffness of the vertical springs was assumed to equal $10^{5}$ times the stiffness of the adjacent steel elements. However, the model in fig. (6.6.c) was analyzed assuming different horizontal spring stiffnesses and the results were compared against those of models representing the infinite and zero shear transfer cases. A plane strain solution was assumed for all computer runs.

Bending stresses in the top elements of the upper beam (results from the various computer runs) were averaged and listed in table (6.1). Generally speaking, bending stresses were larger in the zero shear transfer case than in the infinite shear transfer case. Thus, for the model which includes interface spring elements, results converged toward representing the infinite shear transfer or the zero shear transfer cases, depending on the value of $\mathrm{E}_{\mathrm{SH}}$.

When $\mathrm{E}_{\mathrm{SH}}$ was set to equal $500 \mathrm{Ksi}$, the averaged negative bending stresses in the center elements $(7,8$, and 9) were about 1.1 to $1.7 \%$ larger than in the zero 


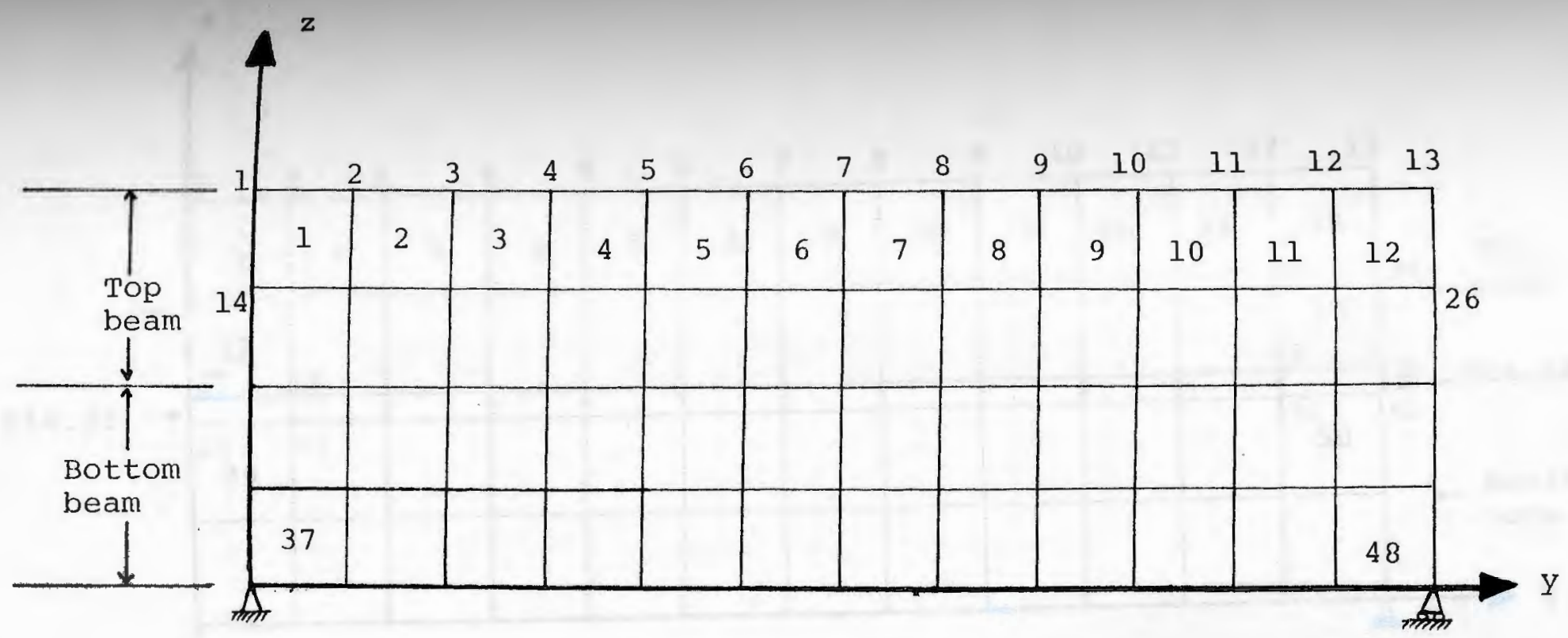

Steel: $\quad E=29000 \mathrm{Ksi}$

$v=0.25$

Fig. (6.6.a) Two beams with infinite shear transfer condition. 


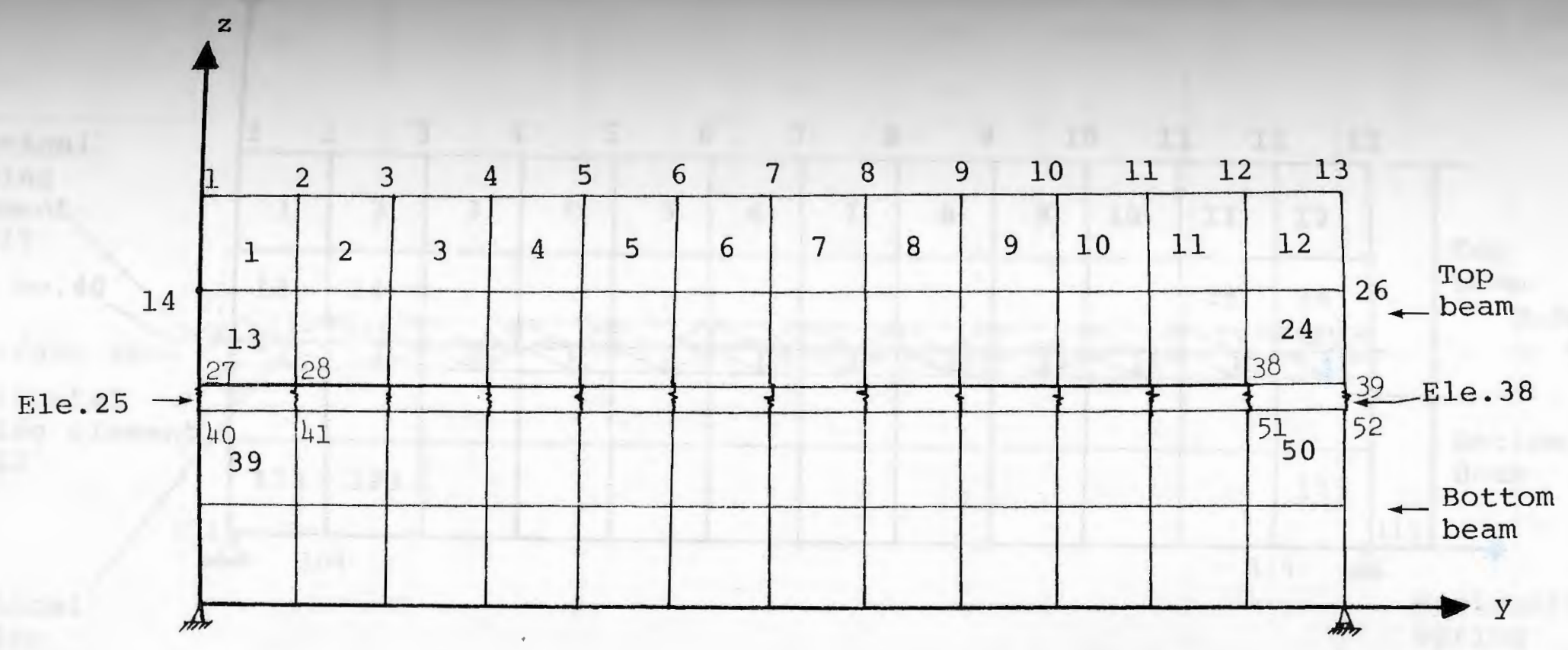

Fig. (6.6.b) Two beams with zero shear transfer condition. 


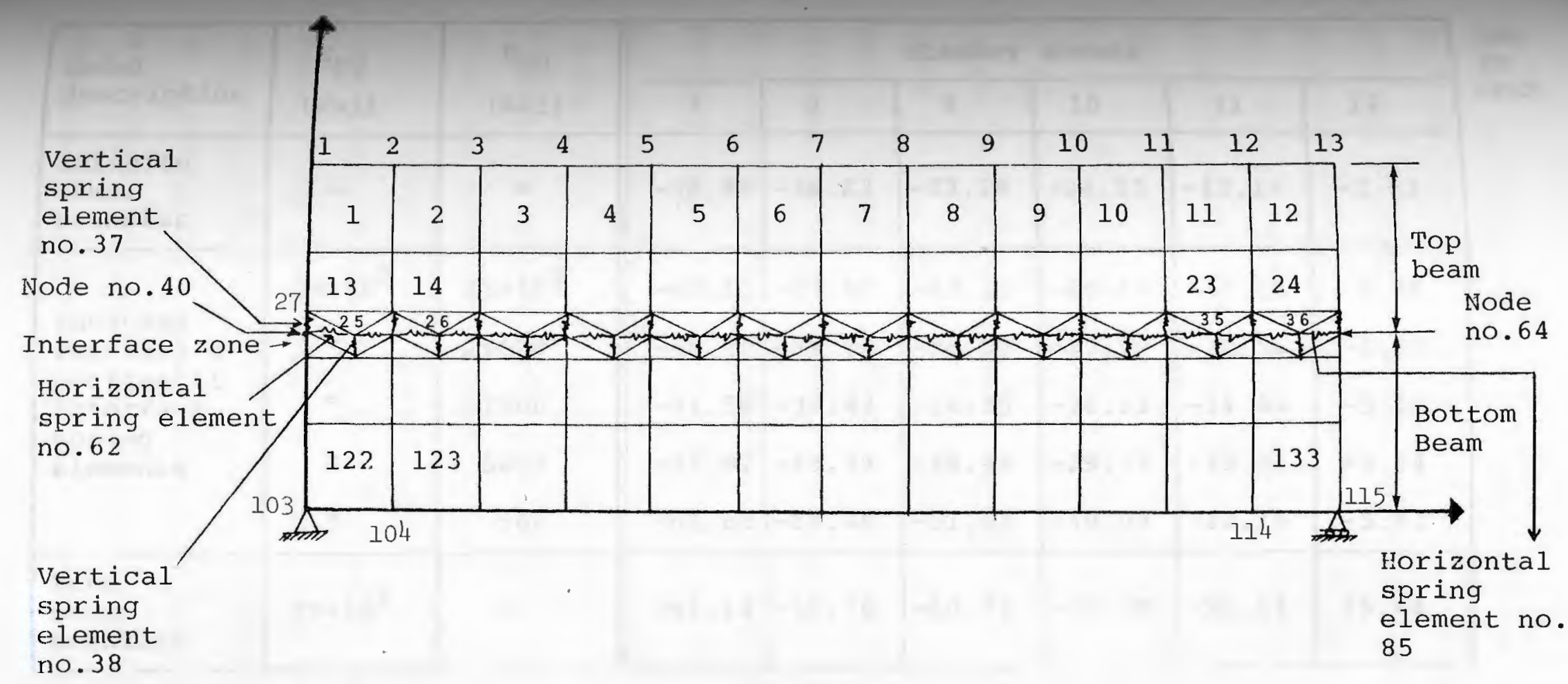

Fig. (6.6.c) Two beams with interface spring elements. 


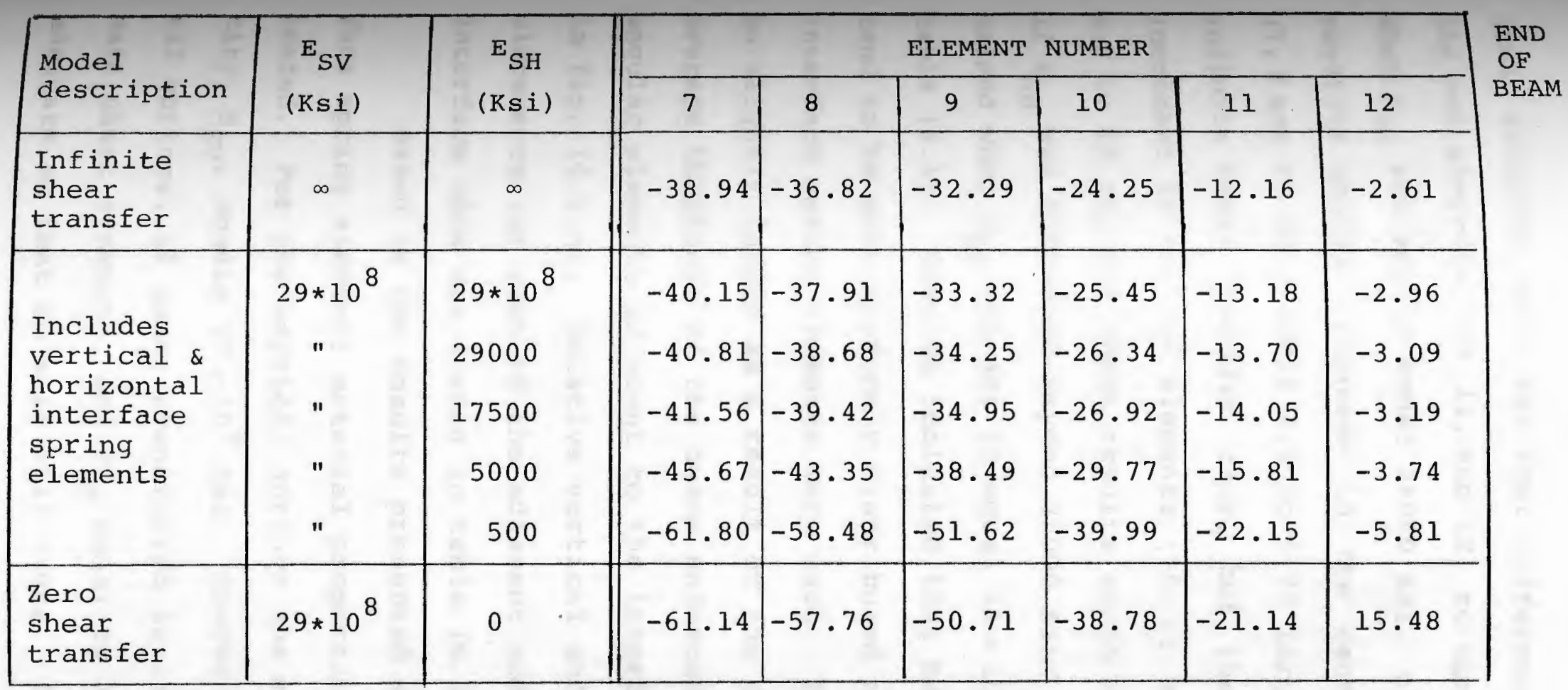

Table (6.1) Plane strain solution. Averaged bending stresses (Ksi) in the top elements of the upper beam. Gauss integration points 2 and 4. 
shear transfer case, but that difference increased in the end elements $(10,11$, and 12$)$ to about 3.0 to $5.6 \%$. When $E_{S H}$ was set to equal $29000 \mathrm{ksi}$, the averaged negative bending stresses in the center elements $(7,8$ and 9) were about 4.6 to $5.7 \%$ larger than in the infinite shear transfer case, but that difference mcreased in the end elements $(10,11$, and 12) to about 8.0 to $15.5 \%$, and those results would not vary by much if $\mathrm{E}_{\mathrm{SH}}$ was increased beyond $29000 \mathrm{Ksi}$; see results obtained when $\mathrm{E}_{\mathrm{SH}}$ was set to equal $29 * 10^{8} \mathrm{Ksi}$ in table (6.1). Results indicated that bending stresses tend to be more uniformly distributed along the beam if interface spring elements were used. They also tend to be slightly larger as a result of the reduction in the average thickness of the beams enforced by using triangular elements adjacent to the interface zone as shown in fig. (6.6.c). Relative vertical and horizontal displacements for some of the adjacent nodes along the interface zone are listed in table (6.2).

Based on the results presented above, the interface spring elements material properties could be approximated. For the vertical springs the modulus of elasticity, $\Sigma_{S V}$ ' equals $29 * 10^{8} \mathrm{rsi}$. However, for the horizontal springs, if shear transferred is less than the ultimate shear strength, and $E_{\mathrm{SH}}$ equal to $29000 \mathrm{Ksi}$ will be dequate so that no slip will occur. If shear stresses 


\begin{tabular}{|c|c|c|c|c|c|c|c|c|c|c|}
\hline Nodes in & models & & $\begin{array}{l}\text { h } \\
\text { erface } \\
\text { ing elements } \\
\text { hout } \\
\text { erface } \\
\text { ing elements }\end{array}$ & $27-40$ & $38-41$ & $32-45$ & $33-46$ & $\begin{array}{l}34-47 \\
34-54\end{array}$ & $\begin{array}{l}38-51 \\
38-62\end{array}$ & $\begin{array}{l}39-52 \\
39-64\end{array}$ \\
\hline $\begin{array}{l}\text { Model } \\
\text { description }\end{array}$ & $\begin{array}{l}{ }_{\text {SV }} \\
\text { (Ksi) }\end{array}$ & $\begin{array}{l}\mathrm{E}_{\mathrm{SH}} \\
\text { (Ksi) }\end{array}$ & $\begin{array}{l}\text { Relative } \\
\text { displacement } \\
\text { (inches) }\end{array}$ & & & & & & & \\
\hline $\begin{array}{l}\text { Infinite } \\
\text { shear } \\
\text { transfer }\end{array}$ & $\infty$ & $\infty$ & $\begin{array}{l}\Delta H \\
\Delta V\end{array}$ & $\begin{array}{l}0.0 \\
0.0\end{array}$ & $\begin{array}{l}0.0 \\
0.0\end{array}$ & $\begin{array}{l}0.0 \\
0.0\end{array}$ & $\begin{array}{l}0.0 \\
0.0\end{array}$ & $\begin{array}{l}0.0 \\
0.0\end{array}$ & $\begin{array}{l}0.0 \\
0.0\end{array}$ & $\begin{array}{l}0.0 \\
0.0\end{array}$ \\
\hline \multirow{2}{*}{$\begin{array}{l}\text { Includes } \\
\text { interface } \\
\text { spring } \\
\text { elements }\end{array}$} & \multirow{2}{*}{$\begin{array}{l}29 * 10^{8} \\
29 * 10^{8}\end{array}$} & 29000 & $\begin{array}{l}\Delta \mathbf{H} \\
\Delta \mathrm{V}\end{array}$ & $\begin{array}{c}-0.0011 \\
0.0\end{array}$ & $\begin{array}{l}-0.0013 \\
0.0\end{array}$ & $\begin{array}{l}-0.00011 \\
0.0\end{array}$ & $\begin{array}{l}0.0 \\
0.0\end{array}$ & $\begin{array}{c}-0.00011 \\
0.0\end{array}$ & $\begin{array}{c}+0.0013 \\
0.0\end{array}$ & $\begin{array}{c}+0.0011 \\
0.0\end{array}$ \\
\hline & & 500 & $\begin{array}{l}\Delta H^{\prime} \\
\Delta V^{\prime}\end{array}$ & $\begin{array}{c}-0.064 \\
0.0\end{array}$ & $\begin{array}{c}-0.062 \\
0.0\end{array}$ & $\begin{array}{c}-0.016 \\
0.0\end{array}$ & $\begin{array}{l}0.0 \\
0.0\end{array}$ & $\begin{array}{c}+0.016 \\
0.0\end{array}$ & $\begin{array}{c}+0.062 \\
0.0\end{array}$ & $\begin{array}{c}+0.064 \\
0.0\end{array}$ \\
\hline $\begin{array}{l}\text { Zero } \\
\text { shear } \\
\text { transfer }\end{array}$ & $29 * 10^{8}$ & 0.0 & $\begin{array}{l}\Delta H \\
\Delta V\end{array}$ & $\begin{array}{c}-0.059 \\
0.0\end{array}$ & $\begin{array}{c}-0.056 \\
0.0\end{array}$ & $\begin{array}{c}-0.0016 \\
0.0\end{array}$ & $\begin{array}{c}+0.018 \\
0.0\end{array}$ & $\begin{array}{c}+0.037 \\
0.0\end{array}$ & $\begin{array}{c}+0.092 \\
0.0\end{array}$ & $\begin{array}{c}+0.094 \\
0.0\end{array}$ \\
\hline
\end{tabular}

Table (6.2) Plane strain solution.

List of relative vertical and horizontal displacements between various nodes adjacent to the interface zone (inches). 
transferred in the horizontal springs reach the ultimate shear strength value, then an $\mathrm{E}_{\mathrm{SH}}$ equal to $500 \mathrm{Ksi}$ will be adequate to represent a slip condition. The crossectional areas and lengths of the springs were calculated to be geometrically proportional to the elements adjacent to the interface zone.

\subsection{THE BEARING SYSTEM MODELED WITH INTERFACE SPRING ELEMENTS}

A finite element grid system of the bearing system modeled with vertical and horizontal interface spring elements was shown in fig. (4.7). The bearing system was analyzed assuming different interface spring elements stiffness values; results were compared against those of bearing system models representing zero and infinite shear transfer conditions, shown in fig. (4.5) and fig. (4.6) respectively. The analysis was carried out using axisymmetric and plane strain solution methods. Interface spring elements were assumed to be 0.25 inches long, and their cross-sectional areas were calculated to be geometrically proportional to the steel and concrete elements adjacent to the interface zone. Rertical and horizontal springs calculated crossPectional areas for both solution methods were listed in tables $(6.3 . a)$ and $(6.3 . b)$ respectively. The vertical springs modulus of elasticity assumed to be $10^{5}$ times the adjacent steel elements modulus of elasticity, equals 


\begin{tabular}{lcc}
$\begin{array}{l}\text { vertical } \\
\text { spring }\end{array}$ & Axisymetric solution & $\begin{array}{l}\text { Plane strain } \\
\text { solution }\end{array}$ \\
element no. & $A_{S}-$ In $^{2}$ & A $_{\text {S }}{ }^{2}$ \\
\hline 63 & 0.01 & 0.125 \\
64 & 0.04 & 0.25 \\
65 & 0.09 & 0.25 \\
66 & 0.14 & 0.25 \\
67 & 0.18 & 0.25 \\
68 & 0.22 & 0.25 \\
69 & 0.27 & 0.25 \\
70 & 0.32 & 0.25 \\
71 & 0.36 & 0.25 \\
72 & 0.40 & 0.25 \\
73 & 0.45 & 0.25 \\
74 & 0.50 & 0.25 \\
75 & 0.54 & 0.25 \\
76 & 0.58 & 0.25 \\
77 & 0.63 & 0.25 \\
78 & 0.68 & 0.25 \\
79 & 0.72 & 0.25 \\
80 & 0.76 & 0.25 \\
81 & 0.81 & 0.25 \\
82 & 0.86 & 0.25 \\
83 & 0.90 & 0.25 \\
84 & 0.94 & 0.25 \\
85 & 0.99 & 0.25 \\
86 & 1.04 & 0.25 \\
87 & 1.08 & 0.25 \\
88 & 1.12 & 0.25 \\
89 & 1.17 & 0.125 \\
90 & 1.22 & \\
91 & 0.31 & \\
\hline
\end{tabular}

Table (6.3.a) Vertical interface spring elements cross-sectional areas. 


\begin{tabular}{ccc}
$\begin{array}{l}\text { Horizontal } \\
\text { spring } \\
\text { element no. }\end{array}$ & Axisymmetric solution & $\begin{array}{l}\text { Plane strain } \\
\text { solution } \\
A_{S}-i^{2}\end{array}$ \\
\hline 92 & 1.00 & 1.25 \\
93 & 0.12 & 0.25 \\
94 & 0.20 & 0.25 \\
95 & 0.30 & 0.25 \\
96 & 0.38 & 0.25 \\
97 & 0.48 & 0.25 \\
98 & 0.56 & 0.25 \\
99 & 0.66 & 0.25 \\
100 & 0.74 & 0.25 \\
101 & 0.84 & 0.25 \\
102 & 0.92 & 0.25 \\
103 & 1.02 & 0.25 \\
104 & 1.10 & 0.25 \\
105 & 1.20 & 0.25
\end{tabular}

Table (6.3.b) Horizontal interface spring elements cross-sectional areas. 
$29 * 10^{8} \mathrm{ksi}$. The horizontal springs modulus of elasticity was assumed to equal $29000 \mathrm{ksi}$ representing the infinite shear transfer condition (initial no slip modulus, $\left.\mathrm{E}_{\mathrm{SH}}\right)$, and $29 \mathrm{Ksi}$ representing the zero shear transfer condition (slip modulus, $E_{p}$ ), see fig. (6.2.a) and fig. (6.2.b).

Results from the analyzed models representing the infinite and zero shear transfer conditions with and without using the interface spring elements for both solution methods, were compared anc tabulated. Averaged bending stresses in top of the pot bearing were listed in tables $(6.4 . a)$ and $(6.4 . b)$; averaged bending stresses in top of the masonry plate were listed in tables $(6.5 . a)$ and (6.5.b); averaged concrete vertical stresses were listed in tables $(6.6 . a)$ and $(6.6 . b)$; averaged concrete shearing stresses were listed in tables (6.7.a) and (6.7.b); refer to fig. (6.7). Generally speaking, results indicated that negative bending stresses in the pot bearing and the masonry steel plates were slightly lower in models which included the interface spring elements. That could be attributed to the fact that horizontal Interface spring elements actually connect nodes adjacent to the interface zone rather than connecting adjacent surfaces, hence the shear transferred along the interface would be concentrated in those springs instead of being miformly distributed. Therefore the restraint against 


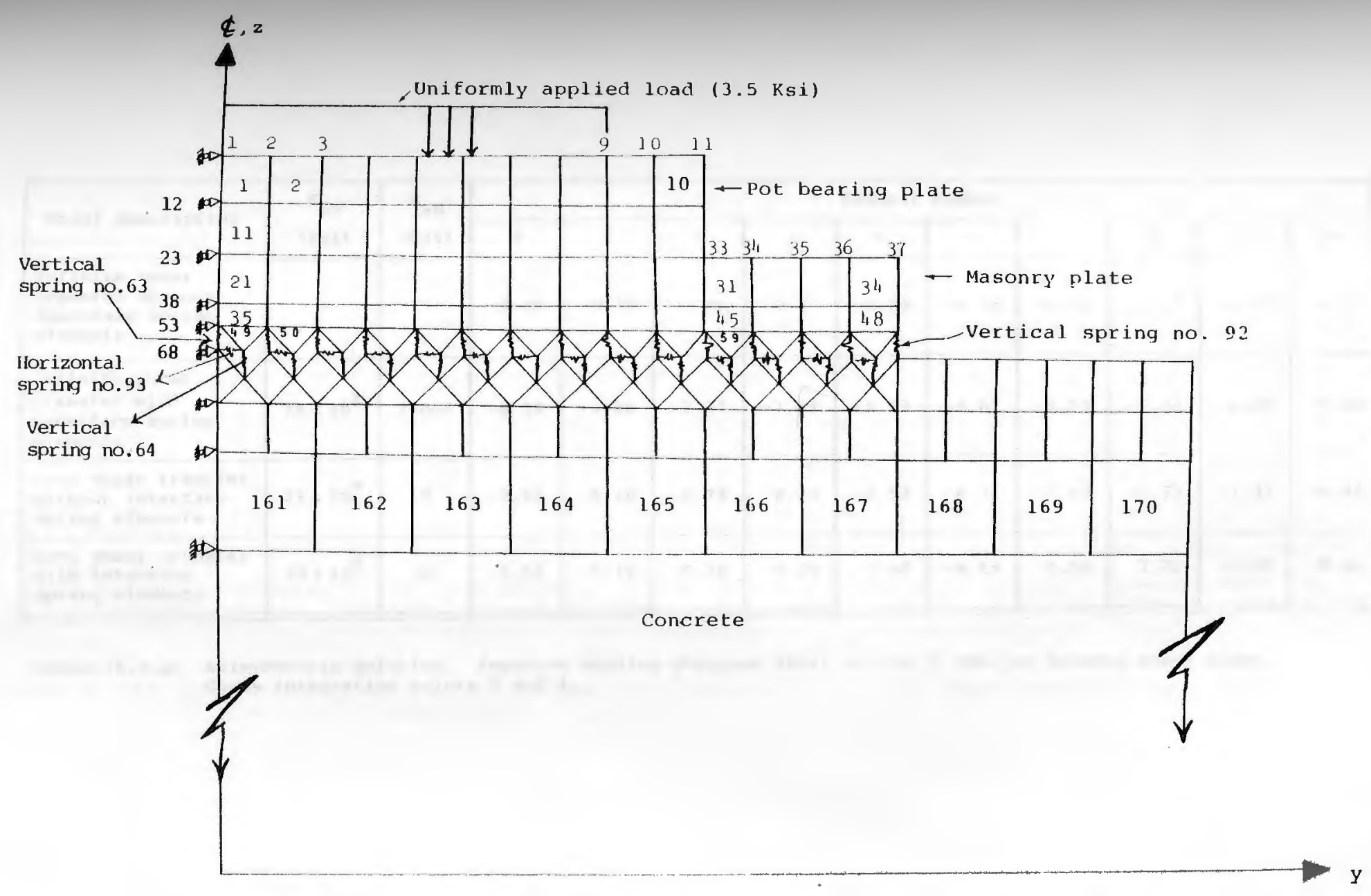

Fig. (6.7) Top part of the bearing system including interface spring elements. 


\begin{tabular}{|c|c|c|c|c|c|c|c|c|c|c|c|c|}
\hline \multirow{2}{*}{ Model description } & \multirow{2}{*}{$\begin{array}{l}\mathbf{E}_{\mathrm{SV}} \\
(\mathrm{Ksi})\end{array}$} & \multirow{2}{*}{$\begin{array}{l}{ }_{\mathrm{SH}} \\
(\mathrm{Ksi})\end{array}$} & \multicolumn{10}{|c|}{ Element number } \\
\hline & & & 1 & 2 & 3 & 4 & 5 & 6 & 7 & $\varepsilon$ & 9 & 10 \\
\hline $\begin{array}{l}\text { Infinite shear } \\
\text { transfer without } \\
\text { interface spring } \\
\text { elements }\end{array}$ & $\infty$ & $\infty$ & -8.65 & -8.30 & -7.88 & -7.43 & -6.84 & -6.10 & -5.13 & -3.37 & -1.07 & -0.08 \\
\hline $\begin{array}{l}\text { Infinite shear } \\
\text { transfer with } \\
\text { interface spring } \\
\text { elements }\end{array}$ & $29 * 10^{8}$ & 29000 & -8.59 & -8.26 & -7.87 & -7.43 & -6.83 & -6.07 & -5.09 & -3.32 & -1.06 & -0.08 \\
\hline $\begin{array}{l}\text { Zero shear transfer } \\
\text { without interface. } \\
\text { spring elements }\end{array}$ & $29 * 10^{8}$ & 0 & -9.63 & -9.20 & -8.73 & -8.20 & -7.53 & -6.71 & -5.65 & -3.78 & -1.31 & -0.16 \\
\hline $\begin{array}{l}\text { Zero shear transfer } \\
\text { with interface } \\
\text { spring elements }\end{array}$ & $29 * 10^{8}$ & 29 & -9.53 & -9.12 & -8.70 & -8.19 & -7.52 & -6.68 & -5.59 & -3.71 & -1.29 & -0.16 \\
\hline
\end{tabular}

Table (6.4.a) Axisymmetric solution. Averaged bending stresses (Ksi) in top of the pot bearing steel plate. Gauss integration points 2 and 4 . 


\begin{tabular}{|c|c|c|c|c|c|c|c|c|c|c|c|c|}
\hline \multirow{2}{*}{ Model description } & \multirow{2}{*}{$\begin{array}{l}\mathrm{E}_{\mathrm{SV}} \\
(\mathrm{Ksi})\end{array}$} & \multirow{2}{*}{$\begin{array}{c}{ }_{\mathrm{SH}} \\
(\mathrm{Ksi})\end{array}$} & \multicolumn{10}{|c|}{ Element number } \\
\hline & & & 1 & 2 & 3 & 4 & 5 & 6 & 7 & 8 & 9 & 10 \\
\hline $\begin{array}{l}\text { Infinite shear } \\
\text { transfer without } \\
\text { interface spring } \\
\text { elements }\end{array}$ & $\infty$ & $\infty$ & -9.74 & -9.60 & -9.33 & -8.90 & -8.30 & -7.50 & -6.42 & -4.47 & -1.77 & -0.25 \\
\hline $\begin{array}{l}\text { Infinite shear } \\
\text { transfer with } \\
\text { interface spring } \\
\text { elements }\end{array}$ & $29 * 10^{8}$ & 29000 & -9.38 & -9.33 & -9.15 & -8.78 & -8.20 & -7.40 & -6.31 & -4.37 & -1.72 & -0.24 \\
\hline $\begin{array}{l}\text { Zero shear transfer } \\
\text { without interface } \\
\text { spring elements }\end{array}$ & $29 * 10^{8}$ & 0 & -10.35 & -10.21 & -9.92 & -9.47 & -8.84 & -8.00 & -6.87 & -4.84 & -2.02 & -0.33 \\
\hline $\begin{array}{l}\text { Zero shear transfer } \\
\text { with interface } \\
\text { spring elements }\end{array}$ & $29 * 10^{8}$ & 29 & -10.02 & -9.89 & -9.63 & -9.20 & -8.58 & -7.75 & -6.62 & -4.64 & -1.92 & -0.31 \\
\hline
\end{tabular}

Table (6.4.b) Plane strain solution. Averaged bending stresses (Ksi) in top of the pot bearing steel plate. Gauss integration points 2 and 4 . 


\begin{tabular}{|c|c|c|c|c|c|c|c|c|c|c|c|c|c|c|c|c|}
\hline \multirow{2}{*}{ Model description } & \multirow{2}{*}{$\begin{array}{c}E_{S V} \\
(K s i)\end{array}$} & \multirow{2}{*}{$\begin{array}{c}E_{S H} \\
(K s i)\end{array}$} & \multicolumn{14}{|c|}{ Element number } \\
\hline & & & 21 & 22 & 23 & 24 & 25 & 26 & 27 & 28 & 29 & 30 & 31 & 32 & 33 & 34 \\
\hline $\begin{array}{l}\text { Infinite shear } \\
\text { transfer without } \\
\text { interface spring } \\
\text { elements }\end{array}$ & $\infty$ & $\infty$ & $=0.84$ & -0.85 & -0.84 & -0.81 & -0.75 & $-0.68 \mid$ & -0.71 & $-0.97 \mid$ & -1.43 & -2.02 & -2.97 & -0.78 & +0.05 & +0.03 \\
\hline $\begin{array}{l}\text { Infinite shear } \\
\text { transfer with } \\
\text { interface spring } \\
\text { element }\end{array}$ & $29 * 10^{8}$ & 29000 & -0.36 & -0.36 & $-0.36 \mid$ & -0.36 & -0.36 & -0.36 & -0.46 & -0.77 & -1.26 & -1.82 & $-2,56$ & -0.47 & +0.13 & +0.08 \\
\hline $\begin{array}{l}\text { Zero shear transfer } \\
\text { without interface } \\
\text { spring elements }\end{array}$ & $29 * 10^{8}$ & 0 & +0.36 & +0.32 & +0.28 & +0.25 & +0.22 & +0.19 & +0.05 & -0.33 & -0.98 & -1.78 & -2.91 & -0.85 & $-0.22 \mid$ & +0.06 \\
\hline $\begin{array}{l}\text { Zero shear transfer } \\
\text { with interface } \\
\text { spring elements }\end{array}$ & $29 * 10^{8}$ & 29 & +0.85 & +0.81 & +0.77 & +0.71 & +0.63 & +0.54 & +0.33 & -0.11 & -0.78 & -1.52 & -2.37 & -0.36 & +0.14 & +0.07 \\
\hline
\end{tabular}

Table (6.5.a) Axisymmetric solution. Averaged bending stresses (Ksi) in top of the masonry steel plate. Gauss integration points 2 and 4 . 


\begin{tabular}{|c|c|c|c|c|c|c|c|c|c|c|c|c|c|c|c|c|}
\hline \multirow{2}{*}{ Model description } & \multirow{2}{*}{$\begin{array}{l}\mathrm{E}_{\mathrm{SV}} \\
(\mathrm{Ksi})\end{array}$} & \multirow{2}{*}{$\begin{array}{c}{ }_{\mathrm{SH}} \\
(\mathrm{Ksi})\end{array}$} & \multicolumn{12}{|c|}{ Element number } & \multirow[b]{2}{*}{33} & \multirow[b]{2}{*}{34} \\
\hline & & & 21 & 22 & 23 & 24 & 25 & 26 & 27 & 28 & 29 & 30 & 31 & 32 & & \\
\hline $\begin{array}{l}\text { Infinite shear } \\
\text { transfer without } \\
\text { interface spring } \\
\text { elements }\end{array}$ & $\infty$ & $\infty$ & -0.77 & -0.76 & -0.73 & -0.68 & -0.61 & -0.52 & -0.52 & -0.76 & -1.31 & -2.06 & -3.26 & -0.81 & +0.0 & +0.09 \\
\hline $\begin{array}{l}\text { Infinite shear } \\
\text { transfer with } \\
\text { interface spring } \\
\text { elements }\end{array}$ & $29 * 10^{8}$ & 29000 & -0.34 & -0.34 & -0.26 & -0.21 & -0.18 & -0.16 & -0.23 & -0.53 & -1.10 & -1.82 & -2.73 & -0.39 & +0.29 & +0.18 \\
\hline $\begin{array}{l}\text { Zero shear transfer } \\
\text { without interface } \\
\text { spring elements }\end{array}$ & $29 * 10^{8}$ & 0 & +1.01 & +0.99 & +0.97 & +0.94 & +0.90 & +0.86 & +0.71 & +0.30 & -0.46 & -1.44 & -2.69 & -0.64 & -0.08 & +0.01 \\
\hline $\begin{array}{l}\text { Zero shear transfer } \\
\text { with interface } \\
\text { spring elements }\end{array}$ & $29 * 10^{8}$ & 29 & +1.43 & +1.41 & +1.38 & +1.32 & +1.24 & +1.15 & +0.94 & +0.48 & -0.25 & -1.09 & -1.82 & +0.15 & +0.53 & +0.24 \\
\hline
\end{tabular}

Table (6.5.b) Plane strain solution. Averaged bending stresses (Ksi) in top of the masonry steel plate. Gauss integration points 2 and 4 . 


\begin{tabular}{|c|c|c|c|c|c|c|c|c|c|c|c|c|}
\hline \multirow{2}{*}{ Model description } & \multirow{2}{*}{$\begin{array}{l}E_{S V} \\
\text { (Ksi) }\end{array}$} & \multirow{2}{*}{$\begin{array}{l}\mathrm{E}_{\mathrm{SH}} \\
(\mathrm{Ksi})\end{array}$} & \multicolumn{10}{|c|}{ Element number } \\
\hline & & & 161 & 162 & 163 & 164 & 165 & 166 & 167 & 168 & 169 & 170 \\
\hline $\begin{array}{l}\text { Infinite shear } \\
\text { transfer without } \\
\text { interface spring } \\
\text { elements }\end{array}$ & $\infty$ & $\infty$ & -1.648 & -1.757 & -1.576 & -1.390 & -1.094 & -0.825 & -0.504 & -0.294 & -0.130 & -0.034 \\
\hline $\begin{array}{l}\text { Infinite shear } \\
\text { transfer with } \\
\text { interface spring } \\
\text { elements }\end{array}$ & $29 * 10^{8}$ & 29000 & -1.739 & -1.854 & -1.654 & -1.440 & -1.114 & -0.833 & -0.509 & -0.272 & -0.104 & -0.012 \\
\hline $\begin{array}{l}\text { Zero shear transfer } \\
\text { without interface } \\
\text { spring elements }\end{array}$ & $29 * 10^{8}$ & 0 & -2.050 & -2.169 & -1.917 & -1.651 & -1.243 & -0.850 & -0.392 & -0.169 & -0.051 & +0.029 \\
\hline $\begin{array}{l}\text { zero shear transfer } \\
\text { with interface } \\
\text { spring elements }\end{array}$ & $29 * 10^{8}$ & 29 & -2.129 & -2.254 & -1.985 & -1.693 & -1.254 & -0.883 & -0.356 & -0.141 & -0.045 & +0.028 \\
\hline
\end{tabular}

Table (6.6.a) Axisymmetric solution. Averaged vertical stresses (Ksi) in concrete elements. Gauss integration points 2 and 4 . 


\begin{tabular}{|c|c|c|c|c|c|c|c|c|c|c|c|c|}
\hline \multirow{2}{*}{ Model description } & \multirow{2}{*}{$\begin{array}{c}\mathrm{E}_{\mathrm{SV}} \\
(\mathrm{K} \mathbf{s i})\end{array}$} & \multirow{2}{*}{$\underset{(K \mathrm{SH}}{\mathrm{E}_{\mathrm{SH}}}$} & \multicolumn{10}{|c|}{ Element number } \\
\hline & & & 161 & 162 & 163 & 164 & 165 & 166 & 167 & 168 & 169 & 170 \\
\hline $\begin{array}{l}\text { Infinite shear } \\
\text { transfer without } \\
\text { interface spring } \\
\text { elements }\end{array}$ & $\infty$ & $\infty$ & -2.675 & -2.583 & -2.357 & -2.095 & -1.690 & -1.290 & -0.787 & -0.448 & -0.198 & -0.020 \\
\hline $\begin{array}{l}\text { Infinite shear } \\
\text { transfer with } \\
\text { interface spring } \\
\text { elements }\end{array}$ & $29 * 10^{8}$ & 29000 & -2.718 & -2.634 & -2.398 & -2.112 & -1.680 & -1.271 & -0.776 & -0.418 & -0.164 & +0.013 \\
\hline $\begin{array}{l}\text { Zero shear transfer } \\
\text { without interface } \\
\text { spring elements }\end{array}$ & $29 * 10^{8}$ & 0 & -2.999 & -2.879 & -2.587 & -2.235 & -1.700 & -1.150 & -0.519 & -0.223 & -0.049 & +0.097 \\
\hline $\begin{array}{l}\text { Zero shear transfer } \\
\text { with interface } \\
\text { spring elements }\end{array}$ & $29 * 10^{8}$ & 29 & -3.028 & -2.904 & -2.600 & -2.229 & -1.677 & -1.129 & -0.496 & -0.201 & -0.054 & +0.085 \\
\hline
\end{tabular}

Table (6.6.b) Plane strain solution. Averaged vertical stresses (Ksi) in concrete elements. Gauss integration points 2 and 4 . 


\begin{tabular}{|c|c|c|c|c|c|c|c|c|c|c|c|c|}
\hline \multirow{2}{*}{ Model description } & \multirow{2}{*}{$\begin{array}{l}\mathrm{E}_{\mathrm{SV}} \\
(\mathrm{Ksi})\end{array}$} & \multirow{2}{*}{$\begin{array}{l}\mathrm{E}_{\mathrm{SH}} \\
(\mathrm{Ksi})\end{array}$} & \multicolumn{10}{|c|}{ Element number } \\
\hline & & & 161 & 162 & 163 & 164 & 165 & 166 & 167 & 168 & 169 & 170 \\
\hline $\begin{array}{l}\text { Infinite shear } \\
\text { transfer without } \\
\text { interface spring } \\
\text { elements }\end{array}$ & $\omega$ & 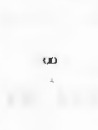 & +0.2718 & +0.2101 & +0.3894 & +0.4005 & +0.4861 & +0.4300 & +0.3835 & +0.2313 & +0.1118 & +0.0246 \\
\hline $\begin{array}{l}\text { Infinite shear } \\
\text { transfer with } \\
\text { interface spring } \\
\text { elements }\end{array}$ & $29 * 10^{8}$ & 29000 & +0.2873 & +0.2216 & +0.4155 & +0.4271 & +0.5028 & +0.4262 & +0.3719 & +0.2200 & +0.0878 & +0.0145 \\
\hline $\begin{array}{l}\text { Zero shear transfer } \\
\text { without interface } \\
\text { spring elements }\end{array}$ & $29 * 10^{8}$ & 0 & +0.2940 & +0.1570 & +0.3194 & +0.3034 & +0.4010 & +0.3657 & +0.3081 & +0.1195 & +0.0193 & -0.0114 \\
\hline $\begin{array}{l}\text { Zero shear transfer } \\
\text { with interface } \\
\text { spring elements }\end{array}$ & $29 * 10^{8}$ & 29 & +0.3056 & +0.1668 & +0.3454 & +0.3337 & +0.4276 & +0.3864 & +0.3207 & +0.1075 & +0.0139 & -0.0116 \\
\hline
\end{tabular}

Table (6.7.a) Axisymmetric solution. Averaged shearing stresses (Ksi) in concrete elements. Gauss integration points 2 and 4 . 


\begin{tabular}{|c|c|c|c|c|c|c|c|c|c|c|c|c|}
\hline Model description & $\begin{array}{l}\mathrm{E}_{\mathrm{SV}} \\
(\mathrm{Ksi})\end{array}$ & $\begin{array}{l}\mathrm{E}_{\mathrm{SH}} \\
(\mathrm{Ksi})\end{array}$ & \multicolumn{10}{|c|}{ Element number } \\
\hline $\begin{array}{l}\text { Infinite shear } \\
\text { transfer without } \\
\text { interface spring } \\
\text { elements }\end{array}$ & $\infty$ & $\infty$ & +0.1700 & +0.2449 & +0.5261 & +0.5469 & +0.6971 & +0.6271 & +0.5861 & +0.3392 & +0.1580 & +0.0301 \\
\hline $\begin{array}{l}\text { Infinite shear } \\
\text { transfer with } \\
\text { interface spring } \\
\text { elements }\end{array}$ & $29 * 10^{8}$ & 29000 & +0.1637 & +0.2549 & +0.5494 & +0.5724 & +0.7110 & +0.6179 & +0.5631 & +0.3224 & +0.1295 & +0.0139 \\
\hline $\begin{array}{l}\text { Zero shear transfer } \\
\text { without interface } \\
\text { spring elements }\end{array}$ & $29 * 10^{8}$ & 0 & +0.1363 & +0.1502 & +0.3945 & +0.3829 & +0.5325 & +0.4834 & +0.3985 & +0.1251 & -0.0118 & -0.0387 \\
\hline $\begin{array}{l}\text { Zero shear transfer } \\
\text { with interface } \\
\text { spring elements }\end{array}$ & $29 * 10^{8}$ & 29 & +0.1463 & +0.1737 & +0.4351 & +0.4324 & +0.5750 & +0.5119 & +0.4319 & +0.1317 & -0.0041 & -0.0337 \\
\hline
\end{tabular}

Table (6.7.b) Plane strain. Averaged shearing stresses (Ksi) in concrete elements. Gauss integration points 2 and 4 . 
plates bending would be higher. Add to that in the case of zero shear transfer the fact that a horizontal spring modulus of elasticity equalling $29 \mathrm{Ksi}$ is small but not zero makes the plates bending restraint even higher. wotice that the effect of using interface spring elements on bending stresses was different in the two-beams example problem presented in sec. (6.3.1). However, here a different structure is considered, and the interface spring elements connect steel to concrete rather than steel to steel. The concrete negative vertical and positive shearing stresses were lower in models which included interface spring elements due to the lower bending stresses resulting in those models as discussed above. Weduction of steel plate bending against the concrete surface would cause less compression in the vertical spring elements. Furthermore, in the model representing the case of infinite shear transfer, a vertical spring modulus of elasticity equal to $29 * 10^{8}$ is very large but not really infinite. Add to that for the case of infinite shear transfer, the fact that a horizontal spring modulus of elasticity equal to $29000 \mathrm{Ksi}$ is considerably less than infinity. Therefore, shear stresses transferred to the poncrete would be lower. Effect of using interface spring elements on the maximum averaged stresses in the bearing system modeled to represent the cases of infinite and zero shear transfer conditions for the axisymmetric and plane 
hrain solution methods, is summarized in table (6.8). In general, the use of interface spring elements induces a larger effect on the bearing stresses in the plane strain solution than in the axisymmetric solution, because the horizontal springs have no effect on the drcumferential stresses which are induced by circumferential displacements in the axisymmetrical solution and neglected in the plane strain solution. Furthermore, the averaged maximum bending stress in top of the masonry plate, was the most to be affected by the use of the interface spring elements. That portion of the masonry plate being relatively thin and close to the interface zone, it has been the part of the bearing system most affected by the geometrical change of the elements adjacent to the interface zone. Notice that the pot plate is modeled with the part of the masonry plate beneath it as a continuum acting as a thick plate.

Based on the discussion presented above, it has been found that for those specified interface spring element lengths and cross-sectional areas, the vertical springs modulus of elasticity equalling $29 * 10^{8} \mathrm{Ksi}$ provides a satisfactory interface normal stiffness. For the horizontal interface spring elements, a modulus of plasticity equalling $29000 \mathrm{ksi}$ provides a satisfactory no slip interface horizontal stiffness, and a value 


\begin{tabular}{|c|c|c|c|c|c|}
\hline $\begin{array}{l}\text { Solution } \\
\text { method }\end{array}$ & $\begin{array}{l}\text { Shear } \\
\text { transfer } \\
\text { condition } \\
\quad \frac{8}{8}\end{array}$ & $\begin{array}{l}\text { Maximum } \\
\text { averaged } \\
\text { bending } \\
\text { stress in } \\
\text { top of pot } \\
\text { bearing } \\
\frac{0}{5}\end{array}$ & $\begin{array}{l}\text { Maximum } \\
\text { averaged } \\
\text { bending } \\
\text { stress in } \\
\text { top of } \\
\text { masonry } \\
\text { plate } \\
\text { \% }\end{array}$ & $\begin{array}{l}\text { Maximum } \\
\text { averaged } \\
\text { vertical } \\
\text { stress in } \\
\text { concrete } \\
\text { elements } \\
\qquad\end{array}$ & $\begin{array}{l}\text { Maximum } \\
\text { averaged } \\
\text { shearing } \\
\text { stress in } \\
\text { concrete } \\
\text { elements } \\
\qquad \text { 웅 }\end{array}$ \\
\hline \multirow{2}{*}{ Axisymmetric } & $\begin{array}{l}\text { Infinite } \\
\text { shear } \\
\text { transfer }\end{array}$ & -0.7 & -13.8 & +5.2 & +3.3 \\
\hline & $\begin{array}{l}\text { Zero } \\
\text { shear } \\
\text { transfer }\end{array}$ & -1.0 & -18.6 & +3.8 & +6.2 \\
\hline \multirow{2}{*}{$\begin{array}{l}\text { Plane } \\
\text { strain }\end{array}$} & $\begin{array}{l}\text { Infinite } \\
\text { shear } \\
\text { transfer }\end{array}$ & -3.7 & -16.3 & +1.9 & +2.0 \\
\hline & $\begin{array}{l}\text { Zero } \\
\text { shear } \\
\text { transfer }\end{array}$ & -3.2 & -32.3 & +0.9 & +7.4 \\
\hline
\end{tabular}

Table (6.8) Effect of using interface spring elements on maximum bearing system stresses modeled to represent the cases of infinite and zero shear transfer conditions for axisymmetric and plane strain solution methods. 
equalling $29 \mathrm{Ksi}$ could satisfactorily be considered as the full slip modulus.

\section{A NONLINEAR DESCRIPTION OF SLIP}

The masonry steel plate will start to slip when shear stresses transferred through the horizontal interface spring elements reach an ultimate shear strength, where slip will actually occur in the individual spring elements. The ultimate shear strength in the horizontal spring interface elements used in the bearing system will be defined as the point on the spring's stress strain diagram where the modulus of elasticity starts to decrease nonlinearly from the no slip modulus equalling $29000 \mathrm{Ksi}$, indicating start of slip, until it reaches the full slip modulus equalling $29 \mathrm{Ksi}$, indicating complete slip of the spring element, see fig. (6.8). The exact ultimate shear strength in the horizontal springs is not known; however, it will be assumed that it equals $\mathrm{X}:$ of the maximum shear stress value transferred in any horizontal interface spring element in the model representing the case of infinite shear transfer condition, where slip is not allowed. Shear stresses transferred hrough the horizontal springs in the model representing infinite shear transfer condition in both axisymmetric and plane strain solution methods are listed in table (6.9), refer to fig. (6.7). In both solution 
methods the maximum shear stress transferred appeared to be in spring element no. 102, where in the axisymmetric solution it equals $1.39189 \mathrm{Ksi}$, and in the plane strain solution it equals $1.29987 \mathrm{Ksi}$. The value of $\mathrm{X}$ was selected randomly to equal $(30,50$, and 70$)$. Data for the stress-strain relation of the different induced slip conditions for both solution methods is presented in appendix B.

\subsection{REMARKS}

It should be noted that the moethod of representing the interface by the use of the interface spring elements proposed here involves a physical change in the Geometry of the structure. Note also that the thickness of the interface cannot be let very small approaching zero as in reality, because if it is, an ill-conditioning problem will occur, resulting from dividing the large normal modulus of elasticity by the small length of the spring when the normal stiffness of the interface becomes very large in the case of joint closing or perfect contact.

There has been no tension cut-off consideration for the vertical interface spring elements to account for the separation of the masonry plate and the concrete abutment. Results from analyzing a model representing the case of zero shear transfer condition, (horizontal inter- 


\begin{tabular}{|cll|}
\hline $\begin{array}{l}\text { Spring } \\
\text { element } \\
\text { number }\end{array}$ & $\begin{array}{l}\text { Axisymmetric solution } \\
\text { Transferred } \\
\text { shearing stress }\end{array}$ & $\begin{array}{l}\text { Plane strain } \\
\text { solution } \\
\text { Transferred } \\
\text { shearing stress }\end{array}$ \\
\hline 92 & $+0.633897 \mathrm{D}-01$ & $+0.440319 \mathrm{D}+00$ \\
93 & $+0.336047 \mathrm{D}+00$ & $+0.317365 \mathrm{D}+00$ \\
94 & $+0.603019 \mathrm{D}+00$ & $+0.494136 \mathrm{D}+00$ \\
95 & $+0.785314 \mathrm{D}+00$ & $+0.663890 \mathrm{D}+00$ \\
96 & $+0.100999 \mathrm{D}+01$ & $+0.838462 \mathrm{D}+00$ \\
97 & $+0.114836 \mathrm{D}+01$ & $+0.999273 \mathrm{D}+00$ \\
98 & $+0.130028 \mathrm{D}+01$ & $+0.113609 \mathrm{D}+01$ \\
99 & $+0.133951 \mathrm{D}+01$ & $+0.121588 \mathrm{D}+01$ \\
100 & $+0.136297 \mathrm{D}+01$ & $+0.124478 \mathrm{D}+01$ \\
101 & $+0.134815 \mathrm{D}+01$ & $+0.126545 \mathrm{D}+01$ \\
102 & $+0.139189 \mathrm{D}+01$ & $+0.129987 \mathrm{D}+01$ \\
103 & $+0.133600 \mathrm{D}+01$ & $+0.126031 \mathrm{D}+01$ \\
104 & $+0.126027 \mathrm{D}+01$ & $+0.116754 \mathrm{D}+01$ \\
105 & $+0.125103 \mathrm{D}+01$ & $+0.114125 \mathrm{D}+01$ \\
\hline
\end{tabular}

Table (6.9) Shear stresses transferred through the horizontal interface spring elements in the case of infinite shear transfer. 
face spring elements not included, see fig. (4.5)), have shown that all vertical springs along the interface were in compression except for the end spring. That end spring in tension was taken out of the model and the analysis was repeated. Resulting normal stresses in the vertical spring elements are listed in table (B.4) of Appendix B. The elimination of that end vertical spring does not have a significant effect on the resulting stresses in the bearing system, because in the early loading stages, (initial load increments), before the spring goes in tension, it is only expected to transfer a very little portion of the normal stresses to the concrete elements. *ormal stresses transferred through vertical interface spring elements (model including horizontal and vertical interface spring elements, see fig. (4.7)), for different shear strength value along the interface, were listed in tables (B.5.a) and (B.5.b) for an axisymmetric and a plane strain solution method, respectively, see Fpendix B sec. (B.3). Results indicated that when the slip along the interface was described as a nonlinear Punction, separation of the masonry plate from the oncrete became more obvious due to the nonlinear variation of the bending stresses along the steel plate elements; the explanation of that behavior will be left for hapter 7 . Notice that because the masonry plate is 
assumed to be rigidly connected with the concrete abutment (no tension cut-off), very large tension could appear in some of the vertical interface spring elements due to the multiplication of positive relative displacements by the large normal stiffness values, refer to equation (6.4). However, there appeared to be some inconsistencies in the results where vertical springs along the interface alternated from negative to positive unrealistically.

Referring to fig. (6.1), notice that vertical spring elements located in the interface similar to spring $B$ tend to become in tension (separation) before springs similar to spring A. Moreover, in the interface zone where separation is not likely to happen, springs similar to spring $B$ in fig. (6.1) will have larger compression stresses than springs similar to spring A. Those inconsistencies are due to the geometry of the interface where it was modeled such that elements adjacent to the interface were altered to have a triangular shape so that nodes such as $j$ and $k$ in fig. (6.1) could be connected by a horizontal interface spring element as shown in fig. (6.1). Problems resulting from the geometry of the interface could be resolved by using interface spring elements having a geometry similar to the linkage element shown in fig. (5.3), where there 
will be no need to change the geometry of the steel and wncrete elements adjacent to the interface. The interface behavior described above could also be improved by considering tension cut-off for the vertical interface elements, so that the separation of the masonry plate and the concrete abutment would be allowed along the interface. Nevertheless, for an axisymmetric model, a special interface element could be used to account for di placements in the circumferential direction, see element formulation in Appendix A, sec. (A.2). 


\section{CHAPTER 7 \\ EFEECT OF SHEAR TRANSFER}

It is customary to analyze the bearing system ssuming either infinite or zero shear transfer conditions without paying much attention to the effect of the shear transfer. However, simulating the behavior of the interface between the masonry steel plate and the concrete abutment by the method proposed in the previous chapter, the bearing system was analyzed with different shear transfer conditions.

\subsection{ASSUMED DIFFERENT SHEAR TRANSFER CONDITIONS}

Shear stresses transferred through the horizontal spring elements will keep increasing as the load increments applied on the bearing system increase until slip starts in those spring elements whose ultimate shear trength value is reached. Since the slip is described by a nonlinear relation, spring elements which started to slip will transfer nonlinearly decreasing shear stress increments. Hence, the shear stress transferred through a horizontal spring element depends on its ultimate shear strength value, such that larger shear stresses will be 
transferred through horizontal interface spring elements with higher shear strength values.

The horizontal spring elements ultimate shear thength value is not known. However, three different shear transfer conditions were induced by assuming the horizontal interface spring elements ultimate shear trength value to equal $70 \%, 50 \%$, and $30 \%$ of the maximum shear stress value transferred in the infinite shear transfer condition, see Appendix B, sec. (B.1) for complete information about the formulation of the horizontal spring elements stress-strain relations for the three ultimate shear strength values. The bearing system was analyzed under those different shear transfer conditions and results were compared against those of infinite and zero shear transfer conditions. Both axisymmetric and plane strain solution methods were considered, and the bearing system was loaded by $3.5 \mathrm{Ksi}$ uniformly applied load in all computer runs. For all shear transfer conditions, horizontal spring elements shear stresses, slip status, and the slip modulus were listed in tables (7.1.a), (7.1.b), (7.1.c), (7.1.d) and (7.1.e), see fig. (6.7). The average percentage change in the shear stresses transferred through the interface for the different shear transfer conditions with respect to the shear stresses transferred through the interface in the infinite shear transfer condition, are listed in 
table (7.2).

Shear stresses transferred in the horizontal Interface spring elements near the end of the interface are higher because as the plates bend uncer the uniformly applied load, the end steel elements of the relatively thin masonry plate would tend to slip over the oncrete. Therefore, slip will occur first in those horizontal spring elements transferring larger shear stresses. As the ultimate shear strength of the springs is decreased, more of them would slip and shear stresses transferred through the interface zone would decrease nonlinearly because of the nonlinear slip function, see stress - strain curve in Appendix B, fig. (B.I). Shear stress distributions for the different shear transfer conditions were approximated by the continuous curves shown in fig. (7.1), where $\tau_{u}$ represents the ultimate shear strength for the horizontal springs and $\tau_{\max }$ represents the maximum shear stress transferred in the infinite shear transfer condition. Notice that shear stresses become more uniformly distributed as the ultimate shear strength of the horizontal spring elements decreases.

Shear stresses transferred through the horizontal interface spring elements are higher in the axisymmetric solution than in the plane strain solution because of shear stresses resulting from the circumferential 
Asplacements, which are not restrained by the horizontal spring elements in the axisymmetric elements. Therefore, the horizontal spring elements in the axisymmetric solution will slip earlier, causing more reduction in the shear stresses transferred in the interface zone than in the plane strain solution for the same reduction in the spring elements ultimate shear strength, see table (7.2). Hence, in the shear transfer condition where $\tau_{u}$ was reduced to equal $30 \%$ of $\tau_{\max }$ ' and in the zero shear transfer condition, shear stresses transferred through the horizontal interface spring elements became larger in the plane strain solution than in the axisymmetric solution.

From a physical point of view, it is expected that slip should occur only in those horizontal spring elements which are near the end of the interface zone; however, results from both solution methods indicated that when the horizontal spring elements ultimate shear ptrength was as high as $70 \%$ of $\tau_{\text {max }}$, slip still occurred in spring elements closer to the center, see table (7.1.b). Therefore, the horizontal interface spring elements shear strength value is expected to be higher than $70 \%$ of $\tau_{\max }$. Nevertheless, the assumed shear strength values sufficiently represent various shear transfer conditions. 
Table (7.1.a) Infinite shear transfer condition

\begin{tabular}{|c|c|c|c|c|c|c|}
\hline \multirow{2}{*}{$\begin{array}{l}\text { spring } \\
\text { flement } \\
\text { number }\end{array}$} & \multicolumn{3}{|c|}{ Axisymmetric solution } & \multicolumn{3}{|c|}{ Plane strain solution } \\
\hline & $\begin{array}{l}\text { Shear } \\
\text { stress } \\
\text { (Ksi) }\end{array}$ & $\begin{array}{l}\text { slip } \\
\text { status }\end{array}$ & $\begin{array}{l}\text { Slip } \\
\text { modulus } \\
(\text { Ksi) }\end{array}$ & $\begin{array}{l}\text { Shear } \\
\text { stress } \\
\text { (Ksi) }\end{array}$ & $\begin{array}{l}\text { slip } \\
\text { status }\end{array}$ & $\begin{array}{l}\text { slip } \\
\text { modulus } \\
\text { (Ksi) }\end{array}$ \\
\hline 92 & +0.0633897 & $\begin{array}{l}\text { No } \\
\text { slip }\end{array}$ & 29000 & +0.440319 & $\begin{array}{l}\text { No } \\
\text { slip }\end{array}$ & 29000 \\
\hline 93 & +0.336047 & $"$ & $"$ & +0.317365 & $"$ & $"$ \\
\hline 94 & +0.603019 & $"$ & $"$ & +0.494136 & $"$ & $"$ \\
\hline 95 & +0.785314 & $"$ & $"$ & +0.663890 & $"$ & $"$ \\
\hline 96 & +1.00999 & $"$ & $"$ & +0.838462 & $"$ & $"$ \\
\hline 97 & 1.14836 & $"$ & $"$ & +0.999273 & $"$ & $"$ \\
\hline 98 & 1.30028 & $"$ & $"$ & +1.13609 & $"$ & $"$ \\
\hline 99 & 1.33951 & $"$ & $"$ & +1.21588 & $"$ & $"$ \\
\hline 100 & 1.36297 & $"$ & $"$ & +1.24478 & $"$ & $"$ \\
\hline 101 & 1.34815 & $"$ & $"$ & +1.26545 & $"$ & $"$ \\
\hline 102 & 1.39189 & $"$ & $"$ & +1.29987 & $"$ & $"$ \\
\hline 103 & 1.33600 & $"$ & $"$ & +1.26031 & $"$ & $"$ \\
\hline 104 & 1.26027 & $"$ & $"$ & +1.16754 & $"$ & $"$ \\
\hline 105 & 1.25103 & $"$ & $"$ & +1.14125 & $"$ & $"$ \\
\hline
\end{tabular}


Table (7.1.b) Shear transfer condition resulting from assuming the horizontal spring elements equal $70 \%$ of the maximum shear stress transferred in the infinite shear transfer condition.

\begin{tabular}{|c|c|c|c|c|c|c|}
\hline \multirow[b]{2}{*}{$\begin{array}{l}\text { Spring } \\
\text { element } \\
\text { number }\end{array}$} & \multicolumn{3}{|c|}{ Axisymmetric solution } & \multicolumn{3}{|c|}{ Plane strain solution } \\
\hline & $\begin{array}{l}\text { Shear } \\
\text { stress } \\
\text { (Ksi) }\end{array}$ & $\begin{array}{l}\text { slip } \\
\text { status }\end{array}$ & $\begin{array}{l}\text { Slip } \\
\text { modulus } \\
\text { (Ksi) }\end{array}$ & \begin{tabular}{|l} 
Shear \\
stress \\
(Ksi)
\end{tabular} & $\begin{array}{l}\text { Slip } \\
\text { status }\end{array}$ & $\begin{array}{l}\text { Slip } \\
\text { modulus } \\
\text { (Ksi) }\end{array}$ \\
\hline 92 & +0.0639190 & $\begin{array}{l}\text { No } \\
\text { slip }\end{array}$ & 29000 & +0.441935 & $\begin{array}{l}\text { No } \\
\text { slip }\end{array}$ & 29000 \\
\hline 93 & +0.355382 & $"$ & $"$ & +0.330101 & $"$ & $"$ \\
\hline 94 & +0.649642 & $"$ & $"$ & +0.520400 & $"$ & $"$ \\
\hline 95 & +0.861154 & $"$ & $"$ & +0.707766 & $"$ & $"$ \\
\hline 96 & +1.01219 & Slipped & 2900 & +0.907023 & $"$ & $"$ \\
\hline 97 & +1.10441 & $"$ & 290 & +1.00361 & Slipped & 290 \\
\hline 98 & +1.13225 & $"$ & 290 & +1.00921 & $"$ & 290 \\
\hline 99 & +1.17219 & $"$ & 29 & +1.09659 & $"$ & 29 \\
\hline 100 & +1.17417 & $"$ & $"$ & +1.10061 & $"$ & $"$ \\
\hline 101 & +1.17449 & $"$ & $"$ & +1.10356 & $"$ & $"$ \\
\hline 102 & +1.17560 & $"$ & $"$ & +1.10626 & $"$ & $"$ \\
\hline 103 & +1.17308 & $"$ & $"$ & +1.10512 & $"$ & $"$ \\
\hline 104 & +1.13836 & $"$ & 290 & +1.10111 & $"$ & $"$ \\
\hline 105 & +1.13021 & $"$ & 290 & +1.09927 & $"$ & $"$ \\
\hline
\end{tabular}


Table (7.1.c) Shear transfer condition resulting from Lssuming the horizontal spring elements equal 50\% of the 耳aximum shear stress transferred in the infinite shear transfer condition.

\begin{tabular}{|c|c|c|c|c|c|c|}
\hline \multirow[b]{2}{*}{$\begin{array}{l}\text { Spring } \\
\text { element } \\
\text { number }\end{array}$} & \multicolumn{3}{|c|}{ Axisymmetric solution } & \multicolumn{3}{|c|}{ Plane strain solution } \\
\hline & $\begin{array}{l}\text { Shear } \\
\text { stress } \\
\text { (Ksi) }\end{array}$ & $\begin{array}{l}\text { slip } \\
\text { status }\end{array}$ & $\begin{array}{l}\text { Slip } \\
\text { modulus } \\
\text { (Ksi) }\end{array}$ & $\begin{array}{l}\text { Shear } \\
\text { stress } \\
\text { (Ksi) }\end{array}$ & $\begin{array}{l}\text { slip } \\
\text { status }\end{array}$ & $\begin{array}{l}\text { Slip } \\
\text { modulus } \\
\text { (Ksi) }\end{array}$ \\
\hline 92 & +0.0664691 & $\begin{array}{l}\text { No } \\
\text { slip }\end{array}$ & 29000 & +0.464894 & $\begin{array}{l}\text { No } \\
\text { Slip }\end{array}$ & 29000 \\
\hline 93 & +0.483019 & $"$ & $"$ & +0.456233 & $"$ & $"$ \\
\hline 94 & +0.785027 & Slipped & 290 & +0.674586 & Slipp & ed 2900 \\
\hline 95 & +0.835160 & $"$ & 29 & +0.772402 & $"$ & 290 \\
\hline 96 & +0.855361 & $"$ & $"$ & +0.801996 & $"$ & 29 \\
\hline 97 & +0.866509 & $"$ & $"$ & +0.817552 & $"$ & $"$ \\
\hline 98 & +0.875867 & $"$ & $"$ & +0.833375 & $"$ & $"$ \\
\hline 99 & +0.882820 & $"$ & $"$ & +0.844934 & $"$ & $"$ \\
\hline 100 & +0.887012 & " & $"$ & +0.853055 & $"$ & $"$ \\
\hline 101 & +0.889261 & $"$ & $"$ & +0.859819 & $"$ & $"$ \\
\hline 102 & +0.891770 & $"$ & $"$ & +0.865047 & $"$ & $"$ \\
\hline 103 & +0.889983 & $"$ & $"$ & +0.864591 & $"$ & $"$ \\
\hline 104 & +0.886308 & $"$ & $"$ & +0.861204 & $"$ & $"$ \\
\hline 105 & +0.883179 & $"$ & $"$ & +0.858193 & $"$ & $"$ \\
\hline $\operatorname{tat}$ & $+11=-13$ & & & & & \\
\hline
\end{tabular}


Table (7.1.d) Shear transfer condition resulting from Lssuming the horizontal spring elements equal $30 \%$ of the maximum shear stress transferred in the infinite shear transfer condition.

\begin{tabular}{|c|c|c|c|c|c|c|}
\hline \multirow[b]{2}{*}{$\begin{array}{l}\text { spring } \\
\text { element } \\
\text { number }\end{array}$} & \multicolumn{3}{|c|}{ Axisymmetric solution } & \multicolumn{3}{|c|}{ Plane strain solution } \\
\hline & $\begin{array}{l}\text { Shear } \\
\text { stress } \\
\text { (Ksi) }\end{array}$ & $\begin{array}{l}\text { Slip } \\
\text { status }\end{array}$ & $\begin{array}{l}\text { Slip } \\
\text { modulus } \\
\text { (Ksi) }\end{array}$ & $\begin{array}{l}\text { Shear } \\
\text { stress } \\
\text { (Ksi) }\end{array}$ & $\begin{array}{l}\text { slip } \\
\text { status }\end{array}$ & $\begin{array}{l}\text { Slip } \\
\text { modulus } \\
\text { (Ksi) }\end{array}$ \\
\hline 92 & +0.0694736 & $\begin{array}{l}\text { No } \\
\text { slip }\end{array}$ & 29000 & +0.437055 & Slipped & 290 \\
\hline 93 & +0.502030 & Slipped & 29 & +0.474454 & " & 29 \\
\hline 94 & +0.522173 & $"$ & $"$ & +0.496576 & $"$ & $"$ \\
\hline 95 & +0.539746 & $"$ & $"$ & +0.519480 & $"$ & $"$ \\
\hline 96 & +0.557222 & $"$ & $"$ & +0.542826 & $n$ & $"$ \\
\hline 97 & +0.571878 & $"$ & $"$ & +0.565416 & $"$ & $"$ \\
\hline 98 & +0.584116 & $"$ & $"$ & +0.585614 & $"$ & $"$ \\
\hline 99 & +0.593045 & $"$ & $"$ & +0.601413 & $"$ & $"$ \\
\hline 100 & +0.598572 & $"$ & $"$ & +0.613039 & $"$ & $"$ \\
\hline 101 & +0.601955 & $"$ & $"$ & +0.621925 & $"$ & $"$ \\
\hline 102 & +0.604980 & $"$ & $"$ & +0.628754 & $"$ & $"$ \\
\hline 103 & +0.603457 & $"$ & $"$ & +0.629735 & $"$ & $"$ \\
\hline 104 & +0.598822 & $"$ & $"$ & +0.626008 & $"$ & $"$ \\
\hline 105 & +0.593708 & $"$ & $"$ & +0.621533 & $"$ & $"$ \\
\hline
\end{tabular}


Table (7.1.e) Zero shear stress condition

\begin{tabular}{|c|c|c|c|c|c|c|}
\hline \multirow[b]{2}{*}{$\begin{array}{l}\text { Spring } \\
\text { element } \\
\text { number }\end{array}$} & \multicolumn{3}{|c|}{ Axisymmetric solution } & \multicolumn{3}{|c|}{ Plane strain solution } \\
\hline & $\begin{array}{l}\text { Shear } \\
\text { stress } \\
\text { (Ksi) }\end{array}$ & $\begin{array}{l}\text { slip } \\
\text { status }\end{array}$ & $\begin{array}{l}\text { Slip } \\
\text { modulus } \\
\text { (Ksi) }\end{array}$ & $\begin{array}{l}\text { Shear } \\
\text { stress } \\
\text { (Ksi) }\end{array}$ & $\begin{array}{l}\text { Slip } \\
\text { status }\end{array}$ & $\begin{array}{l}\text { Slip } \\
\text { modulus } \\
\text { (Ksi) }\end{array}$ \\
\hline 92 & +0.00262226 & slipped & 29 & +0.0120080 & 0 slipped & 29 \\
\hline 93 & +0.0293357 & $"$ & " & +0.0510859 & $"$ & $"$ \\
\hline 94 & +0.0612690 & " & " & +0.0899531 & 1 & $"$ \\
\hline 95 & +0.0883243 & $"$ & $"$ & +0.127343 & $"$ & $"$ \\
\hline 96 & +0.112601 & " & " & +0.162675 & " & " \\
\hline 97 & +0.132979 & " & " & +0.194923 & $"$ & $"$ \\
\hline 98 & +0.149670 & $"$ & " & +0.223000 & $"$ & $"$ \\
\hline 99 & +0.161191 & " & " & +0.245191 & " & $"$ \\
\hline 100 & +0.168472 & $"$ & $"$ & +0.261605 & $"$ & $"$ \\
\hline 101 & +0.173255 & $"$ & $"$ & +0.273976 & $"$ & $"$ \\
\hline 102 & +0.176532 & $"$ & " & +0.282719 & $"$ & $"$ \\
\hline 103 & +0.174406 & $"$ & $"$ & +0.284153 & $"$ & $"$ \\
\hline 104 & +0.167586 & $"$ & $"$ & +0.279378 & $"$ & $"$ \\
\hline 105 & +0.158688 & $"$ & " & +0.271861 & " & $"$ \\
\hline
\end{tabular}


Table (7.2)

\begin{tabular}{|c||c|c|}
\hline $\begin{array}{l}\text { Horizontal spring elements } \\
\text { shear strength values with } \\
\text { respect to the maximum } \\
\text { shear transferred in the } \\
\text { infinite shear transfer } \\
\text { condition } \\
\left(\frac{8}{8}\right)\end{array}$ & $\begin{array}{l}\text { Change in the shear stresses transferred through the } \\
\text { interface spring elements }\end{array}$ & Plane strain solution \\
\hline $70 \%$ & -5.75 & $(\%)$ \\
$50 \%$ & -15.63 & -4.07 \\
$30 \%$ & -37.10 & -31.81 \\
0 & -88.75 & -80.74 \\
\hline
\end{tabular}




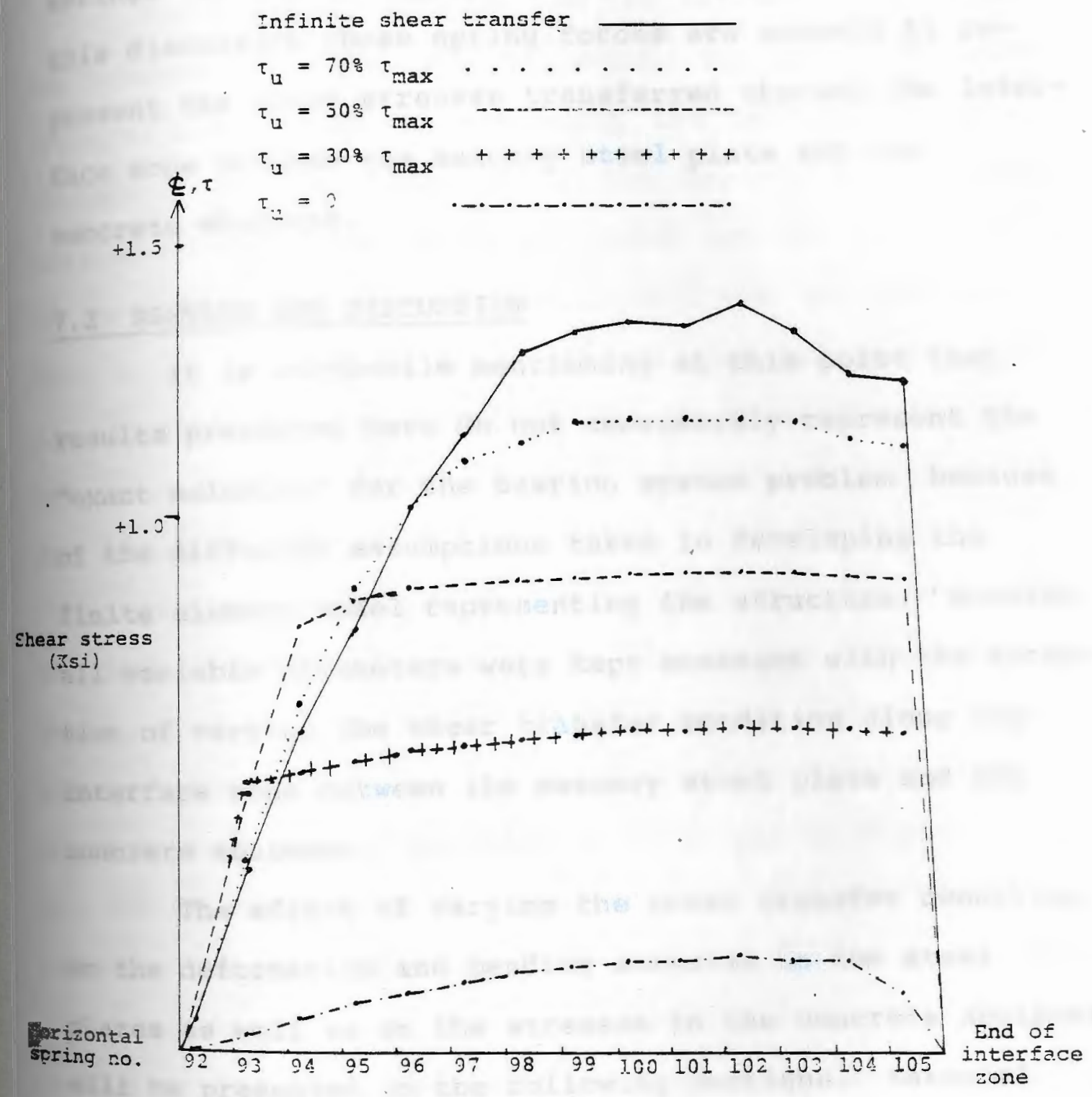

Fig. (7.1) Dxismmetric solution. Jhear stress distribution along the horizontal interfaco spring elenents. 
Notice that the shear stresses transferred through the horizontal interface spring elements are actually the springs forces defined in equation (6.4). However, in this discussion those spring forces are assumed to represent the shear stresses transferred through the interface zone between the masonry steel plate and the ancrete abutment.

\section{RESULTS AND DISCUSSION}

It is worthwhile mentioning at this point that results presented here do not necessarily represent the "exact solution" for the bearing system problem because of the different assumptions taken in developing the finite element model representing the structure. However, all variable parameters were kept constant with the exception of varying the shear transfer condition along the interface zone between the masonry steel plate and the concrete abutment.

The effect of varying the shear transfer condition on the deformation and bending stresses in the steel plates as well as on the stresses in the concrete abutment will be presented in the following sections. Material poperties used in analyzing the bearing system are presented in Appendix $c$. 
\begin{tabular}{l} 
7.2.1 EFFECT OF SHEAR TRANSFER ON \\
THE POT BEARING AND MASONRY \\
STEEL PLATES DEFORMATION \\
\hline
\end{tabular}

Since the pot bearing and the masonry steel plates are assumed to behave as a continuum, the effect of shear transfer was studied by examining the deformation of a horizontal section taken along the masonry steel plate passing through nodes 53 to 67 , which are the top nodes of the triangular steel elements adjacent to the interface zone, see fig. (6.7). Vertical and horizontal dismements of the nodes along the horizontal section resulting from axisymmetric and plane strain solutions are listed in tables (7.3.a) and (7.3.b) respectively. Results from sec. (7.1) have shown that shear stresses transferred through the horizontal interface spring elements have higher values beneath the end of the masonry steel plate for all shear transfer conditions. Maximum shear stress appeared to be, in spring element no. 102 which is under the section where the pot bearing ends and the masonry steel plate extends freely on top of the concrete surface. The non-uniform shear stress distribution could be physically attributed to the fact that the pot bearing and the masonry plates tend to bend over the concrete surface such that the end steel elements ould slip over the concrete surface and separate away from it. Horizontal displacement curves for the different shear kransfer conditions in the axisymmetric solution are 
shown in fig. (7.2). Notice that the horizontal disHacements along the masonry plate are actually conrolled by the nonlinear function which describes the slip along the interface zone, see Appendix B (sec. (B.1)). Consider the approximated shear stress distribution curves along the interface zone, shown in fig. (7.1), for the axisymmetric solution. In general, it was found that the shear stress increases along the interface zone until it reaches a maximum value, which was in all shear transfer conditions in the horizontal interface spring lement no. 102 located under the portion of the bearing system where the pot bearing ends and the masonry steel plate extends freely on top of the concrete surface, see fig. (6.7). Referring back to fig. (7.2), it was found that horizontal displacements near the center of the masonry plate elements above the portion of the interface where low shear stresses are transferred, were small. As the shear stress increased along the interface, the horizontal displacements of the masonry plate increased as well. Notice also that the maximum horizontal dispacement in the masonry plate was near the part where the pot bearing ends and above the portion of the interface where maximum shear stresses were transferred. Nowever, the horizontal displacements increased nonlinearly along the masonry plate depending on the nonlinear stress - strain relation that describes the slip along the interface zone, see fig. (B.I). If the 
ultimate shear strength value of the horizontal interface spring elements was lowered, slip along the interface would increase depending on the slip modulus. Nevertheless, at a low ultimate shear strength, $\left(\tau_{\mathrm{u}}=30 \% \tau_{\max }\right.$ ' or $\tau_{\mathrm{u}}=0$ ), most of the horizontal interface spring elements were in the full slip range (slip modulus equals $29 \mathrm{Ksi}$ and the horizontal displacements tend to increase "linearly" along the masonry plate, see fig. (7.2); refer to tables (7.1.d), and (7.1.e). Hence, the end of the horizontal displacement curve, representing the displacements of the end part of the masonry plate, became more uniform. At the case representing infinite shear transfer condition, the maximum horizontal displacement pppeared at node no. 62 and was about $18.72 \%$ higher than the horizontal displacement at node no. 67 located at the end of the masonry plate. However, in the case representing the zero shear transfer condition, the horizontal displacement at node no. 62 was only about $8.04 \%$ higher than at node no. 67 .

It appeared that if high shear stresses are transferred along the interface zone, they act as a restraint gainst the deformation of the pot bearing and the thasonry steel plates. As the ultimate shear strength of the horizontal interface spring elements was lowered, the masonry plate slipped over the concrete surface as discussed above, where the horizontal displacements freased nonlinearly along the plate. Since the plates 
steel elements were assumed to be linear isotropic, the nonlinear increase of the horizontal displacements along the plate must be attributed to the bending of the plate. The vertical displacement distribution curves of the masonry steel plate for the different shear transfer conditions in the axisymmetric solution are shown in fig. (7.3) .

The masonry plate was assumed to be rigidly connected to the concrete abutment, therefore, separation of the masonry plate steel elements from the concrete elements is not allowed. Therefore, general deformation curves of the masonry steel plate shown in fig. (7.4) for different shear transfer conditions did not look as one would expect. Horizontal and vertical displacement distribution curves for the plane strain solution are shown in figs. (7.5.a) and $(7.5 .3)$ respectively. Notice the difference in results due to absence of circumferential stresses and strains; however, the effect of shear transfer on the deformation of the pot bearing and the masonry steel plates is the same for both the axisymmetric and the plane strain solution methods.

7.2.2 EFFECT OF SHEAR TRANSFER ON THE POT BEARING AND MASONRY STEEL PLATES BENDING STRESSES

It was shown in the previous section how shear stresses transferred through the interface zone control the behavior of the steel plates represented by a 
wection taken along the masonry steel plate. Results indicated that as the ultimate shear strength of the horizontal spring elements decreases, slip along the interface increases and so does the horizontal and ertical displacement of the steel plate elements. Therefore, it could be stated at this point that shear stresses transferred through the interface actually act as a restraint against plates bending. Hence, it is rected that bending stresses in the pot bearing and the masonry steel plates would increase if the shear stresses transferred along the interface zone are lecreased.

Averaged bending stresses in the top of the pot bearing were listed in tables (7.4.a) and (7.4.b) for the axisymmetric and the plane strain solution methods, respectively. Results showed that the averaged negative pending stresses increased nonlinearly in the pot bearing steel elements above the portion of the interface zone which slipped. For example, results from the plane strain solution showed that bending stresses in elements nos. 1,2 , and 3 , in the case $\tau_{u}=70 \% \tau_{\text {max' }}$ have actually, even though insignificantly, decreased with respect to resulting bending stresses from the infinite shear transfer condition. In element no. 4, the bending stress has only increased by $0.11 \%$, and in element no. 5 the bending stress has only increased by $1.00 \%$. Referring to 
Table (7.3.a) Axisymmetric solution. Vertical and horizontal displacements in top of the triangular steel elements adjacent to the interface zone.

\begin{tabular}{|c|c|c|c|c|c|c|c|c|c|}
\hline \multicolumn{2}{|c|}{ Node number } & \multirow[b]{2}{*}{53} & \multirow[b]{2}{*}{54} & \multirow[b]{2}{*}{55} & \multirow[b]{2}{*}{56} & \multirow[b]{2}{*}{57} & \multirow[b]{2}{*}{58} & \multirow[b]{2}{*}{59} & \multirow[b]{2}{*}{60} \\
\hline $\begin{array}{l}\text { Shear } \\
\text { transfer } \\
\text { condition }\end{array}$ & $\begin{array}{l}\text { Displace- } \\
\text { ment } \\
\text { (inch) }\end{array}$ & & & & & & & & \\
\hline $\begin{array}{l}\text { Infinite } \\
\text { shear } \\
\text { transfer }\end{array}$ & $\begin{array}{l}\mathrm{V} \\
\mathrm{H}\end{array}$ & $\begin{array}{l}-0.00638 \\
0.0\end{array}$ & $\begin{array}{l}-0.00637 \\
+0.000076\end{array}$ & $\begin{array}{l}-0.00629 \\
+0.000148\end{array}$ & $\begin{array}{l}-0.00615 \\
+0.000216\end{array}$ & $\begin{array}{l}-0.00596 \\
+0.000279\end{array}$ & $\begin{array}{l}-0.00572 \\
+0.000334\end{array}$ & $\begin{array}{l}-0.00544 \\
+0.000378\end{array}$ & $\begin{array}{l}-0.00513 \\
+0.000407\end{array}$ \\
\hline $\begin{array}{l}\text { Shear stress } \\
\text { transferred } \\
\text { reduced by } \\
5.75 \%\end{array}$ & $\begin{array}{l}\mathrm{V} \\
\mathrm{H}\end{array}$ & $\begin{array}{c}-0.09642 \\
0.0\end{array}$ & $\begin{array}{l}-0.00641 \\
+0.000077\end{array}$ & $\begin{array}{l}-0.00633 \\
+0.000150\end{array}$ & $\begin{array}{l}-0.00619 \\
+0.000220\end{array}$ & $\begin{array}{l}-0.00600 \\
+0.000285\end{array}$ & $\begin{array}{l}-0.00576 \\
+0.000342\end{array}$ & $\begin{array}{l}-0.00548 \\
+0.000389\end{array}$ & $\begin{array}{l}-0.00516 \\
+0.000421\end{array}$ \\
\hline $\begin{array}{l}\text { Shear stress } \\
\text { transferred } \\
\text { reduced by } \\
15.63 \%\end{array}$ & $\begin{array}{l}\mathrm{V} \\
\mathrm{H}\end{array}$ & $\begin{array}{l}-0.00659 \\
0.0\end{array}$ & $\begin{array}{l}-0.00659 \\
+0.000084\end{array}$ & $\begin{array}{l}-0.00650 \\
+0.000164\end{array}$ & $\begin{array}{l}-0.00636 \\
+0.000242\end{array}$ & $\begin{array}{l}-0.00616 \\
+0.000316\end{array}$ & $\begin{array}{l}-0.00590 \\
+0.000384\end{array}$ & $\begin{array}{l}-0.00561 \\
+0.000438\end{array}$ & $\begin{array}{l}-0.00527 \\
+0.000475\end{array}$ \\
\hline $\begin{array}{l}\text { Shear stress } \\
\text { transferred } \\
\text { reduced by } \\
378\end{array}$ & $\begin{array}{l}\mathrm{V} \\
\mathrm{H}\end{array}$ & $\begin{array}{l}-0.00678 \\
0.0\end{array}$ & $\begin{array}{l}-0.00678 \\
+0.000095\end{array}$ & $\begin{array}{l}-0.00669 \\
+0.000185\end{array}$ & $\begin{array}{l}-0.00653 \\
+0.000273\end{array}$ & $\begin{array}{l}-0.00631 \\
+0.000355\end{array}$ & $\begin{array}{l}-0.00604 \\
+0.000428\end{array}$ & $\begin{array}{l}-0.00573 \\
+0.000488\end{array}$ & $\begin{array}{l}-0.00537 \\
+0.000530\end{array}$ \\
\hline $\begin{array}{l}\text { Shear stress } \\
\text { transferred } \\
\text { reduced by } \\
88.758\end{array}$ & $\mathrm{H}$ & $\begin{array}{l}-0.00708 \\
0.0\end{array}$ & +0.000112 & +0.000217 & +0.000318 & +0.000411 & +0.000494 & +0.000562 & -0.00553 \\
\hline
\end{tabular}

\section{$\mathrm{V}=$ vertical displacements}

$\mathrm{H}=$ horizontal displacements 
Continuation of Table (7.3.a)

\begin{tabular}{|c|c|c|c|c|c|c|}
\hline \multirow{2}{*}{61} & 62 & 63 & 64 & 65 & 66 & 67 \\
\hline-0.00481 & -0.00447 & -0.00413 & -0.00378 & -0.00344 & -0.00313 & -0.00286 \\
+0.000420 & +0.000422 & +0.000418 & +0.000405 & +0.000381 & +0.000357 & +0.000343 \\
\hline-0.00483 & -0.00449 & -0.00414 & -0.00377 & -0.00343 & -0.00312 & -0.00284 \\
+0.000437 & +0.000441 & +0.000438 & +0.000424 & +0.000398 & +0.000372 & +0.000358 \\
\hline-0.00492 & -0.00455 & -0.00410 & -0.00379 & -0.00341 & -0.00307 & -0.00276 \\
+0.000497 & +0.000505 & +0.000506 & +0.000496 & +0.000473 & +0.000449 & +0.000434 \\
\hline-0.00499 & -0.00461 & -0.00421 & -0.00380 & -0.00339 & -0.00302 & -0.00268 \\
\hline 0.000555 & +0.000566 & +0.000570 & +0.000562 & +0.000541 & +0.000518 & +0.000502 \\
\hline-0.00512 & -0.00470 & -0.00426 & -0.00381 & -0.00336 & -0.00294 & +0.00255 \\
\hline+0.000642 & +0.000659 & +0.000667 & +0.000663 & +0.000645 & +0.000623 & +0.000606 \\
\hline
\end{tabular}


Table (7.3.b) Plane strain solution. Vertical and horizontal displacements in top of the triangular steel elements adjacent to the interface zone.

\begin{tabular}{|c|c|c|c|c|c|c|c|c|c|}
\hline \multicolumn{2}{|c|}{ Node number } & \multirow[b]{2}{*}{53} & \multirow[b]{2}{*}{54} & \multirow[b]{2}{*}{55} & \multirow[b]{2}{*}{56} & \multirow[b]{2}{*}{57} & \multirow[b]{2}{*}{58} & \multirow[b]{2}{*}{59} & \multirow[b]{2}{*}{60} \\
\hline $\begin{array}{l}\text { Shear } \\
\text { transfer } \\
\text { condition }\end{array}$ & $\begin{array}{l}\text { Displace- } \\
\text { ments } \\
\text { (inches) }\end{array}$ & & & & & & & & \\
\hline $\begin{array}{l}\text { Infinite } \\
\text { shear } \\
\text { transfer }\end{array}$ & $\begin{array}{l}\mathrm{V} \\
\mathrm{H}\end{array}$ & $\begin{array}{c}-0.0113 \\
0.0\end{array}$ & $\begin{array}{l}-0.0113 \\
+0.000096\end{array}$ & $\begin{array}{l}-0.0112 \\
+0.000209\end{array}$ & $\begin{array}{l}-0.0110 \\
+0.000315\end{array}$ & $\begin{array}{l}-0.0107 \\
+0.000416\end{array}$ & $\begin{array}{l}-0.0104 \\
+0.000509\end{array}$ & $\begin{array}{l}-0.0100 \\
+0.000591\end{array}$ & $\begin{array}{l}-0.0095 \\
+0.000657\end{array}$ \\
\hline $\begin{array}{l}\text { Shear stress } \\
\text { transferred } \\
\text { reduced by } \\
4.078\end{array}$ & H & $\begin{array}{l}-0.0113 \\
0.0\end{array}$ & $\begin{array}{l}-0.0113 \\
+0.000097\end{array}$ & $\begin{array}{l}-0.0112 \\
+0.000210\end{array}$ & $\begin{array}{l}-0.0110 \\
+0.000317\end{array}$ & $\begin{array}{l}-0.0108 \\
+0.000419\end{array}$ & $\begin{array}{l}-0.0104 \\
+0.000515\end{array}$ & $\begin{array}{l}-0.0100 \\
+0.000600\end{array}$ & $\begin{array}{l}-0.0096 \\
+0.000670\end{array}$ \\
\hline $\begin{array}{l}\text { Shear stress } \\
\text { transferred } \\
\text { reduced by } \\
11.218\end{array}$ & $\mathrm{H}$ & $\begin{array}{c}-0.0115 \\
0.0\end{array}$ & $\begin{array}{l}-0.0115 \\
+0.000103\end{array}$ & $\begin{array}{l}-0.0114 \\
+0.000224\end{array}$ & $\begin{array}{l}-0.0112 \\
+0.000341\end{array}$ & $\begin{array}{l}-0.0109 \\
+0.000458\end{array}$ & $\begin{array}{l}-0.0105 \\
+0.000569\end{array}$ & $\begin{array}{l}-0.0101 \\
+0.000668\end{array}$ & $\begin{array}{l}-0.0096 \\
+0.000750\end{array}$ \\
\hline $\begin{array}{l}\text { Shear stress } \\
\text { transferred } \\
\text { reduced by } \\
31.818\end{array}$ & u & $\begin{array}{c}-0.0117 \\
0.0\end{array}$ & $\begin{array}{l}-0.0117 \\
+0.000120\end{array}$ & $\begin{array}{l}-0.0115 \\
+0.000259\end{array}$ & $\begin{array}{l}-0.0113 \\
+0.000393\end{array}$ & $\begin{array}{l}-0.0110 \\
+0.000523\end{array}$ & $\begin{array}{l}-0.0106 \\
+0.000645\end{array}$ & $\begin{array}{l}-0.0102 \\
+0.000753\end{array}$ & $\begin{array}{l}-0.0097 \\
+0.000843\end{array}$ \\
\hline $\begin{array}{l}\text { Shear stress } \\
\text { transferred } \\
\text { reduced by } \\
80.748\end{array}$ & H & $\begin{array}{l}-0.0120 \\
0.0\end{array}$ & $\begin{array}{l}-0.0119 \\
+0.000162\end{array}$ & $\begin{array}{l}-0.0118 \\
+0.000321\end{array}$ & $\begin{array}{l}-0.0116 \\
+0.000476\end{array}$ & $\begin{array}{l}-0.0112 \\
+0.000625\end{array}$ & +0.000762 & $\begin{array}{l}-0.0103 \\
+0.000885\end{array}$ & $\begin{array}{l}-0.0098 \\
+0.000986\end{array}$ \\
\hline
\end{tabular}


Continuation of Table (7.3.b)

\begin{tabular}{|l|l|l|l|l|l|l|}
\hline \multicolumn{1}{|c|}{61} & 62 & 63 & 64 & 65 & 66 & 67 \\
\hline-0.0090 & -0.0085 & -0.0079 & -0.0074 & -0.0068 & -0.0062 & -0.0057 \\
+0.000703 & +0.000733 & +0.000752 & +0.000756 & +0.000713 & +0.000726 & +0.000717 \\
\hline-0.0090 & -0.0085 & -0.0079 & -0.0073 & -0.0068 & -0.0062 & -0.0057 \\
+0.000720 & +0.000753 & +0.000773 & +0.000777 & +0.00076 & +0.000741 & +0.000731 \\
\hline-0.0091 & -0.0085 & -0.0079 & -0.0073 & -0.0067 & -0.0061 & -0.0055 \\
+0.000810 & +0.000852 & +0.000881 & +0.000891 & +0.000881 & +0.000866 & +0.000858 \\
\hline-0.0091 & -0.0085 & -0.0079 & -0.0072 & -0.0065 & -0.0059 & -0.0053 \\
+0.000910 & +0.000957 & +0.000990 & +0.00100 & +0.00100 & +0.00098 & +0.00098 \\
\hline-0.0091 & -0.0085 & -0.0078 & -0.0071 & -0.0064 & -0.0057 & -0.0050 \\
+0.00106 & +0.00112 & +0.00116 & +0.00118 & +0.00118 & +0.00117 & +0.00116 \\
\hline
\end{tabular}




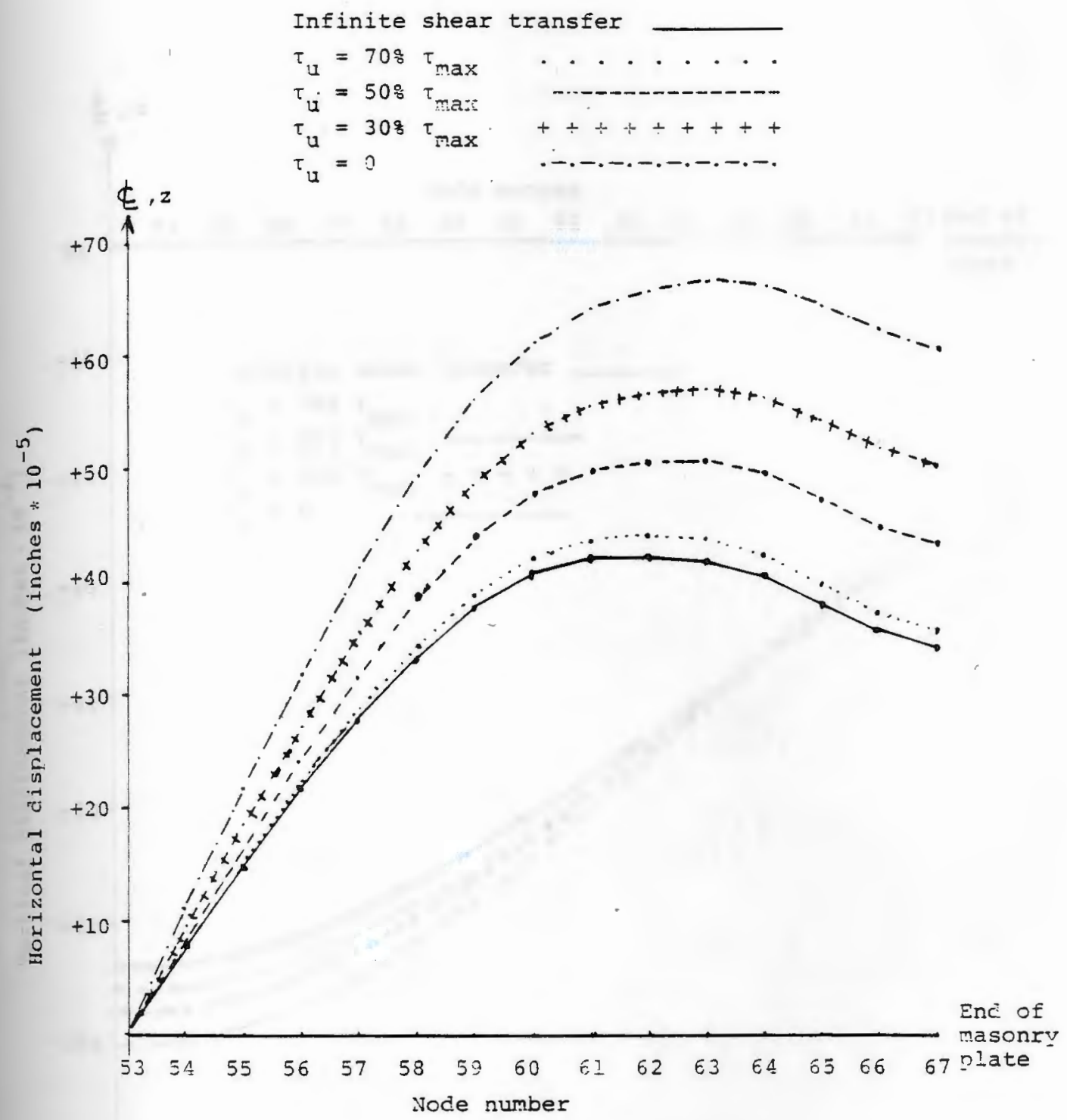

Eig. (7.2) Axisymetric solution. Forizontal cisplacement surves for the different shear transfer conditions. 


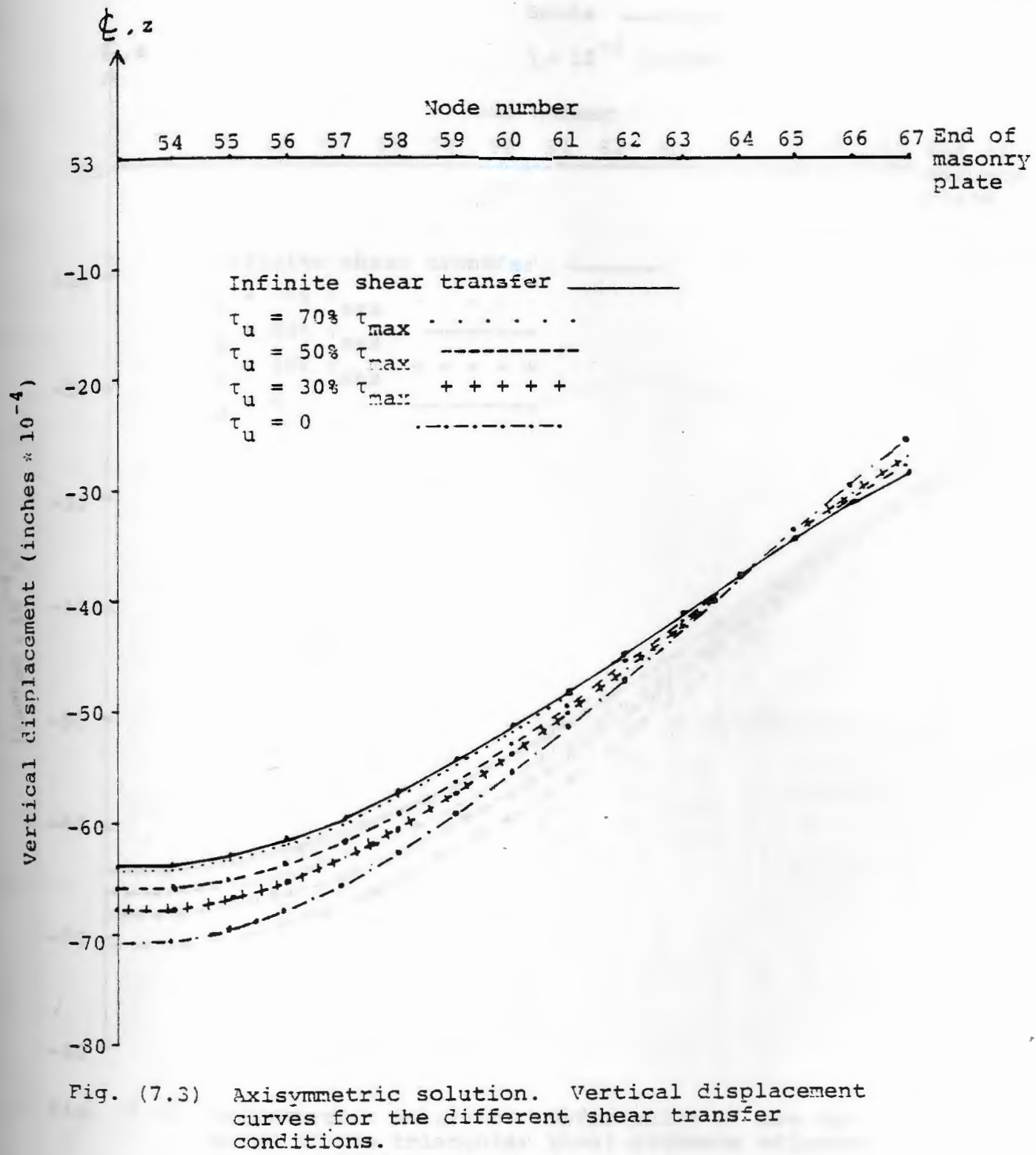




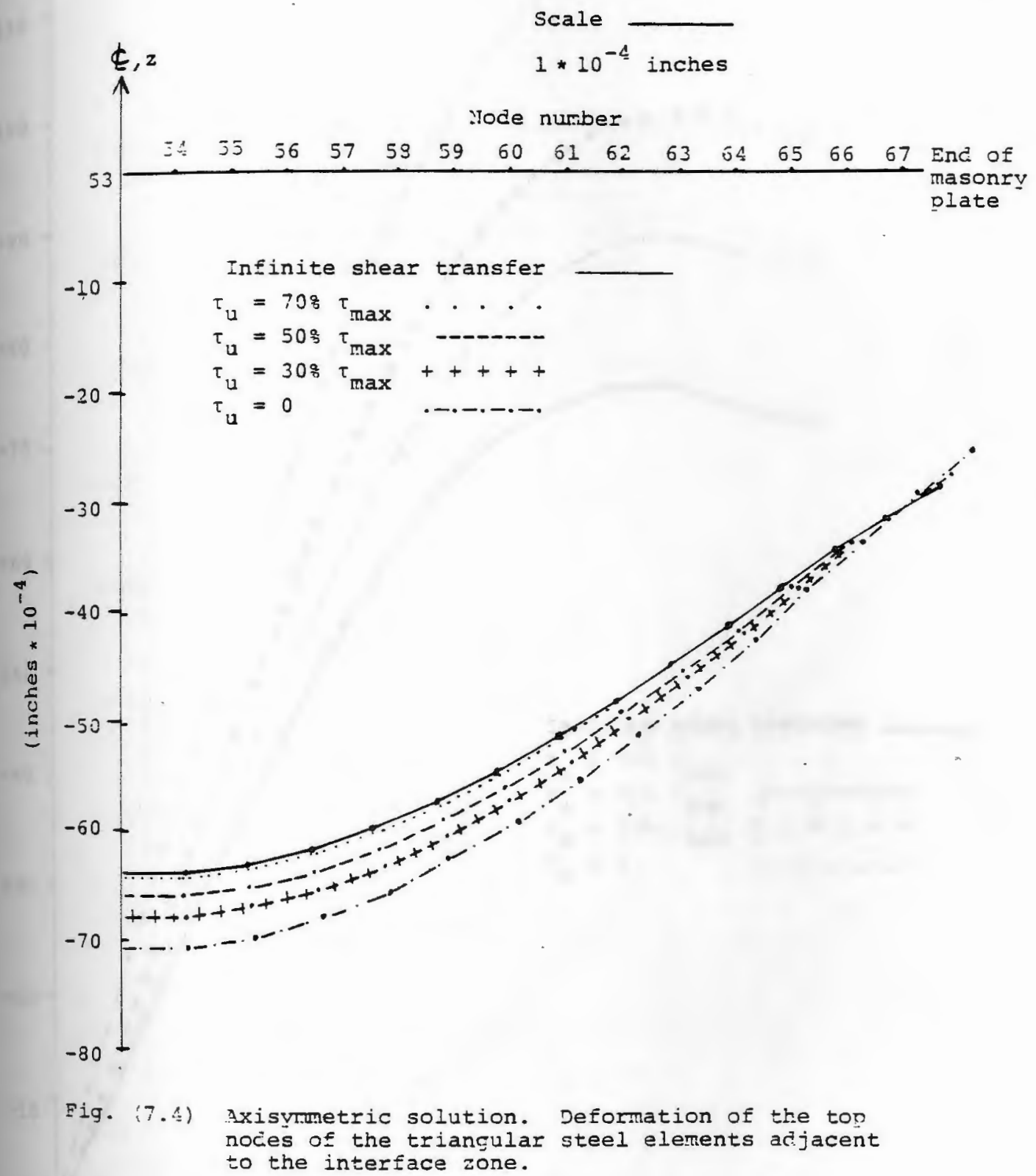




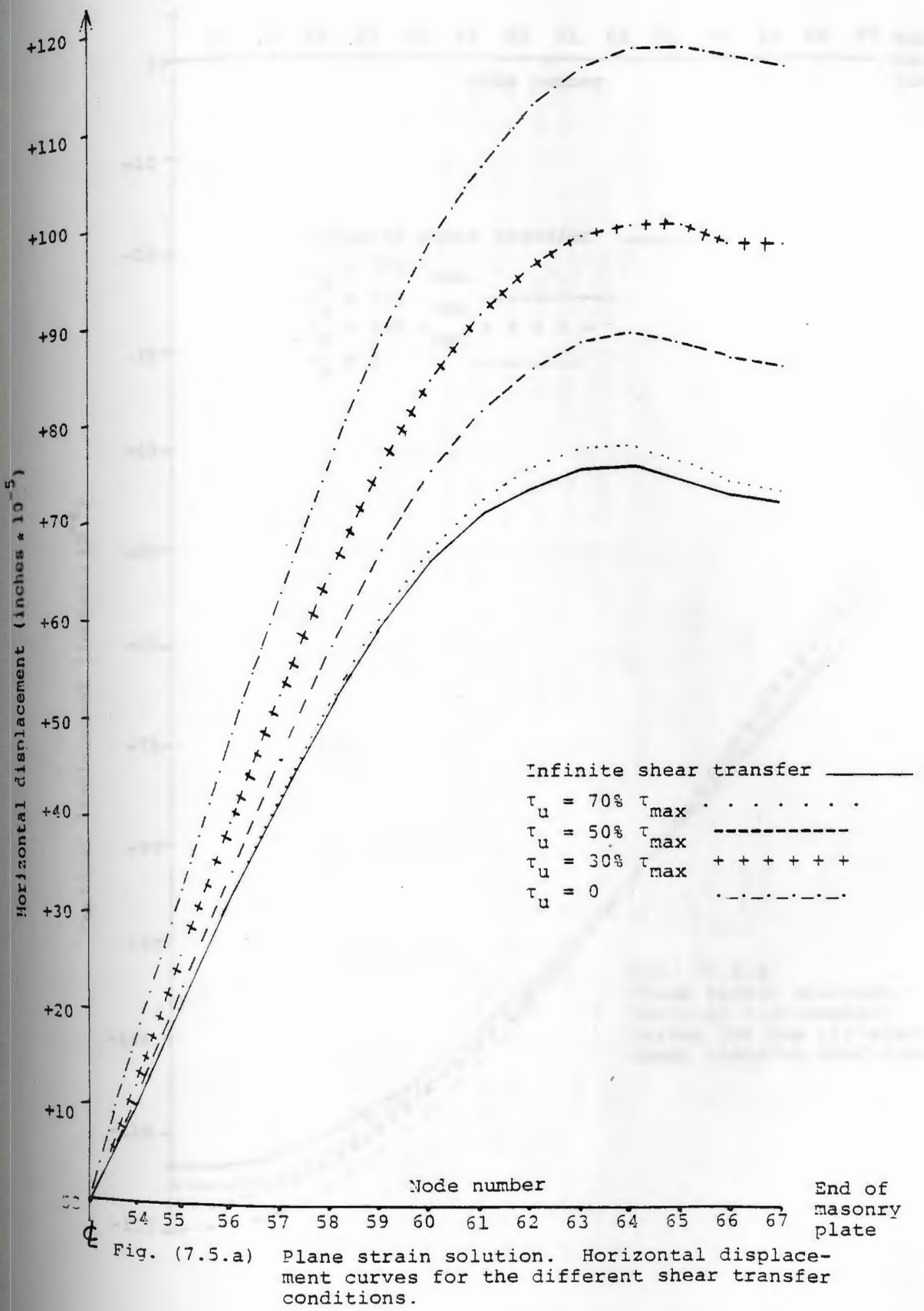




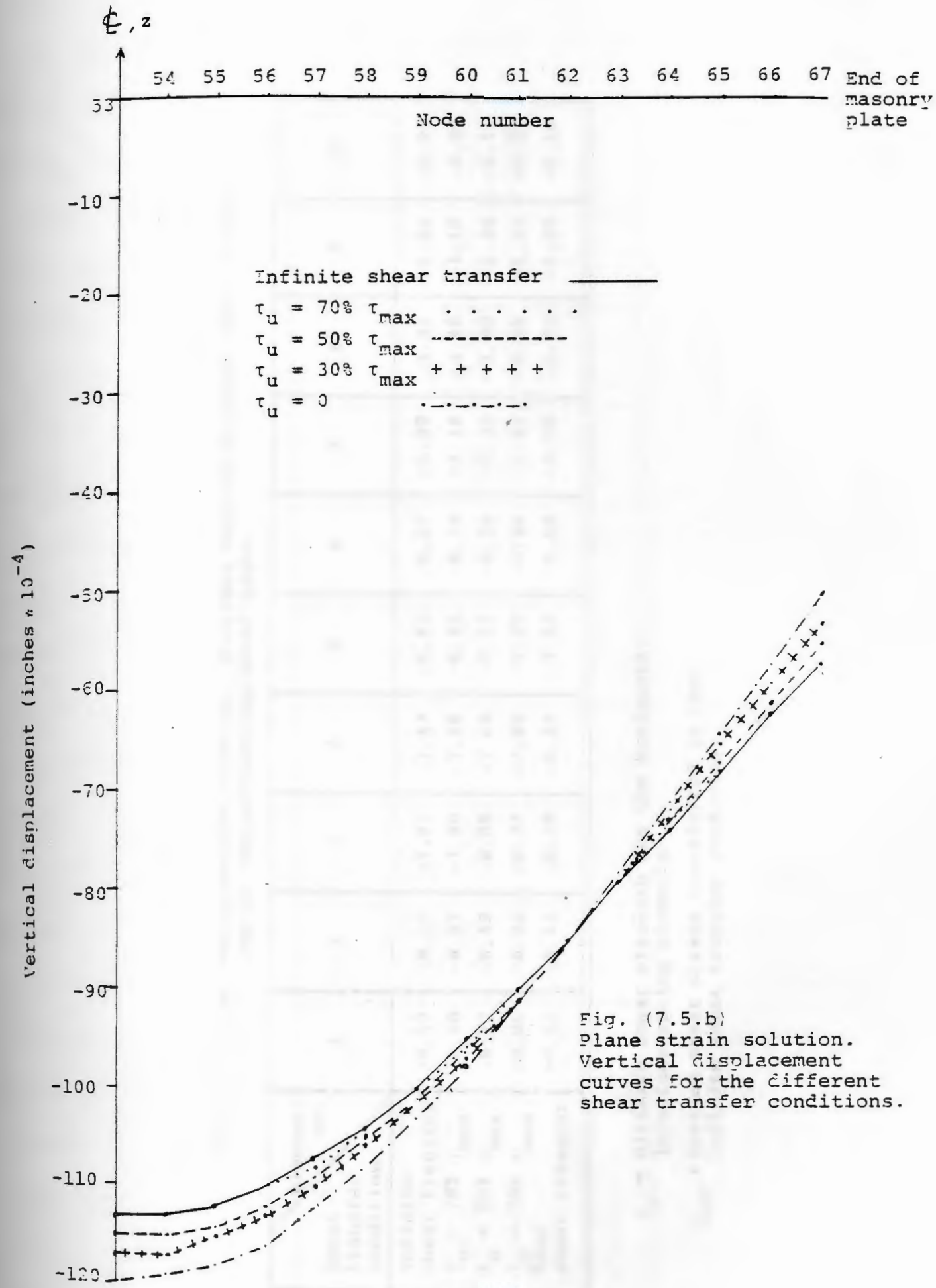


Table (7.4.a) Axisymmetric solution. Averaged bending stresses (Ksi) in the top of the pot bearing steel plate.

\begin{tabular}{|c|c|c|c|c|c|c|c|c|c|c|}
\hline $\begin{array}{l}\text { Shear } \\
\text { transfer } \\
\text { condition }\end{array}$ & 1 & 2 & 3 & 4 & 5 & 6 & 7 & 8 & 9 & 10 \\
\hline $\begin{array}{l}\text { Infinite } \\
\text { shear transfer }\end{array}$ & -8.59 & -8.26 & -7.87 & -7.43 & -6.83 & -6.07 & -5.09 & -3.32 & -1.06 & -0.08 \\
\hline$\tau_{u}=70 \% \tau_{\max }$ & -8.60 & -8.27 & -7.90 & -7.48 & -6.91 & -6.16 & -5.18 & -3.40 & -1.10 & -0.09 \\
\hline$\tau_{u}=50 \% \tau_{\max }$ & -8.72 & -8.42 & -8.09 & -7.69 & -7.11 & -6.34 & -5.32 & -3.50 & -1.16 & -0.11 \\
\hline$\tau_{u}=30 \% \tau_{\max }$ & -9.06 & -8.72 & -8.34 & -7.89 & -7.27 & -6.46 & -5.42 & -3.58 & -1.21 & -0.13 \\
\hline $\begin{array}{l}\text { Zero } \\
\text { shear transfer }\end{array}$ & -9.53 & -9.12 & -8.70 & -8.19 & -7.52 & -6.68 & -5.59 & -3.71 & -1.29 & -0.16 \\
\hline
\end{tabular}

$\tau_{u}=u l t i m a t e$ shear strength for the horizontal interface spring elements

$\tau_{\max }=$ maximum shear stress transferred in the infinite shear transfer condition 
Table (7.4.b) Plane strain solution. Averaged bending stresses (Ksi) in the top of the pot bearing steel plate.

Gauss integration points 2 and 4 .

\begin{tabular}{|c|c|c|c|c|c|c|c|c|c|c|}
\hline $\begin{array}{l}\text { Shear } \\
\text { transfer } \\
\text { condition }\end{array}$ & 1 & 2 & 3 & 4 & 5 & 6 & 7 & 8 & 9 & 10 \\
\hline $\begin{array}{l}\text { Infinite } \\
\text { shear transfer }\end{array}$ & -9.38 & -9.33 & -9.15 & -8.78 & -8.20 & -7.40 & -6.31 & -4.37 & -1.72 & -0.24 \\
\hline$\tau_{u}=708 \tau_{\max }$ & -9.35 & -9.30 & -9.14 & -8.79 & -8.24 & -7.47 & -6.40 & -4.45 & -1.77 & -0.25 \\
\hline $\mathrm{T}_{\mathbf{u}}=508 \mathrm{\tau}_{\max }$ & -9.23 & -9.24 & -9.17 & -8.91 & -8.42 & -7.65 & -6.55 & -4.57 & -1.84 & -0.28 \\
\hline$\tau_{u}=30 q \tau_{\max }$ & -9.48 & -9.47 & -9.36 & -9.04 & -8.49 & -7.68 & -6.57 & -4.59 & -1.87 & -0.29 \\
\hline $\begin{array}{l}\text { Zero shear } \\
\text { transfer }\end{array}$ & -10.02 & -9.89 & -9.63 & -9.20 & -8.58 & -7.75 & -6.62 & -4.64 & -1.92 & -0.31 \\
\hline
\end{tabular}


table (7.1.b) and fig. (6.7), notice that slip did not occur in the horizontal interface spring elements beneath steel elements nos. 1, 2, 3, and 4, while the horizontal spring beneath steel element no. 5 has just slipped with a slip modulus equalling $2900 \mathrm{Ksi}$. That indicates that shear stresses do in fact restrain bending of the steel plates. The percentage change of negative bending stresses in the top of the pot bearing plate steel elements is shown in fig. (7.6). Bending stresses increase nonlinearly along the pot bearing steel elements following the nonlinear slip function. When all the horizontal interface spring elements are in full slip (slip modulus equal $29 \mathrm{Ksi}$ ), bending stress along the pot bearing steel elements tends to change linearly because the modulus of slip becomes the same in all horizontal spring elements. Bending stress distribution curves for the different shear transfer conditions are shown in fig. (7.7.a) and fig. (7.7.b) for the axisymmetric and the plane strain solution methods, respectively. However, the effect of varying the shear transfer conditions on the negative pending stresses along the top of the pot plate is practically insignificant, due to the thickness of the plate which is assumed to behave with the masonry plate as a continuum. Figure (7.8) represents the change of the bending stresses, along a vertical section taken through the center of the pot bearing and the masonry 


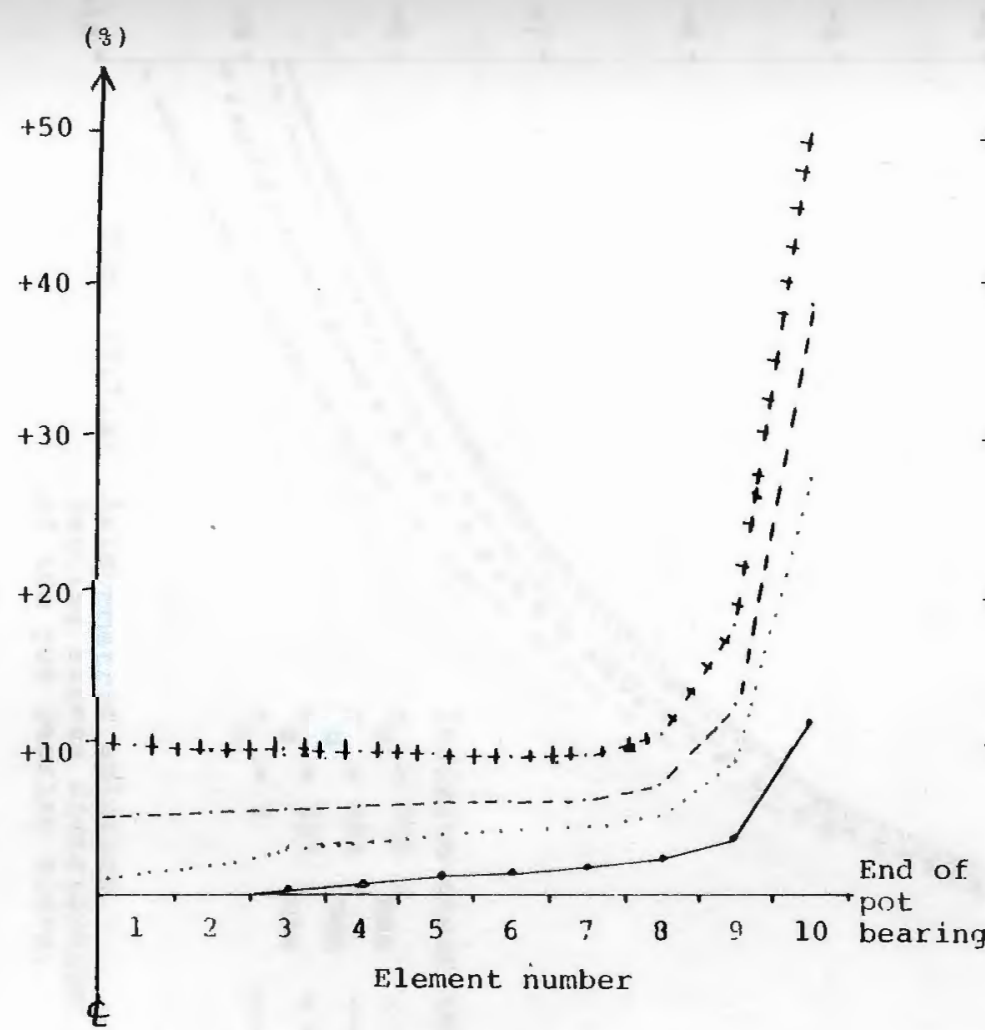

(a) Axisymetric solution

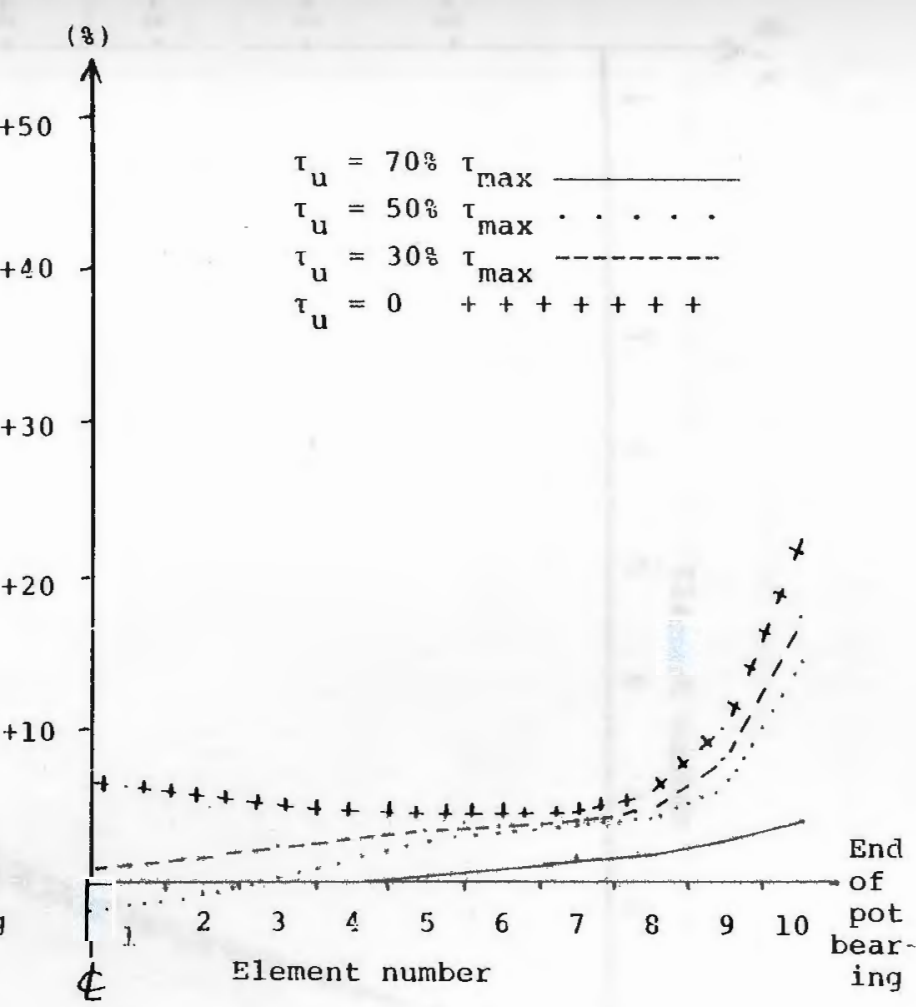

(b) Flane strajn solution

Fig. (7.6) Percentage of change in bending stresses in top of the pot bearing steel plate 


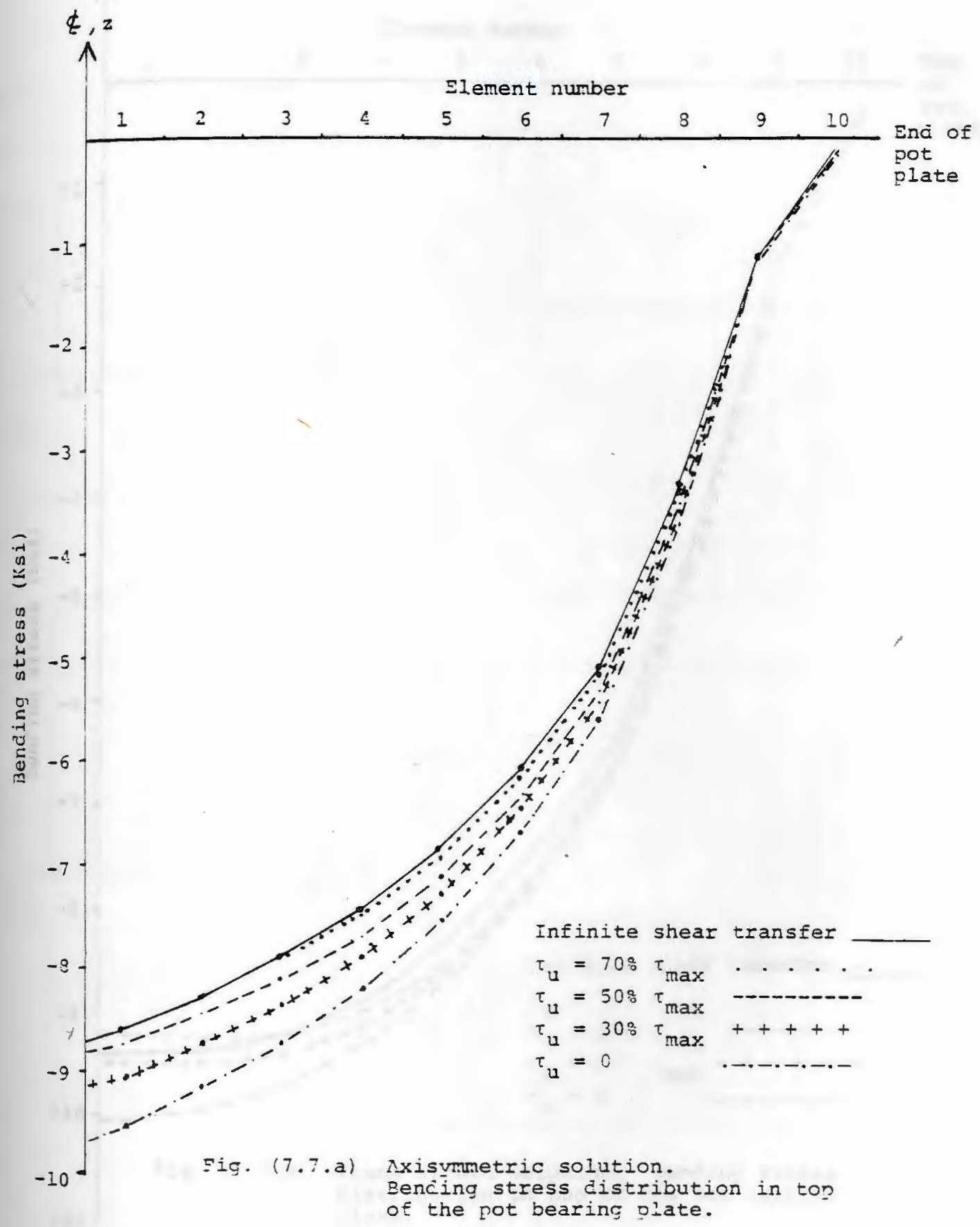




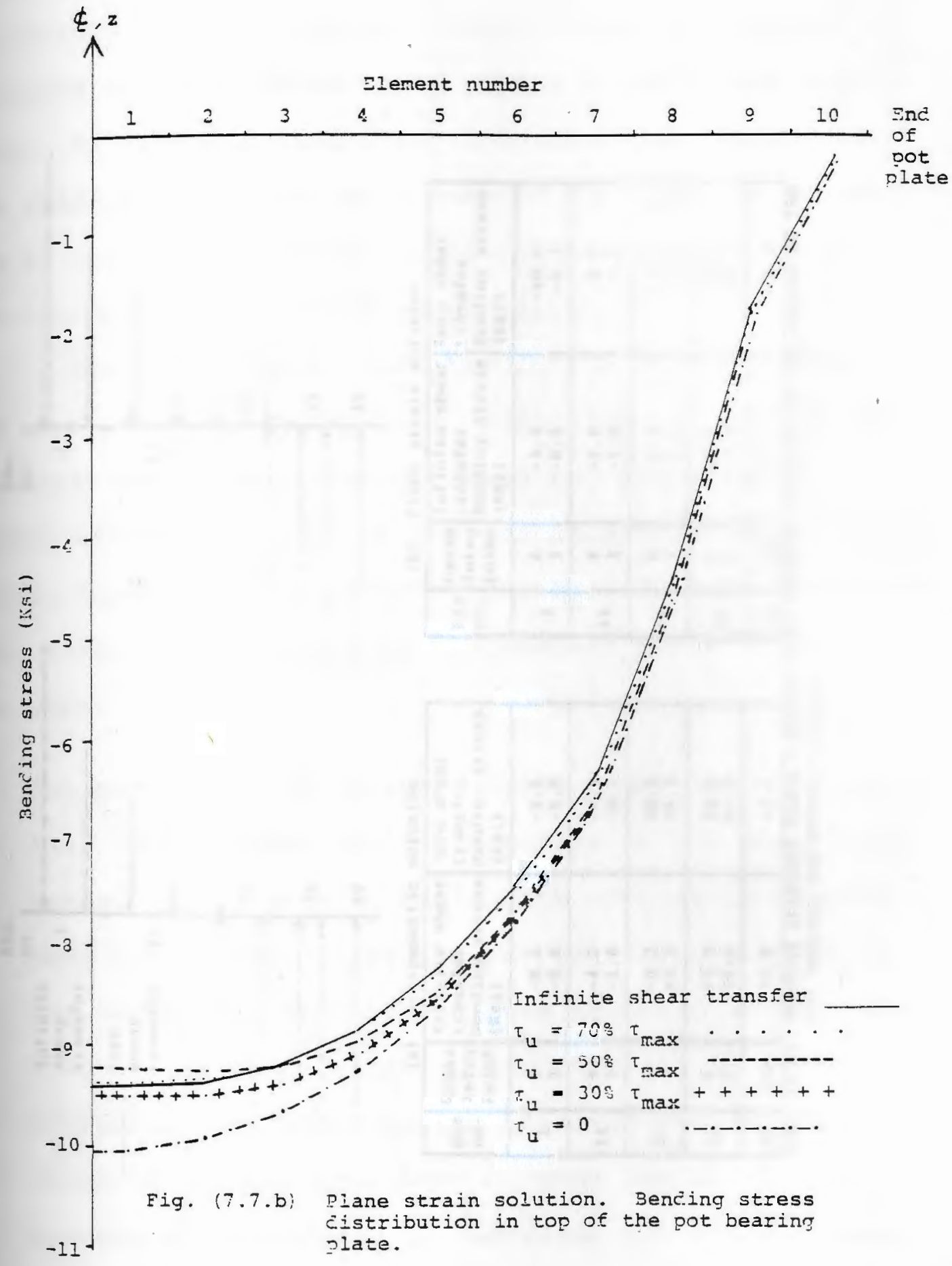


Srale: $1 / A^{*}=1 \mathrm{ksi}$

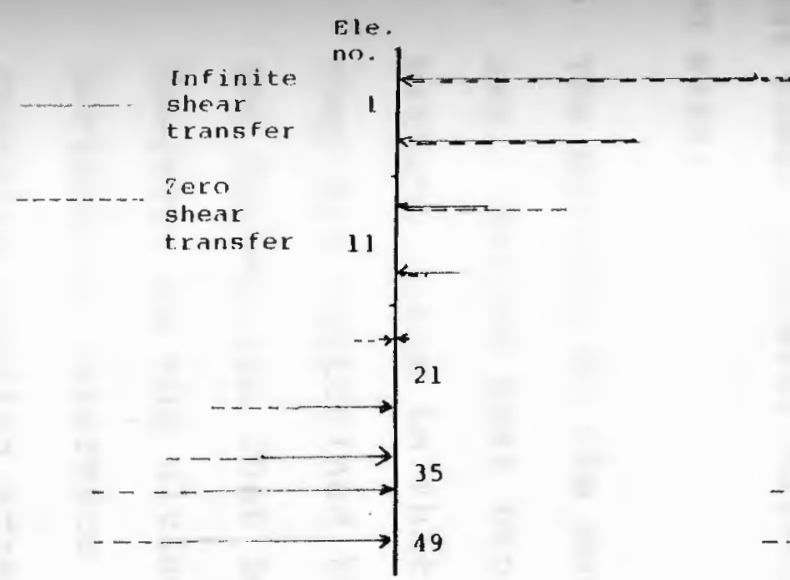

(a) Axisymmetric solution

\begin{tabular}{|c|c|c|c|}
\hline $\begin{array}{c}\text { Ele } \\
\text { no. }\end{array}$ & $\begin{array}{l}\text { Gauss } \\
\text { integ } \\
\text { point }\end{array}$ & $\begin{array}{l}\text { Infinite shear } \\
\text { transfer } \\
\text { Bending stress } \\
\text { (Ksi) }\end{array}$ & $\begin{array}{l}\text { rero shear } \\
\text { transfer } \\
\text { Ilending stress } \\
\text { (Ksi) }\end{array}$ \\
\hline 1 & 4 & $\begin{array}{l}-8.6 \\
-5.6\end{array}$ & $\begin{array}{l}-9.6 \\
-5.8\end{array}$ \\
\hline 11 & 4 & -4.2 & -4.1 \\
3 & -1.6 & -0.7 \\
\hline 21 & 4 & -0.3 & +0.9 \\
\hline 35 & 4 & +2.4 & +4.4 \\
\hline 49 & 3 & +4.3 & +5.5 \\
+7.3 & +4.8 & +7.2 \\
\hline
\end{tabular}

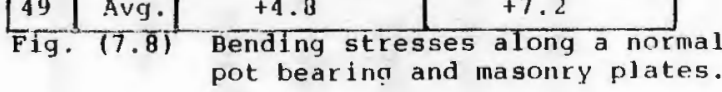

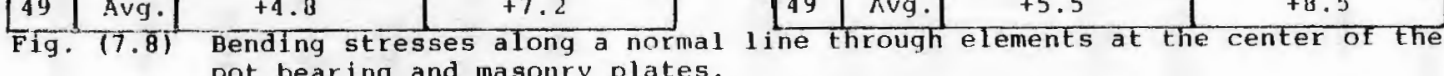

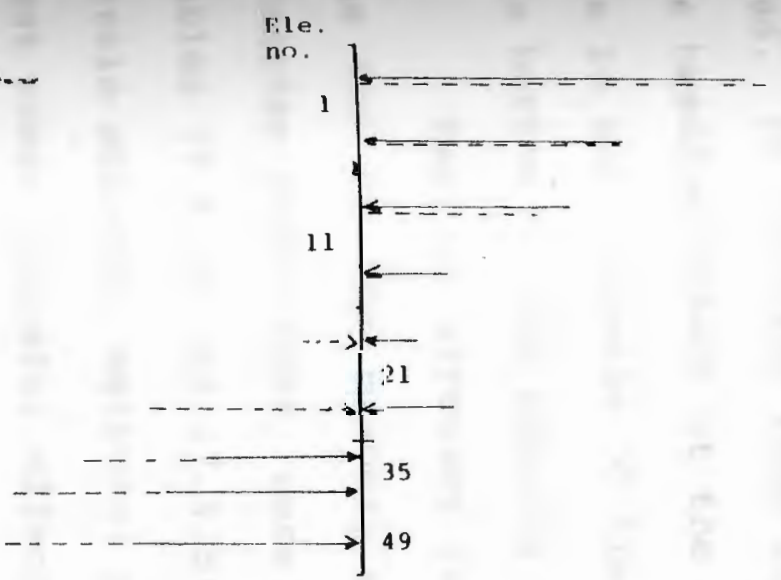

b) Plane strain solution

\begin{tabular}{|c|c|c|c|}
\hline $\begin{array}{l}\text { Ele } \\
\text { no. }\end{array}$ & $\begin{array}{l}\text { Gauss } \\
\text { integ } \\
\text { point }\end{array}$ & $\begin{array}{l}\text { Infinite shear } \\
\text { transfer } \\
\text { Bending stress } \\
\text { (Ksi) }\end{array}$ & $\begin{array}{l}\text { Zero shear } \\
\text { transfer } \\
\text { Benrljng gtress } \\
\text { (Ksi) }\end{array}$ \\
\hline 1 & $\begin{array}{l}4 \\
3\end{array}$ & $\begin{array}{l}-9.4 \\
-6.4\end{array}$ & $\begin{array}{r}-10.0 \\
-6.3\end{array}$ \\
\hline 11 & $\begin{array}{l}4 \\
3\end{array}$ & $\begin{array}{l}-4.8 \\
-1.9\end{array}$ & $\begin{array}{l}-4.2 \\
-0.6\end{array}$ \\
\hline 21 & $\begin{array}{l}4 \\
3\end{array}$ & $\begin{array}{l}-1.3 \\
-2.1\end{array}$ & $\begin{array}{l}+1.4 \\
+5.1\end{array}$ \\
\hline 35 & $\begin{array}{l}4 \\
3\end{array}$ & $\begin{array}{r}+3.7 \\
+4.7\end{array}$ & $\begin{array}{l}+6.6 \\
+8.1\end{array}$ \\
\hline 49 & Avg. & +5.5 & +8.5 \\
\hline
\end{tabular}

Fig. (7.8) Bending stresses along a normal 1 ine through elements at the center of the pot bearing and masonry plates. 
steel plates, for the infinite and zero shear transfer conditions. for triangular steel elements, bending stresses in Gauss integration points 3 and 4 were averaged. It appeared from fig. (7.8) that the increase in the bending moment at the center of the plate is actually due to the increase of the positive bending stress at the bottom of the masonry steel plate.

Bending stresses resulted in the steel elements at the top of the masonry steel plate from different shear transfer conditions, were averaged and listed in tables (7.5.a) and (7.5.b) for the axisymmetric and plane strain solution methods, respectively. Pesults indicated that shear transfer affects the masonry steel plate in two ways:

1) The portion of the masonry plate under the pot bearing. Notice that bending stresses in the top of the masonry plate in that region are very small because they are restrained by the pot bearing olate due to the assumption that both plates behave as a continuum. However, as the ultimate shear strength of the horizontal interface spring elements was redcued, negative bencing stresses in that region of the masonry plate started to decrease, converging toward becoming positive bending stresses as the slip in the interface increased. Bending stress distribution curves, for both solution methods, are shown in 
Table (7.5.a) Axisymmetrical solution. Averaged bending stresses (Ksi) in the top of the masonry steel plate. Gauss inteqration points 2 and 4 .

\begin{tabular}{|c|c|c|c|c|c|c|c|c|c|c|c|c|c|c|}
\hline $\begin{array}{l}\text { Shear Element } \\
\text { transfer no. } \\
\text { condition }\end{array}$ & 21 & 22 & 23 & 24 & 25 & 26 & 27 & 28 & 29 & 30 & 31 & 32 & 33 & 34 \\
\hline $\begin{array}{l}\text { Infinite shear } \\
\text { transfer }\end{array}$ & -0.36 & -0.36 & -0.36 & -0.36 & -0.36 & -0.36 & -0.46 & -0.77 & -1.26 & -1.82 & -2.56 & -0.47 & +0.13 & +0.08 \\
\hline$\tau_{u}=708 \tau_{\max }$ & -0.31 & -0.31 & -0.30 & -0.29 & -0.28 & -0.28 & -0.38 & -0.70 & -1.22 & -1.79 & -2.50 & -0.38 & +0.19 & +0.10 \\
\hline$\tau_{\mathrm{u}}=50 \mathrm{~g} \mathrm{I}_{\max }$ & -0.04 & -0.03 & -0.02 & -0.00 & +0.01 & -0.01 & -0.15 & -0.51 & -1.07 & -1.70 & -2.46 & -0.39 & +0.16 & +0.09 \\
\hline$\tau_{u}=308 t_{\max }$ & +0.31 & +0.30 & +0.30 & +0.29 & +0.26 & +0.21 & +0.04 & -0.35 & -0.95 & -1.62 & -2.40 & -0.37 & +0.16 & +0.08 \\
\hline $\begin{array}{l}\text { Zero shear } \\
\text { transfer }\end{array}$ & +0.85 & +0.81 & +0.77 & +0.71 & +0.63 & +0.54 & +0.33 & -0.11 & -0.78 & -1.52 & -2.37 & -0.36 & +0.14 & +0.07 \\
\hline
\end{tabular}

$T_{u}=$ ultimate shear strength value for the horizontal interface spring elements.

$\tau$ maximum shear stress transferred in the

infinite shear transfer condition. 
Table (7.5.b) plane strain solution. Averaged bending stresses (Ksi) in the top of the masonry steel plate. Gauss integration points 2 and 4 .

\begin{tabular}{|c|c|c|c|c|c|c|c|c|c|c|c|c|c|c|}
\hline $\begin{array}{l}\text { Shear Element } \\
\text { transfer no. } \\
\text { condition }\end{array}$ & 21 & 22 & 23 & 24 & 25 & 26 & 27 & 28 & 29 & 30 & 31 & 32 & 33 & 34 \\
\hline $\begin{array}{l}\text { Infinite shear } \\
\text { transfer }\end{array}$ & -0.34 & -0.34 & -0.26 & -0.21 & -0.18 & -0.16 & -0.23 & -0.53 & -1.10 & -1.82 & -2.73 & -0.39 & +0.29 & +0.18 \\
\hline$\tau_{u}=708 \tau_{\max }$ & -0.30 & -0.30 & -0.21 & -0.15 & -0.11 & -0.08 & -0.15 & -0.46 & -1.04 & -1.78 & -2.66 & -0.25 & +0.39 & +0.22 \\
\hline$\tau_{u}=508 \tau_{\max }$ & +0.02 & +0.04 & +0.16 & +0.25 & +0.31 & +0.33 & +0.23 & -0.13 & -0.78 & -1.58 & -2.45 & -0.17 & +0.41 & +0.22 \\
\hline$\tau_{u}=308 \tau_{\max }$ & +0.56 & +0.56 & +0.65 & +0.70 & +0.70 & +0.66 & +0.52 & +0.12 & -0.56 & -1.37 & -2.17 & -0.02 & +0.47 & +0.23 \\
\hline $\begin{array}{l}\text { Zero shear } \\
\text { transfer }\end{array}$ & +1.43 & +1.41 & +1.38 & +1.32 & +1.24 & +1.15 & +0.94 & +0.48 & -0.25 & -1.09 & -1.82 & +0.15 & +0.53 & +0.24 \\
\hline
\end{tabular}


figs. (7.9.a) and (7.9.b). Considering the plane strain solution, in the shear transfer condition where $\tau_{u}=70 \% \tau_{\text {max }}$, bending stresses in the top of the masonry plate under the pot bearing were all negative; the minimum negative bending stress appeared to be in steel element no. 26, lying exactly above the horizontal interface element where slip has started with a slip modulus equal to $290 \mathrm{Ksi}$, see table (7.1.b) and fig. (6.7). In the shear transfer condition where $\tau_{\mathrm{u}}=50 \% \tau_{\max }$ ' the bending stresses became positive in element no. 22 and started to increase nonlinearly until they peaked in steel element no. 26 , which lies above the horizontal interface spring element where slip has started with a slip modulus equal to $290 \mathrm{Ksi}$. Nevertheless, in the case representing zero shear transfer, the positive bending stresses were uniformly distributed along that portion of the interface zone because most horizontal spring elements slipped with a uniform slip modulus. Thus as the ultimate shear strength value of the horizontal interface spring elements decreases, the pot bearing and the masonry plate modeled as a continuum, will have an increasing bending moment in the center, refer to fig. (7.8). 


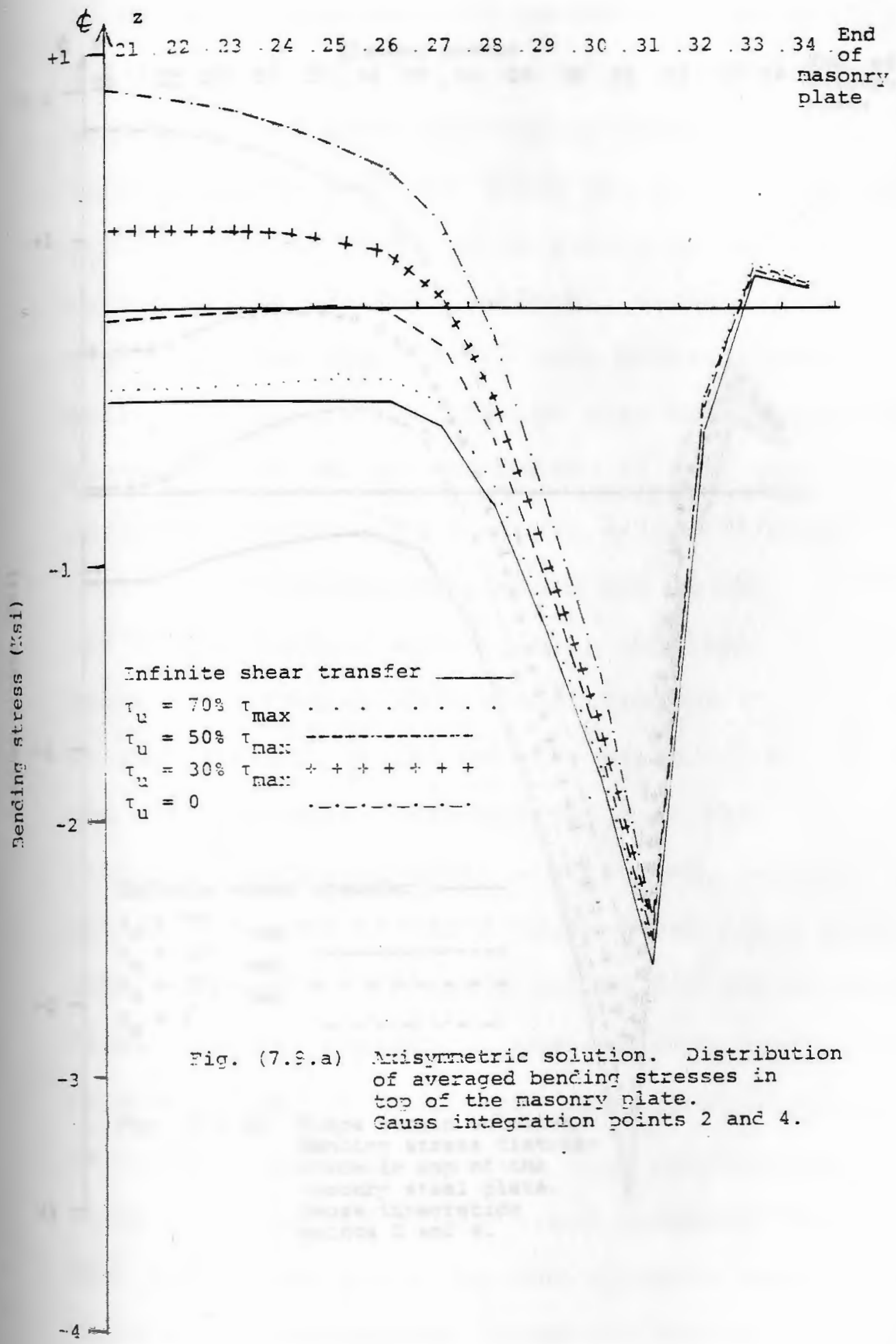




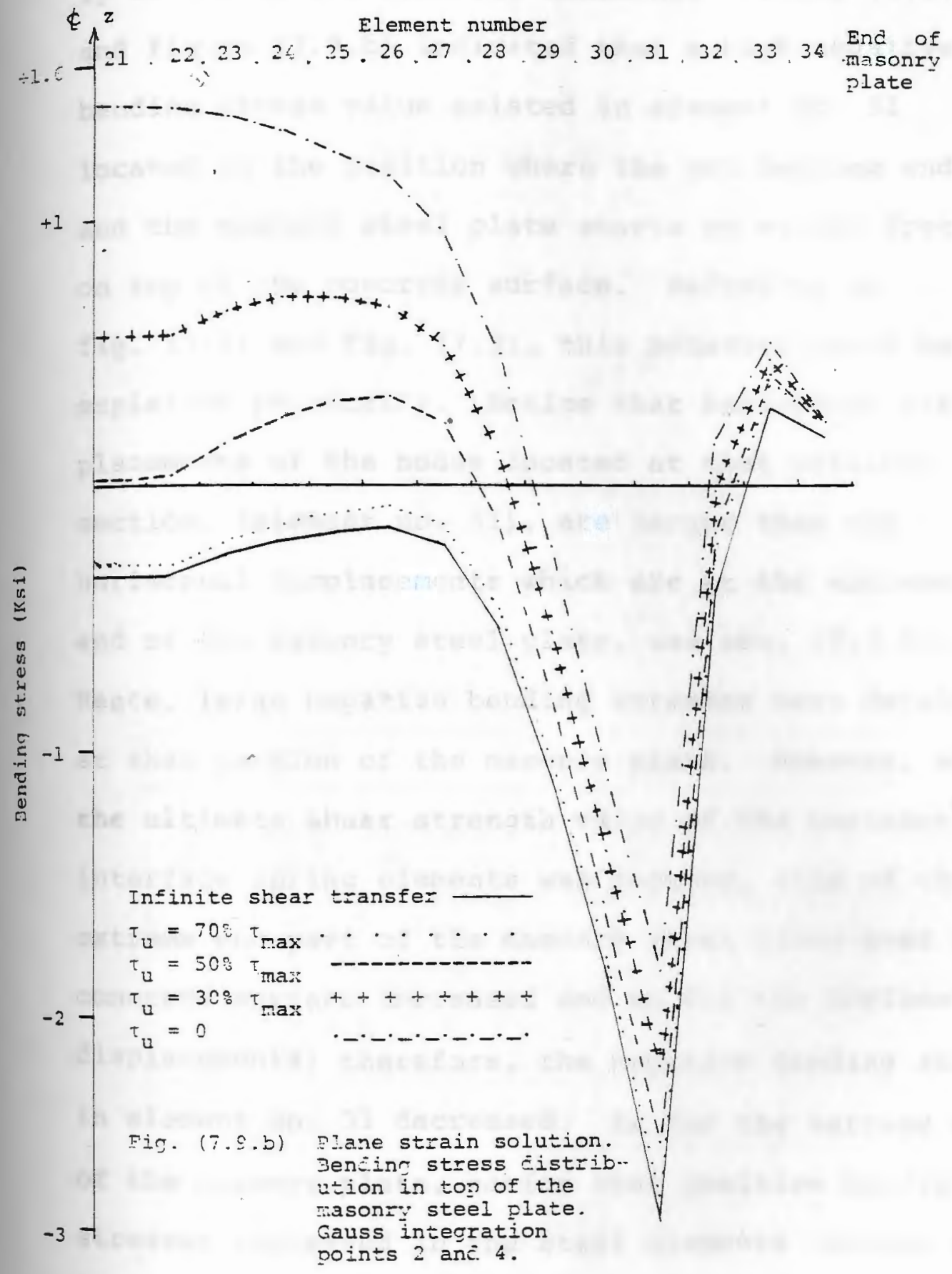


2) The portion of the masonry steel plate extending freely on top of the concrete abutment. Figure (7.9.a) and figure (7.9.b) indicated that a high negative bending stress value existed in element no. 31 located in the position where the pot bearing ends and the masonry steel plate starts to extend freely on top of the concrete surface. Referring to fig. (7.2) and fig. (7.3), this behavior could be explained physically. Notice that horizontal displacements of the nodes located at that critical section, (element no. 31), are larger than the horizontal displacements which are at the extreme end of the masonry steel plate, see sec. (7.3.1). Hence, large negative bending stresses were developed at that portion of the masonry plate. However, when the ultimate shear strength value of the horizontal interface spring elements was reduced, slip of the extreme end part of the masonry steel plate over the concrete surface increased and so did the horizontal displacements; therefore, the negative bending stress in element no. 31 decreased. As for the extreme end of the masonry plate, notice that positive bending stresses increased in the steel elements located at that end of the plate, as the ultimate shear strength value of the horizontal interface spring elements was decreased. 


\section{Bending stress (Ksi)}

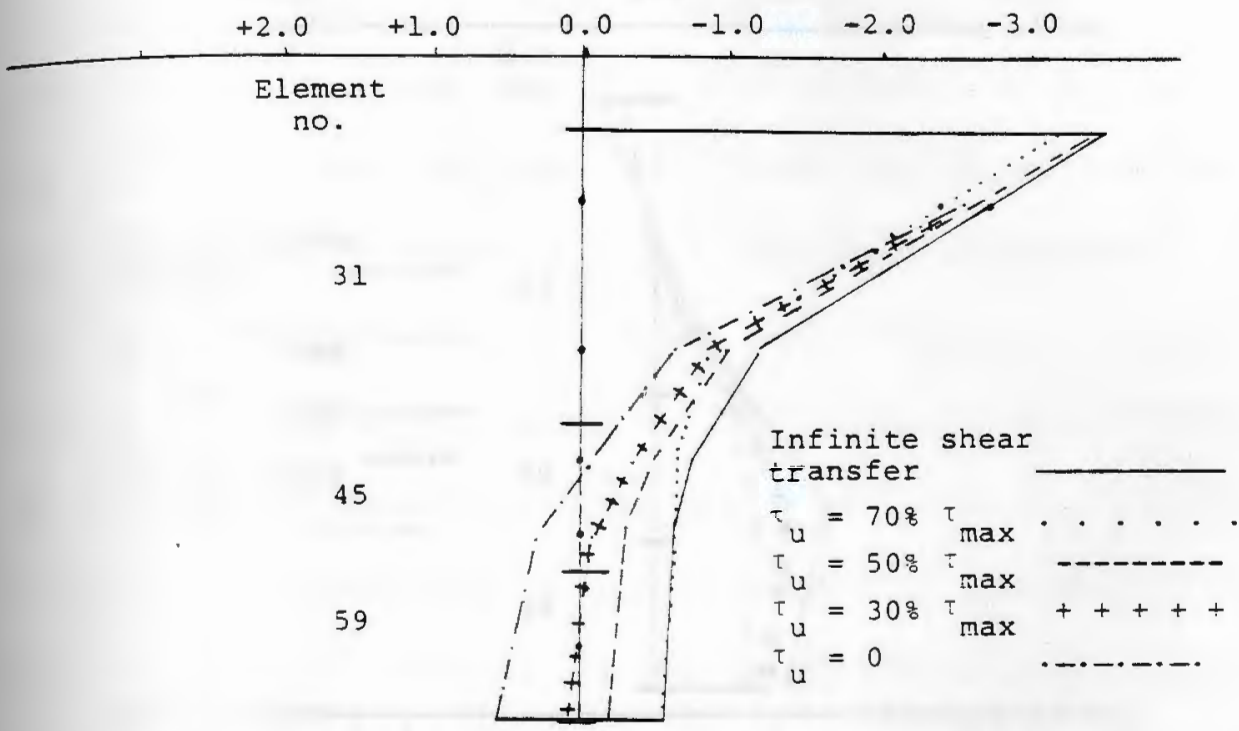

\begin{tabular}{|c|c|c|c|c|c|c|}
\hline \multicolumn{2}{|c|}{$\begin{array}{l}\text { Shear transfer } \\
\text { condition }\end{array}$} & \multicolumn{5}{|c|}{ Bending stresses (K'si) } \\
\hline $\begin{array}{l}\text { sle. } \\
\text { no. }\end{array}$ & $\begin{array}{l}\text { Gauss } \\
\text { integ. } \\
\text { point }\end{array}$ & $\begin{array}{l}\text { Infinite } \\
\text { shear } \\
\text { transfer }\end{array}$ & $\begin{array}{l}\tau_{\mathrm{U}}= \\
70 \% \\
\tau_{\max }\end{array}$ & $\begin{array}{l}\tau_{u}= \\
50 \% \\
\tau_{\text {max }}\end{array}$ & $\begin{array}{l}\tau_{u}= \\
30 \% \\
\tau_{\text {max }}\end{array}$ & $\tau_{u}=0$ \\
\hline 31 & $\begin{array}{l}2 \\
1\end{array}$ & $\begin{array}{l}-2.69 \\
-1.18\end{array}$ & $\begin{array}{l}-2.64 \\
-1.16\end{array}$ & $\begin{array}{l}-2.60 \\
-0.97\end{array}$ & $\begin{array}{l}-2.55 \\
-0.83\end{array}$ & $\begin{array}{l}-2.52 \\
-0.61\end{array}$ \\
\hline 45 & $\begin{array}{l}2 \\
1\end{array}$ & $\begin{array}{l}-0.74 \\
-0.61\end{array}$ & $\begin{array}{l}-0.74 \\
-0.62\end{array}$ & $\begin{array}{l}-0.49 \\
-0.30\end{array}$ & $\begin{array}{l}-0.32 \\
-0.07\end{array}$ & $\begin{array}{l}-0.03 \\
+0.30\end{array}$ \\
\hline 59 & $\begin{array}{c}1 \text { \& } 2 \\
\text { averaged }\end{array}$ & -0.53 & -0.59 & -0.23 & +0.03 & +0.45 \\
\hline
\end{tabular}

Fig. (7.10.a) Axisymmetric solution. Bending stress distribution alond a vertical line nassing through the critical section of the masonry steel plate. 
Bending stress (Ksi)

$+1.0$

0.0

$-1.0$

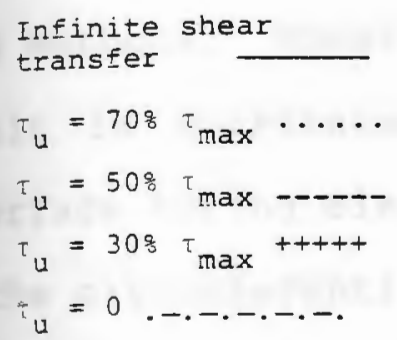

Ele.

no.

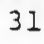

45

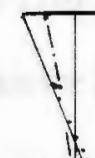

1

i.

39

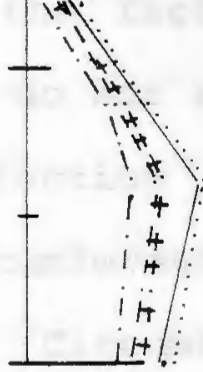

\begin{tabular}{|c|c|c|c|c|c|c|}
\hline \multicolumn{2}{|c|}{$\begin{array}{l}\text { Shear transfer } \\
\text { condition }\end{array}$} & \multicolumn{2}{|c|}{ Bending } & \multicolumn{3}{|c|}{ stresses (Ksi) } \\
\hline $\begin{array}{l}\text { Ele. } \\
\text { no. }\end{array}$ & $\begin{array}{l}\text { Gauss } \\
\text { integ. } \\
\text { point }\end{array}$ & $\begin{array}{l}\text { Infinite } \\
\text { shear } \\
\text { stress }\end{array}$ & $\begin{array}{l}\tau_{u}= \\
70 \% \\
\tau_{\max }\end{array}$ & $\begin{array}{l}\tau_{u}= \\
508 \\
\tau_{\max }\end{array}$ & $\begin{array}{l}\tau_{u}= \\
308 \% \\
\tau_{\max }\end{array}$ & $\tau_{u}=0$ \\
\hline 34 & $\begin{array}{l}2 \\
1\end{array}$ & $\begin{array}{l}+0.05 \\
-0.11 \\
\end{array}$ & $\begin{array}{l}+0.06 \\
-0.12 \\
\end{array}$ & $\begin{array}{l}+0.05 \\
-0.09\end{array}$ & $\begin{array}{l}+0.05 \\
-0.07\end{array}$ & $\begin{array}{l}+0.04 \\
-0.03\end{array}$ \\
\hline 48 & $\begin{array}{l}2 \\
1 \\
\end{array}$ & $\begin{array}{l}-0.31 \\
-0.45\end{array}$ & $\begin{array}{l}-0.32 \\
-0.47\end{array}$ & $\begin{array}{l}-0.24 \\
-0.35\end{array}$ & $\begin{array}{l}-0.26 \\
-0.36\end{array}$ & $\begin{array}{l}-0.21 \\
-0.28\end{array}$ \\
\hline 62 & $\begin{array}{c}\text { I \& } 2 \\
\text { averaged }\end{array}$ & -0.40 & -0.42 & -0.31 & -0.33 & -0.26 \\
\hline
\end{tabular}

Fig. (7.10.b) Axisymetric solution. Bending stress distribution along a vertical line passing through the end steel elements of the masonry steel plate. 
Bending stress distribution along vertical lines passing through the critical section and the end steel lements of the masonry plate is shown in fig. (7.10.a) and fig. (7.10.b) respectively.

The effect of shear transfer on the bending stresses of the pot bearing and masonry steel plates is the same for the axisymmetric and the plane strain solution methods. However, the numerical difference in the result is attributed to the fact that the horizontal interface spring elements do not affect the deformation in the circumferential direction in the axisymmetric solution; therefore, circumferential stresses and strains are not affected. Circumferential or in general out-of-plane strains are assumed to equal zero in the plane strain solution.

7.2.3 EFFECT OF SHEAR TRANSFER ON THE

NORMAL AND SHEAR STRESS DISTRIBUTION IN THE CONCRETE ABUTMENT

The effect of shear transfer on the vertical and horizontal deformation as well as on the bending of the steel plates on top of the concrete abutment surface, was examined in the previous sections. Vertical disHacement distribution curves along the masonry steel plate for different shear transfer conditions were shown in fig. (7.3) and fig. (7.5.b) for the axisymmetric and the plane strain solution methods, respectively. The general deformation curve representing the deformation 
of the masonry steel plate under different shear transfer assumptions for the axisymetric solution was shown in fig. (7.4). Generally speaking, all deformation curves indicated that as the ultimate shear strength of the horizontal interface spring elements was decreased, vertical displacements of the masonry steel plate tend to increase in the direction normal to the surface of the concrete near the center and decrease toward the end, with respect to results achieved from the infinite shear transfer condition. Furthermore, it has been shown in sec. (7.2.2), that the masonry steel plate tends to bend over the concrete surface at the section of the plate which is above the position where slip starts in the interface zone. Averaged vertical stresses along the concrete elements nos. 161 to 170 , (selected about 1.25 inches below the concrete surface to avoid direct effect from the interface spring elements and the modeling of the interface), for the different shear transfer conditions were listed in tables $(7.6 . a)$ and $(7.6 . b)$ for the axisymetric and plane strain solution methods. Results generally indicate that normal (compression) stresses Greased in the center of the concrete abutment and fecreased at the end, see fig. (7.11.a) and fig. (7.11.b). Towever, with a closer look at the results it was found that maximum increase in the concrete normal stresses for all shear transfer conditions appeared to be at the 


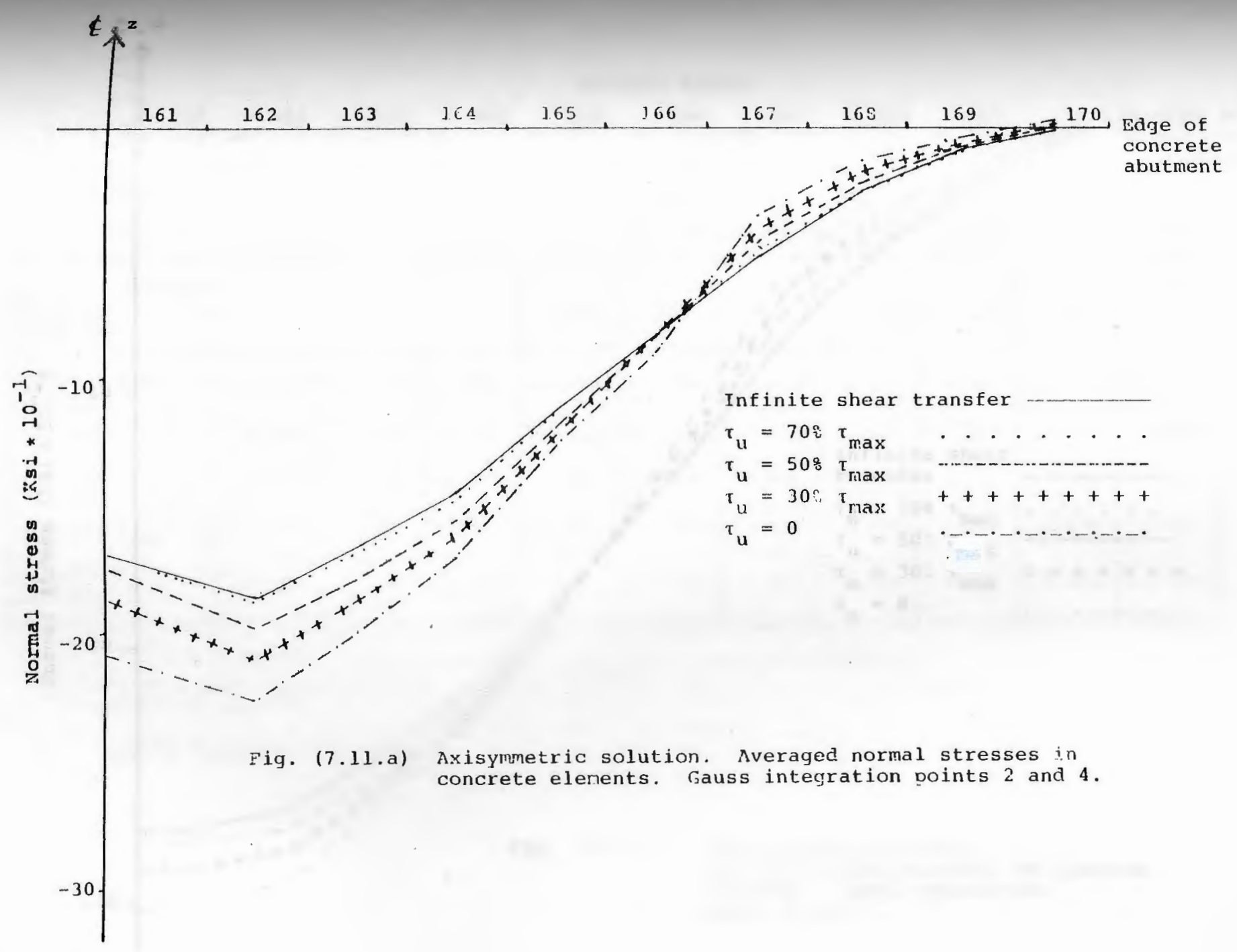




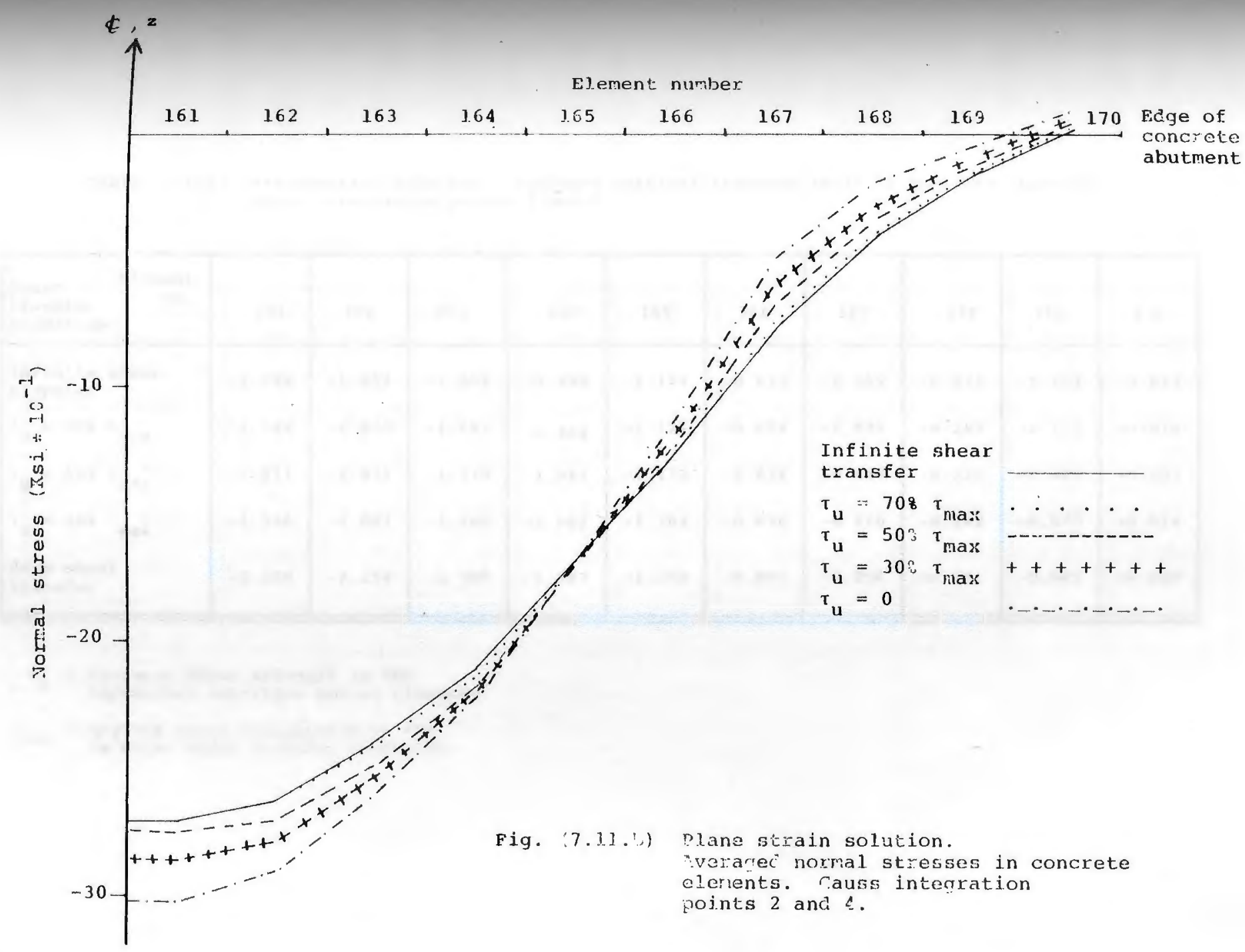


Table (7.6.a) Axisymmetric solution. Averaged vertical stresses (Ksi) in concrete elements Gauss integration points 2 and 4 .

\begin{tabular}{|c|c|c|c|c|c|c|c|c|c|c|}
\hline $\begin{array}{lr}\text { Shear } & \text { Element } \\
\text { transfer } & \text { no. } \\
\text { condition } & \end{array}$ & $161^{\circ}$ & 162 & 163 & 164 & 165 & 166 & 167 & 168 & 169 & 170 \\
\hline $\begin{array}{l}\text { Infinite shear } \\
\text { transfer }\end{array}$ & -1.739 & -1.854 & -1.654 & -1.440 & -1.114 & -0.833 & -0.509 & -0.272 & -0.104 & -0.012 \\
\hline${ }^{\tau}{ }_{u}=708 \tau_{\max }$ & -1.748 & -1.870 & -1.682 & -1.468 & -1.125 & -0.824 & -0.495 & -0.265 & -0.101 & -0.010 \\
\hline$\tau_{u}=508 \tau_{\max }$ & -1.811 & -1.971 & -1.779 & -1.541 & -1.170 & -0.834 & -0.449 & -0.226 & -0.085 & +0.002 \\
\hline$\tau_{u}=308 \tau_{\max }$ & -1.936 & -2.087 & -1.860 & -1.602 & -1.204 & -0.836 & -0.410 & -0.192 & -0.070 & +0.014 \\
\hline $\begin{array}{l}\text { Zero shear } \\
\text { transfer }\end{array}$ & -2.129 & -2.254 & -1.985 & -1.693 & -1.254 & -0.883 & -0.356 & -0.141 & -0.045 & +0.028 \\
\hline
\end{tabular}

${ }^{\mathrm{T}} \mathrm{u}=$ ultimate shear strength in the

horizontal interface spring elements

$\mathrm{T}_{\text {max }}=$ maximum shear transferred in the infinite shear transfer condition. 
Table (7.6.b) Plane strain solution. Averaged vertical stresses (Ksi) in concrete elements. Gauss integration points 2 and 4 .

\begin{tabular}{|c|c|c|c|c|c|c|c|c|c|c|}
\hline $\begin{array}{lr}\text { Shear } & \text { Element } \\
\text { transfer } & \text { no. } \\
\text { condition }\end{array}$ & 161 & 162 & 163 & 164 & 165 & 166 & 167 & 168 & 169 & 170 \\
\hline $\begin{array}{l}\text { Infinite shear } \\
\text { transfer }\end{array}$ & -2.718 & -2.634 & -2.398 & -2.112 & -1.680 & -1.271 & -0.776 & -0.418 & -0.164 & +0.013 \\
\hline$u=708$ max & -2.721 & -2.639 & -2.414 & -2.133 & -1.684 & -1.252 & -0.760 & -0.412 & -0.162 & +0.014 \\
\hline$u=50 \%$ max & -2.755 & -2.710 & -2.493 & -2.183 & -1.701 & -1.230 & -0.675 & -0.342 & -0.127 & +0.040 \\
\hline $\mathrm{u}=30 \mathrm{z} \quad \max$ & -2.862 & -2.792 & -2.536 & -2.201 & -1.692 & -1.189 & -0.599 & -0.285 & -0.099 & +0.060 \\
\hline $\begin{array}{l}\text { Zero shear } \\
\text { transfer }\end{array}$ & -3.028 & -2.904 & -2.600 & -2.229 & -1.677 & -1.129 & -0.496 & -0.201 & $-0,054$ & +0.085 \\
\hline
\end{tabular}


woncrete element under the horizontal interface spring elements which fully slipped (slip modulus equal 29 Ksi). The percentage changes in the concrete elements normal compressive stress resulting from the different shear transfer conditions, with respect to results from the infinite shear transfer condition, were listed in

table $(7.6 . c)$ considering an axisymmetric solution. In the shear transfer condition where $\tau_{\mathrm{u}}=70 \% \tau_{\max }$, maximum increase in the average normal compressive stress ppoared to be in element no. 164 which is aligned. wertically with horizontal interface spring elements nos. 99 and 100, see fig. (6.7). Referring to table (7.1.b), notice that element no. 99 was the first horizontal spring element in the full slip range (slip modulus equals $29 \mathrm{ksi}$. Similarly, in the shear transfer condition where $\tau_{u}=50 \% \tau_{\text {max }}$ ' maximum change appeared in element no. 163 which is aligned vertically with horizontal interface spring elements nos. 96 and 97. Referring to table (7.I.C), notice that elements 96 and 97 have fully slipped. Maximum change in this case did not appear in foncrete element no. 162, even though it is below the horizontal spring element no. 95 which was the first in the full slip range. However, since average stresses were considered, it came out that for maximum change in normal compression stresses to appear in one of those analyzed concrete elements, both horizontal interface 
Table (7.6.c) Axisymmetric solution. Percentage of change in averaged normal concrete compressive stresses.

\begin{tabular}{|c|c|c|c|c|}
\hline \multirow{2}{*}{$\begin{array}{l}\text { Concrete } \\
\text { element } \\
\text { number }\end{array}$} & \multicolumn{4}{|c|}{ Shear transfer condition } \\
\cline { 2 - 5 } & $\tau_{\mathrm{u}}=70 \% \tau_{\max }$ & $\tau_{\mathrm{u}}=50 \% \tau_{\max }$ & $\tau_{\mathrm{u}}=30 \% \tau_{\max }$ & $\tau_{\mathrm{u}}=0$ \\
& $\%$ & $\frac{\circ}{\circ}$ & $\%$ & $\%$ \\
\hline 161 & +0.52 & +4.14 & +11.33 & +22.43 \\
162 & +0.86 & +6.31 & +12.57 & +21.57 \\
163 & +1.69 & +7.56 & +12.45 & +20.01 \\
164 & +1.94 & +7.01 & +11.25 & +17.57 \\
165 & +0.99 & +5.03 & +8.08 & +12.57 \\
166 & -1.09 & +0.12 & +0.36 & +6.00 \\
167 & -2.83 & -13.36 & -24.15 & -42.98 \\
168 & -2.64 & -20.35 & -41.67 & -92.91 \\
169 & -2.97 & -22.35 & -48.57 & -231.11 \\
170 & -16.67 & -120.00 & -216.67 & -333.33 \\
\hline
\end{tabular}

Notice: Change > $100 \%$ should indicate a change from compression to tension.]

$\tau_{u}=$ ultimate shear strength in the horizontal interface spring elements.

$\tau_{\max }=$ maximim shear transferred in the infinite shear transfer condition. 
spring elements aligned vertically with it must be in full slip range. Notice similsrly that when $\tau_{u}=30 \% \tau_{\max }$ maximum change in concrete normal compressive stress appeared in element no. 162 near the center, and in the case of zero shear transfer the maximum change appeared in concrete element no. 161, at the center, because in this case all horizontal interface spring elements slipped by assumption. Normal stresses near the edge of the concrete abutment decreased as shown due to the increase of plate bending.

Shear stresses in concrete elements nos. 161 to 170 for all shear transfer conditions, were listed in tables (7.7.a) and (7.7.b). Results indicated that shear stresses in the concrete decreased as the ultimate shear Frength value of the horizontal interface spring elements was lowered. That is because the masonry plate was allowed to slip more over the surface of the concrete while less shear stresses were transferred to the concrete abutment. The average decrease of concrete shear stresses in conjunction with average decrease of the shear stresses transferred through the interface zone for the axisymmetric and the plane strain solution methods were listed in table $(7.8 . a)$ and $(7.8 . b)$ respectively. Shear stress distribution curves for the different shear transfer conditions in the axisymmetric solution are shown in fig. (7.12). Generally speaking, the shear stress 


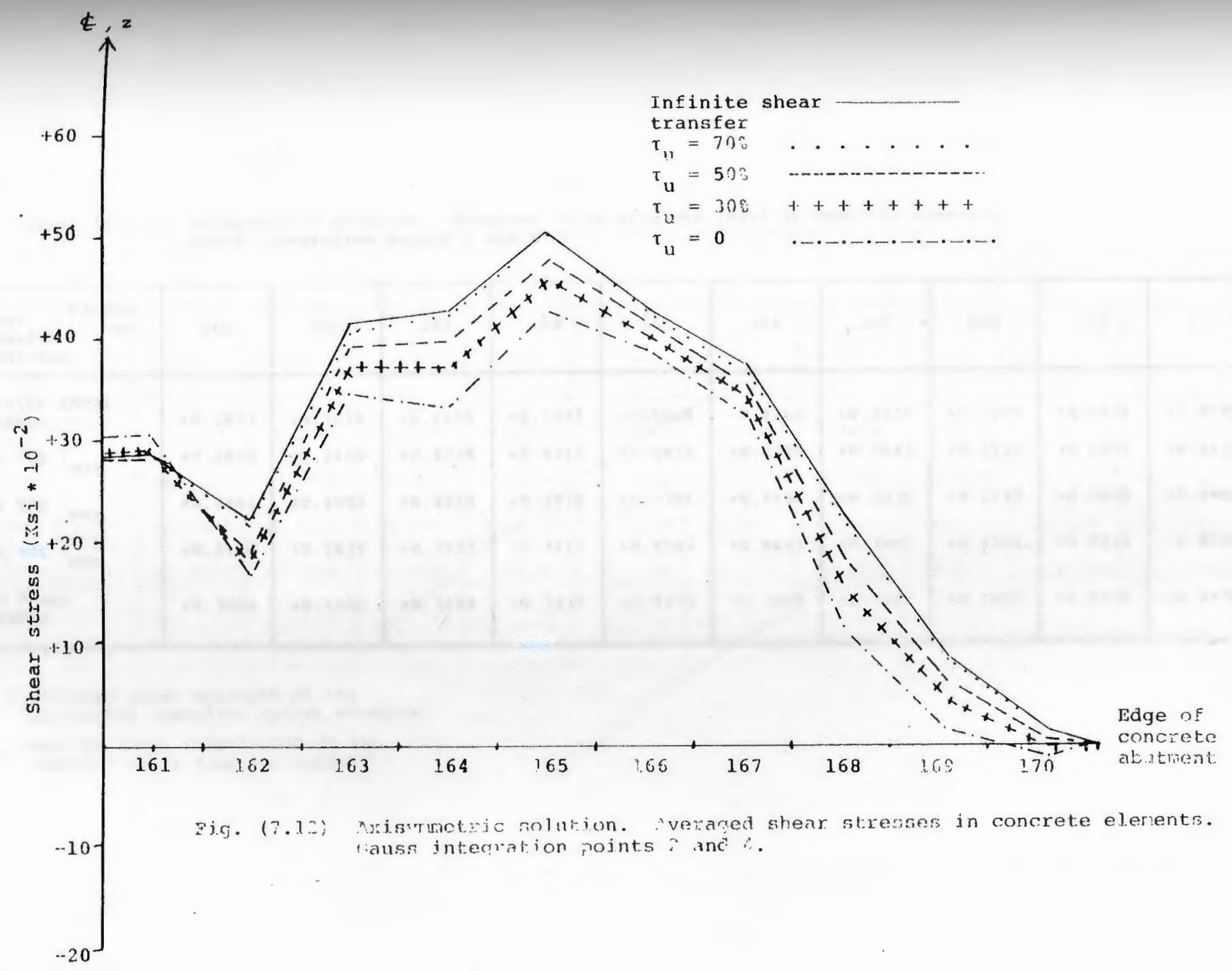


Table (7.7.a) Axisymmetric solution. Averaned shear stresses (Ksi) in concrete elements. Gauss integration points 2 and 4 .

\begin{tabular}{|c|c|c|c|c|c|c|c|c|c|c|}
\hline $\begin{array}{l}\text { Shear } \\
\text { transfer nomt } \\
\text { condition }\end{array}$ & .161 & 162 & 163 & 164 & 165 & 166 & 167 & 168 & 169 & 170 \\
\hline $\begin{array}{l}\text { Infinite shear } \\
\text { transfer }\end{array}$ & +0.2873 & +0.2216 & +0.4155 & +0.4271 & +0.5028 & +0.4262 & +0.3719 & +0.2200 & +0.0878 & +0.0145 \\
\hline$\tau_{u}=708 \tau_{\max }$ & +0.2878 & +0.2160 & +0.4074 & +0.4214 & +0.5014 & +0.4245 & +0.3641 & +0.2127 & +0.0842 & +0.0133 \\
\hline$\tau_{u}=508 \tau_{\max }$ & +0.2842 & +0.1903 & +0.3919 & +0.3978 & +0.4791 & +0.4140 & +0.3535 & +0.1792 & +0.0635 & +0.0053 \\
\hline$\tau_{u}=308 \tau_{\max }$ & +0.2907 & +0.1835 & +0.3737 & +0.3717 & +0.4583 & +0.4027 & +0.3402 & +0.1501 & +0.0448 & -0.0018 \\
\hline $\begin{array}{l}\text { Zero shear } \\
\text { transfer }\end{array}$ & +0.3056 & +0.1668 & +0.3454 & +0.3337 & +0.4276 & +0.3864 & +0.3207 & +0.1075 & +0.0139 & -0.0116 \\
\hline
\end{tabular}

$T_{u}=$ ultimate shear strength of the

horizontal interface spring elements.

$\tau_{\max }=$ maximum shear transferred in the

infinite shear transfer condition. 
Table (7.7.b) Plane strain solution. Averaged shear stresses (Ksi) in concrete elements. Gauss integration points 2 and 4 .

\begin{tabular}{|c|c|c|c|c|c|c|c|c|c|c|}
\hline $\begin{array}{l}\text { Shear Element } \\
\text { transfer no. } \\
\text { condition }\end{array}$ & 161 & 162 & 163 & 164 & 165 & 166 & 167 & 168 & 169 & 170 \\
\hline $\begin{array}{l}\text { Infinite shear } \\
\text { transfer }\end{array}$ & +0.1637 & +0.2549 & +0.5494 & +0.5724 & +0.7110 & +0.6179 & +0.5631 & +0.3224 & +0.1295 & +0.0139 \\
\hline$\tau_{u}=70 \% \tau_{\max }$ & +0.1638 & +0.2532 & +0.5424 & +0.5677 & +0.7108 & +0.6153 & +0.5506 & +0.3144 & +0.1258 & +0.0125 \\
\hline$\tau_{u}=508 \tau_{\max }$ & +0.1524 & +0.2227 & +0.5218 & +0.5373 & +0.6736 & +0.5883 & +0.5213 & +0.2577 & +0.0840 & -0.0040 \\
\hline$\tau_{u}=30 \% \tau_{\max }$ & +0.1428 & +0.2046 & +0.4867 & +0.4944 & +0.6338 & +0.5575 & +0.4854 & +0.2072 & +0.0499 & -0.0172 \\
\hline $\begin{array}{l}\text { Zero shear } \\
\text { transfer }\end{array}$ & +0.1463 & +0.1737 & +0.4351 & +0.4324 & +0.5750 & +0.5119 & +0.4319 & +0.1317 & -0.0041 & -0.0337 \\
\hline
\end{tabular}


Table (7.8.a) Axisymmetric solution. Average decrease of concrete shear stresses in conjunction with the average decrease of shear stresses transferred through the interface zone.

\begin{tabular}{|l|c|c|}
\hline $\begin{array}{l}\text { Shear transfer } \\
\text { condition }\end{array}$ & $\begin{array}{l}\text { Average decrease in shear stresses } \\
\text { transferred through the interface } \\
\text { zone } \\
\tau_{u}=70 \% \tau_{\max }\end{array}$ & $\begin{array}{l}\text { Average decrease in } \\
\text { concrete shear stresses } \\
\text { so }\end{array}$ \\
$\tau_{u}=50 \% \tau_{\max }$ & 15.63 & 1.41 \\
$\tau_{u}=30 \% \tau_{\max }$ & 37.10 & 7.26 \\
$\tau_{u}=0$ & 88.75 & 12.13 \\
\hline
\end{tabular}

$\tau_{u}=u l t i m a t e$ shear strength in the horizontal interface spring elements.

$\tau_{\max }=$ maximum shear transferred in the infinite shear transfer condition. 
Table (7.8.b) Plane strain solution. Average decrease of concrete shear stresses in conjunction with the average decrease of shear stresses transferred through the interface zone.

\begin{tabular}{|l|l|l|}
\hline $\begin{array}{l}\text { Shear transfer } \\
\text { condition }\end{array}$ & $\begin{array}{l}\text { Average decrease in shear stresses } \\
\text { transferred through the interface } \\
\text { zone }\end{array}$ & $\begin{array}{l}\text { Average decrease in } \\
\text { concrete shear stresses } \\
\text { o }\end{array}$ \\
\hline$\tau_{\mathrm{u}}=70 \% \tau_{\max }$ & 4.07 & 1.07 \\
$\tau_{\mathrm{u}}=50 \% \tau_{\max }$ & 11.21 & 8.80 \\
$\tau_{\mathrm{u}}=30 \% \tau_{\max }$ & 31.81 & 16.75 \\
$\tau_{\mathrm{u}}=0$ & 80.74 & 28.17 \\
\hline
\end{tabular}

$\tau_{u}=$ ultimate shear strength in the horizontal interface spring elements.

$\tau_{\text {max }}=$ maximum shear transferred in the infinite shear transfer condition. 
distribution curves indicate that shear stresses drop with different slopes depending on the ultimate shear thength of the horizontal interface spring elements. For lower shear strength value, the shear stresses in concrete elements 161 and 162, see fig. (7.12) dropped with a steeper slope; however, the variation of the curve along the concrete elements became more consistent for the different shear transfer conditions, where at element no. 162, concrete shear stresses started to increase as positive bending stresses increased at the bottom steel elements of the masonry plate, see fig. (7.9.a) and (7.9.b). (Plane strain and axisymmetric solution methods showed similar behavior in all conditions.) Maximum shear stress in the concrete elements for all shear transfer conditions appeared in element no. 165, which is beneath the critical section in the masonry plate. Beyond concrete element no. 167, beneath the unloaded concrete surface, shear stresses dxopped very steeply.

It is worthwhile at this point to examine the effect of the variation in the concrete yield status resulting from different shear transfer conditions. The concrete has been modeled as an elastic-plastic model with strain hardening properties, see sec. (5.2), and was assumed to follow von Mises yield criterion, 
sec. (5.2.1), which considers the octahedral shearing stress as the key factor of causing the yield in the concrete. The yield status for concrete elements nos. 161 to 170 is presented in tables (7.9.a) and (7.9.b), resulting in the axisymmetric and plane strain solution methods, respectively. Notice that yield is defined as the point on the concrete stress - strain diagram where normal stresses and strains are in the elastic-plastic range in a uniaxial compression test. However, that is not exactly the case for the concrete abutment being considered in this study because of an internal lateral confining pressure coming from surrounding elements. Therefore, yield status shown in tables (7.9.a) and (7.9.b) does not really mean that concrete has actually yielded, but as mentioned above, it means that, based on the concrete material constants taken from a uniaxial compression and tension tests, see Appendix C (sec. (C.2)), concrete would have yielded at that level of stress. Thus, results indicated that as the shear stresses transferred through the interface zone decreased, concrete elements at the edge of the abutment would stay in the elastic range. Notice that this is consistent with the results of normal and shear stress distribution in the concrete elements. Whereas the shear stresses transferred through the interface zone decreased, normal compressive and shear stresses 
at the edge of the concrete abutment decreased as shown in figs. no. (7.11.a), (7.11.b) and (7.12). 
Table (7.9.a) Axisymmetric solution. Concrete yield status in different shear transfer conditions.

\begin{tabular}{|c|c|c|c|c|c|c|}
\hline \multicolumn{2}{|c|}{$\begin{array}{l}\text { Shear } \\
\text { transfer } \\
\text { condition }\end{array}$} & \multicolumn{5}{|c|}{ Concrete yield status } \\
\hline $\begin{array}{l}\text { Ele- } \\
\text { ment } \\
\text { no. }\end{array}$ & $\begin{array}{l}\text { Gauss } \\
\text { integ. } \\
\text { point }\end{array}$ & $\begin{array}{l}\text { Infinite } \\
\text { shear } \\
\text { transfer }\end{array}$ & $\begin{array}{r}\tau_{\mathrm{u}}=70 \% \\
\tau_{\max }\end{array}$ & $\begin{aligned} \tau & =50 \% \\
& \tau_{\max }\end{aligned}$ & $\begin{array}{r}\tau_{\mathrm{u}}=30 \% \\
\tau_{\max }\end{array}$ & $\tau_{u}=0$ \\
\hline 161 & $\begin{array}{l}2 \\
4\end{array}$ & plastic & plastic & plastic & plastic & plastic \\
\hline 162 & $\begin{array}{l}2 \\
4\end{array}$ & $"$ & $"$ & $"$ & $"$ & $"$ \\
\hline 163 & $\begin{array}{l}2 \\
4\end{array}$ & $"$ & $"$ & $"$ & $"$ & $"$ \\
\hline 164 & $\begin{array}{l}2 \\
4\end{array}$ & $"$ & $"$ & ": & $"$ & " \\
\hline 165 & $\begin{array}{l}2 \\
4\end{array}$ & $"$ & $"$ & $"$ & $"$ & $"$ \\
\hline 166 & $\begin{array}{l}2 \\
4\end{array}$ & $"$ & $"$ & $"$ & " & $"$ \\
\hline 167 & $\begin{array}{l}2 \\
4\end{array}$ & $"$ & $"$ & $"$ & $"$ & " \\
\hline 168 & $\begin{array}{l}2 \\
4\end{array}$ & $"$ & $"$ & $"$ & $"$ & elastic \\
\hline 169 & $\begin{array}{l}2 \\
4\end{array}$ & $"$ & $"$ & $"$ & elastic & $\begin{array}{l}\text { elastic } \\
\text { elastic }\end{array}$ \\
\hline 170 & $\begin{array}{l}2 \\
4\end{array}$ & $"$ & elastic & $\begin{array}{l}\text { elastic } \\
\text { elastic }\end{array}$ & $\begin{array}{l}\text { elastic } \\
\text { elastic }\end{array}$ & $\begin{array}{l}\text { elastic } \\
\text { elastic }\end{array}$ \\
\hline
\end{tabular}


Table (7.9.b) Plane strain solution. Concrete yield status in different shear transfer conditions.

\begin{tabular}{|c|c|c|c|c|c|c|}
\hline \multicolumn{2}{|c|}{$\begin{array}{l}\text { Shear } \\
\text { transfer } \\
\text { condition }\end{array}$} & \multicolumn{5}{|c|}{ Concrete yield status } \\
\hline $\begin{array}{l}\text { Ele- } \\
\text { ment } \\
\text { no. }\end{array}$ & $\begin{array}{l}\text { Gauss } \\
\text { integ. } \\
\text { point }\end{array}$ & $\begin{array}{l}\text { Infinite } \\
\text { shear } \\
\text { transfer }\end{array}$ & $\begin{array}{r}\tau_{\mathrm{u}}=70 \% \\
\tau_{\max } \\
\end{array}$ & $\begin{array}{r}{ }^{{ }_{u}}=50 \% \\
\tau_{\max }\end{array}$ & $\begin{array}{r}\tau_{\mathrm{u}}=30 \% \\
\tau_{\max }\end{array}$ & $\tau_{u}=0$ \\
\hline 161 & $\begin{array}{l}2 \\
4\end{array}$ & $\underset{"}{\text { plastic }}$ & $\underset{"}{\text { plastic }}$ & plastic & $\underset{*}{\text { plastic }}$ & $\underset{"}{\text { plastic }}$ \\
\hline 162 & $\begin{array}{l}2 \\
4\end{array}$ & $"$ & $"$ & " & $"$ & $"$ \\
\hline 163 & $\begin{array}{l}2 \\
4\end{array}$ & $"$ & $"$ & " & $"$ & $"$ \\
\hline 164 & $\begin{array}{l}2 \\
4\end{array}$ & $"$ & $"$ & $"$ & $"$ & " \\
\hline 165 & $\begin{array}{l}2 \\
4\end{array}$ & $"$ & " & $"$ & $"$ & $"$ \\
\hline 166 & $\begin{array}{l}2 \\
4\end{array}$ & " & $"$ & $"$ & $"$ & $"$ \\
\hline 167 & $\begin{array}{l}2 \\
4\end{array}$ & $"$ & $"$ & $"$ & $"$ & $"$ \\
\hline 168 & $\begin{array}{l}2 \\
4\end{array}$ & $"$ & $n$ & elastic & $"$ & elastic \\
\hline 169 & $\begin{array}{l}2 \\
4\end{array}$ & $"$ & $"$ & $\begin{array}{l}\text { elastic } \\
\text { elastic }\end{array}$ & $\begin{array}{l}\text { elastic } \\
\text { elastic }\end{array}$ & $\begin{array}{l}\text { elastic } \\
\text { elastic }\end{array}$ \\
\hline 170 & $\begin{array}{l}2 \\
4\end{array}$ & $\begin{array}{l}\text { elastic } \\
\text { elastic }\end{array}$ & $\begin{array}{l}\text { elastic } \\
\text { elastic }\end{array}$ & $\begin{array}{l}\text { elastic } \\
\text { elastic }\end{array}$ & $\begin{array}{l}\text { elastic } \\
\text { elastic }\end{array}$ & $\begin{array}{l}\text { elastic } \\
\text { plastic }\end{array}$ \\
\hline
\end{tabular}


CHAPTER 8

\section{SUMMARY AND CONCLUSIONS}

The standard procedure followed in practice for the design of the bearing system, is to assume that concrete stresses beneath the masonry plate have a uniform distribution. However, a previous finite element analysis of the bearing system has shown that there is in fact a little lateral distribution in concrete stresses beneath the masonry plate. It has also shown that bending stresses of opposite sign can result in the unloaded area of the masonry plate if tension forces can develop between the plate and the concrete, as might be the situation with anchor bolts. Therefore, the finite element analysis was carried out in this study to examine the effect of the shear transfer along the interface between the masonry plate and the concrete.

The anslysis conducted here is based on the assumption that shear stresses continue to be transferred along the interface zone until a certain ultimate shear strength is reached, then the bonds between the steel and concrete elements will break causing the masonry steel plate to slip over the surface of the concrete abutment. Vertical and horizontal interface spring elements were used to 
simulate the behavior of the interface with a nonlinear description of slip. The stiffnesses of the interface spring elements selected to represent varying shear transfer conditions, were based on trying different values and comparing outcoming results against those of the known infinite and zero shear transfer conditions. The ultimate shear strength value for the horizontal interface spring elements was randomly set to equal $70 \%, 50 \%$, and $30 \%$ of the maximum shear stress transferred through the horizontal spring elements in the infinite shear transfer condition. The analysis was carried out by using both axisymmetric and plane strain solution methods.

Results of the study show that:

1) The behavior of stresses and deformation of the bearing system was essentially the same in both the axisymmetric and the plane strain solution methods. However, the numerical difference in the results could be attributed to the displacement in the circumferential direction in the axisymmetric elements. Nevertheless, the axisymmetric solution represents a more realistic approximation of the actual threedimensional solid structure and shows that compression stresses in the concrete are not as high as anticipated in the previous finite element analysis of the bearing system. 
2) As the ultimate shear strength of the horizontal interface spring elements decreases, the masonry plate starts to slip increasingly and bend over the concrete abutment. Bending stresses in top of the bearing plate in the area beneath the uniformly applied load were not significantly affected by the slip. However, bending stresses increased greatly in the unloaded portion. Positive bending stresses increased in the masonry plate more significantly, however, negative bending stresses appeared in the masonry steel elements beneath the end of the pot bearing plate. Nevertheless, those negative bending stresses decreased as the masonry plate was permitted to slip. Therefore, it could be stated that bending stresses could change signs in the critical section of the masonry plate, if tension forces can develop between the plate and the concrete.

3). The increased bending in the plate resulting from the decrease of the shear stresses transferred through the interface, cause the compression stresses transferred to the concrete near the center of the abutment to increase, and to decrease in the area beyond where the load ends. This leads to the conclusion, at least for the geometry considered here, that the applied load is transferred to the concrete essentially by direct compression with little lateral distribution of load. 
It also results in significant bending action occurring at the end of the plate if it is permitted to deform. Hence, shear stresses transferred through the interface zone plate a restraining role against the bending action of the plates.

4) Shear stresses in the concrete decrease if less shear is transferred through the interface. However, it has been noticed that there has been no significant change in the concrete shear stress distribution, at least for the nonlinear slip function used in this study.

Examining the results from a practical viewpoint, they indicate the following:

1) In the case where the ultimate shear strength in the horizontal interface spring elements equals $70 \%$ of the maximum shear stress transferred in the infinite shear transfer condition, shear stresses transferred through the interface decreased, on the average, only about $5.75 \%$ in the axisymmetric solution, and about $4.07 \%$ in the plane strain solution. However, slip occurred in approximately $70 \%$ of the interface spring elements, representing $70 \%$ slip of the interface zone, $20 \%$ being in the full slip range in both solution methods. Physically, that represents a lot of slip for that low reduction in the shear stresses transferred in the interface. Therefore it might be concluded that interface spring elements with a shear strength value 
less than $70 \%$ would not be considered practical. Results from the case where $\tau_{u}=70 \% \tau_{\text {max' }}$ did not vary by much from the infinite shear transfer condition. Hence, when $\tau_{u}>70 \%$ ' max , the change in bearing stresses with respect to the infinite shear transfer condition will be practically insignificant.

2) The maximum bending stresses in the critical section of the masonry plate are considerably less than those obtained when assuming a uniform stress distribution beneath the plate. When analyzed as a circular plate with central constraint by assuming uniform stress distribution [22], resulting maximum bending stress at the critical section was equal to $15.12 \mathrm{Ksi}$ compared to $-2.56 \mathrm{ksi}$ resulting in the axisymmetric solution, table (7.5.a). When the free portion of the masonry plate was analyzed as a cantilever beam, resulting maximum bending stress at the critical section came out to be $-13.71 \mathrm{Ksi}$, compared to $-2.73 \mathrm{Ksi}$ in the plane strain solution, table (7.5.b).

Based on the above findings, it could be concluded, at least for the interface spring elements used in this study, that the effect of shear transfer in the interface zone does not have practical significance on the design of the bearing system. However, results indicated that the normal procedure followed in the design of pot 
bearings is too conservative. A circular or parabolic function representing the normal stress distribution in the concrete beneath the masonry plate could probably give a safe and more economical design than assuming uniform stress distribution. However, more research is needed to define an exact stress distribution function. Finally, results indicated that stresses in the concrete supporting structure are actually less than the resulting stresses from plane solution methods. Hence, failure level of the concrete is higher than anticipated due to existing lateral out-of-plane and in-plane confining pressure in the three-dimensional solid structure. 


\section{REFERENCES}

[ 11 "Standard Specifications for Highway Bridges" AASHTO, 12th Ed., 1977.

[2] McEwen, E. E. "Behavior of Masonry Bearing Plates", unpublished report at the University of Rhode Island, Kingston, December 1979.

[ 3 ] Chen, W. F. "Plasticity in Reinforced Concrete" McGraw-Hill, Inc., New York, lst Ed., 1982.

[4] Bathe, K. J., Wilson, E. L., Iding, R. H. "NONSAP A Structural Analysis Program for Static and Dynamic Response of Nonlinear Systems", University of California, Berkeley, Report No. UC SESM 74-3, February 1974.

[ 5 ] Holand, I., Bell, K.. (Editors), "Finite Element Methods in Stress Analysis", TAPIR, The Technical University of Norway, Trondheim-Norway, 2nd printing, 1970 .

[6] Cook, R. D. "Concepts and Applications of Finite Element Analysis", John Wiley and Sons, Inc., New York, 2nd Ed., 1974.

[ 7 ] Gallagher, R. H. "Finite Element Analysis Fundamentals", Prentice-Hall Inc., Englewood Cliffs, New Jersey, lst Ed., 1975.

[8] Cheung, Y. K., Yeo, M. F. "A Practical Introduction to Finite Element Analysis", Pitman Publishing Limited, 39 Parker St., London WC2B 5PB, lst Ed., 1979 . 
[9] Bathe, K. J., Wilson, E. I., Ozdemir, H. "Static and Dynamic Geometric and Nonlinear Analysis", University of California, Berkeley, Report No. UC SESM 74-4, February 1974.

[10] "Dixon Shortspan Bearings", (catalog) Spencer Dynamics Corporation, Promenade Street, Providence, RI, 02908, USA.

[11] "Steel Construction Manual", American Institute of Steel Construction, Inc., 8th Ed., pp. (2-47)-(2-49).

[12] Zienkiewicz, O. C. "The Finite Element Method", McGraw-Hill, Inc., New York, 3rd Ed., 1977.

[13] "Elastomeric Bearings Design, Construction and Materials", National Cooperative Highway Research Program, Report No. 248, University of Washington, Seattle, Washington, August 1982.

[14] Wang, C., Salmon, C. G. "Reinforced Concrete Design", Harper and Row, Inc., New York, 3rd Ed., 1979 .

[15] Goodman, R. E., Taylor, R., Brekke, T. L. "A Model for the Mechanics of Jointed Rock", Journal of Soil Mechanics and Foundations Division, ASCE, vol. 94, No. SM3, Proc. paper 5937, May 1968, pp. 637-659.

[16] Ngo, D., Scordelis, A. C. "Finite Element Analysis of Reinforced Concrete Beams", Journal of American Concrete Institute, Title No. 64-14, March 1967 , pp. 152-163.

[17] Ghaboussi, J., Wilson, E. L., Isenberg, J. "Finite Element for Rock Joints and Interfaces", Journal of Soil Mechanics and Foundations Division, ASCE, vol. 99, No. SMl0, Proc. paper 10095, October 1973, pp. 833-847. 
[18] Gudehus, G. (Ed.), "Finite Element in Geomechanics", John Wiley and Sons, Inc., New York, lst Ed., 1977 Chapter 10.

[19] Schafer, H. "A Contribution to the Solution of Contact Problems with the Aid of Bond Elements", Computer Methods in Applied Mechanics and Engineering 6, North Holland Publishing Company, February 20, 1975, pp. 335-353.

[20] Buragohain, D. N., Shah, V. I. "Curved Interface Elements for Interaction Problems", Journal of the Structural Division, ASCE, Vol. 104 No. Stl, January 1978, pp. 205-209.

[21] Buragohain, D. N., Shah, V. I. "Curved Interface Elements for Interaction Problems", Proceedings, International Symposium on Soil-Structure Interaction, University of Roorkee, Roorkee, India, January 1977, pp. 197-201.

[22] Alexander, B. "Practical Stress Analysis Engineering Design", Marcel Dekker Inc., New York and Basel, lst Ed., 1982 . 
193

APPENDIX 


\section{APPENDIX A}

\section{A.I FORMULATION OF THE LINKAGE ELEMENT} BY NGO AND SCORDELIS

For the linkage element shown in fig. (5.3), let the springs in elements local axes $\mathrm{H}$ and $\mathrm{V}$ have the stiffness $\mathrm{K}_{\mathrm{H}}$ and $\mathrm{K}_{\mathrm{V}}$ respectively.

The stress - strain relation is given by:

$$
\left\{\begin{array}{c}
\sigma_{H} \\
\sigma_{V}
\end{array}\right\}=\left[\begin{array}{cc}
\mathrm{K}_{\mathrm{H}} & 0 \\
0 & \mathrm{~K}_{\mathrm{V}}
\end{array}\right]\left\{\begin{array}{l}
\varepsilon_{\mathrm{H}} \\
\varepsilon_{\mathrm{V}}
\end{array}\right\}
$$

where $\varepsilon_{H}$ and $\varepsilon_{V}$ are the components of the relative strain in the spring connecting points $I$ and $J . \sigma_{H}$ and $\sigma_{\mathrm{V}}$ are the corresponding stress components. Note that the strain components are shown in the elements local coordinates and they are positive when the spring connecting points $I$ and $J$ is in tension.

Rewriting (A.I) symbolically:

$$
\left\{\sigma^{L}\right\}=\left[K^{L}\right] \quad\left\{\varepsilon^{L}\right\}
$$

where $\sigma^{L}$ and $\varepsilon^{L}$ are the springs stress and strain components written in local coordinates, and $\left[\mathrm{K}^{L}\right]$ is the spring's stiffness matrix in local coordinates. 
However, if the spring's stiffness matrix is to be added to the structure stiffness matrix, it has to be transferred into global coordinates.

Let the transformation matrix, [A], relate the strains and displacements as such,

$$
\left\{\varepsilon^{L}\right\}=[A]\left\{\delta^{G}\right\}
$$

where $\delta^{G}$ are displacements of joints $I$ and $J$ written in global coordinates.

Substituting (A.3) in (A.2),

$$
\left\{\sigma^{L}\right\}=\left[K^{L}\right][A]\left\{\delta^{G}\right\}
$$

The transformation matrix [A] is an orthogonal matrix by definition, therefore its transpose equals its inverse.

Multiplying [A] transpose, by both sides of (A.4),

$$
[A]^{T}\left\{\sigma^{L}\right\}=[A]^{T}\left[K^{L}\right][A]\left\{\delta^{G}\right\}
$$

but

$$
\left\{\sigma^{G}\right\}=[A]^{T}\left\{\sigma^{L}\right\}
$$

where $\sigma^{G}$ are the stresses at nodes $I$ and $J$ written in global coordinates. 
Rewriting (A.5),

$\left\{\sigma^{G}\right\}=[A]^{T}\left[K^{L}\right][A]\left\{\delta^{G}\right\}$

However, the element stress - strain relation in global coordinates is

$\left\{\sigma^{G}\right\}=\left[K^{G}\right] \quad\left\{\delta^{G}\right\}$

where $\left[\mathrm{K}^{\mathrm{G}}\right]$ is the global stress - strain relation.

By comparing matrices of equations (A.7) and (A.8), it must be concluded that the global stiffness matrix for the linkage element is defined as

$\left[K^{G}\right]=[A]^{T}\left[K^{L}\right][A]$

or

$\left[K^{G}\right]=\left[\begin{array}{cc}-C & s \\ -s & -C \\ c & -s \\ s & c\end{array}\right]\left[\begin{array}{cc}K_{H} & 0 \\ 0 & K_{V}\end{array}\right]\left[\begin{array}{cccc}-c & -s & c & s \\ s & -C & -s & c\end{array}\right]$

The linkage element global stiffness matrix is shown in table (A. 1).

Note that in this element formulation a linear stress - strain relation was assumed to describe the relationship between bond slip and bond stress, see 
Table (A.1) Linkage element's global stiffness matrix

$$
\left[\begin{array}{cccc}
K_{H} c^{2}+K_{V} s^{2} & K_{H} s c-K_{V} s c & -K_{H} c^{2}-K_{V} s^{2} & -K_{H} s c+K_{V} s c \\
& K_{H} s^{2}+K_{V} c^{2} & -K_{H} s c+K_{V} s c & -K_{H} s^{2}-K_{V} c^{2} \\
\text { symmetric } & & K_{H} c^{2}+K_{V} s^{2} & K_{H} s c-K_{V} s c \\
& & & K_{H} s^{2}+K_{V} c^{2}
\end{array}\right]
$$


equations (A.2) and (A.8). It was suggested here that $\mathrm{K}_{\mathrm{H}}$ and $\mathrm{K}_{\mathrm{V}}$ values are not easily determined but they could be found experimentally. 


\section{A.2 FORMULATION OF THE TWO-DIMENSIONAL INTERFACE} ELEMENT BY GHABOUSSI, WILSON AND ISENBERG

\section{A.2.1 PLANE INTERFACE ELEMENT}

The interface element uses relative displacements as the independent degrees of freedom. The displacement degrees of freedom adjacent to the interface have been transformed in the top continuum element into relative displacements between the two sides of the slip surface. The transformation relations are as follows:

$u_{y i}^{T}=u_{y \ell}^{B}+\Delta_{y i}$

$u_{z i}^{T}=u_{z l}^{B}+\Delta_{z i}$

$u_{y j}^{T}=u_{y k}^{B}+\Delta_{y j}$

$u_{z j}^{T}=u_{z k}^{B}+\Delta_{z j}$

where $\Delta$ 's represent relative displacements, and $\mathrm{u}^{\mathrm{T}}$ 's and $u^{B}$ 's represent nodal displacements of the top and bottom continuum elements, respectively, following the notation shown in fig. (A.I).

To avoid numerical difficulties, the element stiffness was formulated in the element's local coordinates and then was transformed into global coordinates, see fig. (A.2). The element thickness, h, is small relative to the size of the continuum elements, therefore, the relative displacement is considered 


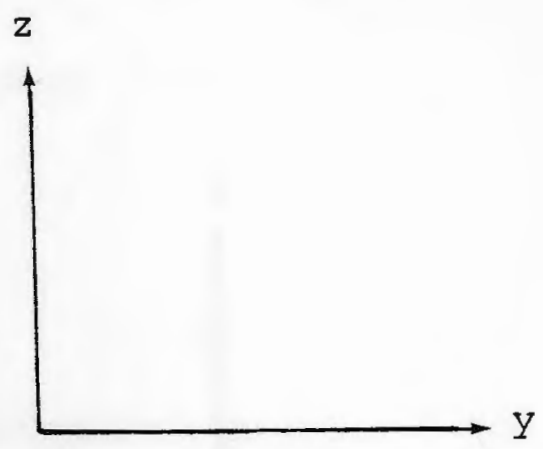

Global coordinates

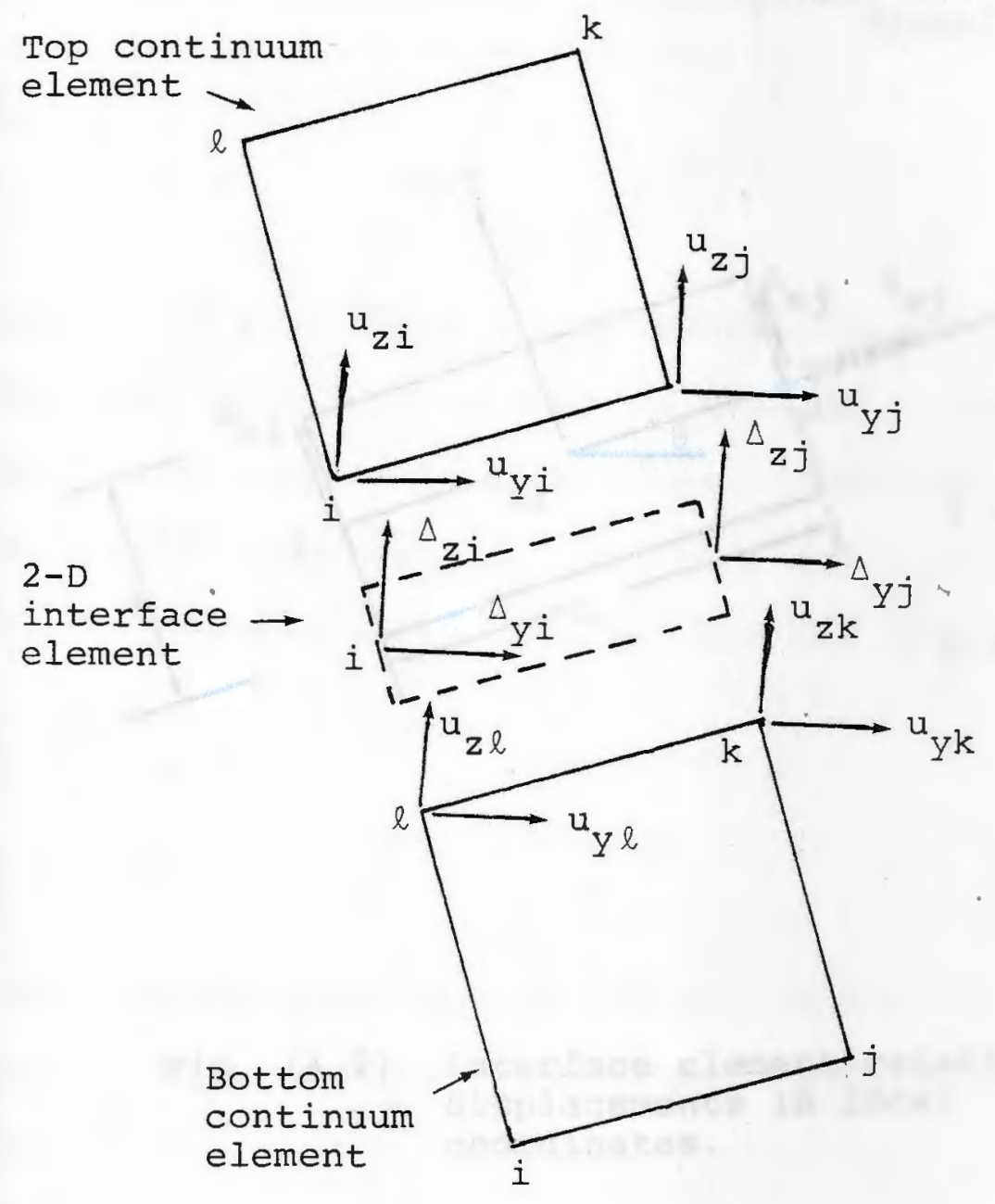

Fig. (A.1) Geometry of the 2-D interface element. 
201
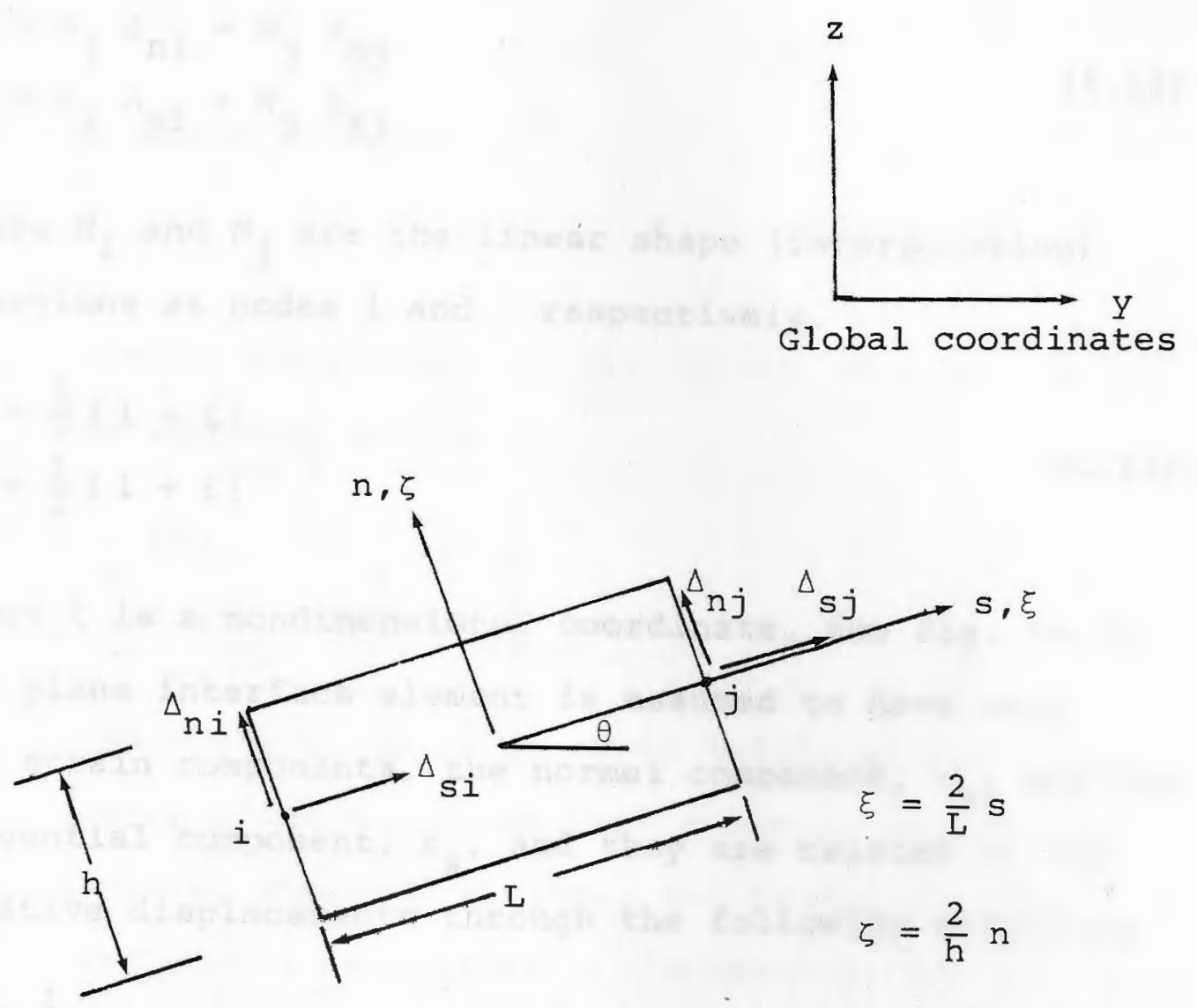

Fig. (A.2) Interface element relative displacements in local coordinates. 
constant across the thickness. However, the normal and tangential displacements, $\Delta_{n}$ and $\Delta_{s}$ are considered to vary linearly along the elements as follows:

$\Delta_{n}=N_{i} \Delta_{n i}+N_{j} \Delta_{n j}$

$\Delta_{s}=N_{i} \Delta_{s i}+N_{j} \Delta_{s j}$

where $\mathrm{N}_{i}$ and $\mathrm{N}_{j}$ are the linear shape (interpolation) functions at nodes $i$ and $j$ respectively.

$\mathrm{N}_{i}=\frac{1}{2}(1-\xi)$

$\mathrm{N}_{j}=\frac{1}{2}(1+\xi)$

where $\xi$ is a nondimensional coordinate, see fig. (A.2). The plane interface element is assumed to have only two strain components, the normal component, $\varepsilon_{n}$, and the tangential component, $\varepsilon_{S}$, and they are related to the relative displacements through the following relations:

$$
\begin{aligned}
& \varepsilon_{n}=\frac{1}{h} \Delta_{n} \\
& \varepsilon_{s}=\frac{1}{h} \Delta_{s}
\end{aligned}
$$

Substituting equations (A.12) and (A.13) in (A.14) results in the strain-displacement relations for the element: 
$\left\{\begin{array}{l}\varepsilon_{n} \\ \varepsilon_{s}\end{array}\right\}=\frac{1}{2 h}\left[\begin{array}{cccc}(1-\xi) & 0 & (1+\xi) & 0 \\ 0 & (1-\xi) & 0 & (1+\xi)\end{array}\right]\left\{\begin{array}{c}\Delta_{n i} \\ \Delta_{s i} \\ \Delta_{n j} \\ \Delta_{s j}\end{array}\right\}$ (A.15)

written symbolically as

$\{\varepsilon\}=[B]\{\Delta\}$

The stresses are related to the strains through the material property matrix [C],

$$
\left\{\begin{array}{c}
\sigma_{n} \\
\sigma_{s}
\end{array}\right\}=\left[\begin{array}{cc}
c_{n n} & 0 \\
0 & c_{s s}
\end{array}\right]\left\{\begin{array}{c}
\varepsilon_{n} \\
\varepsilon_{s}
\end{array}\right\}
$$

Notice that the material property matrix represents a nondilatant element meaning that there is no volume change due to shearing strains, and therefore, the shear and normal components of deformation are uncoupled. $C_{n n}$ and $C_{s s}$ are nonlinear functions. In relating stress to deformation in the direction normal to the element, three distinct stages are defined, refer to fig. (5.6.a).

1) Separation, $C_{n n}=C_{s s}=0$ when $\varepsilon_{n} \geq 0$.

2) Crushing of the surface irregularities, if any, $C_{n n}=E_{C}\left(\varepsilon_{n}^{C}<\varepsilon_{n}<0\right)$.

3) Contact, $C_{n n}=E_{f}\left(\varepsilon_{n}<\varepsilon_{n}^{c}\right)$. 
The tangential stress - strain relationship is assumed to be elastic-perfectly plastic using a Mohr-Coulomb yield criterion, [3], refer to fig. $(5.6 . b)$ :

$C_{\text {SS }}=\mathrm{G}$ for $\sigma_{\mathrm{S}}<\mathrm{c}+\sigma_{\mathrm{n}} \tan \phi \quad$ (elastic)

$c_{s s}=0$ for $\sigma_{s}=c+\sigma_{n} \tan \phi \quad$ (plastic, $\sigma_{s}$ has reached the ultimate shear strength)

where $G$ is the interface element shear stiffness, and $c$ and $\phi$ are the cohesion and the angle of friction, respectively.

The element stiffness matrix in the local coordinates $(s, n)$ is formed as follows:

$$
\left[\mathrm{K}^{\mathrm{L}}\right]=\int_{\mathrm{VOl}}[\mathrm{B}]^{\mathrm{T}}[\mathrm{C}][\mathrm{B}] \mathrm{d}_{\mathrm{VOl}}
$$

The global element stiffness matrix is:

$$
\left[K^{G}\right]=[T]^{T}\left[K^{L}\right][T]
$$

where [T] is the transformation matrix containing the direction cosines.

The complete global element stiffness matrix for a nondilatant material is shown in table (A.2). 
Table (A.2) Plane interface element global stiffness matrix for nondilatant materials.

$\frac{\mathrm{L}}{6 \mathrm{~h}}\left[\begin{array}{cccc}2 \mathrm{~A}_{1} & 2 \mathrm{~A}_{3} & \mathrm{~A}_{1} & \mathrm{~A}_{3} \\ & 2 \mathrm{~A}_{2} & \mathrm{~A}_{3} & \mathrm{~A}_{2} \\ & & 2 \mathrm{~A}_{1} & 2 \mathrm{~A}_{3} \\ \text { symmetric } & & 2 \mathrm{~A}_{2}\end{array}\right]$

$$
\text { where } \begin{array}{rlrl}
A_{1} & =C_{s s} a^{2}+C_{n n} b^{2} \quad \text { and } a=\frac{1}{L}\left(y_{j}-y_{i}\right) \\
A_{2} & =C_{n n} a^{2}+C_{s s} b^{2} & b & =\frac{1}{L}\left(z_{j}-z_{i}\right) \\
A_{3} & =\left(C_{n n}-C_{s s}\right) a b & &
\end{array}
$$




\section{A.2.2 AXISYMMETRIC INTERFACE ELEMENT}

A similar joint element has been developed for axisymmetric problems, where the integration in equation (A.18) is carried out over the volume of the axisymmetric element, which includes the circumferential direction also.

The geometry and the independent degrees of freedom for the axisymmetric element are exactly as shown in fig. (A.1) and fig. (A.2), except that the global y-axis is substituted by the global radial $r$-axis. However, the strain displacement relation now involves three equations:

$$
\begin{aligned}
& \varepsilon_{\mathrm{n}}=\frac{1}{h} \Delta_{\mathrm{n}} \\
& \varepsilon_{s}=\frac{1}{h} \Delta_{s} \\
& \varepsilon_{\theta}=\frac{1}{r}\left(u_{r}^{B}+\frac{\Delta_{r}}{2}\right)
\end{aligned}
$$

where $\varepsilon_{\theta}$ is the circumferential strain component and $u_{r}^{B}$ is the radial displacement of the surface of the bottom elements as shown in fig. (A.1).

The axisymmetric displacement functions are defined as:

$$
\begin{aligned}
& \Delta_{r}=N_{1} \Delta_{r i}+N_{2} \Delta_{r j} \\
& \Delta_{z}=N_{1} \Delta_{z i}+N_{2} \Delta_{z j} \\
& u_{r}^{B}=N_{1} u_{r i}^{B}+N_{2} u_{r j}^{B}
\end{aligned}
$$


The strain-displacement may be expressed as:

$$
\left\langle\begin{array}{c}
\varepsilon_{n} \\
\varepsilon_{s} \\
\varepsilon_{\theta}
\end{array}\right\}=[B]\left\{\begin{array}{c}
\Delta_{r i} \\
\Delta_{z i} \\
\Delta_{r j} \\
\Delta_{z j} \\
u_{r i}^{B} \\
u_{r j}^{B}
\end{array}\right\}
$$

where $[B]$ is shown in table (A.3).

The stress-strain relation is defined as:

$$
\left\{\begin{array}{c}
\sigma_{n} \\
\sigma_{s} \\
\sigma_{\theta}
\end{array}\right\}=\left[\begin{array}{ccc}
c_{n n} & 0 & 0 \\
0 & c_{s s} & 0 \\
0 & 0 & c_{\theta \theta}
\end{array}\right]\left\{\begin{array}{c}
\varepsilon_{n} \\
\varepsilon_{s} \\
\varepsilon_{\theta}
\end{array}\right\}
$$

where $C_{n n}$ and $C_{S s}$ are defined as in equation (A.17), and $\mathrm{C}_{\theta \theta}$ is added to account for the stress and strain components in the $\theta$ direction, but its physical meaning is not clear and is assumed to equal zero. The global stiffness matrix for the axisymmetric element is shown in table (A.4). For more details see the source $[17,18]$. 
Table (A.3) [B] matrix in the axisymmetric element strain-displacement relation.

$\frac{1}{2}\left[\begin{array}{ccccc}-\frac{s}{h}(1-\xi) & \frac{c}{h}(1-\xi) & -\frac{s}{h}(1+\xi) & \frac{c}{t}(1+\xi) & 0 \\ \frac{c}{h}(1-\xi) & \frac{s}{h}(1-\xi) & \frac{c}{h}(1+\xi) & \frac{s}{t}(1+\xi) & 0 \\ \frac{1-\xi}{2 r_{i}} & 0 & \frac{1+\xi}{2 r_{j}} & 0 & \frac{1-\xi}{r_{i}}\end{array}\right]$

where $\mathbf{s}=\sin \theta$ and $\mathbf{c}=\cos \theta$. 
Table (A.4) Axisymmetric interface element global stiffness matrix or nondilatant material.

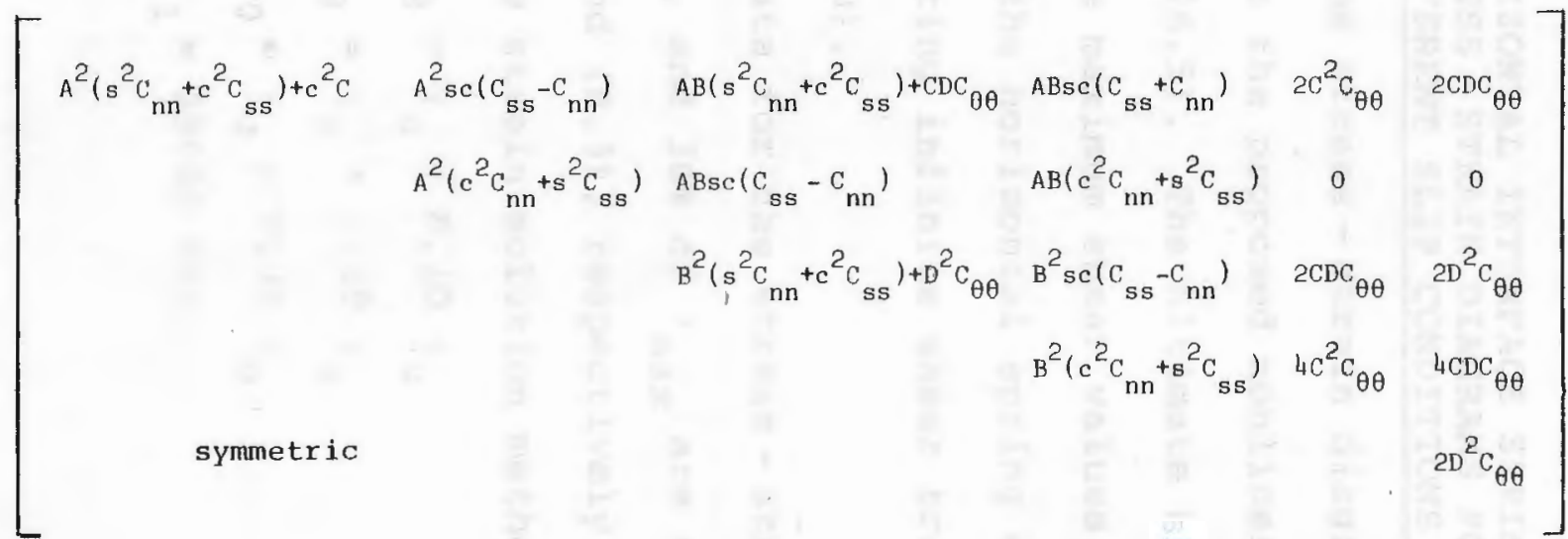

$$
\begin{aligned}
& \text { where } A^{2}=\frac{L}{3 h^{2}}\left(r_{j}-3 r_{i}\right) \text { and } c^{2}=\frac{L}{2\left(r_{j}-r_{i}\right)^{2}}\left(r_{i}-3 r_{j}\right)+\frac{2 r_{j}^{2}}{r_{j}-r_{i}} \log \left(\frac{r_{j}}{r_{i}}\right) \\
& B^{2}=-\frac{L}{3 h^{2}}\left(3 r_{j}-r_{i}\right) \quad D^{2}=\frac{L}{2\left(r_{j}-r_{i}\right)^{2}}\left(r_{j}-3 r_{i}\right)+\frac{2 r_{i}^{2}}{r_{j}-r_{i}} \log \left(\frac{r_{j}}{r_{i}}\right) \\
& A B=\frac{L}{3 h^{2}}\left(r_{i}+r_{j}\right) \quad C D=\frac{L}{2\left(r_{j}-r_{i}\right)^{2}} r_{j}+r_{i}-\frac{r_{j} r_{1}}{r_{j}-r_{i}} \log \left(\frac{r_{j}}{r_{i}}\right)
\end{aligned}
$$




\section{APPENDIX B}

B.1 HORIZONTAL INTERFACE SPRING ELEMENT STRESS - STRAIN DIAGRAMS FOR THE DIFFERENT SLIP CONDITIONS

The stress - strain diagram, shown in fig. (B.1), describes the proposed nonlinear slip relation presented in sec. $(6.5)$. The ultimate shear strength, $\tau_{u}$, equals $x \%$ of the maximum shear values, $\tau_{\text {max }}$ ' transferred through the horizontal spring elements in the model representing infinite shear transfer condition (no slip condition).

Data for the stress - strain relation assuming $\tau_{u}$ $70 \%, 50 \%$, and $30 \%$ of $\tau_{\max }$ are shown in tables (B.I), (B.2), and (B.3), respectively, for both axisymmetric and plane strain solution methods, where

$$
\begin{aligned}
& \tau_{8}=\tau_{u}+0.10 \tau_{u} \\
& \tau_{9}=\tau_{u}+0.20 \tau_{u} \\
& \tau_{10}=\tau_{u}+0.30 \tau_{u} \\
& \tau_{11}=29000 \mathrm{Ksi} .
\end{aligned}
$$




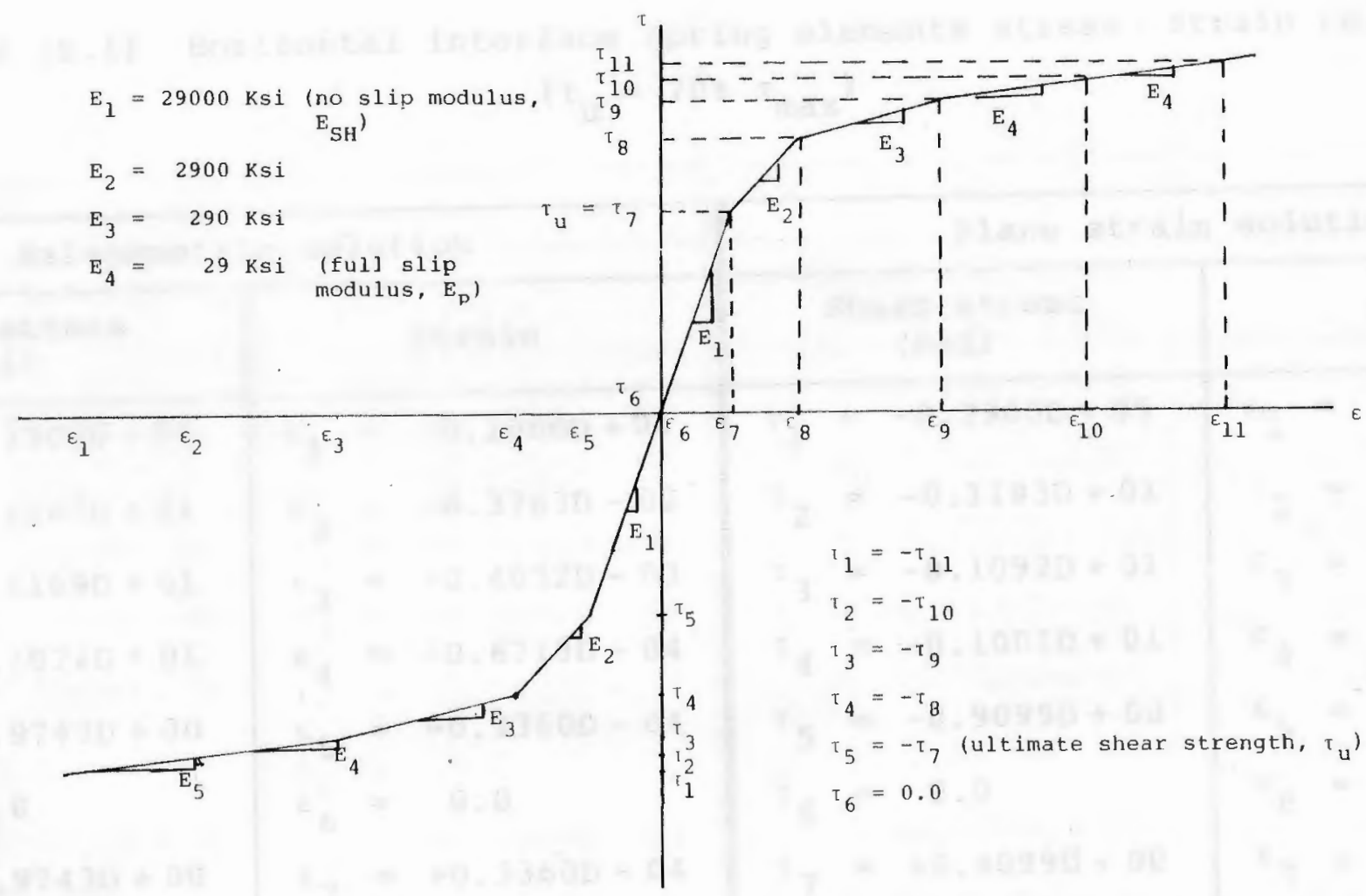

Fig. (B.1) Horizontal interface spring elements stress - strain diagram (not to scale), 
Table (B.1) Horizontal interface spring elements stress - strain relation

$$
\left(\tau_{\mathrm{u}}=70 \% \tau_{\max }\right)
$$

\begin{tabular}{|c|c|c|c|c|c|c|}
\hline \multicolumn{4}{|c|}{ Axisymmetric solution } & \multicolumn{3}{|c|}{ Plane strain solution } \\
\hline & $\begin{array}{l}\text { Shear stress } \\
\text { (Ksi) }\end{array}$ & & strain & $\begin{array}{l}\text { Shear stress } \\
\text { (Ksi) }\end{array}$ & & Strain \\
\hline $\mathrm{\tau}_{1}$ & $=-0.2900 \mathrm{D}+05$ & $\varepsilon_{1}=$ & $-0.1000 \mathrm{D}+04$ & $\tau_{1}=-0.2900 \mathrm{D}+05$ & $\varepsilon_{1}=$ & $-0.1000 \mathrm{D}+04$ \\
\hline${ }^{\tau} 2$ & $=-0.1267 \mathrm{D}+01$ & $\varepsilon_{2}=$ & $-0.3763 D-02$ & $\tau_{2}=-0.1183 \mathrm{D}+01$ & $\varepsilon_{2}=$ & $-0.3514 \mathrm{D}-02$ \\
\hline$\tau_{3}$ & $=-0.1169 \mathrm{D}+01$ & $\varepsilon_{3}=$ & $-0.4032 D-03$ & $\tau_{3}=-0.1092 \mathrm{D}+01$ & $\varepsilon_{3}=$ & $-0.3765 \mathrm{D}-03$ \\
\hline${ }^{\mathrm{\tau}} 4$ & $=-0.1072 \mathrm{D}+01$ & $\varepsilon_{4}=$ & $-0.6719 D-04$ & $\tau_{4}=-0.1001 \mathrm{D}+01$ & $\varepsilon_{4}=$ & $-0.6275 \mathrm{D}-04$ \\
\hline$\tau_{5}$ & $=-0.9743 \mathrm{D}+00$ & $\varepsilon_{5}=$ & $-0.3360 \mathrm{D}-04$ & $\tau_{5}=-0.9099 \mathrm{D}+00$ & $\varepsilon_{5}=$ & $-0.3138 \mathrm{D}-04$ \\
\hline & $=0.0$ & $\varepsilon_{6}=$ & 0.0 & $\tau_{6}=0.0$ & $\varepsilon_{6}=$ & 0.0 \\
\hline & $=+0.9743 \mathrm{D}+00$ & $\varepsilon_{7}=$ & $+0.3360 \mathrm{D}-04$ & $\tau_{7}=+0.9099 \mathrm{D}+00$ & $\varepsilon_{7}=$ & $+0.3138 \mathrm{D}-04$ \\
\hline${ }^{\tau} 8$ & $=+0.1072 \mathrm{D}+01$ & $\varepsilon_{8}=$ & $+0.6719 \mathrm{D}-04$ & ${ }^{\tau} 8=-0.1001 D+01$ & $\varepsilon_{8}=$ & $+0.6275 \mathrm{D}-04$ \\
\hline${ }^{\mathrm{\tau}} 9$ & $=+0.1169 D+01$ & $\varepsilon_{9}=$ & $+0.4032 \mathrm{D}-03$ & $\tau_{9}=+0.1092 \mathrm{D}+01$ & $\varepsilon_{9}=$ & $+0.3765 \mathrm{D}-03$ \\
\hline${ }^{\tau} 10$ & $=+0.1267 \mathrm{D}+01$ & $\varepsilon_{10}=$ & $+0.3763 \mathrm{D}-02$ & $\tau_{10}=+0.1183 \mathrm{D}+01$ & $\varepsilon_{10}=$ & $+0.3514 \mathrm{D}-02$ \\
\hline${ }^{\tau} 11$ & $=+0.2900 \mathrm{D}+05$ & $\varepsilon_{11}=$ & $+0.1000 \mathrm{D}+04$ & $\tau_{11}=+0.2900 \mathrm{D}+05$ & $\varepsilon_{11}=$ & $+0.1000 \mathrm{D}+04$ \\
\hline
\end{tabular}


Table (B.2) Horizontal interface spring elements stress - strain relation

$$
\left(\tau_{u}=50 \% \tau_{\max }\right)
$$

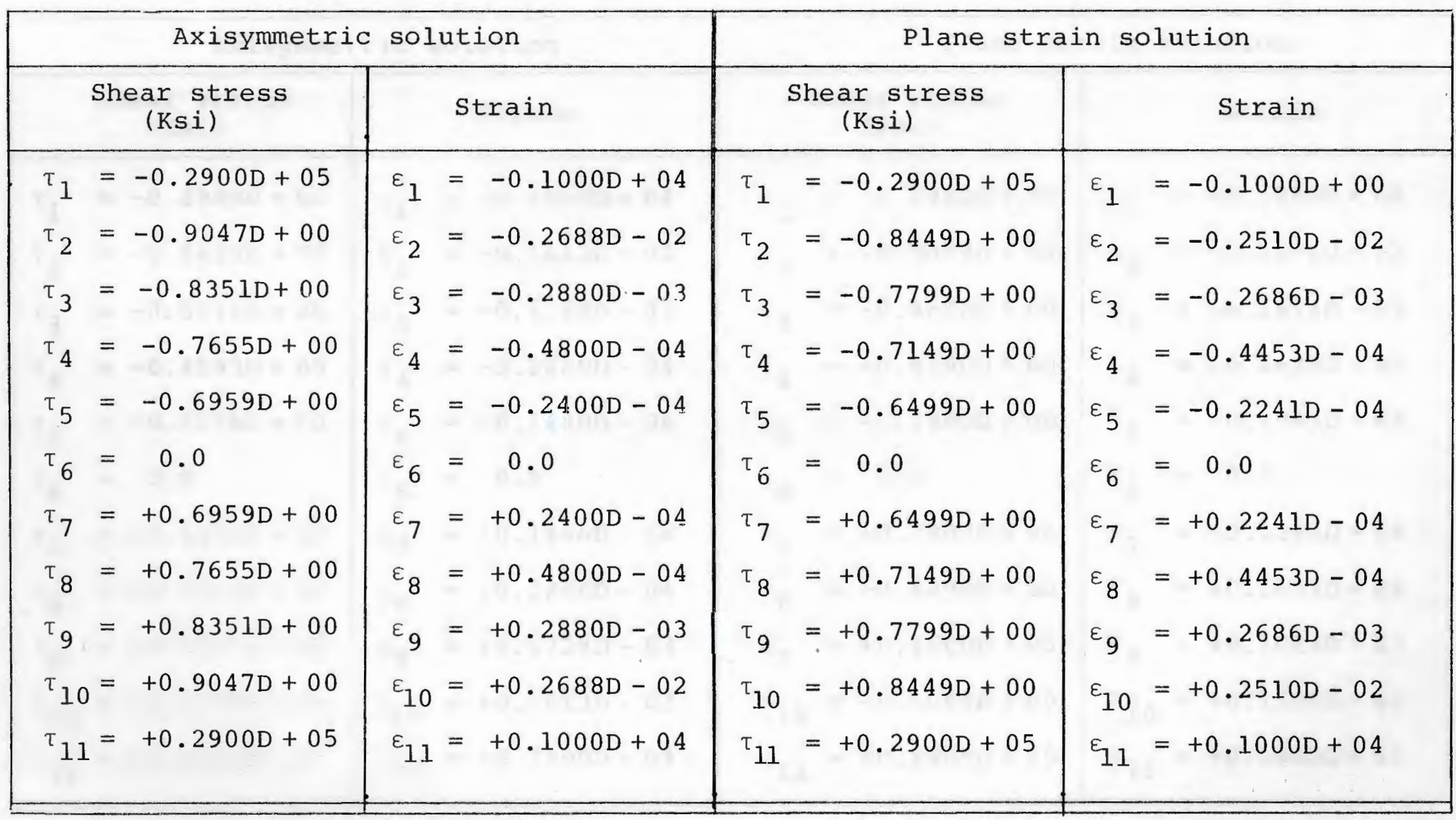


Table (B.3) Horizontal interface spring elements stress - strain relation

$$
\left(\tau_{u}=30 \% \tau_{\max }\right)
$$

\begin{tabular}{|c|c|c|c|c|c|c|c|c|c|c|c|}
\hline \multicolumn{5}{|c|}{ Axisymmetric solution } & \multicolumn{3}{|r|}{ Plane } & \multicolumn{2}{|c|}{ strain } & \multicolumn{2}{|c|}{ solution } \\
\hline & $\begin{array}{c}\text { Shear stress } \\
\text { (isi) }\end{array}$ & & & strain & & She & $\begin{array}{l}\text { ar stress } \\
(\mathrm{Ks} i)\end{array}$ & & & & Strain \\
\hline$\tau_{1}$ & $=-0.2900 D+05$ & $\varepsilon_{1}$ & $=$ & $-0.1000 D+04$ & $\tau_{1}$ & $=$ & $-0.2900 \mathrm{D}+0$ & & $\varepsilon_{1}$ & $=$ & $-0.1000 D+04$ \\
\hline$\tau_{2}$ & $=-0.5428 \mathrm{D}+00$ & $\varepsilon_{2}$ & $=$ & $-0.1613 D-02$ & $\tau_{2}$ & $=$ & $-0.5069 D+0$ & 00 & $\varepsilon_{2}$ & $=$ & $-0.1506 \mathrm{D}-02$ \\
\hline$\tau_{3}$ & $=-0.5011 D+00$ & $\varepsilon_{3}$ & $=$ & $-0.1728 D-03$ & $\tau_{3}$ & $=$ & $-0.4680 D+0$ & 00 & $\varepsilon_{3}$ & $=$ & $-0.1614 D-03$ \\
\hline$\tau_{4}$ & $=-0.4593 D+00$ & $\varepsilon_{4}$ & $=$ & $-0.2880 \mathrm{D}-04$ & $\tau_{4}$ & $=$ & $-0.4290 D+0$ & 00 & $\varepsilon_{4}$ & $=$ & $-0.2689 D-04$ \\
\hline$\tau_{5}$ & $=-0.4176 \mathrm{D}+00$ & $\varepsilon_{5}$ & $=$ & $-0.1440 D-04$ & ${ }^{\mathrm{T}} 5$ & $=$ & $-0.3900 \mathrm{D}+0$ & 00 & $\varepsilon_{5}$ & $=$ & $-0.1345 D-04$ \\
\hline$\tau_{6}$ & $=0.0$ & $\varepsilon_{6}$ & $=$ & 0.0 & $\tau_{6}$ & $=$ & 0.0 & & $\varepsilon_{6}$ & $=$ & 0.0 \\
\hline$\tau_{7}$ & $=+0.4176 D+00$ & $\varepsilon_{7}$ & & $+0.1440 D-04$ & $\tau_{7}$ & $=$ & $+0.3900 D+0$ & 00 & $\varepsilon_{7}$ & $=$ & $+0.1345 D-04$ \\
\hline$\tau_{8}$ & $=+0.4593 \mathrm{D}+00$ & $\varepsilon_{8}$ & & $+0.2880 D-04$ & ${ }^{\top} 8$ & $=-$ & $+0.4290 \mathrm{D}+0$ & 00 & $\varepsilon_{8}$ & $=$ & $+0.2689 D-04$ \\
\hline$\tau_{9}$ & $=+0.5011 \mathrm{D}+00$ & $\varepsilon_{9}$ & & $+0.1728 D-03$ & $\tau_{9}$ & $=-$ & $+0.4680 \mathrm{D}+0$ & 00 & $\varepsilon_{9}$ & $=$ & $+0.1614 \mathrm{D}-03$ \\
\hline${ }^{\mathrm{\tau}} 10$ & $=+0.5428 D+00$ & $\varepsilon_{10}$ & & $+0.1613 D-02$ & ${ }^{\tau} 10$ & $=-$ & $+0.5069 D+0$ & & ${ }^{\varepsilon} 10$ & $=$ & $+0.1506 \mathrm{D}-02$ \\
\hline$\tau_{11}$ & $=+0.2900 D+05$ & $\varepsilon_{11}$ & $=$ & $+0.1000 D+04$ & $\tau_{11}$ & $=$ & $+0.2900 \mathrm{D}+0$ & 05 & $\varepsilon_{11}$ & $=$ & $+0.1000 D+04$ \\
\hline
\end{tabular}


B.2 NORMAL STRESSES TRANSFERRED THROUGH THE VERTICAL SPRINGS

[zero shear transfer condition, interface spring elements not included, see model in fig. (4.6)].

Table (B.4)

\begin{tabular}{llc}
\hline $\begin{array}{l}\text { Element } \\
\text { number }\end{array}$ & $\begin{array}{l}\text { Axisymmetric solution } \\
\text { normal stress } \\
\text { (Ksi) }\end{array}$ & $\begin{array}{l}\text { Plane strain solution } \\
\text { normal stress } \\
\text { (Ksi) }\end{array}$ \\
\hline 49 & -1.167 & -6.162 \\
50 & -2.529 & -6.133 \\
51 & -2.293 & -6.006 \\
52 & -2.259 & -5.869 \\
53 & -2.174 & -5.626 \\
54 & -2.051 & -5.314 \\
55 & -1.880 & -4.900 \\
56 & -1.702 & -4.474 \\
57 & -1.516 & -3.993 \\
58 & -1.344 & -3.518 \\
59 & -1.142 & -2.963 \\
60 & -0.894 & -2.300 \\
61 & -0.603 & -1.479 \\
62 & -0.237 & -0.345 \\
\hline \hline
\end{tabular}


B.3 NORMAL STRESSES TRANSFERRED THROUGH THE INTERFACE SPRING ELEMENTS FOR DIFFERENT SHEAR TRANSFER CONDITIONS

[Model including vertical and horizontal interface spring elements, see fig. (4.7)]

Table (B.5.a) Axisymmetrical solution

\begin{tabular}{|c|c|c|c|c|c|}
\hline \multirow[b]{2}{*}{$\begin{array}{l}\text { Ele- } \\
\text { ment } \\
\text { No. }\end{array}$} & \multicolumn{5}{|c|}{ Shear transfer condition } \\
\hline & $\begin{array}{l}\text { Infinite } \\
\text { shear } \\
\text { transfer } \\
\text { normal } \\
\text { stress } \\
\text { (Ksi }\end{array}$ & $\begin{array}{l}\tau_{\mathrm{u}}=70 \% \tau_{\max } \\
\text { normal } \\
\text { stress } \\
(\text { Ksi) }\end{array}$ & $\begin{array}{l}\tau_{u}=50 \% \tau_{\max } \\
\text { normal } \\
\text { stress } \\
\text { (Ksi) }\end{array}$ & $\begin{array}{l}\tau_{\mathrm{u}}=30 \% \tau_{\max } \\
\text { normal } \\
\text { stress } \\
\text { (Ksi) }\end{array}$ & $\begin{array}{l}\tau_{\mathrm{u}}=0 \\
\text { normal } \\
\text { stress } \\
(\text { Ksi) }\end{array}$ \\
\hline 63 & -0.915 & -0.933 & -1.042 & -1.248 & -1.761 \\
\hline 64 & -5.361 & -5.791 & -6.845 & -5.568 & -4.708 \\
\hline 65 & -1.788 & -1.785 & -2.105 & -3.300 & -2.599 \\
\hline 66 & -4.679 & -4.025 & +3.784 & -1.817 & -4.262 \\
\hline 67 & -1.723 & -1.905 & -22.187 & -0.574 & -2.438 \\
\hline 68 & -4.832 & -1.697 & +31.958 & -1.491 & -5.065 \\
\hline 69 & -1.722 & -2.273 & -59.087 & +1.034 & -2.496 \\
\hline 70 & -4.550 & +3.542 & +70.720 & -41.590 & -5.829 \\
\hline 71 & -1.610 & -7.381 & +19.958 & +2.908 & -2.727 \\
\hline 72 & -4.427 & +15.750 & +50.946 & +1.403 & -6.962 \\
\hline 73 & -1.527 & -34.895 & +24.029 & +4.351 & -3.654 \\
\hline 74 & -4.032 & +38.064 & +46.323 & +2.393 & -8.129 \\
\hline 75 & -1.332 & -51.762 & +15.642 & +5.100 & -4.944 \\
\hline 76 & -3.686 & +58.717 & +40.820 & +3.145 & -9.457 \\
\hline 77 & -1.195 & -12.325 & +22.031 & +5.202 & -7.152 \\
\hline 78 & -3.243 & +62.942 & +35.728 & +3.248 & -10.579 \\
\hline 79 & -1.000 & -6.096 & +22.433 & +4.662 & -9.0239 \\
\hline 80 & -2.881 & +70.695 & +30.962 & +3.315 & -11.407 \\
\hline 81 & -0.892 & -5.617 & +19.140 & +3.924 & -10.460 \\
\hline 82 & -2.507 & +7.694 & +26.124 & +3.010 & -11.690 \\
\hline 83 & -0.727 & -2.671 & +16.311 & +3.152 & -11.180 \\
\hline 84 & -2.064 & +85.153 & +22.071 & +2.984 & -11.308 \\
\hline 85 & -0.547 & -5.530 & +3.736 & +1.683 & -12.223 \\
\hline 86 & -1.572 & +8.570 & +15.316 & +2.115 & -10.129 \\
\hline 87 & -0.367 & -35.947 & +1.405 & -15.321 & -11.986 \\
\hline 88 & -1.147 & +86.424 & +11.073 & +3.269 & -8.762 \\
\hline 89 & -0.319 & -30.019 & -0.883 & -16.605 & -10.738 \\
\hline 90 & -0.313 & +92.199 & +8.748 & +6.275 & -6.226 \\
\hline 91 & -2.382 & +87.26 & +6.027 & +13.576 & -21.039 \\
\hline
\end{tabular}

$\tau_{u}=$ horizontal spring element ultimate shear strength $\tau_{\max }=$ maximum shear stress transferred in the infinite shear transfer condition. 
Table (B.5.b) Plane strain solution

\begin{tabular}{|c|c|c|c|c|c|}
\hline \multirow[b]{2}{*}{$\begin{array}{c}\text { Ele } \\
\text { ment } \\
\text { No. }\end{array}$} & \multicolumn{5}{|c|}{ Shear transfer condition } \\
\hline & $\begin{array}{l}\text { Infinite } \\
\text { shear } \\
\text { transfer } \\
\text { normal } \\
\text { stress } \\
\text { (Ksi) }\end{array}$ & $\begin{array}{l}\tau_{\mathrm{u}}=70 \% \tau_{\max } \\
\text { normal } \\
\text { stress } \\
\text { (Ksi) }\end{array}$ & $\left\{\begin{array}{l}\tau_{\mathrm{u}}=50 \% \tau_{\max } \\
\text { normal } \\
\text { stress } \\
(\text { Ksi) }\end{array}\right.$ & $\mid \begin{array}{ll}\tau_{\mathrm{u}}=30 \% & \tau_{\max } \\
\text { normal } & \\
\text { stress } \\
(\text { Ksi })\end{array}$ & $\begin{array}{l}\tau_{u}=0 \\
\text { normal } \\
\text { stress } \\
(\mathrm{Ksi})\end{array}$ \\
\hline 63 & -1.364 & -1.369 & -1.416 & -1.550 & -1.999 \\
\hline 64 & -4.55 & -5.082 & -6.070 & -6.937 & -4.474 \\
\hline 65 & -1.722 & -1.726 & -1.733 & -17.891 & -2.576 \\
\hline 66 & -4.359 & -4.676 & -1.428 & +27.431 & -6.426 \\
\hline 67 & -1.580 & -1.875 & -6.758 & +0.858 & -3.925 \\
\hline 68 & -4.229 & -3.761 & +16.420 & +22.889 & -10.498 \\
\hline 69 & -1.552 & -2.265 & -109.058 & +9.432 & -6.821 \\
\hline 70 & -4.131 & -1.741 & +69.742 & +30.534 & -16.512 \\
\hline 71 & -1.390 & -2.868 & +6.321 & +21.470 & -10.958 \\
\hline 72 & -3.940 & +4.643 & +80.078 & +37.442 & -24.079 \\
\hline 73 & -1.267 & -15.20 & -25.887 & +36.933 & -17.494 \\
\hline 74 & -3.704 & +19.59 & +77.945 & +42.887 & -33.007 \\
\hline 75 & -1.040 & -120.666 & +34.326 & +42.105 & -25.794 \\
\hline 76 & -3.408 & +55.226 & +93.568 & +46.181 & -42.719 \\
\hline 77 & -0.887 & -74.80 & +31.201 & +43.595 & -37.095 \\
\hline 78 & -3.098 & +82.65 & +89.954 & +45.965 & -52.161 \\
\hline 79 & -0.675 & -100.511 & +33.788 & +42.128 & -48.063 \\
\hline 80 & -2.753 & +115.649 & +88.112 & +44.344 & -60.351 \\
\hline 81 & -0.536 & -119.365 & +60.118 & +38.942 & -58.056 \\
\hline 82 & -2.430 & +138.208 & +91.130 & +40.828 & -66.099 \\
\hline 83 & -0.330 & -131.684 & +61.653 & +34.480 & -65.075 \\
\hline 84 & -2.011 & +150.684 & +90.387 & +37.016 & -68.180 \\
\hline 85 & -0.182 & -116.761 & +59.572 & +28.520 & -71.055 \\
\hline 86 & -0.154 & +121.849 & +85.393 & +32.725 & -66.223 \\
\hline 87 & -0.042 & -164.974 & +39.417 & +23.483 & -71.458 \\
\hline 88 & -1.097 & +92.090 & +75.788 & +29.516 & -62.174 \\
\hline 89 & +0.003 & -135.337 & +29.616 & +20.582 & -67.508 \\
\hline 90 & -0.376 & +104.763 & +71.362 & +28.235 & -54.250 \\
\hline 91 & -1.120 & +107.798 & +66.791 & +27.476 & -43.894 \\
\hline
\end{tabular}




\section{APPENDIX C \\ BEARING SYSTEM MATERIAL PROPERTY CONSTANTS}

\section{C.I POT BEARING AND MASONRY STEEL PLATES}

Steel plates have been represented by isotropic linear elastic elements with the following material property constants:

1) Steel modulus of elasticity, $E=29000 \mathrm{Ksi}$

2) Poisson's ratio, $\nu=0.25$

\section{C.2 CONCRETE ABUTMENT}

Concrete elements have been modeled as an elastic-plastic material model following the von Mises yield criterion. Material property constants were taken from approximating the concrete stress - strain diagram resulting from a uniaxial compression test, see fig. (C.1), where:

1) Concrete modulus of elasticity (elastic range), $E_{C}=3605 \mathrm{Ksi}$.

2) Poisson's ratio, $\nu=0.180$

3) Yield stress in simple tension, $f_{t}=0.1548 \mathrm{Ksi}$.

4) Strain hardening modulus, $E_{t}=2454.5 \mathrm{Ksi}$. (Approximated as tangent modulus at $\mathrm{f}_{C} \cdot$ ) 


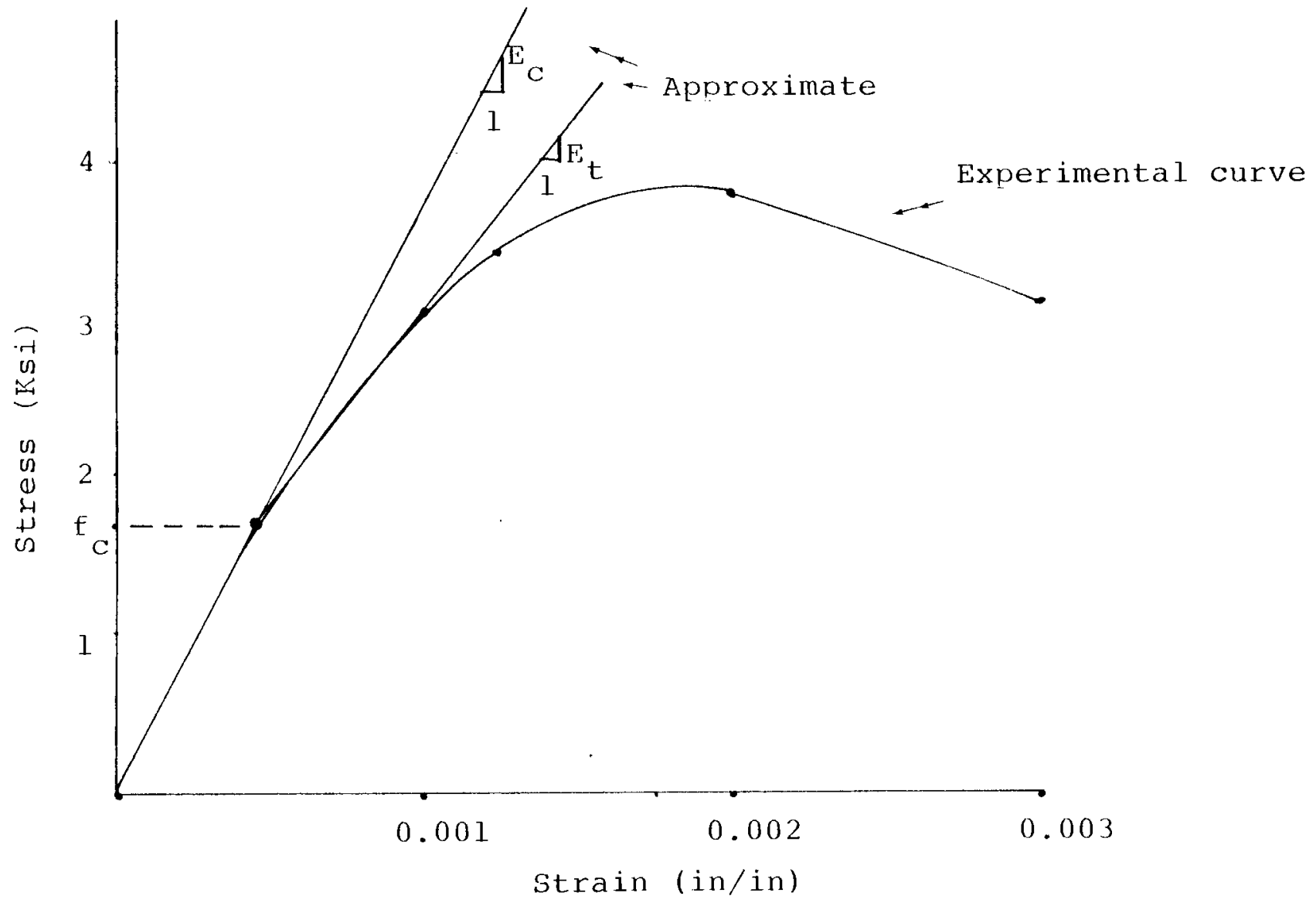

Fig. (C.1) Concrete stress - strain diagram. 
For this investigation, the compressive strength of the concrete, $f_{C}{ }^{\prime}$, is taken as $4 \mathrm{Ksi}$, and the tensile strength, $f_{t}^{\prime}$ as $0.09 \mathrm{f}_{c}^{\prime}$. Initial yielä is taken to be 43\% of the maximum strength such that

$$
\mathrm{f}_{t}=0.43 \mathrm{f}_{t}^{\prime}
$$

and

$$
\mathrm{f}_{\mathrm{C}}=0.43 \mathrm{f}_{\mathrm{C}}^{\prime} \text {. }
$$




\section{$\underline{\text { BIBLIOGRAPHY }}$}

ALEXANDER, B. "Practical Stress Analysis Engineering Design", Marcel Dekker Inc., New York and Basel, lst Ed., 1982 .

BATHE, K. J. "Finite Element Procedures in Engineering Analysis", Prentice-Hall Inc., New Jersey, 1st Ed., 1982. BATHE, K. J., WILSON, E. I., IDING, R. H. "NONSAP A Structural Analysis Program for Static and Dynamic Response of Nonlinear Systems", University of California, Berkeley, Report No. UC SESM 74-3, February 1974. BATHE, K. J., WILSON, E. L., OZDEMIR, H. "Static and Dynamic Geometric and Nonlinear Analysis", University of California, Berkeley, Report No. UC SESM 74-4, February 1974 .

BURAGOHAIN, D. N., SHAH, V. L. "Curved Interface Elements for Interaction Problems", Journal of the Structural Division, ASCE, Vol. 104 No. St1, January 1978, pp. 205-209.

BURAGOHAIN, D. N., SHAH, V. L. "Curved Interface Elements for Interaction Problems", Proceedings, International

Symposium on Soil-Structure Interaction, University of Roorkee, Roorkee, India, January 1977, pp. 197-201. 
CHEN, W. F. "plasticity in Reinforced Concrete" McGraw-Hill, Inc., New York, 1st Ed., 1982.

CHEUNG, Y. K., YEO, M. F. "A Practical Introduction to Finite Element Analysis", Ditman Publishing Limited, 39 Parker St., London WC2B 5PB, lst Ed., 1979.

COOK, R. D. "Concepts and Applications of Finite Element Analysis", John Wiley and Sons Inc., New York, 2nd Ed., 1974.

"Dixon Shortspan Bearings", (catalog), Spencer Dynamics Corporation, Promenade Street, Providence, RI, 02908, USA. "Elastomeric Bearings Design, Construction and Materials", National Cooperative Highway Research Program, Report No. 248, University of Washington, Seattle, Washington, August 1982.

GALIAGHER, R. H. "Finite Element Analysis Fundamentals", Prentice-Hall Inc., Englewood Cliffs, New Jersey, lst Ed., 1975.

GHABOUSSI, J., NILSON, E. L., ISENBERG, J. "Finite Element for Rock Joints and Interfaces", Journal of Soil Mechanics and Foundations Division, ASCE, vol. 99, No. SMil0, Proc. paper 10095, October 1973, pp. 833-847. GOODMAN, R. E., TAYLOR, R., BREEKE, T. L. "A MOdel for the Mechanics of Jointed Rock", Journal of Soil Mechanics and Foundations Division, ASCE, vol. 94, No. SM3, Proc. 
paper 5937, May 1968, pp. 637-659.

GUDEHUS, G. (Ed.), "Finite Element in Geomechanics", John Wiley and Sons, Inc., New York, lst Ed., 1977, Chapter 10 .

HOLAND, I., BELL, K., (Editors), "Finite Element Methods in Stress Analysis", TAPIR, The Technical University of Norway, Trondheim-Norway, 2nd printing, 1970.

MARGUERRE, K., WOERNLE, H. T. "Elastic Plates", Blaisdell Publishing Company, Waltham, Massachusetts, lst Ed., 1969.

MCENEN, E. E. "Behavior of Masonry Bearing Plates", unpublished report, University of Rhode Island, Kingston, RI December 1979.

NGO, D., SCORDELIS, A. C. "Finite Element Analysis of Reinforced Concrete Beams", Journal of American Concrete Institute, Title No. 64-14, March 1967, pp. 152-163.

SCHAFER, H. "A Contribution to the solution of contact Problems with the Aid of Bond Elements", Computer Methods in Applied Mechanics and Engineering 6, North Holland Publishing Company, February 20, 1975, pp. 335-353.

"Standard Specifications for Highway Bridges", AASHTO, 12 th Ed., 1977.

"Steel Construction Manual", American Institute of Steel Construction, Inc., 8th Ed., pp. (2-47)-(2-49). 
SZILARD, R. "Theory and Analysis of Plates, Classical and Numerical Methods", Prentice-Hall Inc., 1st Ed., 1974 .

TUMA, J. J. "Engineering Mathematics Handbook", McGraw-Hill Inc., New York, 2nd Ed., 1979. WANG, C., SALMON, C. G. "Reinforced Concrete Design", Harper and Row Inc., New York, 3rd Ed., 1979. WILBY, C. B. "Concrete for Structural Engineers", Newnes-Butterwurths, London, Boston, lst Ed., 1977. WINTER, G., NILSON, A. H. "Design of Concrete Structures" MIcGraw-Hill Inc., New York, 7th Ed., 1964. ZIENKIEWICZ, O. C. "The Finite Element Method", McGraw-Hill Inc., New York, 3rd Ed., 1977. 